Universidad de Lima

Facultad de Ingeniería Industrial

Carrera de Ingeniería Industrial

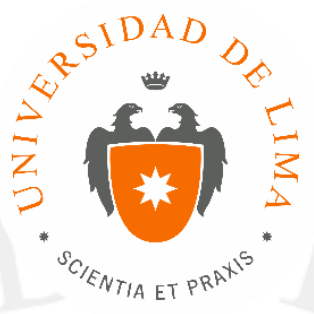

\title{
ESTUDIO DE MEJORA INTEGRAL EN LA EMPRESA DE PASTELERÍA CLAUDIA CUPCAKES
}

Trabajo de Investigación para optar por el Título Profesional de Ingeniero Industrial

\section{Daniela Martínez Montalvo \\ Código 20070655 \\ Elio Pérez Blas \\ Código 20081669}

\section{Asesor}

Elsie Bonilla Pastor

$$
\text { Lima - Perú }
$$

Octubre del 2015 


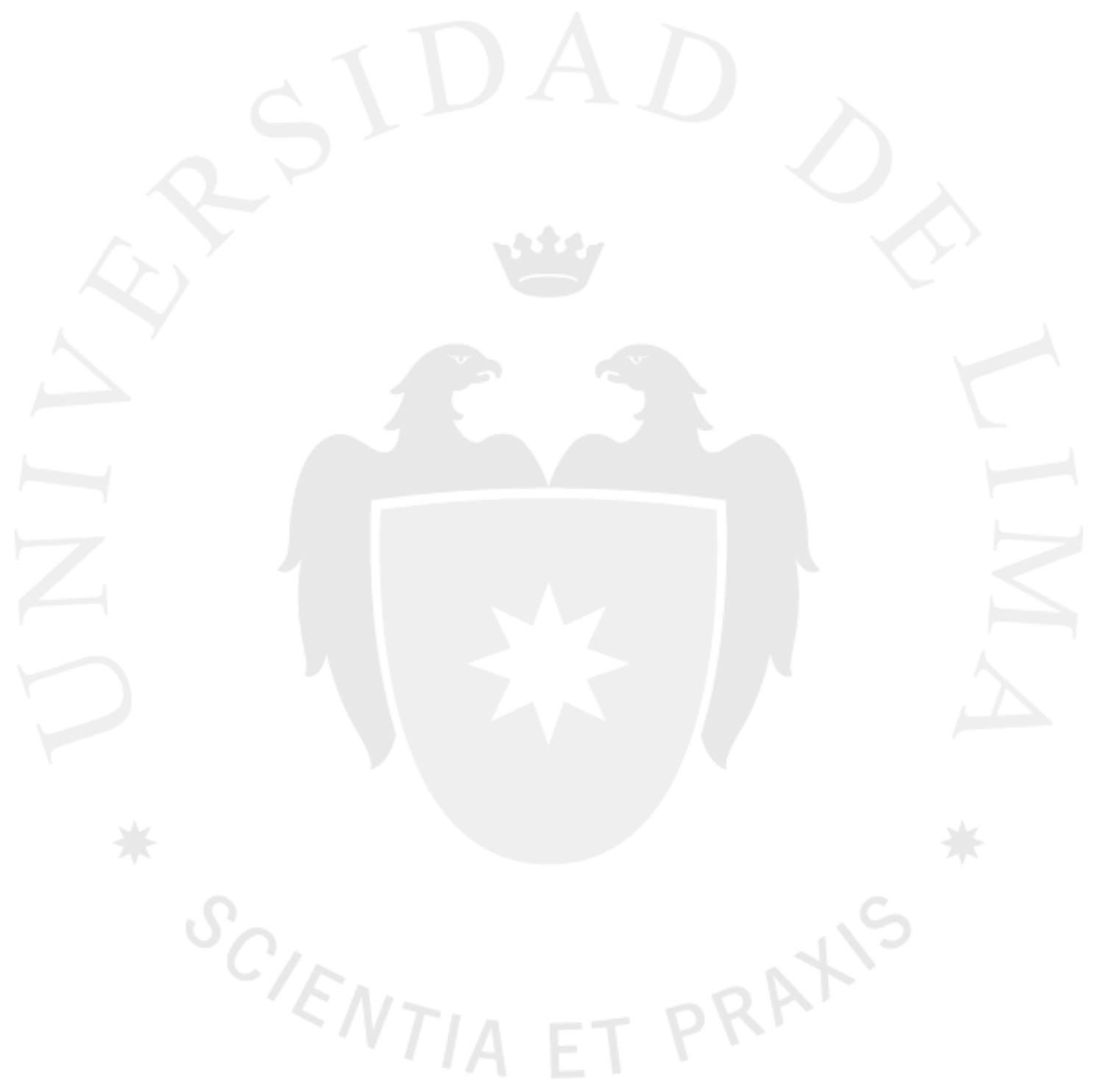




\section{ESTUDIO DE MEJORA INTEGRAL EN LA EMPRESA DE PASTELERÍA CLAUDIA CUPCAKES}




\section{Dedicatoria}

A nuestros Padres y Maestros,

Quienes nos dieron hasta ahora lo más importante:

La Educación 


\section{Agradecimientos}

A Dios y a la Virgen, por estar siempre a mi lado. A mis padres y hermanos, por su dedicación, apoyo y aliento para seguir adelante. A Diana, por ser mi compañera y guía en todo momento.

A Daniela, por su esfuerzo para realizar con éxito este proyecto. A nuestra asesora, por su apoyo y por compartir experiencias y conocimientos con nosotros. Y a Claudia, con quien empezó todo y quien sin ella no hubiera sido posible hacer este trabajo.

Elio Pérez 


\section{Agradecimientos}

A mis padres y a mis hermanos por su apoyo incondicional siempre.

Daniela Martínez 


\section{TABLA DE CONTENIDO}

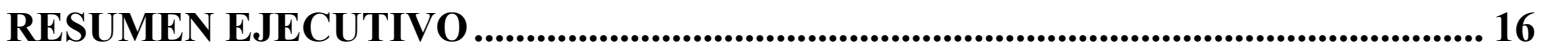

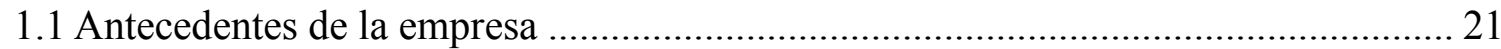

1.1.1 Breve descripción de la empresa y reseña histórica …........................................................21

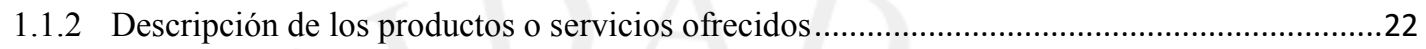

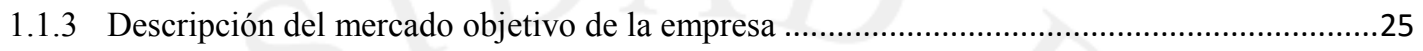

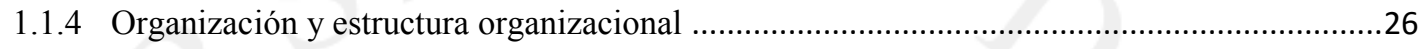

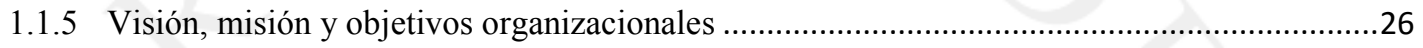

1.2 Objetivos de la Investigación. Justificación de la investigación. .............................. 27

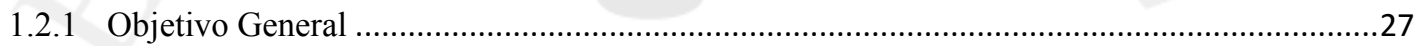

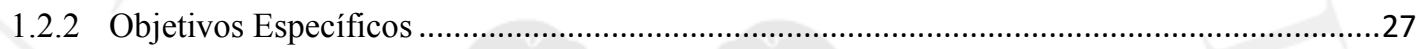

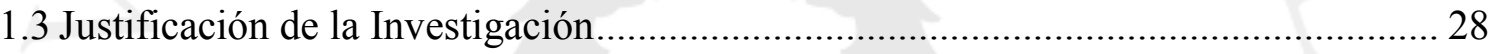

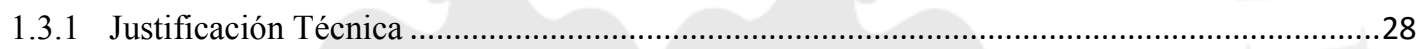

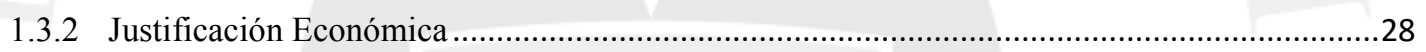

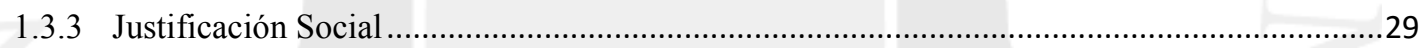

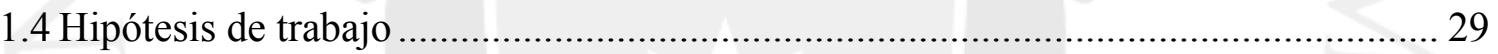

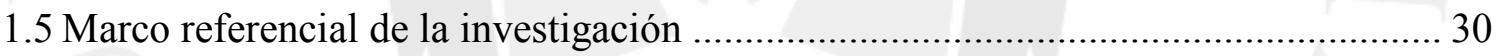

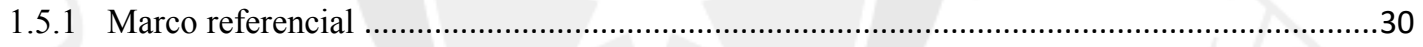

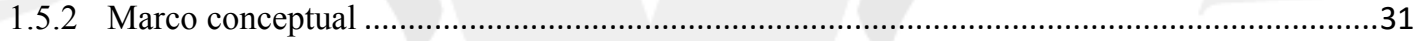

CAPÍTULO II: ANÁLISIS SITUACIONAL DE LA EMPRESA Y SU ENTORNO. 38

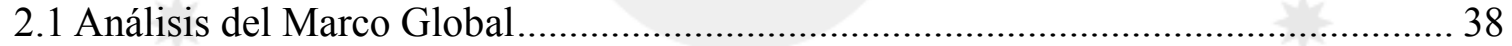

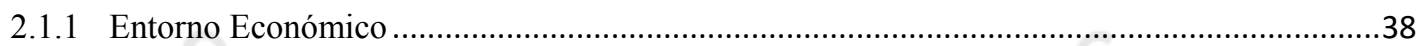

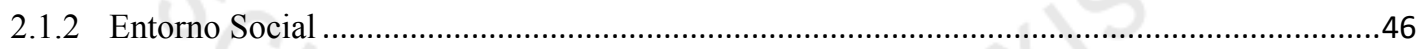

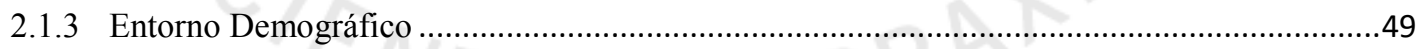

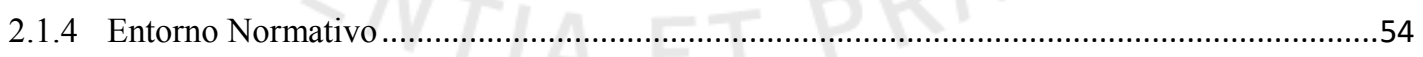

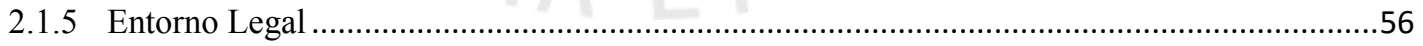

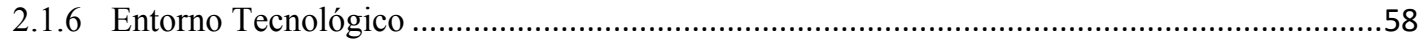

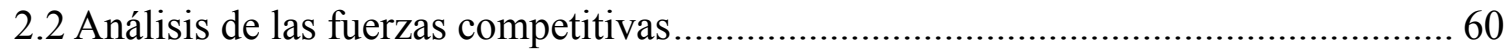

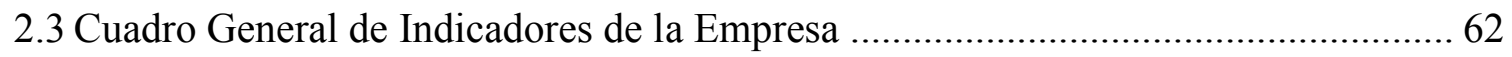




\section{CAPÍTULO III: MERCADO Y COMERCIALIZACIÓN DE LOS PRODUCTOS.. 64}

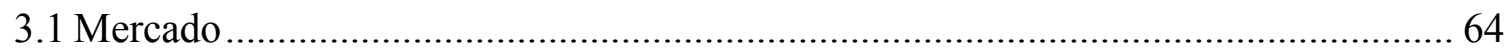

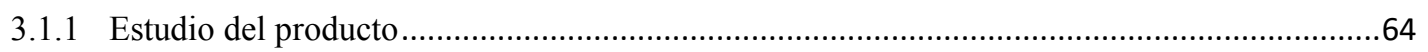

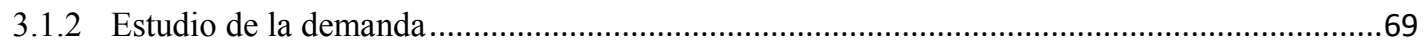

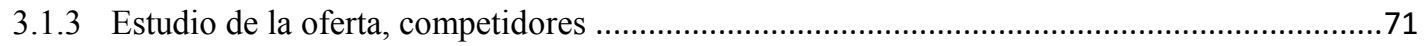

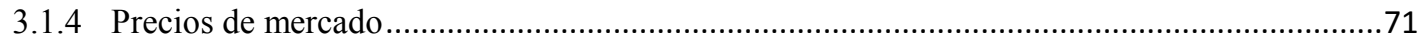

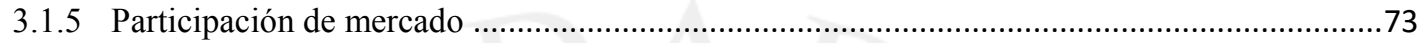

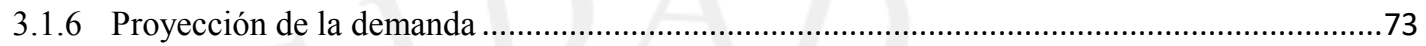

3.1.7 Productos o servicios sustitutos y complementarios ............................................................

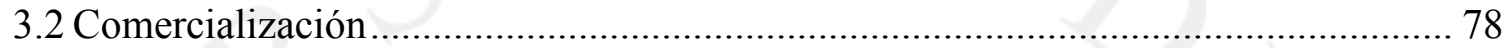

3.2.1 Políticas y estrategias de comercialización de la empresa ......................................................78

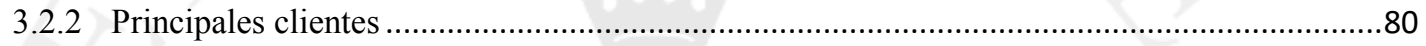

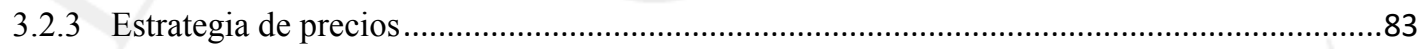

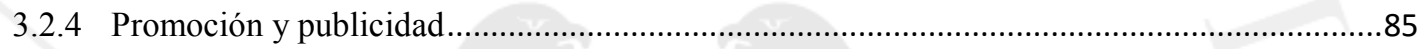

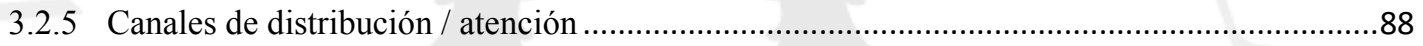

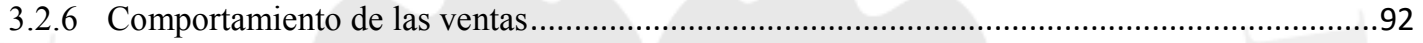

3.2.7 Satisfacción de los clientes / usuarios locales e internacionales ..............................................96

3.3 Resumen de los principales indicadores del capítulo ......................................... 100

CAPÍTULO IV: ASPECTOS TÉCNICOS Y OPERACIONES .................................. 101

4.1 De la planta / centro de operaciones y sus instalaciones ..................................... 101

4.1.1 Características principales de la maquinaria y/o equipos para el servicio .............................101

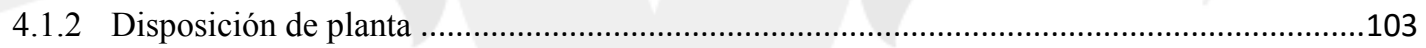

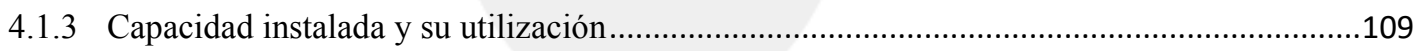

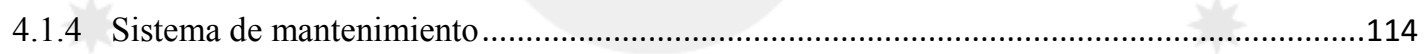

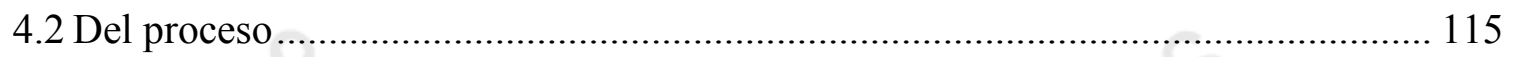

4.2.1 Situación tecnológica de los procesos .............................................................................115

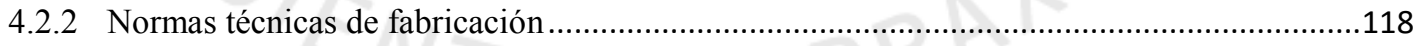

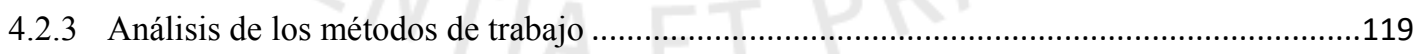

4.2.4 Control del proceso y aseguramiento de la calidad ...........................................................122

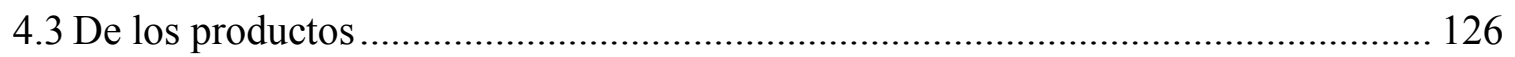

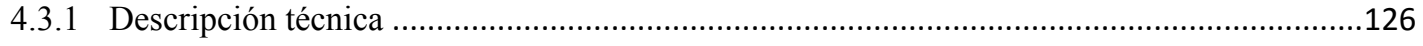

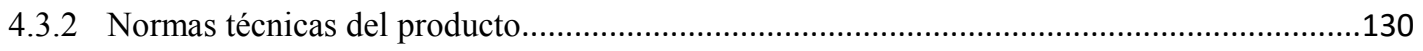

4.3.3 Indicadores de cumplimiento de estándares de calidad .........................................................130 
4.4 De las materias primas .................................................................................... 133

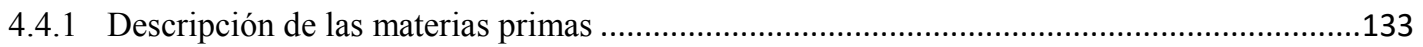

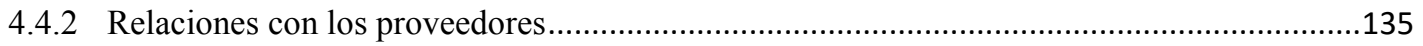

4.4.3 Sistema de control y reposición de existencias........................................................................138

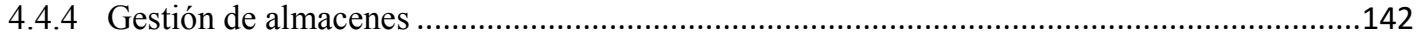

4.5 Planeamiento y control de la producción ............................................................... 149

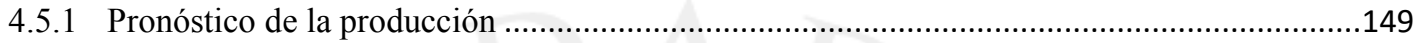

CAPÍTULO V: ASPECTOS DE GESTIÓN .................................................................. 154

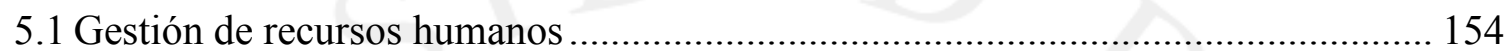

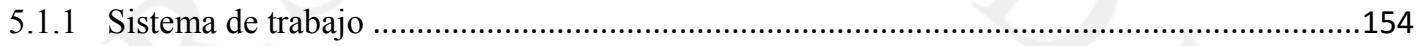

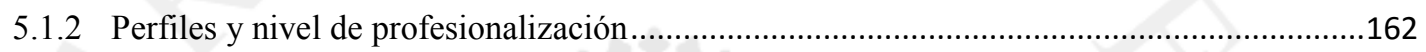

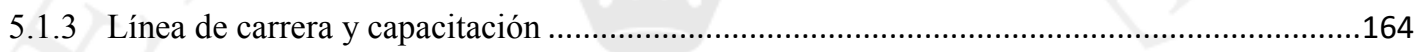

5.2 Gestión de calidad .................................................................................... 166

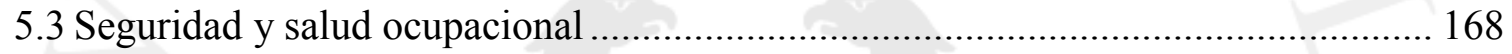

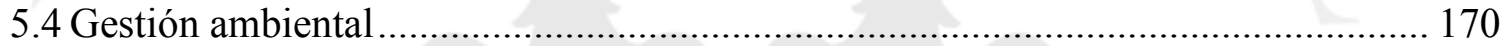

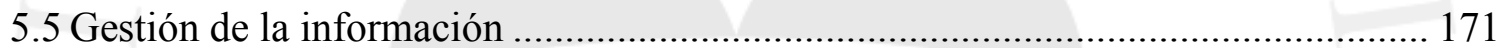

CAPÍTULO VI: ASPECTOS ECONÓMICOS Y FINANCIEROS ............................ 174

6.1 Costos, Gastos e Inversiones .................................................................................... 174

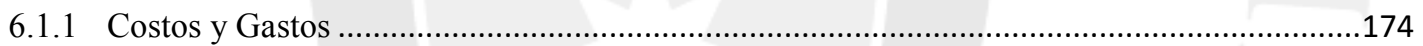

6.2 Situación económica financiera de la empresa...................................................... 175

CAPÍTULO VII: DESCRIPCIÓN DE LAS PRINCIPALES FORTALEZAS Y

DEBILIDADES DE LA EMPRESA

7.1 Mercado y comercialización de los productos o servicios .................................... 180

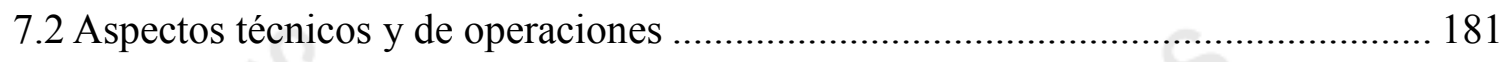

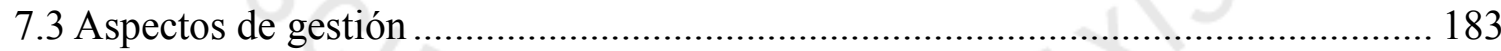

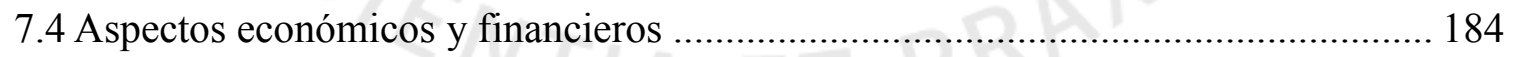

CAPÍTULO VIII: ESTRATEGIAS Y PROPUESTAS DE MEJORA....................... 186

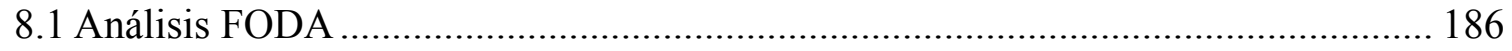

8.1.1 Determinación de los principales indicadores de gestión y definición de metas ....................186

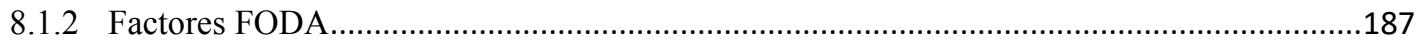

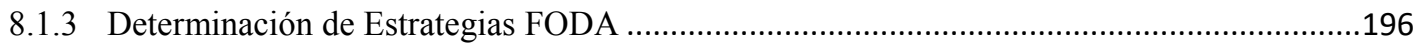




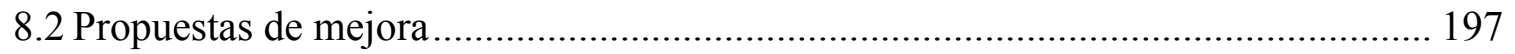

8.2.1 Descripción detallada de las propuestas de mejora ..................................................................197

8.3 Evaluación económica y social de las propuestas ............................................... 265

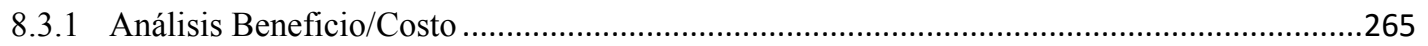

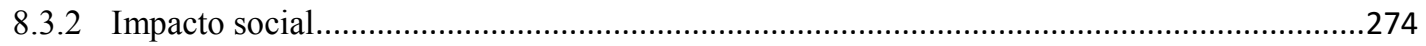

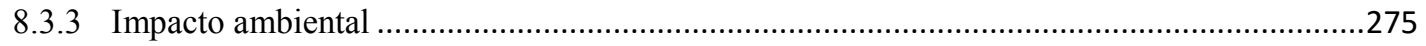

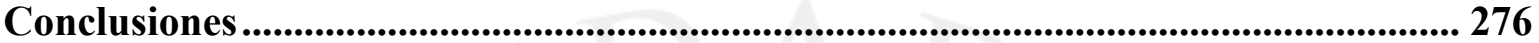

Recomendaciones ............................................................................................... 278

Referencias .................................................................................................................................. 279

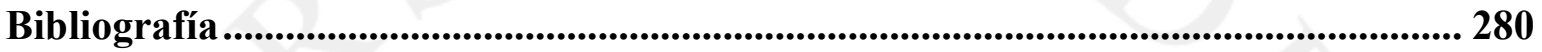

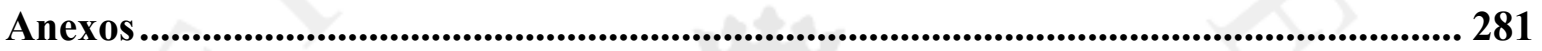




\section{ÍNDICE DE FIGURAS}

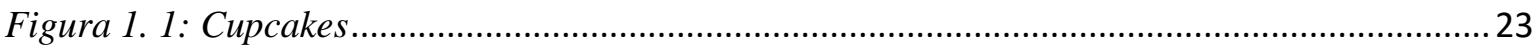

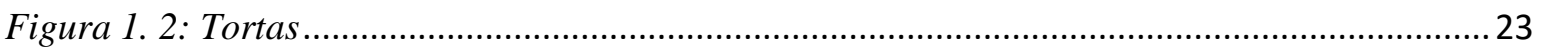

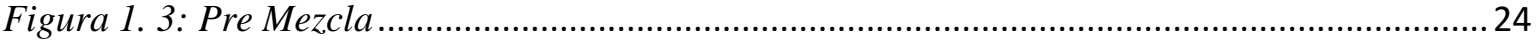

Figura 1. 4: Participación en la ventas internas .............................................................................. 25

Figura 1. 5: Organigrama de la empresa Claudia Cupcakes......................................................26

Figura 2. 1: Evolución del PBI del Perú en los últimos años.........................................................40

Figura 2. 2: Evolución del número de centros comerciales en el Perú ............................................45

Figura 2. 3: Participación de Supermercados en el Perú ............................................................. 47

Figura 2. 4: Asistencia a supermercados por nivel socioeconómico .............................................. 48

Figura 2. 5: Crecimiento de la población en el Perú y su distribución por edades ........................ 49

Figura 2. 6: Distribución por edades de la población peruana al 2013 .........................................50

Figura 2. 7: Distribución de la población Peruana por ciudades al 2013.....................................52

Figura 2. 8: Evolución de la distribución de los NSE en el Perú.................................................53

Figura 2. 9: Evolución de la distribución de los NSE en Lima Metropolitana. ................................53

Figura 2. 10: Aplicación de las CODEX en la cadena alimentaria ...............................................55

Figura 2. 11: Tablero de control de Indicadores principales de la empresa Claudia Cupcakes.....63

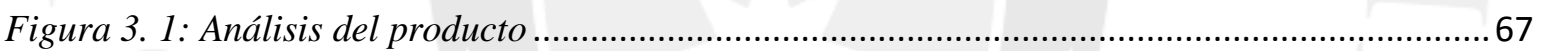

Figura 3. 2: Evolución de las ventas en la empresa Claudia Cupcakes......................................... 74

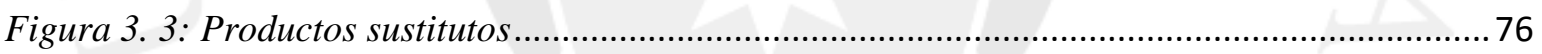

Figura 3. 4: Productos complementarios ............................................................................... 77

Figura 3. 5: Participación de clientes atendidos por la empresa Claudia Cupcakes. ..................... 80

Figura 3. 6: Portada de la página de Facebook de Claudia Cupcakes........................................... 87

Figura 3. 7: Porcentaje de ventas según canal de atención ..........................................................90

Figura 3. 8: Diagrama de flujo para la atención de pedidos .......................................................91

Figura 3. 9: Comportamiento de las ventas 2014 de la empresa Claudia Cupcakes ...................... 92

Figura 3. 10: Comportamiento de las ventas anuales 2010 - 2014 ..............................................93

Figura 3. 11: Ventas de cupcakes 2014 ....................................................................................... 94

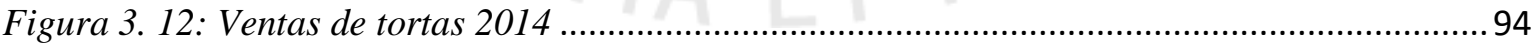

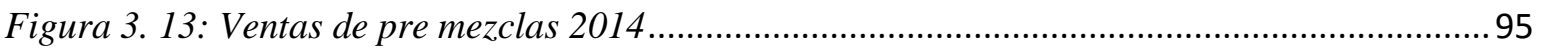

Figura 3. 14: Resultados de encuesta de satisfacción al cliente .....................................................97

Figura 4. 1: Disposición actual del taller de la empresa ...............................................................104

Figura 4. 2: Diagrama de balance de materia para la producción de cupcakes ............................110

Figura 4. 3: Diagrama de Actividades del Proceso de producción de cupcakes ..........................120 
Figura 4. 4: Diagrama de Operaciones y Procesos para la producción de cupcakes .121

Figura 4. 5: Esquema para la elaboración de un plan HACCP .................................................125

Figura 4. 6: Satisfacción de los clientes con el producto ...............................................................131

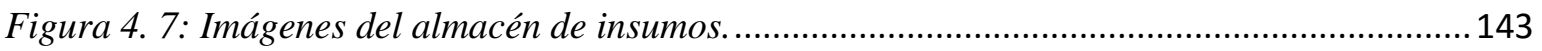

Figura 4. 8: Imágenes del almacén de materia prima........................................................... 144

Figura 5. 1: Organigrama de la empresa Claudia Cupcakes......................................................154

Figura 5. 2: Satisfacción interna en la empresa Claudia Cupcakes............................................159

Figura 8. 1: Tablero de indicadores principales de la empresa Claudia Cupcakes .....................186

Figura 8. 2: Diagrama de Pareto de las Fortalezas de la empresa Claudia Cupcakes .................189

Figura 8. 3: Diagrama de Pareto de las Debilidades de la empresa Claudia Cupcakes................191

Figura 8. 4: Matriz BCG para el análisis del Cupcake ........................................................... 200

Figura 8. 5: Propuesta de Misión, Visión y Objetivos Estratégicos para Claudia Cupcakes........203

Figura 8. 6: Análisis relacional para la distribución de planta ....................................................209

Figura 8. 7: Diagrama relacional para la distribución de planta propuesta................................210

Figura 8. 8: Nueva distribución de planta propuesta................................................................ 211

Figura 8. 9: Propuesta de formato para la clasificación de objetos. ...............................................217

Figura 8. 10: Propuesta de Política del programa 5S..................................................................223

Figura 8. 11: Formato de programa de producción diario. .........................................................244

Figura 8. 12: Mapa de riesgos del taller de Claudia Cupcakes ..................................................253 


\section{ÍNDICE DE TABLAS Y CUADROS}

Tabla 2. 1: Indicadores macroeconómicos del Perú .......................................................................... 40

Tabla 2. 2: Participación de la Industria Manufacturera en el PBI total ....................................... 41

Tabla 2. 3: Valor agregado de la producción manufacturera ......................................................... 42

Tabla 2. 4: Valor agregado de la producción en la industria alimenticia ....................................... 43

Tabla 2. 5: Producción manufacturera en el Perú ............................................................................ 44

Tabla 2. 6: Importaciones y Exportaciones del sector de Panadería y Pastelería ........................... 44

Tabla 2. 7: Importaciones y Exportaciones de máquinas para Panadería y Pastelería. .................58

Tabla 2. 8: Esquema de Análisis de Porter para Claudia Cupcakes..............................................60

Tabla 2. 9: Análisis de las Fuerzas Competitivas de Porter para la empresa Claudia Cupcakes. ..61

Tabla 3. 1: Consumo per cápita de productos de panadería y pastelería del Perú .......................... 70

Tabla 3. 2: Precios de cupcakes en el mercado Peruano ................................................................... 72

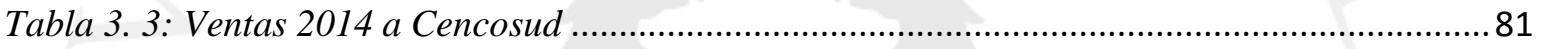

Tabla 3. 4: Ventas 2014 a clientes individuales............................................................................... 82

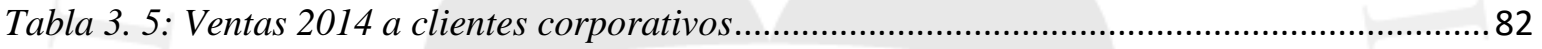

Tabla 3. 6: Indicadores principales del capítulo 3 ................................................................ 100

Tabla 4. 1: Principales equipos en el taller de la empresa ...........................................................102

Tabla 4. 2: Análisis de Guerchet para el área de batido y horneado............................................105

Tabla 4. 3: Análisis de Guerchet para el área de diseño y decoración..........................................106

Tabla 4. 4: Análisis de Guerchet para el área de forrado y empaque..........................................106

Tabla 4. 5: Análisis de Guerchet para el área oficinas administrativas. ......................................107

Tabla 4. 6: Análisis de Guerchet para el área de almacén de materias primas............................107

Tabla 4. 7: Análisis de Guerchet para el área de almacén de insumos......................................... 107

Tabla 4. 8: Escenarios para la disposición del taller de la empresa.................................................108

Tabla 4. 9: Cálculo del factor de utilización de las máquinas en cada área.................................111

Tabla 4. 10: Cálculo del factor de eficiencia para cada área. .....................................................111

Tabla 4. 11: Cálculo de la capacidad de planta actual de la empresa..........................................112

Tabla 4. 12: Cálculo de la utilización de planta de acuerdo a la demanda proyectada. ...............114

Tabla 4. 13: Registro de mantenimientos a equipos 2014. ........................................................ 115

Tabla 4. 14: Detalle de la Norma Sanitaria aplicable al sector de Pastelería...............................118

Tabla 4. 15: Parámetros para la producción de cupcakes ........................................................... 126

Tabla 4. 16: Criterios microbiológicos para productos de panadería y pastelería ........................127

Tabla 4. 17: Especificaciones externas del cupcake ....................................................................128

Tabla 4. 18: Especificaciones físicas finales del cupcake. ........................................................129

Tabla 4. 19: Descripción de las materias primas. ....................................................................... 133 
Tabla 4. 20: Descripción de otros insumos. .134

Tabla 4. 21: Niveles de servicio de proveedores .137

Tabla 4. 22: Pesos de materias primas para cálculo de área de almacén. ...................................145

Tabla 4. 23: Medidas que ocupan las principales materias primas. ............................................145

Tabla 4. 24: Cantidad requerida en unidades de materias primas. ............................................ 146

Tabla 4. 25: Cálculo de unidades de insumos necesarias para el área de almacén. .....................147

Tabla 4. 26: Cantidad de unidades requeridas de insumos para el almacén................................147

Tabla 4. 27: Demanda histórica de la empresa......................................................................150

Tabla 4. 28: Producción histórica de Claudia Cupcakes y PBI per cápita Perú. ...........................151

Tabla 4. 29: Producción proyectada de Claudia Cupcakes acorde al PBI per cápita Perú..........152

Tabla 4. 30: Proyección de la demanda de la empresa Claudia Cupcakes................................... 152

Tabla 5. 1: Esquema de trabajo en la empresa Claudia Cupcakes. ..............................................155

Tabla 5. 2: Resultados de la encuesta de satisfacción interna en la empresa Claudia Cupcakes. 160

Tabla 5. 3: Descripción de puestos en la empresa Claudia Cupcakes. ........................................ 163

Tabla 6. 1: Resumen de costos de la empresa. 174

Tabla 8. 1: Análisis de las Fortalezas de la empresa Claudia Cupcakes ....................................... 188

Tabla 8. 2: Análisis de las Debilidades de la empresa Claudia Cupcakes.....................................190

Tabla 8. 3: Matriz EFI aplicado a la empresa Claudia Cupcakes .............................................. 192

Tabla 8. 4: Oportunidades y Debilidades principales halladas en la empresa. ............................193

Tabla 8. 5: Matriz EFE aplicado a la empresa Claudia Cupcakes. .............................................. 194

Tabla 8. 6: Matriz FODA de la empresa Claudia Cupcakes ........................................................196

Tabla 8. 7: Matriz 5W1H para las propuestas de mejora. ...........................................................198

Tabla 8. 8: Implementación y seguimiento al Plan Estratégico. ..................................................205

Tabla 8. 9: Escenarios propuestos para la nueva distribución de planta. ......................................207

Tabla 8. 10: Valores de proximidad para el análisis relacional de planta. ...................................210

Tabla 8. 11: Beneficios de implementar la nueva distribución de planta.......................................212

Tabla 8. 12: Beneficio económico de la nueva propuesta de distribución de planta. ....................213

Tabla 8. 13: Inversión económica de la nueva propuesta de distribución de planta. ....................214

Tabla 8. 14: Frecuencia de actividades de seguimiento a la implementación de 5S......................224

Tabla 8. 15: Análisis HACCP de la empresa Claudia Cupcakes. ...............................................228

Tabla 8. 16: Límites de control establecidos para la implementación del plan HACCP. ..............230

Tabla 8. 17: Número de cupcakes rechazados en proceso. ........................................................231

Tabla 8. 18: Cálculo de costo de reprocesamiento de cupcakes. ..................................................231

Tabla 8. 19: Costo anual de reprocesos. .................................................................................... 232

Tabla 8. 20: Ahorro anual de reprocesos implementando HACCP.............................................2232

Tabla 8. 21: Límites de control establecidos para la implementación del plan HACCP. ..............232

Tabla 8. 22: Proyección del impacto en número de pedidos defectuosos. .....................................233 
Tabla 8. 23: Costos de reprocesamiento de pedidos. .233

Tabla 8. 24: Proyección de la cantidad de pedidos a reprocesar con la mejora. ...........................233

Tabla 8. 25: Proyección para los costos de reposición anual con la mejora..................................234

Tabla 8. 26: Proyección de ahorros anuales en pedidos defectuosos con la mejora. .....................234

Tabla 8. 27: Proyección de la mejora en el indicador del nivel de pedidos defectuosos. ...............234

Tabla 8. 28: Costos de implementación de HACCP ....................................................................235

Tabla 8. 29: Demanda histórica de la empresa Claudia Cupcakes...............................................238

Tabla 8. 30: Producción histórica anual vs. PBI per cápita Perú................................................2239

Tabla 8. 31: Proyección de la producción en la empresa Claudia Cupcakes. ...............................240

Tabla 8. 32: Demanda histórica de la empresa Claudia Cupcakes.............................................. 240

Tabla 8. 33: Esquema de planeamiento de requerimiento de materiales. .......................................242

Tabla 8. 34: Esquema de plan maestro de la producción...............................................................243

Tabla 8. 35: Esquema de plan maestro de la producción..............................................................245

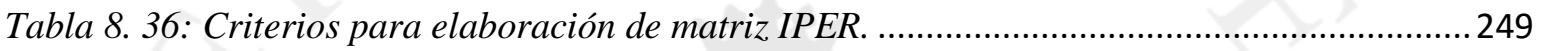

Tabla 8. 37: Propuesta de Matriz IPER para la empresa Claudia Cupcakes. ............................. 251

Tabla 8. 38: Análisis Modal de Falla y Efecto aplicado a la empresa Claudia Cupcakes.............252

Tabla 8. 39: Plan anual de Seguridad y Salud en el Trabajo 2016 propuesto.............................. 262

Tabla 8. 40: Beneficios de implementar un sistema de SST..........................................................263

Tabla 8. 41: Mejora en el indicador de Nivel de accidentes por trabajador....................................264

Tabla 8. 42: Inversión estimada para la implementación de un sistema de SST............................264

Tabla 8. 43: Inversión en la implementación de un plan estratégico. ............................................265

Tabla 8. 44: Costos de inversión para la nueva disposición de planta. ........................................266

Tabla 8. 45: Montos de inversión para la implementación del programa 5S...............................267

Tabla 8. 46: Inversión para la implementación de un sistema HACCP .......................................267

Tabla 8. 47: Costos de implementación de un sistema de PCP ...................................................268

Tabla 8. 48: Inversión para la implementación de un sistema de SST ..........................................268

Tabla 8. 49: Mejora en el número de cupcakes rechazados en proceso.........................................269

Tabla 8. 50: Costos de reprocesamiento de cupcakes. ................................................................ 270

Tabla 8. 51: Ahorro anual de reprocesos implementando HACCP..............................................2 270

Tabla 8. 52: Mejora en el nivel de rechazos de productos en proceso ...........................................270

Tabla 8. 53: Mejora en el número de pedidos defectuosos...........................................................2 271

Tabla 8. 54: Proyección de la cantidad de pedidos a reprocesar con la mejora. ..........................2271

Tabla 8. 55: Proyección para los costos de reposición anual con la mejora...................................2 272

Tabla 8. 56: Proyección de ahorros anuales en pedidos defectuosos con la mejora. .....................272

Tabla 8. 57: Proyección de la mejora en el indicador del nivel de pedidos defectuosos. ...............272 


\section{RESUMEN EJECUTIVO}

Para el presente trabajo de investigación, se decidió hacer un estudio de mejora integral de los procesos en la empresa Claudia Cupcakes E.I.R.L., para lo cual, tomando en cuenta los conocimientos adquiridos a lo largo de la carrera de Ingeniería Industrial, se plantearon algunas propuestas de mejoras para los problemas identificados en la empresa, a fin de contribuir a su crecimiento y desarrollo.

A continuación presentamos un resumen de lo que a lo largo del presente trabajo se podrá encontrar en cada capítulo:

Capítulo I: En este capítulo hacemos un resumen genérico, a manera de introducción, dando a conocer detalles de la empresa en estudio, realizando las justificaciones de cada aspecto de la investigación.

Capítulo II: En este capítulo nos enfocamos en hacer un análisis del entorno en el cual se desenvuelve la empresa, no sólo considerando los aspectos económicos o financieros; si no también, todos aquellos aspectos que, bien conocidos y manejados por la empresa, pueden facilitar su desarrollo, como lo es en el aspecto social, tecnológico, legal, etc.

Capítulo III: En este capítulo nos centramos en aspectos de mercado. Mostramos cómo se comporta actualmente el consumidor peruano con los productos de pastelería. Así, también, hacemos una explicación de cómo están los precios en el mercado en el que se desarrolla la empresa, la proyección de sus demandas, comportamiento de las ventas, estrategias de 
comercialización, etc. Todo esto con la finalidad de poder tener una idea de cómo será el panorama a futuro en el cual podría desarrollarse la empresa.

Capítulo IV: En este capítulo se hace una revisión y análisis más interno de la empresa, enfocándonos en sus procesos actuales, aspectos técnicos de sus operaciones, revisamos los aspectos logísticos, determinando así posibles problemas que impiden el buen desempeño de la empresa.

Capítulo V: En este capítulo analizamos todos los aspectos de gestión de la empresa, relacionados con los temas de recursos humanos, la gestión de la calidad, seguridad y salud en trabajo, medio ambiente, etc., para de ese modo poder identificar qué se está haciendo bien y qué opciones de mejora podrían plantearse para alcanzar los objetivos propuestos por la empresa.

Capítulo VI: En este capítulo nos enfocamos en todos los aspectos económicos y financieros de la empresa. Se obtiene una visión de cómo están compuestos sus costos, gastos e inversiones y de esa manera se logra tener más claro cómo la empresa gestiona tales recursos.

Capítulo VII: En este capítulo se resumen las oportunidades y debilidades de la empresa; aquello nos sirve como input para un posterior análisis FODA y el planteamiento de las estrategias más adecuadas. 
Capítulo VIII: Éste es el capítulo quizá más importante del desarrollo del trabajo. Posterior a todo el análisis desarrollado anteriormente, identificamos ahora los problemas principales encontrados durante el diagnóstico general y, de esa manera, planteamos algunas soluciones que puedan atacar las causas raíces de los problemas.

Finalmente, se presentan algunas conclusiones y recomendaciones que se desprenden de la investigación y se ofrecen recomendaciones para implementar las soluciones. 


\section{EXECUTIVE SUMMARY}

For the recent research, it was decided to make a study of comprehensive improvement of processes in the company Claudia Cupcakes EIRL, for which, taking into account the knowledge acquired throughout the career of Industrial Engineering, some improvements proposals were raised to the problems identified in the company, in order to contribute to their growth and development.

The following is a summary of what along the present work can be found in each chapter:

Chapter I: In this chapter we make a generic summary, as an introduction, revealing details of the study, performing the justifications for every aspect of the investigation.

Chapter II: In this chapter we focus on an analysis of the environment in which the company operates, not only considering the economic and financial aspects; but also all those aspects that well known and managed by the company, may facilitate its development, as it is in the social, technological, legal aspect, etc.

Chapter III: In this chapter we focus on market aspects. We show how Peruvian consumers are currently behaving with pastries. As well as, we do an explanation of how prices are on the market in which the company develops, projecting their demands, sales performance, marketing strategies, etc. All this in order to be able to have an idea of the future scenario in which the company could develop. 
Chapter IV: This chapter reviews and makes an internal analysis of the company, focusing on their current processes, technical aspects of their operations; review the logistics, thus determining possible problems that hinder the company's good performance.

Chapter V: In this chapter we look at all aspects of company management, issues related to human resources, quality management, health and safety at work, environment, etc., thereby to be able to identify what is doing well and the improvements that we could consider to achieve the goals set by the company.

Chapter VI: In this chapter we focus on all economic and financial aspects of the company. A vision of how their costs are structure, expenses and investments, these to be clear of how the company manages its resources.

Chapter VII: This chapter summarizes the opportunities and weaknesses of the company; that serves as an input for further FODA analysis and approaches the most appropriate strategies.

Chapter VIII: This is perhaps the most important chapter of the work. After all the analysis developed above, now we identify the main problems found during the general diagnosis and, that way, we propose some solutions that can attack the root causes of the problems.

Finally, some conclusions and recommendations arising from the investigation and recommendations are offered to implement the solutions presented. 


\title{
CAPÍTULO I: CONSIDERACIONES GENERALES DE LA INVESTIGACIÓN
}

\author{
ATENCIÓN
}

\subsection{Antecedentes de la empresa}

A continuación se presenta la información general de la empresa a ser analizada y mejorada en el presente trabajo de investigación:

a. Razón social: Claudia Cupcakes E.I.R.L.

b. Nombre comercial: Claudia Cupcakes

c. Estado: Activo

d. RUC: 20536445201

e. CIIU: 15417

f. Fecha de fundación: 01/06/2010

g. Sector económico de desempeño: Elaboración de Productos de Panadería.

\subsubsection{Breve descripción de la empresa y reseña histórica}

La empresa “Claudia Cupcakes ${ }^{\circledR}$ E.I.R.L.” se constituyó oficialmente desde el $1^{\circ}$ de Junio del 2010, cuando la actual Gerente General ideó una oportunidad empresarial novedosa en la preparación de cupcakes con diversos diseños de manera casera.

Hoy en día la empresa cuenta con más de 20 colaboradores, con una producción anual cercana a los 200,000 cupcakes y con ventas que bordean 
el millón y medio de nuevos soles, lo que le ha permitido, de acuerdo a estimaciones por parte de la Gerencia General, el poder alcanzar una participación de mercado cercana al 50\% entre las empresas formalmente constituidas, siendo un proveedor exclusivo de cupcakes y otros productos de repostería para Cencosud, y con proyección a iniciar ventas al exterior.

\subsubsection{Descripción de los productos o servicios ofrecidos}

Los productos que la empresa Claudia Cupcakes ${ }^{\circledR}$ E.I.R.L. ofrece son:

\section{a. Cupcakes}

Es el producto principal de la empresa. Son pequeñas porciones de queque de diversos sabores y con una cobertura hecha a base de diversos ingredientes y con diversos diseños, característica principal del producto; Además, gracias a una alianza comercial con otras empresas grandes en el mercado de dulces y golosinas, algunos de los diseños de los cupcakes llevan por cobertura sus productos, como el chocolate triángulo o princesa de la marca D’Onofrio, entre otros (Véase Figura 1.1 Cupcakes). Los cupcakes son comercializados en su mayoría en la cadena de supermercados CENCOSUD a nivel nacional, aunque en situaciones particulares, se producen a pedidos personalizados de algunos clientes. 


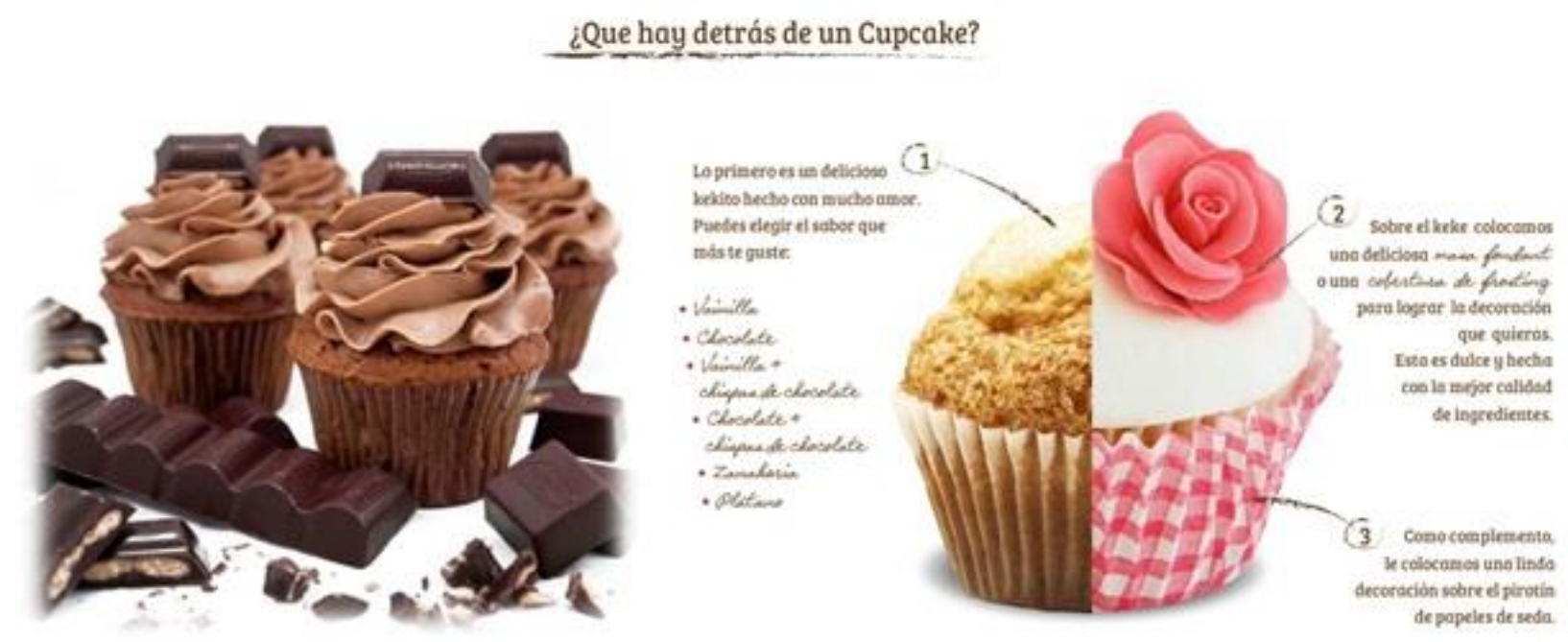

Figura 1. 1: Cupcakes

Fuente: Claudia Cupcakes, 2015

\section{b. Tortas}

Diseño y preparación de novedosas tortas de todo tipo con diversos

detalles, sabores y tamaños, los cuales son comercializados en la misma cadena de supermercados y a pedido de clientes particulares (Véase Figura 1.2 Tortas).
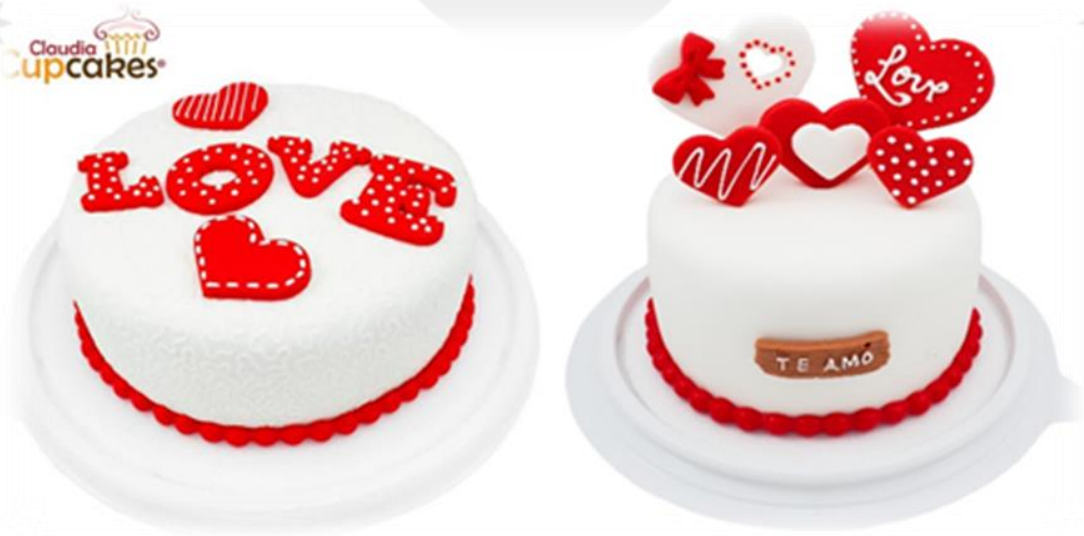

Figura 1. 2: Tortas

Fuente: Claudia Cupcakes, 2015 


\section{c. Pre-Mezclas}

Mediante una alianza comercial con la empresa proveedora de la premezcla para la elaboración de los cupcakes, éste producto es comercializado con la marca Claudia Cupcakes ${ }^{\circledR}$ en los supermercados en que se venden los otros productos. Ésta pre-mezcla es para la elaboración casera de cupcakes (Véase Figura 1.3Pre-Mezclas).

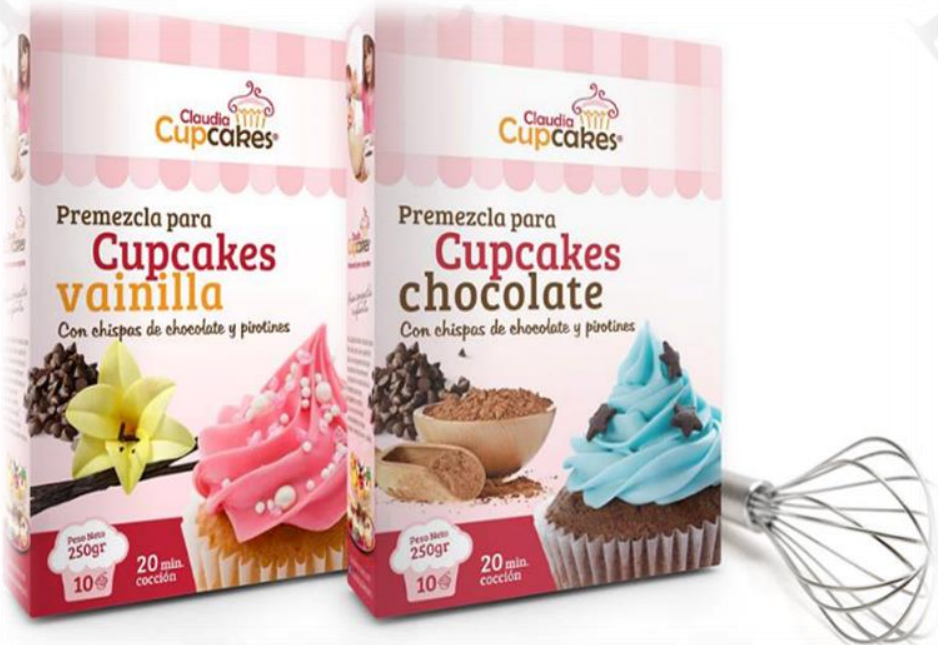

Figura 1. 3: Pre Mezcla

Fuente: Claudia Cupcakes, 2015

A continuación, presentamos un gráfico el cual nos muestra un aproximado de la distribución de la participación en las ventas de los productos vendidos por la empresa, durante el año 2014: 


\section{Participación en las ventas por cada tipo de producto de Claudia Cupcakes}

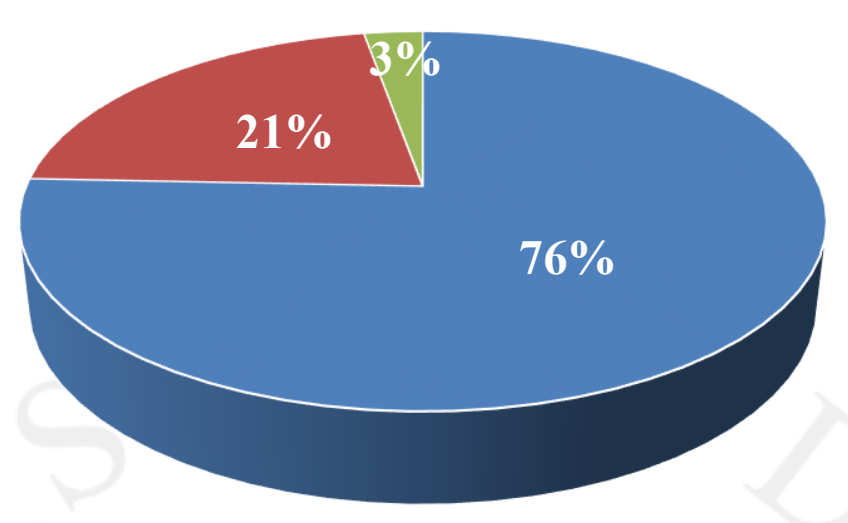

- Cupcakes - Tortas - Pre Mezcla

Figura 1. 4: Participación en la ventas internas

Fuente: Elaboración propia

Para efectos del presente trabajo de investigación, tomaremos como producto principal de estudio a los Cupcakes tratando de enfocar las oportunidades de mejora a nivel empresa en base a estos productos, ya que, tal como podremos apreciar en el gráfico anterior, es el producto que tiene el mayor porcentaje de producción y ventas de la empresa.

\subsubsection{Descripción del mercado objetivo de la empresa}

El mercado objetivo de la empresa Claudia Cupcakes está orientado a las personas que desean consumir productos de pastelería y repostería de una manera diferenciada y exclusiva. Estos consumidores son personas, en su mayoría, jóvenes y adultos entre los 15 - 40 años, de un estrato socioeconómico A y parte del B, con un gran \% de mujeres, quienes buscan productos novedosos para diversas situaciones como cumpleaños, 
aniversarios, celebraciones en general, etc. Además, son consumidores que en su mayoría no escatima en costos y/o precios para poder obtener el producto que más le agrade o que solicite.

\subsubsection{Organización y estructura organizacional}

Actualmente la empresa Claudia Cupcakes está organizada de la siguiente manera:

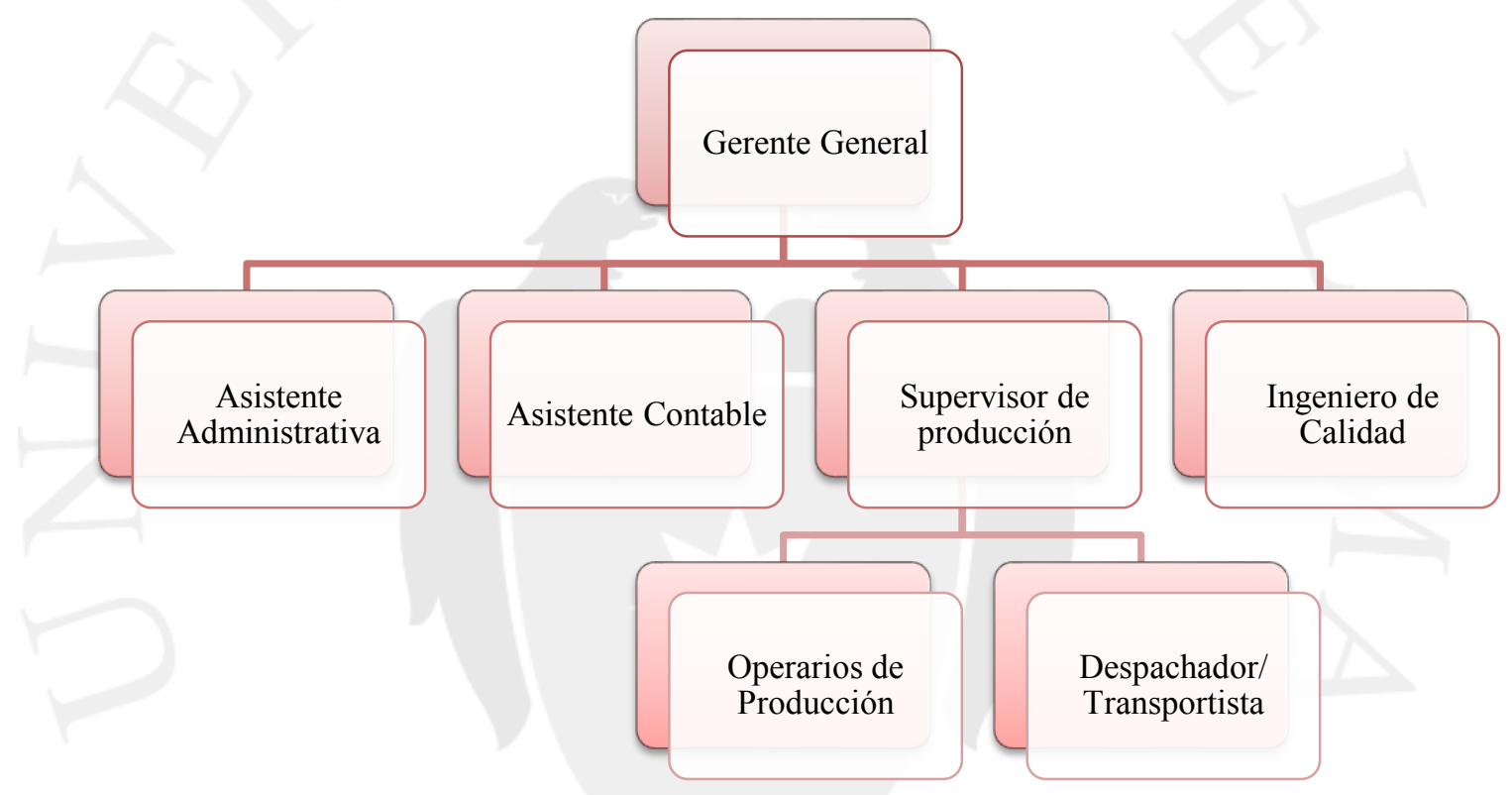

Figura 1. 5: Organigrama de la empresa Claudia Cupcakes.

Fuente: Claudia cupcakes, 2015.

\subsubsection{Visión, misión y objetivos organizacionales}

Observamos que la empresa actualmente no cuenta con una visión, misión y objetivos organizacionales establecidos, lo cual indica una falta de planeamiento estratégico establecida en la Organización. 


\subsection{Objetivos de la Investigación. Justificación de la investigación.}

\subsubsection{Objetivo General}

Realizar un diagnóstico integral a la empresa Claudia Cupcakes ${ }^{\circledR}$ E.I.R.L., dedicada a la elaboración de productos de pastelería y repostería para su comercialización en supermercados y a clientes directos, con la finalidad de aportar propuestas para mejorar los procesos involucrados en su cadena de valor.

\subsubsection{Objetivos Específicos}

El siguiente trabajo de investigación tendrá los siguientes objetivos específicos:

- Realizar un análisis integral de la situación actual de la empresa Claudia Cupcakes.

- Analizar el proceso productivo y de comercialización de cupcakes en la empresa para buscar oportunidades de incrementar la productividad.

- Analizar el nivel de utilización de la capacidad instalada.

- Realizar un análisis de las propuestas para optimizar la calidad e inocuidad alimentaria.

- Evaluar y proponer sugerencias para optimizar el proceso de conducción de la producción. 


\subsection{Justificación de la Investigación}

\subsubsection{Justificación Técnica}

El Proyecto es factible de realizar ya que con él se podrá plantear las mejores alternativas para la optimización de los procesos dentro de la cadena de valor de la empresa, a fin de mejorar la productividad con la capacidad instalada, optimizar los costos y los procesos que aún no se encuentran estandarizados, para obtener un producto de mejor calidad y contribuir con la rentabilidad de la empresa.

Como detalle de este punto, podríamos mencionar que un adecuado registro de la producción y venta histórica para tener la data necesaria con la cual hacer las proyecciones de la demanda. Para esto, debido al tamaño de la empresa la cual por ahora no requiere un mayor nivel de complejidad en sistemas, podría hacerse uso de la herramienta Microsoft Office, con una hoja de cálculo en Microsoft Excel o un aplicativo usado en este mismo software, llamado "Solver", en el cual se pueden realizar proyecciones estimadas por un modelo de ecuación lineal, simulaciones de requerimiento de materiales, el plan maestro de producción y la planeación agregada de producción para un período determinado.

\subsubsection{Justificación Económica}

El proyecto se justifica económicamente en la medida en que la mejora de los procesos de la empresa tendrá un impacto positivo en la rentabilidad, teniendo relación directa con la mejora de productividad y rendimiento en la producción (lo cual podría incluir un rediseño de la disposición de planta, incremento de la capacidad instalada, un mejor manejo de 
inventarios, etc.), y si bien habrá un flujo económico de egresos para la implementación de las mejoras, éste se recuperará en un determinado plazo a raíz de la mejora en el desempeño de los procesos y el cual se verá reflejado en la rentabilidad.

\subsubsection{Justificación Social}

La investigación permitirá a la empresa tomar conciencia sobre la importancia del cuidado en los procesos de producción de alimentos, en cuanto a salubridad y calidad se refiere, con la finalidad de brindar un buen producto asociado a un mejor servicio para la satisfacción y cuidado del consumidor final. Por otro lado, al mejorar los procesos y la rentabilidad, se asegura la sostenibilidad de la empresa y, en consecuencia, la estabilidad en los puestos de trabajo.

\subsection{Hipótesis de trabajo}

La mejora en la eficiencia en los procesos de la empresa Claudia Cupcakes es factible, utilizando las herramientas de la ingeniería para diagnosticar y hacer propuestas que contribuyan a mejorar el desempeño de los procesos y aumentar la rentabilidad. 


\subsection{Marco referencial de la investigación}

\subsubsection{Marco referencial}

Como referencia para la presente investigación, se tomará en cuenta los siguientes trabajos previos, así como revistas, artículos, entre otros:

- Castillo Medina, Aldo. Estudio de pre factibilidad para la instalación de una planta procesadora de productos de pastelería congelados. Trabajo de Investigación presentado para optar por el título profesional de Ingeniero Industrial. Lima, Perú, Universidad de Lima, Facultad de Ingeniería Industrial, 2009. 800 p.

- Brescia Boitano, Alfredo. Estudio preliminar técnico-económico para la implementación de una panadería pastelería en el distrito de La Molina. Trabajo de Investigación para obtener el Grado de Bachiller. Lima, Perú, Universidad de Lima, Facultad de Ingeniería Industrial, 1984. 289

p.

- Donayre, Jáuregui, Juan Ricardo. Estudio de reinversión y redisposición de planta para ampliar la producción y diversificación de productos de panadería y pastelería en la ciudad de Huacho. Trabajo de Investigación para obtener el título profesional de Ingeniero Industrial. Lima, Perú, Universidad de Lima, Facultad de Ingeniería Industrial, 1989. $335 \mathrm{p}$.

- Peralta Vidal, Fernando Enrique. Mejora Integral de un taller de servicios del sector automotriz. Trabajo de Investigación para obtener 
el título profesional de Ingeniero Industrial. Lima, Perú, Universidad de Lima, Facultad de Ingeniería Industrial, 2012. 109 p.

- León-Gambetta Martín-Arranz, Álvaro. Estudio para la mejora integral del fundo San Crispín, productor de café. Trabajo de Investigación para obtener el título profesional de Ingeniero Industrial. Lima, Perú, Universidad de Lima, Facultad de Ingeniería Industrial, 2011. 167 p.

- Delgado Moscoso, Giordano Esaú. Mejora en el proceso de producción de una empresa de artes gráficas. Trabajo de Investigación para obtener el título profesional de Ingeniero Industrial. Lima, Perú, Universidad de Lima, Facultad de Ingeniería Industrial, 2013. 121 p.

- Bernuy Gálvez, Katherine Rosa. Implementación de una propuesta para la mejora de calidad en la atención del Sistema de Transporte Asistido de la Emergencia (STAE) de ESSALUD. Trabajo de Investigación para obtener el título profesional de Ingeniera Industrial. Lima, Perú, Universidad de Lima, Facultad de Ingeniería Industrial, 2006. 413 p.

- Revista Panadería y Pastelería Peruana. Edición Nº 160.

\subsubsection{Marco conceptual}

La Pastelería en el Perú se remonta desde los inicios de la época Colonial. Según Hinostroza Molina de Clausen (2012), en aquel entonces, la nueva aristocracia tenía un gran gusto por los dulces y las monjas traían viejas recetas españolas las cuales realizaban y posteriormente comercializaban; así, en los conventos de esa época se preparaban platos para ofrecer en 
banquetes y ahí las hijas de las familias acaudaladas eran enviadas para ser educadas y protegidas de los problemas del mundo, teniendo en sus celdas las comodidades de las cuales estaban acostumbradas, como por ejemplo, cocinas propias en donde aprendían la preparación de potajes y pasteles, en donde también se inició un intercambio cultural con sus sirvientas, las cuales les enseñaron a sustituir los ingredientes originales por productos Peruanos. Posteriormente en Lima, así como en otras ciudades que los españoles fundaron en todo el Perú, las damas eran educadas, entre otras actividades, en la preparación de una gran variedad de dulces con los recursos propios de cada región, destacando así, por su alta producción azucarera, la zona Norte del país con sus muestras culinarias, hasta que poco a poco ésta pasión por la repostería se fue expandiendo por todo el territorio Peruano, emergiendo así una gran variedad de postres, dulces y pasteles típicos de cada lugar.

Es así que hoy en día la Pastelería Peruana debe adecuarse a las preferencias actuales, con el dinamismo que exige el arte de la repostería, pero sin perder la esencia de sus preparaciones tradicionales.

Dentro de estas variedades de productos que van surgiendo en el mercado de la Pastelería y Repostería Peruana, es que aparecen los cupcakes, los cuales se remontan a sus orígenes en los Estados Unidos a inicios del siglo XIX, aunque comenzaron a llegar con más fuerza a nuestro mercado en el siglo XXI. Su objetivo se asocia a una idea clara: prepararlos y cocinarlos resultaba más económico por su tamaño y, por ende, necesita menos tiempo en el horno. Y aunque hoy en día ésta idea sigue siendo una gran premisa 
para este negocio, es también el ser visualmente muy agradables y deliciosos los que lo hacen muy atractivos en el mercado, en nuestro caso, el Peruano, que tiene un gran gusto por detalles como estos; además, claro está, se tiene una gran rentabilidad con ellos.

Por otro lado, según la Revista de Panadería y Pastelería Peruana (2014), la Industria del Cupcake ha ido en incremento a nivel mundial y, con ello, la modernización ha ido también de la mano. Claro ejemplo es que, en sus inicios, éste producto constaba únicamente de base y cobertura, pero luego se añadieron demás detalles e ingredientes a su estructura, dándole un mayor valor agregado al producto inicial; asimismo, en la actualidad, con el progreso de diversas tecnologías en los alimentos, los cupcakes han podido ser mejorados gracias a nuevos ingredientes e insumos, como enzimas, batidos, etc., los cuales no sólo mejoran el producto, sino también, prevén el fracaso en la producción y perseverancia del mismo y, en consecuencia, el éxito del negocio, con un mejor producto, menos costoso y con una calidad mayor y estandarizada.

Ahora bien, enfocándonos en la gestión de una empresa en el rubro de Pastelería y Repostería especializada en la producción de Cupcakes, como es el caso de esta investigación, es adecuado tener una idea con respecto a ciertos conceptos directamente relacionados con ello, como son los siguientes: 
- Norma ISO 9001-2008 para el Sistema de Gestión de la Calidad

Norma internacional que especifica los requisitos para la implementación de un Sistema de Gestión de la Calidad en una organización. Se basa en 3 aspectos fundamentales: Enfoque basado en procesos, Orientación al cliente y la Mejora Continua.

\section{- Sistema BPM y HACCP para la Seguridad e Inocuidad Alimentaria} Las Buenas Prácticas de Manufactura (BPM) son condiciones mínimas para la obtención de alimentos inocuos, que a su vez es un requisito previo para la obtención del Sistema HACCP. Este último se aplica en la elaboración de alimentos, identificando los peligros para inocuidad alimentaria, estableciendo métodos de control.

\section{- ISO 22000 para la Gestión de la Inocuidad de Alimentos}

Esta norma define y especifica los requerimientos para desarrollar e implementar un Sistema de Inocuidad de Alimentos para mejorar la seguridad alimentaria a lo largo de la cadena de suministro.

\section{- $\quad$ Ley de Seguridad y Salud en el Trabajo $N^{\circ} 29783$}

En ella se establecen los principios, la política nacional, el sistema nacional y el sistema de gestión de la seguridad y salud en el trabajo. Así mismo los derechos y obligaciones, la información de accidentes de trabajo y enfermedades ocupacionales, la inspección de trabajo en seguridad y salud en el trabajo. 


\section{- Decreto Supremo No 005-2012-TR}

Es el reglamento de la Ley $\mathrm{N}^{\circ} 29783$, ley de seguridad y salud en el trabajo, donde se regulan la política, organización, planificación y aplicación del sistema de gestión de la seguridad y salud en el trabajo, el reglamento interno de seguridad y salud en el trabajo, los derechos y obligaciones tanto de los empleadores como de los trabajadores, la notificación de los accidentes de trabajo y enfermedades profesionales, la investigación de accidentes de trabajo y enfermedades ocupacionales e incidentes peligrosos.

\section{- Norma OHSAS 18001:2007. British Standards Institute (BSI)}

Esta norma es un estándar voluntario que fue publicado inicialmente en el año 1999 por el British Standard Institute (BSI) y modificada en el 2007. Su finalidad es proporcionar a las organizaciones un modelo de sistema para la gestión de seguridad y salud en el trabajo. Este estándar determina las exigencias que deben implantarse $y$, por lo tanto, justificarse en las auditorias de certificación que se realicen.

\section{- Balance Scorecard (BSC)}

Una herramienta estratégica para la gestión empresarial que permite establecer los indicadores estratégicos para medir las actividades de la empresa de acuerdo a lo establecido en la visión y el plan estratégico, de acuerdo a las siguientes perspectivas: financiera, del cliente, de procesos y desarrollo de personas y aprendizaje. 
- Cadena de Valor

Nos permitirá describir el desarrollo de las actividades de la empresa maximizando el valor y reduciendo los costos.

- IPER (Identificación de peligros y evaluación de riesgos)

Podremos priorizar los riesgos de acuerdo al nivel crítico establecido. Se realiza un estudio de la situación actual para diagnosticar el estado mediante dos enfoques: Seguridad e Inocuidad alimentaria y Seguridad y Salud en el trabajo.

- AMFE (Análisis modal de fallos y efectos)

Nos ayudará a establecer los posibles fallos de los equipos o procesos, analizando las consecuencias y establecer medidas de protección.

- ISHIKAWA

Mediante este diagrama, conocido también como diagrama de espina de pescado, podremos analizar las causas raíces de los principales problemas que afectan a la cadena de producción lo cual origina una creciente demanda insatisfecha en el mercado, para posteriormente dar solución a estas.

\section{- Diagrama de relaciones o relacional}

Herramienta que permite establecer la ubicación de los distintos departamentos existentes en la empresa, de acuerdo a la relación de la actividad y la información relacionada con el flujo de la información, materiales, etc. 


\section{- Método de Guerchet}

Herramienta que permite calcular el requerimiento total de espacio de acuerdo a tres superficies, estática, gravitacional y evolutiva. 


\section{CAPÍTULO II: ANÁLISIS SITUACIONAL DE LA EMPRESA Y SU ENTORNO}

\subsection{Análisis del Marco Global}

El negocio de la Pastelería y Repostería en el Perú ha tenido un crecimiento considerable en los últimos años. Este se ha dado gracias a una serie de factores en su entorno económico, social, demográfico, legal, tecnológico, entre otros.

A continuación, se hará un breve análisis con respecto a éstos factores y su comportamiento como entorno al negocio estudiado en el presente trabajo, de modo así que podamos tener una idea más clara de se encuentra la empresa actualmente en el mercado.

\subsubsection{Entorno Económico}

Según el analista Elmer Cuba, socio director de la firma de consultoría económica "Macroconsult", el Perú tendría un crecimiento anual durante el 2015 cercano al 4.9\% y, en lo que respecta al sector de manufactura, su crecimiento estaría en el orden del 3.1\%, siendo éste una fuerte recuperación al índice presentado durante el 2014. Asimismo, se espera que el Perú esté dentro del top de los países con mayor crecimiento en el mundo pese a la volatilidad externa. Por otro lado, para los próximos 3 años se espera un ritmo de crecimiento promedio anual alrededor del 5.6\%, el cual contará con el soporte de la aceleración temporal de las exportaciones debido a la entrada 
en operación de grandes proyectos mineros actualmente en ejecución y de una contribución sostenida por el lado de la demanda interna. Así, las perspectivas de crecimiento para el Perú siguen siendo favorables.

Desde hace unos años, nuestro país viene experimentando un crecimiento económico y, como muestra de ello, la llegada y crecimiento de nuevas industrias está generando nuevos y mejores puestos de trabajo, lo que conlleva a una estabilidad y mejoría económica en los peruanos. Claro ejemplo de ello es que, según el portal Perú.com (2013), el último reporte publicado por el Banco Mundial y la Corporación Financiera Internacional (IFC) considera al Perú como el segundo mejor país de América Latina para hacer negocios, por debajo de Chile y por encima de Colombia y México, destacando la facilidad de apertura de nuevos negocios, demostrando así que el crecimiento no sólo impacta internamente sino también, en la imagen que el país proyecta al exterior.

Sin duda todo este crecimiento se ve reflejado en los indicadores macroeconómicos, por ejemplo, el PBI: 
Tabla 2. 1: Indicadores macroeconómicos del Perú

\begin{tabular}{|c|c|c|c|c|}
\hline \multicolumn{5}{|c|}{$\begin{array}{c}\text { INDICADORES MACROECONÓMICOS PERÚ } \\
\text { Valores a precios constantes (reales) al año 2007. }\end{array}$} \\
\hline Año & $\begin{array}{c}\text { PBI } \\
\text { En millones de } \\
\text { NS) }\end{array}$ & $\begin{array}{c}\text { Variación \% } \\
\text { anual PBI }\end{array}$ & $\begin{array}{c}\text { PBI Per Cápita } \\
\text { (En nuevos soles) }\end{array}$ & $\begin{array}{c}\text { Variación \% anual } \\
\text { PBI P/C }\end{array}$ \\
\hline 2000 & 222,207 & 2.69 & $8,551.82$ & 1.13 \\
\hline 2001 & 223,580 & 0.62 & $8,479.69$ & -0.84 \\
\hline 2002 & 235,773 & 5.45 & $8,817.44$ & 3.98 \\
\hline 2003 & 245,593 & 4.17 & $9,061.32$ & 2.77 \\
\hline 2004 & 257,770 & 4.96 & $9,387.08$ & 3.60 \\
\hline 2005 & 273,971 & 6.29 & $9,851.34$ & 4.95 \\
\hline 2006 & 294,598 & 7.53 & $10,464.76$ & 6.23 \\
\hline 2007 & 319,693 & 8.52 & $11,224.43$ & 7.26 \\
\hline 2008 & 348,923 & 9.14 & $12,112.42$ & 7.91 \\
\hline 2009 & 352,584 & 1.05 & $12,102.97$ & -0.08 \\
\hline 2010 & 382,380 & 8.45 & $12,978.78$ & 7.24 \\
\hline 2011 & 407,052 & 6.45 & $13,660.52$ & 5.25 \\
\hline 2012 & 431,273 & 5.95 & $14,310.95$ & 4.76 \\
\hline 2013 & 456,103 & 5.76 & $14,966.46$ & 4.58 \\
\hline
\end{tabular}

PBI PERÚ A PRECIOS CONSTANTES AL 2007 Y VARIACIÓN \% ANUAL

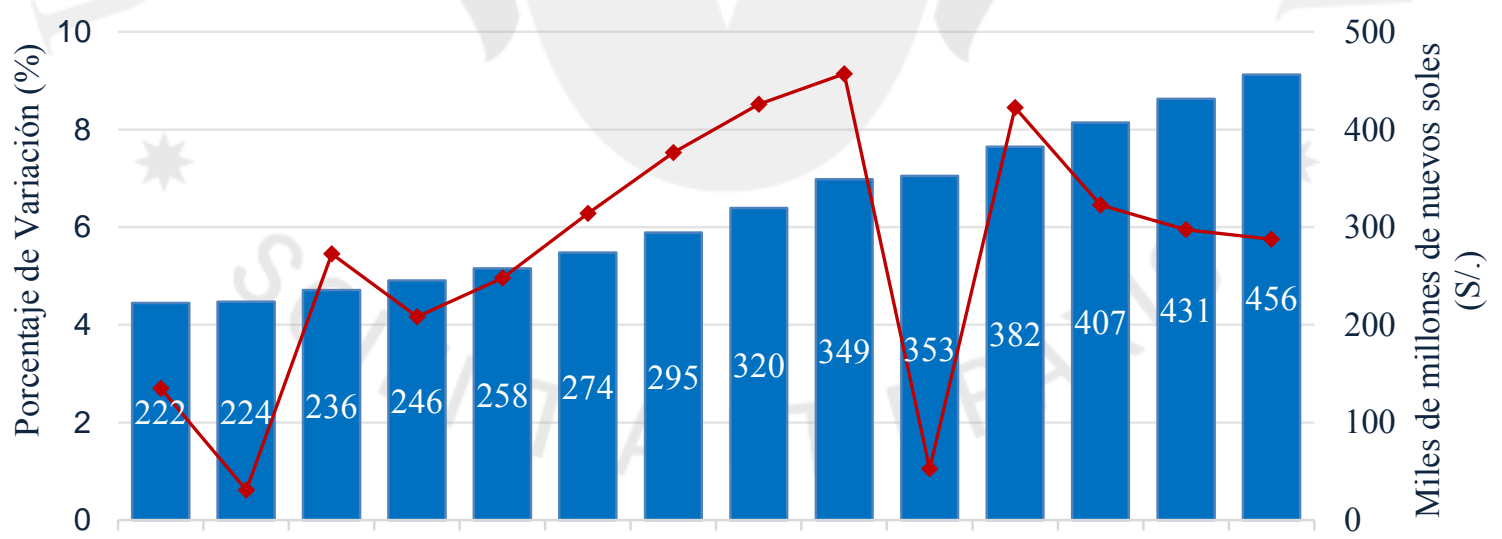

20002001200220032004200520062007200820092010201120122013

$\longrightarrow$ PBI $\longrightarrow \%$

Figura 2. 1: Evolución del PBI del Perú en los últimos años

Fuente: INEI, 2014 
Observamos que el país ha tenido altas tasas de crecimiento y éstas se han mantenido en los últimos años, y aunque por ahora se empieza a frenar ligeramente, éste sigue teniendo aún un panorama alentador para los próximos años.

Ahora bien, al tener una idea más clara con respecto al entorno Económico del Perú a nivel macro, nos enfocamos al análisis del sector al cual pertenece la industria de la Pastelería, de modo que se tenga también una idea del comportamiento del mercado en este aspecto, y considerando que éste rubro está dentro del concepto de transformación de materias primas en productos terminados o elaborados, se entiende que está dentro del sector de Manufactura.

Así entonces, podríamos considerarla participación de éste sector dentro del PBI, enfocándonos en la Industria Alimenticia, a la cual pertenece:

Tabla 2. 2: Participación de la Industria Manufacturera en el PBI total

\begin{tabular}{|c|c|c|c|}
\hline Año & PBI & $\begin{array}{c}\text { Industrias } \\
\text { Manufactureras }\end{array}$ & \% Participación \\
\hline 2008 & 348,923 & 57,354 & 16.44 \\
\hline 2009 & 352,584 & 53,502 & 15.17 \\
\hline 2010 & 382,380 & 59,255 & 15.50 \\
\hline 2011 & 407,052 & 64,330 & 15.80 \\
\hline 2012 & 431,273 & 65,265 & 15.13 \\
\hline 2013 & 456,103 & 69,002 & 15.13 \\
\hline
\end{tabular}


De acuerdo al cuadro, se observa que la participación de la Industria Manufacturera en el PBI ha tenido un promedio cercano al 16\% en los últimos años. Aunque se ve también que este ha tenido un ligero descenso debido el crecimiento de otros sectores; situación muy parecida que sucede en la Industria Alimenticia como parte de éste sector, la cual, del total del valor agregado de la industria, tiene un promedio de participación del 23\%, tal como se aprecia a continuación:

Tabla 2. 3: Valor agregado de la producción manufacturera

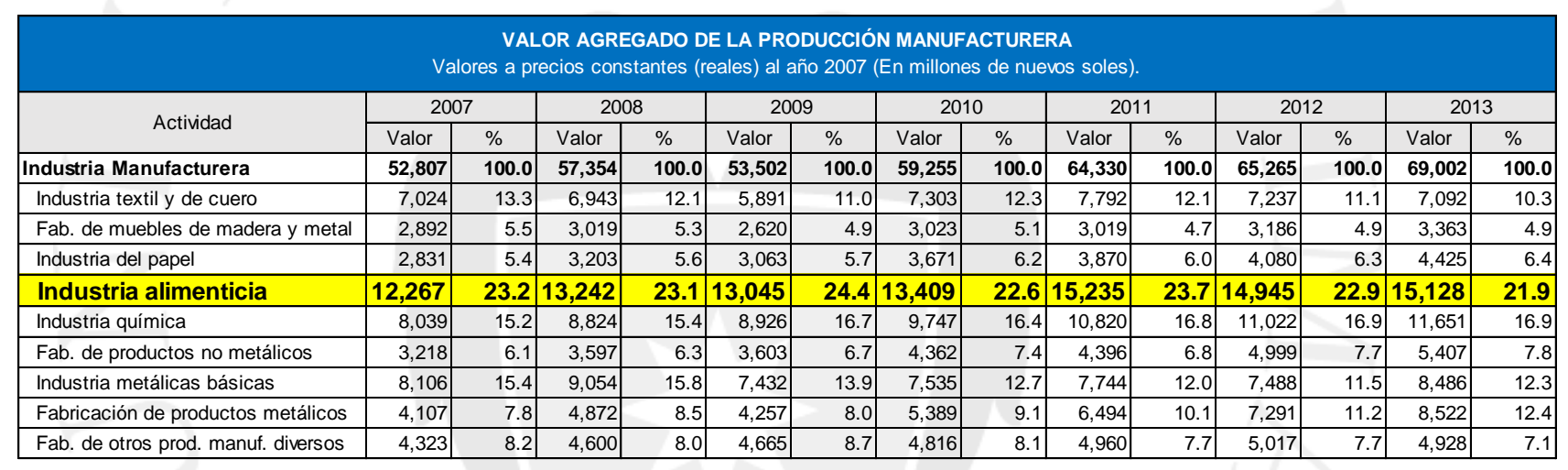

Asimismo, yendo un poco más allá en nuestro análisis, podemos profundizar con el valor agregado de cada sub-sector dentro de la Industria Alimenticia, de modo que podamos tener una visión más exacta del sector al cual pertenece la empresa en estudio: 
Tabla 2. 4: Valor agregado de la producción en la industria alimenticia

\begin{tabular}{|c|c|c|c|c|c|c|c|c|c|c|c|c|c|c|}
\hline \multicolumn{15}{|c|}{$\begin{array}{l}\text { VALOR AGREGADO DE LA PRODUCCIÓN EN LA INDUSTRIA ALIMENTICIA } \\
\text { Valores a precios constantes (reales) al año } 2007 \text { (En millones de nuevos soles). }\end{array}$} \\
\hline \multirow{2}{*}{ Actividad } & \multicolumn{2}{|c|}{2007} & \multicolumn{2}{|c|}{2008} & \multicolumn{2}{|c|}{2009} & \multicolumn{2}{|c|}{2010} & \multicolumn{2}{|c|}{2011} & \multicolumn{2}{|c|}{2012} & \multicolumn{2}{|c|}{2013} \\
\hline & Valor & $\%$ & Valor & $\%$ & Valor & $\%$ & Valor & $\%$ & Valor & $\%$ & Valor & $\%$ & Valor & $\%$ \\
\hline Industria alimenticia & 12,267 & 100.0 & 13,242 & 100.0 & 13,045 & 100.0 & 13,409 & 100.0 & 15,235 & 100.0 & 14,945 & 100.0 & 15,128 & 100.0 \\
\hline Procesamiento y conservación de carnes & 1,347 & 11.0 & 1,471 & 11.1 & 1,495 & 11.5 & 1,625 & 12.1 & 1,709 & 11.2 & 1,838 & 12.3 & 1,894 & 12.5 \\
\hline Elaboración y preservación de pescado & 990 & 8.1 & 1,059 & 8.0 & 875 & 6.7 & 773 & 5.8 & 1,219 & 8.0 & 1,091 & 7.3 & 970 & 6.4 \\
\hline Elaboración de harina y aceite de pescado & 1,638 & 13.4 & 1,631 & 12.3 & 1,576 & 12.1 & 988 & 7.4 & 1,880 & 12.3 & 1,060 & 7.1 & 1,023 & 6.8 \\
\hline Fabricación de productos lácteos & 867 & 7.1 & 952 & 7.2 & 915 & 7.0 & 1,037 & 7.7 & 1,089 & 7.1 & 1,167 & 7.8 & 1,209 & 8.0 \\
\hline Molinería, fideos y otras pastas & 1,455 & 11.9 & 1,583 & 12.0 & 1,629 & 12.5 & 1,708 & 12.7 & 1,662 & 10.9 & 1,818 & 12.2 & 1,802 & 11.9 \\
\hline Panadería y pastelería & 1,186 & 9.7 & 1,233 & 9.3 & 1,273 & 9.8 & 1,356 & 10.1 & 1,378 & 9.0 & 1,416 & 9.5 & 1,543 & 10.2 \\
\hline Elaboración y refinación de azúcar & 466 & 3.8 & 524 & 4.0 & 556 & 4.3 & 546 & 4.1 & 565 & 3.7 & 582 & 3.9 & 621 & 4.1 \\
\hline Otros & 4,318 & 35.2 & 4,789 & 36.2 & 4,726 & 36.2 & 5,376 & 40.1 & 5,733 & 37.6 & 5,973 & 40.0 & 6,066 & 40.1 \\
\hline
\end{tabular}

De éste último cuadro vemos cómo la participación de la actividad de panadería y pastelería, tiene un índice bastante bueno dentro de la estructura de la Industria Alimenticia, incluso dentro del top 5 de todos los sub sectores en ésta industria, teniendo en promedio muy cercano al 10\% en los últimos años y manteniendo un ligero crecimiento sostenido, lo cual también se ve en los datos de la evolución y desarrollo en la producción, así como en la importación y exportación de algunos insumos y/o ciertos productos relacionados a éste sub sector: 
Tabla 2. 5: Producción manufacturera en el Perú

\begin{tabular}{|c|c|c|c|}
\hline \multicolumn{4}{|c|}{$\begin{array}{l}\text { PRODUCCIÓN MANUFACTURERA EN EL PERÚ } \\
\text { (miles de Ton.) }\end{array}$} \\
\hline Año & Harina de trigo & $\begin{array}{c}\text { Chocolates } \\
\text { diversos }\end{array}$ & $\begin{array}{c}\text { Postres } \\
\text { Instantáneos }\end{array}$ \\
\hline 2008 & 1,044 & 12.03 & 7.48 \\
\hline 2009 & 1,081 & 11.40 & 8.04 \\
\hline 2010 & 1,214 & 15.35 & 8.55 \\
\hline 2011 & 1,236 & 15.20 & 9.01 \\
\hline 2012 & 1,248 & 21.51 & 9.42 \\
\hline 2013 & 1,202 & 22.50 & 10.09 \\
\hline
\end{tabular}

Tabla 2. 6: Importaciones y Exportaciones del sector de Panadería y Pastelería

\begin{tabular}{|c|c|c|c|c|c|}
\hline \multicolumn{6}{|c|}{ IMPORTACIONES Y EXPORTACIONES PARA EL SECTOR PANADERÍA Y PASTELERÍA } \\
\hline \multirow{2}{*}{ Tipo } & \multirow{2}{*}{ Año } & \multicolumn{2}{|c|}{ Productos de Panadería y Pastelería } & \multicolumn{2}{|c|}{ Insumos para Panadería y Pastelería } \\
\hline & & $\mathrm{Kg}$ & FOB US\$ & $\mathrm{Kg}$ & FOB US\$ \\
\hline \multirow{5}{*}{ Imp. } & 2009 & 693,131 & $1,853,402.17$ & 95,966 & $180,173.91$ \\
\hline & 2010 & $1,191,809$ & $3,048,674.25$ & 136,447 & $274,461.82$ \\
\hline & 2011 & $1,267,749$ & $3,541,703.38$ & 202,948 & $599,999.35$ \\
\hline & 2012 & $1,258,488$ & $3,153,458.94$ & 303,904 & $834,046.60$ \\
\hline & 2013 & $1,379,282$ & $3,532,017.73$ & 304,783 & $925,561.11$ \\
\hline \multirow{5}{*}{ Exp. } & 2009 & $1,612,685$ & $5,016,268.00$ & 32,494 & $58,568.00$ \\
\hline & 2010 & $1,518,730$ & $4,835,889.00$ & 37,258 & $55,495.00$ \\
\hline & 2011 & $1,814,439$ & $6,049,437.00$ & 19,922 & $34,467.00$ \\
\hline & 2012 & $1,863,739$ & $6,250,978.00$ & 11,052 & $52,912.00$ \\
\hline & 2013 & $1,848,445$ & $5,455,143.00$ & 224,680 & $203,102.00$ \\
\hline
\end{tabular}

Como se observa, de la mano con el crecimiento de la economía peruana está también el crecimiento de la industria de panadería y pastelería, lo cual podría significar una estabilidad de este sector en el mercado.

Finalmente, un factor de análisis en el Perú actualmente es el crecimiento y expansión del número de centros comerciales, lo cual tiene también relación 
con el crecimiento sostenido de la Economía. Así, la evolución en los últimos años en cuanto al número de centros comerciales en el país se ha dado como se muestra a continuación:

\section{Centros Comerciales en el Perú}

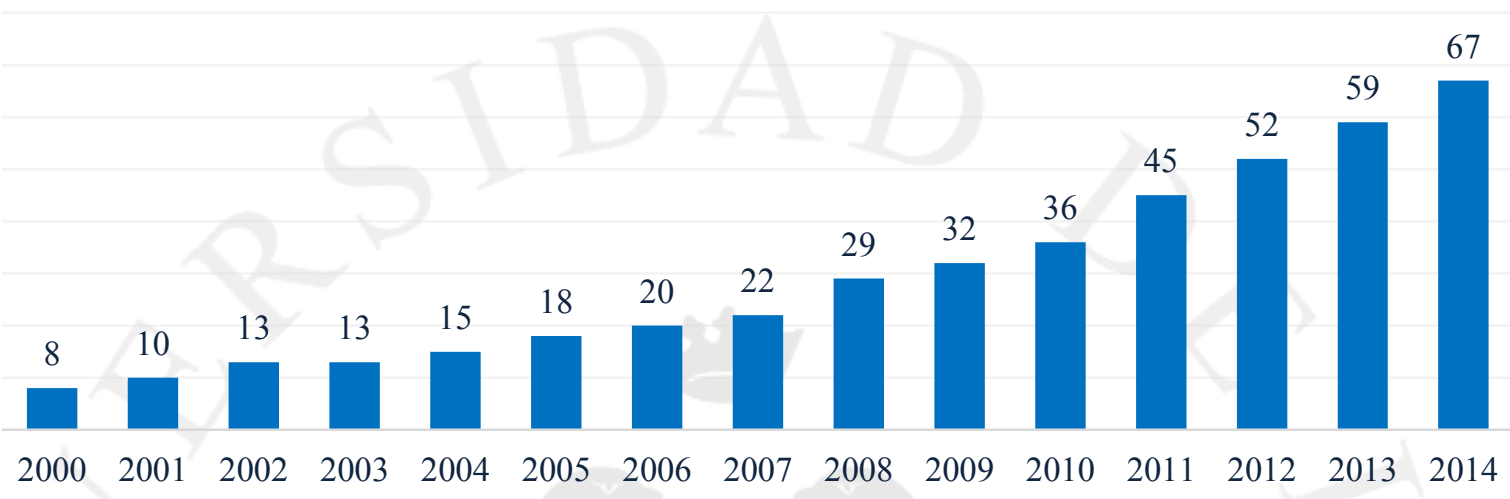

Figura 2. 2: Evolución del número de centros comerciales en el Perú

Fuente: Diario Gestión, 2014.

Según estimaciones brindadas por el diario Gestión (2014), para el 2019 todas las ciudades del país contarán con al menos un centro comercial, lo que podría representar también para el sector de pastelería y repostería una oportunidad de crecimiento y expansión, considerando además que hoy en día existe un centro comercial por cada 500 mil habitantes en el Perú, según cita dicha fuente también; sin embargo, se está aún por debajo de países como México o Ecuador, donde la presencia de centros comerciales es de uno por cada 200 mil y por cada 160 mil habitantes, respectivamente. Asimismo, estimaciones hechas por estudios de mercado, durante el 2014 se habría alcanzado una facturación que bordearía los US\$ 7,000 MM, con un flujo superior a las 40 millones de visitas de clientes. 


\subsubsection{Entorno Social}

Un factor muy importante en el entorno social en el que se desarrolla la pastelería es la gastronomía Peruana, considerada como el boom actual en nuestra sociedad, ya que gracias a sociedades como APEGA (Sociedad Peruana de Gastronomía), entre otros promotores, incentivaron el crecimiento y desarrollo de este sector. Estos vieron un gran potencial debido a nuestra variedad en recursos alimenticios, así como también grandes agentes impulsadores de cultura culinaria; así por ejemplo Mistura, un proyecto de APEGA, se ha convertido en un festival gastronómico internacional cuyo objetivo es el de promover la cocina peruana como base de identidad cultural y como factor de desarrollo económico, y es que el Perú tiene tanto potencial como para competir con las grandes capitales gastronómicas a nivel mundial y no es para menos, pues fuimos elegidos por segunda vez como "El mejor destino culinario del mundo" en los premios "World Travel Award", el premio más prestigioso de la industria turística global.

Actualmente la gastronomía peruana continúa con el crecimiento sostenible dentro y fuera del país, contribuyendo así a la transformación de la sociedad mediante la inclusión social, aportando optimismo y orgullo, y prueba de ello es el aumento de restaurantes en el país, ya que desde el año 2009 ha habido un incremento en un 17\% de restaurantes a nivel nacional, así como también la expansión de algunos restaurantes nacionales al extranjero llevando nuestra gastronomía a los paladares más exigentes. 
Sin embargo, así como éste factor es importante en el análisis del entorno social, el estudio a la persona también es igual o más importante aún; así, por ejemplo, si nos enfocamos en el segmento de estudio para este trabajo como mercado objetivo, tenemos algunos detalles que nos ayudan a entender el comportamiento del consumidor. Siguiendo esa línea, según una encuesta realizada en el año 2013 por IPSOS para el perfil de consumidor, tenemos como dato que el adulto joven asiste al supermercado en un promedio 2.6 veces al mes; además, se puede verificar que Metro es el supermercado más concurrido por este segmento según podemos apreciar a continuación:

\section{PARTICIPACIÓN DE SUPERMERCADOS EN EL PERÚ}

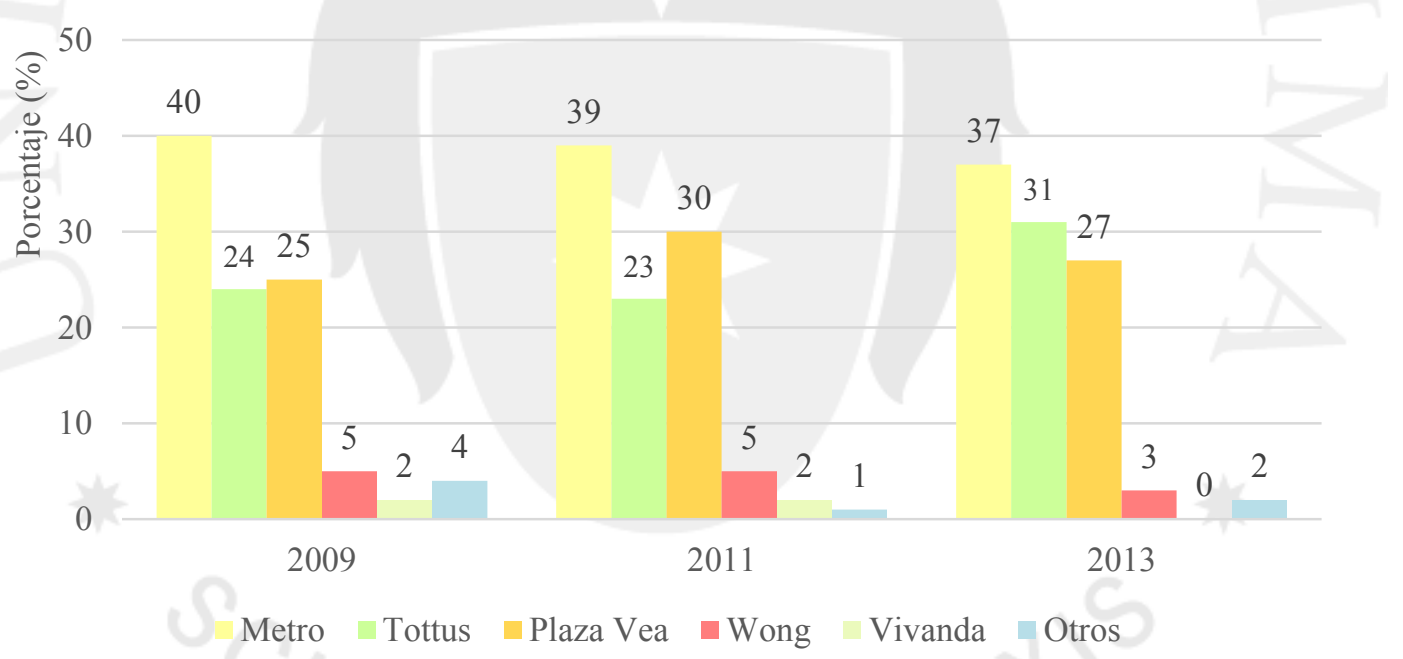

Figura 2. 3: Participación de Supermercados en el Perú

Fuente: IPSOS Perú, 2014.

Por otro lado, enfocando el análisis en base a la asistencia a los supermercados como uno de los canales de venta de los productos en estudio en el presente trabajo en función a los NSE, según un estudio realizado por 
IPSOS observamos, por ejemplo, que los NSE A y B tienen en conjunto mayor concentración en los supermercados Metro, Plaza Vea, Tottus y Wong, siendo un dato interesante el hecho que aparezca como preferencia en estos segmentos los supermercados Tottus dada su estrategia de brindar productos de calidad a precios bajos en el mercado, lo cual si se relaciona de manera más directa con la preferencia en los estratos más bajos, tal como se observa a continuación:

ASISTENCIA A SUPERMERCADOS POR NIVEL SOCIOECONÓMICO

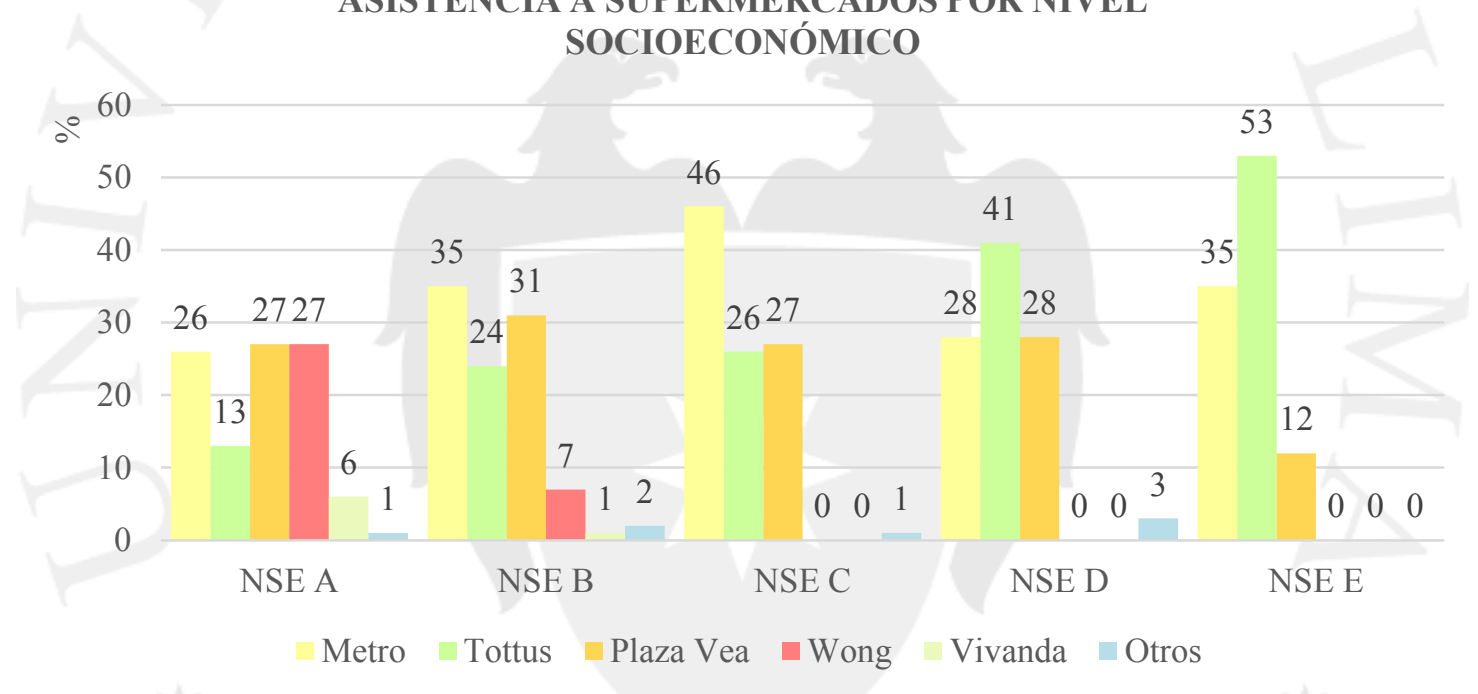

Figura 2. 4: Asistencia a supermercados por nivel socioeconómico Fuente: IPSOS Perú, 2014. 


\subsubsection{Entorno Demográfico}

El análisis del entorno demográfico lo enfocamos a nivel nacional y en Lima metropolitana, considerando el mercado en donde haremos el estudio de la empresa en los capítulos posteriores. Para ello, comenzamos analizando la población y su crecimiento en el tiempo, haciendo un particular enfoque en el rango de las edades que nos interesa estudiar para nuestro trabajo. Así tenemos:

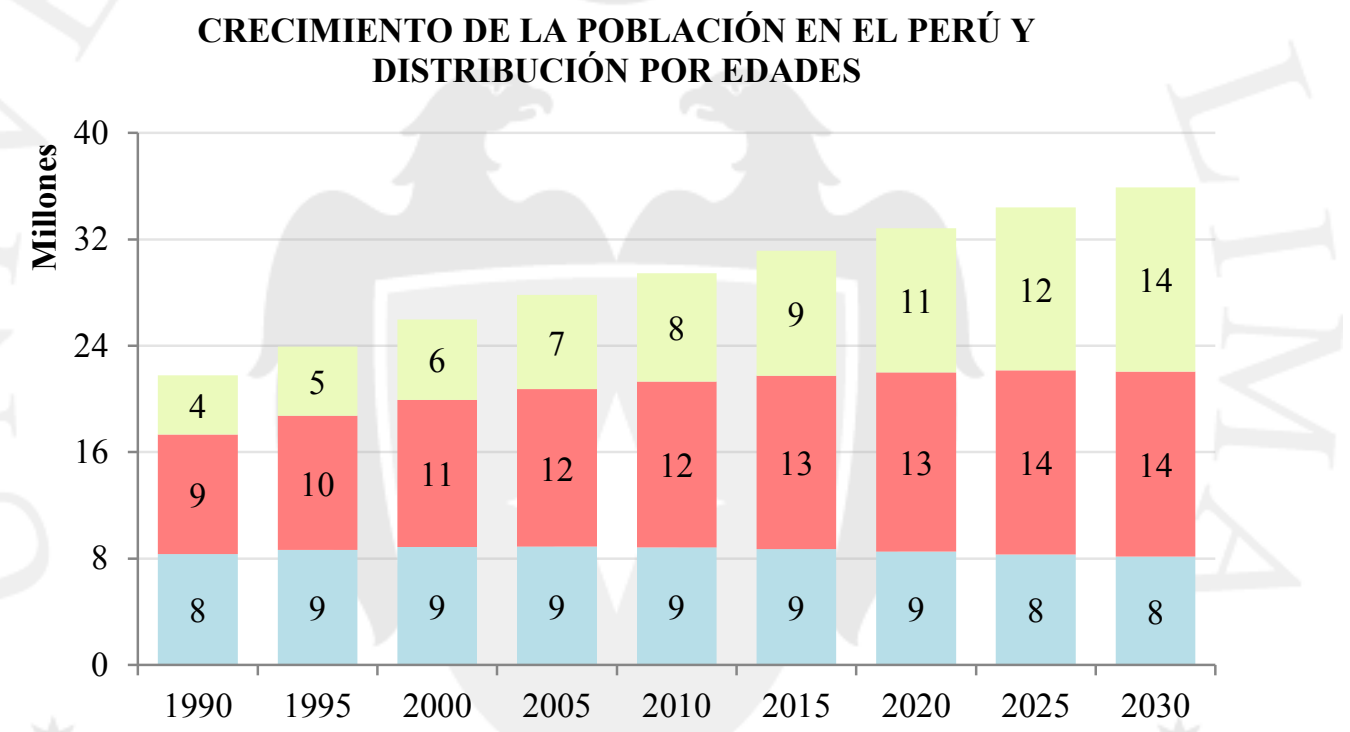

Figura 2. 5: Crecimiento de la población en el Perú y su distribución por edades Fuente: INEI, 2014. 


\section{Distribución de la población peruana al 2013}

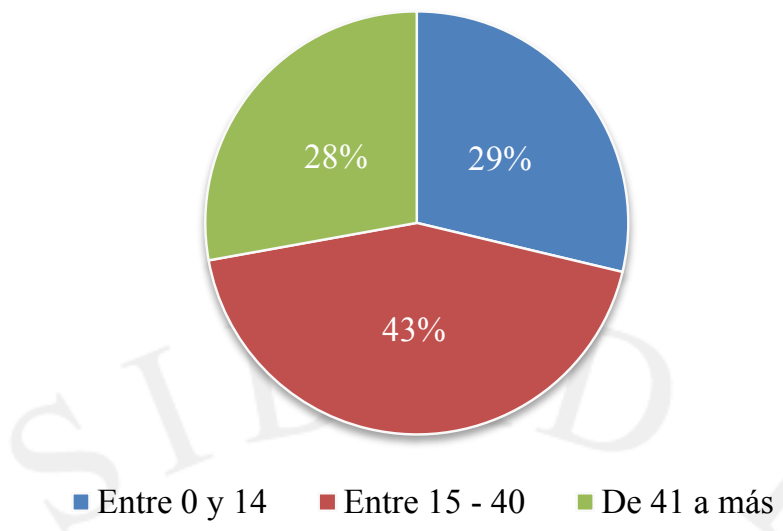

Figura 2. 6: Distribución por edades de la población peruana al 2013

Observamos que la población ha ido en crecimiento y se proyecta que la tendencia se mantenga en los próximos años; así también, si nos enfocamos particularmente en la población entre 15 y 40 años, quienes son básicamente el público objetivo de la empresa, vemos que en los últimos años el porcentaje que representa del total de la población ha ido también creciendo, siendo a la fecha aproximadamente el $43 \%$ del total, aunque en el futuro se espera que éste rango de edad tenga la misma proporción que la población en edades de 41 años a más; cabe mencionar que, aunque no está en los gráficos arriba mostrados, de acuerdo a la información analizada se sabe que la cantidad de hombres y mujeres del total de la población en el país están casi igualados y dicha tendencia se mantiene en todos los rangos de edades, habiendo en promedio una mínima diferencia de aproximadamente $0.22 \%$ más hombres que mujeres. Ahora, haciendo un análisis cualitativo entre las diferencias de la población en cuanto a la edad, vemos ciertos rasgos para 
analizar. Por ejemplo, de acuerdo a cifras de IPSOS Perú (2013), de la población considerada dentro del rango de Adultos Jóvenes (21 - 35 años aprox.), es decir, gran parte del mercado objetivo de la empresa en estudio, un 79\% destina sus ingresos a gastos de alimentación. Por otro lado, según Álvarez \& Cánepa (2013), estiman que un 74\% de esta población tiene la costumbre de, al menos, comprar regalos a amigos $y / o$ familiares en ocasiones especiales. Para lo cual podríamos considerar al cupcake como una buena alternativa. Así también, los mismos autores muestran que, dentro del grupo de población en edad de niñez (hasta los 13 años aprox.), un 77\% invierte el monto que recibe en propinas en golosinas $y / u$ otros dulces y un $7 \%$ compra lo que se considera propiamente como comida, lo cual podría dar a entender que enfocar el mercado de compra directamente en este segmento no sería algo adecuado ya que la mayoría de consumidores en este rango de edad lo hacen mediante la compra es por parte de sus padres o tutores.

Es también un factor importante a tomar en cuenta la distribución actual de la población según las ciudades más importantes del país, tomando en cuenta principalmente a aquellas en las que la empresa enfoca la mayor cantidad de sus ventas actualmente: 


\section{Dsitribución de la Población total en algunas de las principales ciudades del Perú al 2013}

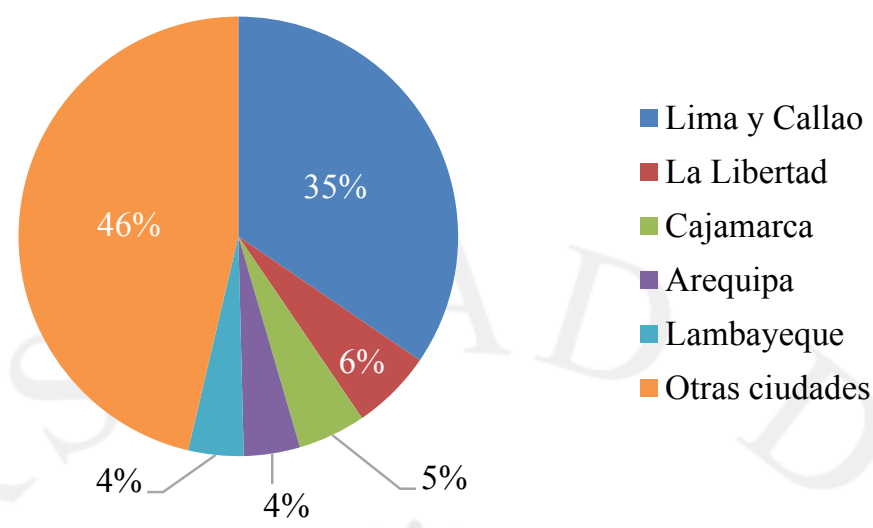

Figura 2. 7: Distribución de la población Peruana por ciudades al 2013.

Fuente: INEI, 2014.

Se observa que más de la tercera parte de la población total del Perú está en Lima y Callao, lugares en donde se desarrolla con mayor fuerza la empresa en estudio y lo cual es un factor a favor; asimismo, se muestra el porcentaje que representan las demás ciudades como Cajamarca, Arequipa, Chiclayo y Trujillo, ya que son éstas las ciudades donde también hay presencia de la empresa, aunque en menor medida que en Lima y Callao. Vemos también que un $46 \%$ del total de los peruanos están en otras ciudades, lo cual es un factor de análisis para apuntar la estrategia de ventas y expansión en otras ciudades a futuro.

Por otro lado, un factor de análisis demográfico es la distribución de los niveles socioeconómicos en el mercado donde se desarrolla la empresa y a nivel general, observando su evolución en el tiempo: 


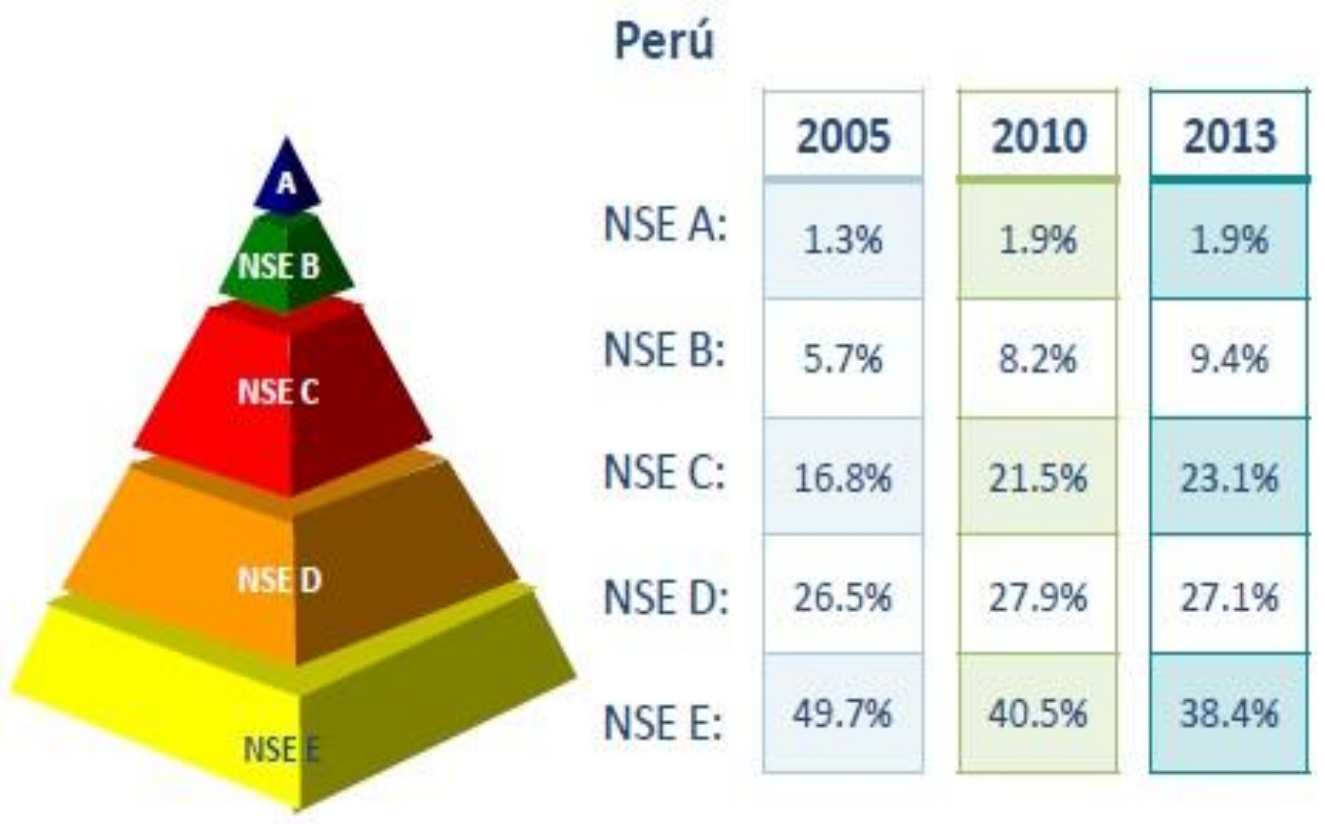

Figura 2. 8: Evolución de la distribución de los NSE en el Perú. Fuente: IPSOS Perú, 2014.

EVOLUCIÓN DE LOS NSE EN LIMA METROPOLITANA

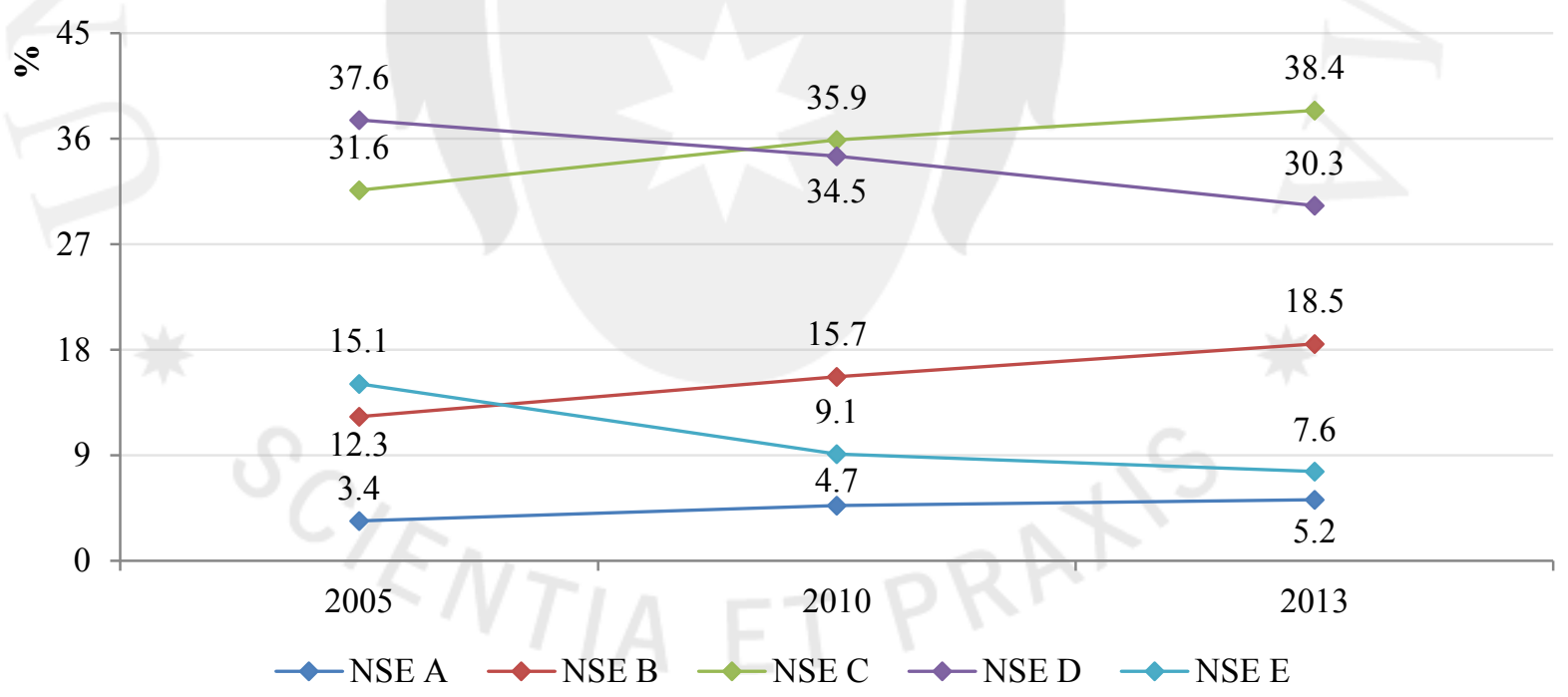

Figura 2. 9: Evolución de la distribución de los NSE en Lima Metropolitana.

Fuente: Elaboración Propia. 
Podemos observar que los niveles A y B, principales nichos de mercado a los que apunta la empresa en estudio por el tipo de producto y, sobretodo, por el precio, ha tenido un ligero crecimiento en los últimos 8 años, siendo un poco mayor en el segmento B; no obstante, el porcentaje que representan del total de la población a nivel país y a nivel de Lima Metropolitana, no es alto a comparación, por ejemplo, del NSE C, el cual también ha tenido un crecimiento. Este es casi el doble de lo que representa el total de los NSE A y B juntos y se consideraría como el grueso de la población, por lo que podría ser un elemento a evaluar en el futuro. Además, vemos que a nivel general, los NSE considerados en estado de pobreza ha disminuido en los últimos años, lo cual indica también que quizá más adelante podría analizarse la posibilidad de ingresar a este mercado con alguna estrategia que apunte a ellos.

\subsubsection{Entorno Normativo}

En la industria de alimentos se debe asegurar la inocuidad alimentaria a lo largo de toda la cadena productiva, por lo que el entorno legal en donde se desarrolla esta industria tiene, básicamente, la función de implementar normas o leyes que cuiden al consumidor, por lo que se ha visto la necesidad de introducir mejoras en los sistemas nacionales de producción alimentaria, basándose en las reglamentaciones del riesgo y unificándolas con el Codex Alimentarius. 
El Codex Alimentarius es un conjunto de normas y reglamentos que se crearon con el objetivo de proteger la salud de los consumidores y garantizar la equidad en las prácticas comerciales de alimentos. Asimismo, esta información podrá servir como guía para establecer definiciones y requisitos aplicables en alimentos con el fin de armonizar el comercio internacional. Las normas CODEX se podrán aplicar a todo aquello que formará parte de la producción del alimento. Líneas abajo se puede apreciar un gráfico en el cual se detalla el ámbito al cual aplican las normas CODEX a lo largo de la cadena alimentaria.

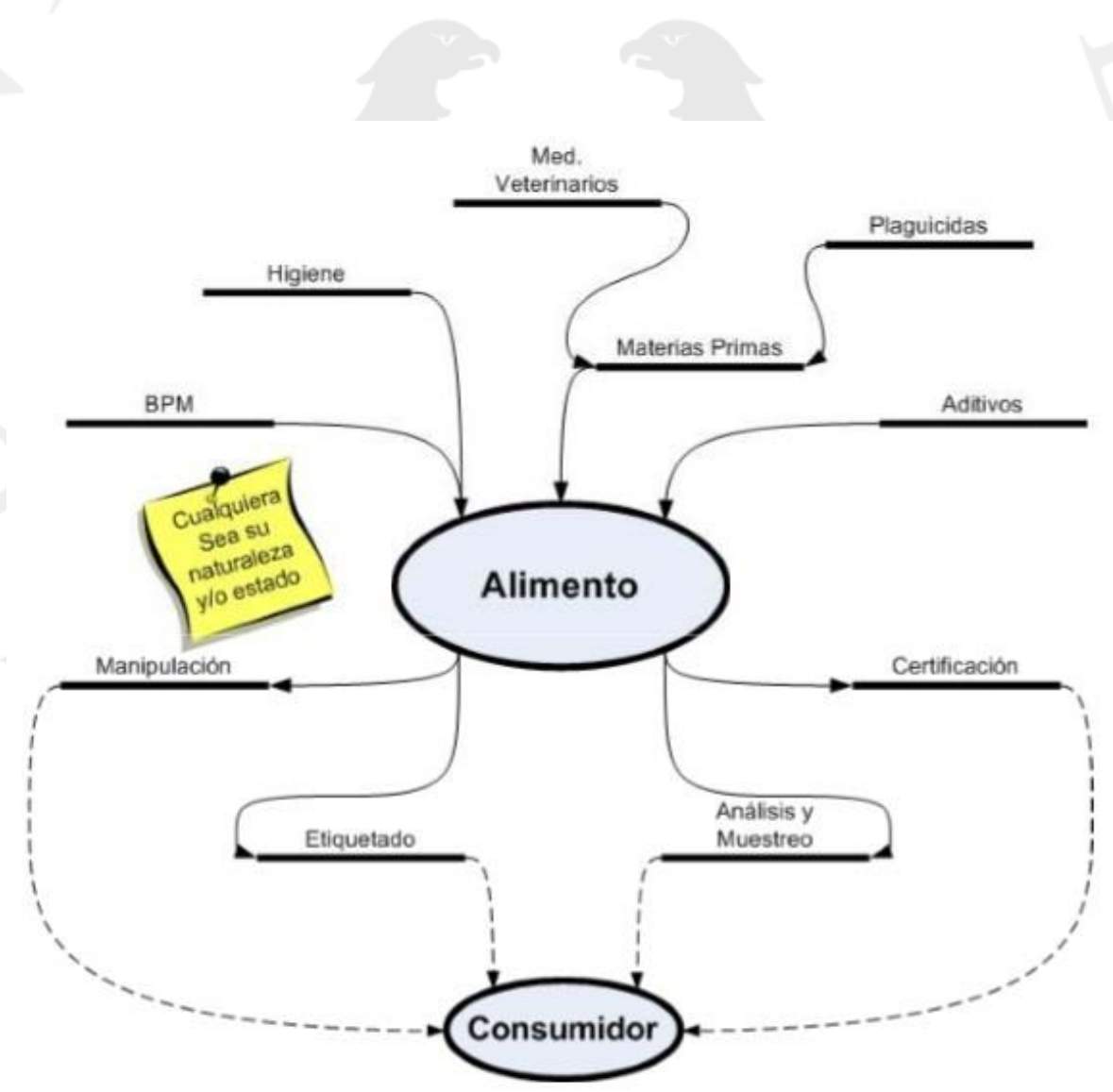

Figura 2. 10: Aplicación de las CODEX en la cadena alimentaria.

Fuente: DIGESA, 2012. 


\subsubsection{Entorno Legal}

Las autoridades nacionales son responsables de proteger la salud pública reduciendo los riesgos de contraer enfermedades transmitidas por los alimentos y de educar e informar a los consumidores y a la industria alimentaria de todos los aspectos relativos a la inocuidad de los alimentos; sin embargo, a nivel nacional no todas las empresas en esta industria cumplen con brindar un producto de calidad y la mayoría de veces actúan de manera más reactiva que preventiva.

Es entonces cuando el gobierno se ve en la necesidad de introducir leyes y normas en las cuales se puedan regular las prácticas para la producción y comercialización de estos productos alimenticios, así como su entorno productivo. Enfocándonos en la línea de pastelería y panadería, tenemos las siguientes leyes y normas aplicables:

\section{a. Ley $\mathrm{N}^{\circ} 26842$, Ley General de Salud}

b. Ley No 29571, Código de protección y defensa del consumidor.

c. Decreto Legislativo $\mathrm{N}^{\circ} 1062$ que aprueba la Ley de Inocuidad de los Alimentos.

d. Decreto Supremo No $034-2008-A G$ que aprueba el Reglamento de la Ley de Inocuidad de los Alimentos.

e. Decreto Supremo No 012-2006-SA, que aprueba el Reglamento de la Ley $\mathrm{N}^{\circ}$ 28314, Ley que dispone la fortificación de harinas con micronutrientes. 
f. Decreto Supremo No 003-2005-SA, que aprueba el Reglamento de la Ley $N^{\circ} 27932$, Ley que prohíbe el uso de la sustancia química bromato de potasio en la elaboración del pan y otros productos alimenticios destinados al consumo humano.

g. Decreto Supremo 007-98-SA que aprueba el Reglamento sobre Vigilancia y Control Sanitario de Alimentos y Bebidas.

h. Resolución Ministerial N 449-2006/MINSA que aprueba la Norma Sanitaria para la aplicación del Sistema HACCP en la fabricación de alimentos y bebidas.

i. Resolución Ministerial $N^{\circ}$ 461-2007/MINSA, que aprueba la Guía Técnica para el Análisis Microbiológico de Superficies en contacto con Alimentos y Bebidas.

j. Resolución Ministerial N 591-2008/MINSA que aprueba la Norma sanitaria que establece los criterios microbiológicos de calidad sanitaria e inocuidad para los alimentos y bebidas de consumo humano.

k. Resolución Ministerial No 363-2005/MINSA que aprueba la Norma Sanitaria para el funcionamiento de restaurantes y servicios afines.

l. Ley No. 29783, Ley de Seguridad y Salud en el Trabajo y su respectivo reglamento D.S. 005-2012-TR. 


\subsubsection{Entorno Tecnológico}

Finalmente, pero no menos importante, hacemos un análisis general de cómo está el entorno tecnológico en donde se sitúa la industria de la Pastelería y Repostería, considerando que, como industria manufacturera, la tecnología es un factor clave para su adecuado desarrollo y crecimiento.

En primer lugar, podríamos comenzar observando el comportamiento de la denominada "Tecnología Dura", llamado así a todo el entorno relacionado a la maquinaria que se usa en la industria y la manera en cómo se desarrolla en el mercado:

Tabla 2. 7: Importaciones y Exportaciones de máquinas para Panadería y Pastelería.

\begin{tabular}{|c|c|c|c|c|c|c|c|}
\hline \multicolumn{8}{|c|}{$\begin{array}{l}\text { IMPORTACIONES Y EXPORTACIONES DE MAQUINARIA PARA EL SECTOR DE } \\
\text { PANADERÍA Y PASTELERÍA }\end{array}$} \\
\hline \multirow{2}{*}{ Tipo } & \multirow{2}{*}{ Año } & \multicolumn{2}{|c|}{ Hornos de Tonel } & \multicolumn{2}{|c|}{ Otros tipos de hornos } & \multicolumn{2}{|c|}{ Maquinaria en General } \\
\hline & & Unidades & FOB US\$ & Unidades & FOB US\$ & Unidades & FOB US\$ \\
\hline \multirow{5}{*}{ Imp. } & 2009 & 11 & $1,032,528.81$ & 49 & $485,271.13$ & 1,143 & $4,034,217.01$ \\
\hline & 2010 & 22 & $932,684.21$ & 148 & $1,161,543.00$ & 1,821 & $7,887,675.47$ \\
\hline & 2011 & 19 & $1,462,784.95$ & 68 & $659,430.74$ & 1,203 & $4,909,827.85$ \\
\hline & 2012 & 3 & $610,054.65$ & 183 & $3,269,028.00$ & 1,848 & $9,177,282.57$ \\
\hline & 2013 & 5 & $67,388.94$ & 169 & $962,522.47$ & 1,530 & $5,182,391.26$ \\
\hline \multirow{5}{*}{ Exp. } & 2009 & - & - & 26 & $211,474.00$ & 208 & $805,840.00$ \\
\hline & 2010 & 1 & $98,000.00$ & 48 & $498,434.00$ & 276 & $567,526.00$ \\
\hline & 2011 & 1 & $1,020.00$ & 60 & $542,303.00$ & 269 & $407,005.00$ \\
\hline & 2012 & - & - & 47 & $512,065.00$ & 297 & $634,535.00$ \\
\hline & 2013 & - & - & 93 & $584,202.00$ & 281 & $451,636.00$ \\
\hline
\end{tabular}


Tal como se aprecia en el cuadro anterior, el mercado de importación y exportación de maquinaria para el sector en estudio ha ido en crecimiento en los últimos 5 años, lo cual refleja también que su desarrollo no sólo está en el Perú sino también en el exterior.

Por otro lado, podríamos también diferenciar un segundo tipo de tecnología a la que podríamos definir como "Tecnología Blanda", considerada a las diversas normas y/o certificaciones a las que están sometidos los productos en este mercado, las cuales fueron mencionadas anteriormente en el capítulo

\subsubsection{Marco Conceptual.}

Finalmente, podemos clasificar como un tercer tipo de tecnología el cual engloba los diversos canales que las empresas utilizan hoy en día para interactuar de manera virtual con el mercado y así pueda llegar a más opciones de compra según lo requiera el cliente. Para ello, se cuenta con la parte "suave" de éstas tecnologías denominada Software, el cual implica los diversos programas y/o aplicativos que permiten esta interacción, tales como el internet mediante las páginas web, redes sociales, etc. Así por ejemplo, según IPSOS Perú (2013), se sabe que actualmente, del grupo denominado como adultos jóvenes, un $52 \%$ se conecta al menos entre 3 a 4 días por semana a internet. Por otro lado, según Álvarez \& Cánepa (2013), el 61\% cuenta con Facebook y accede a él con frecuencia (en su mayoría aquellos dentro del NSE A y B). Asimismo, hoy en día dentro de ésta tecnología ‘suave' están también los ERP, los cuales son aplicativos que brindan un adecuado soporte para la gestión de las organizaciones en el campo de la 
logística, finanzas, etc. También, está la parte "dura" de este tercer tipo de tecnología, denominada hardware, el cual engloba a todos los equipos e instrumentos con los que hoy en día las organizaciones cuentan para el uso adecuado de las herramientas antes mencionadas, como las computadoras, laptops, celulares, etc.

\subsection{Análisis de las fuerzas competitivas}

Para el análisis de las fuerzas competitivas, se utilizó el esquema de Porter:

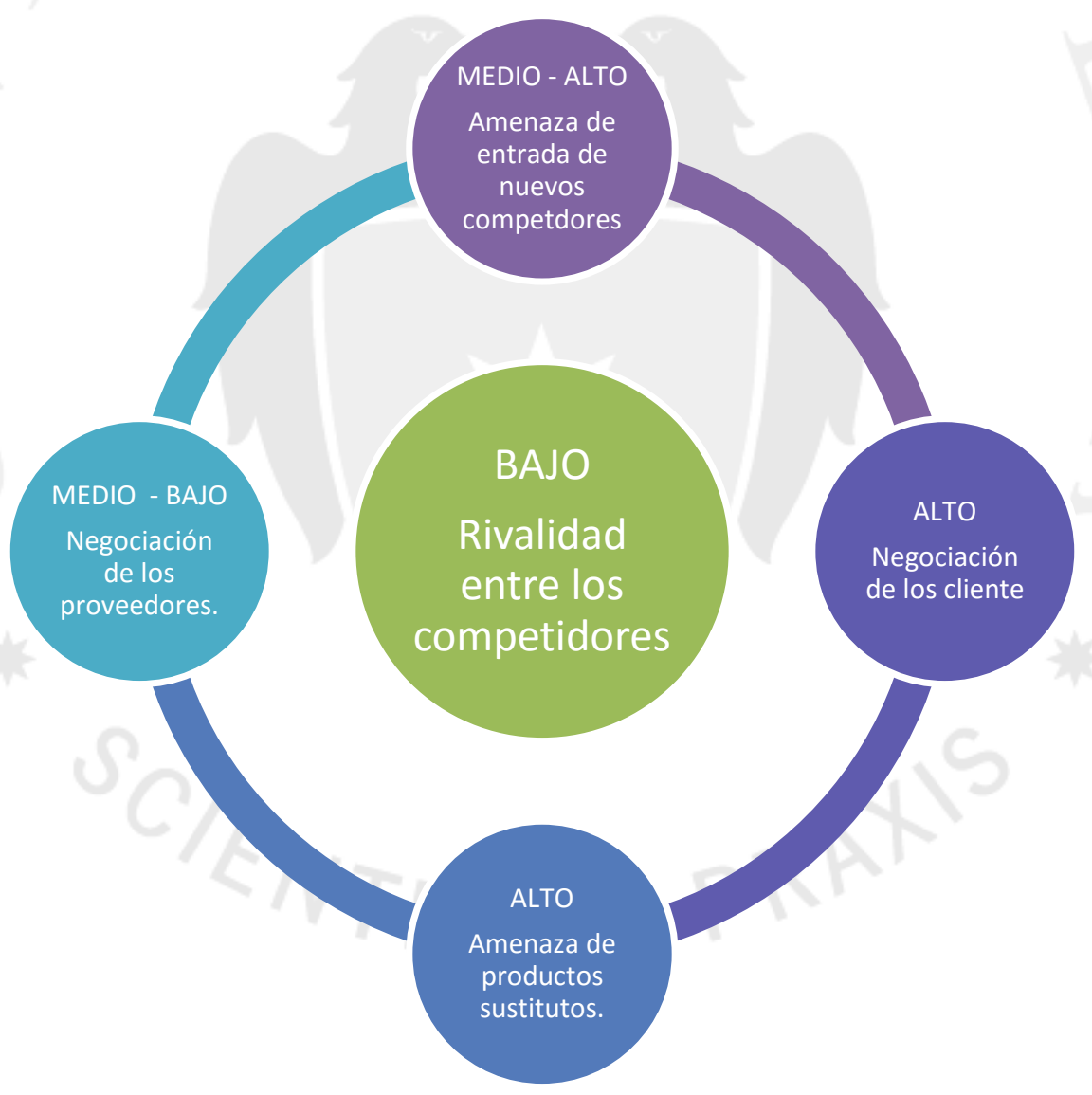

Tabla 2. 8: Esquema de Análisis de Porter para Claudia Cupcakes.

Fuente: Elaboración Propia. 


\section{Tabla 2. 9: Análisis de las Fuerzas Competitivas de Porter para la empresa Claudia Cupcakes.}

\begin{tabular}{|c|c|c|}
\hline FUERZA & NIVEL & DESCRIPCIÓN \\
\hline $\begin{array}{l}\text { F1: Poder de } \\
\text { negociación } \\
\text { de los clientes. }\end{array}$ & Alto & $\begin{array}{l}\text { - Considerando que el cliente principal es la cadena de supermercados CENCOSUD, } \\
\text { no existen en el mercado tantos compradores de gran tamaño como este }(\mathrm{N}) \text {. } \\
\text { - El cliente no necesita de mucha información del producto }(\mathrm{N}) \text {. } \\
\text { - Cencosud, por su tamaño como empresa, podría integrarse hacia atrás y ser, a la vez, } \\
\text { su propio proveedor de éstos productos (N). } \\
\text { - Cliente, en su mayoría, no son sensibles al precio puesto que éste está orientado en } \\
\text { gran medida al sector A/B }(+) \text {. } \\
\text { - Marca reconocida en el mercado, pero no es un producto único en este rubro }(\mathrm{N}) \text {. } \\
\text { - Su principal cliente tiene como finalidad el comercializar los productos de Claudia, } \\
\text { es decir, es un negocio lucrativo }(+) \text {. }\end{array}$ \\
\hline $\begin{array}{l}\text { F2: Poder de } \\
\text { negociación } \\
\text { de los } \\
\text { proveedores. }\end{array}$ & $\begin{array}{c}\text { Medio - } \\
\text { Bajo }\end{array}$ & $\begin{array}{l}\text { - La mayoría de insumos e ingredientes de la empresa son estándar, aunque hay } \\
\text { algunos elementos que son parte de la cadena, como los moldes, que para poder ser } \\
\text { exclusivos tienen que ser traídos, incluso, del extranjero. } \\
\text { - Los proveedores no tendrían mucho interés en integrarse hacia atrás. } \\
\text { - Los costos de los insumos representan gran parte del esquema general de costos, por } \\
\text { lo que variaciones fuertes podrían ser desfavorables para el desarrollo de la empresa. }\end{array}$ \\
\hline $\begin{array}{l}\text { F3: Amenaza } \\
\text { de nuevos } \\
\text { competidores } \\
\text { entrantes. }\end{array}$ & $\begin{array}{l}\text { Medio - } \\
\text { Alto }\end{array}$ & $\begin{array}{l}\text { - En el mercado de pastelería hay marcas ya establecidas y que son reconocidas por el } \\
\text { público consumidor. } \\
\text { - Para el mercado de cupcakes, no es necesario tener una gran inversión y la curva de } \\
\text { aprendizaje es moderada. } \\
\text { - No hay mucha dificultad en acceder a los insumos pero si quizá para el recurso } \\
\text { humano adecuado. } \\
\text { - Los clientes pueden conseguir los cupcakes a un precio similar en el mercado. } \\
\text { - Las características necesarias para hacer frente a la competencia, como el diseño, } \\
\text { encarece al producto final. } \\
\text { - Ante una posible entrada de un nuevo competidor, se espera una respuesta inmediata } \\
\text { de la competencia. }\end{array}$ \\
\hline $\begin{array}{l}\text { F4: Amenaza } \\
\text { de productos } \\
\text { sustitutos. }\end{array}$ & Alto & $\begin{array}{l}\text { - En cuanto al diseño propiamente del producto, no hay un sustituto claro que pueda } \\
\text { cumplir esa necesidad; sin embargo, la necesidad alimenticia puede ser cubierta por } \\
\text { algunas otras opciones. } \\
\text { - Existen productos con características similares al cupcake, a un precio asequible. } \\
\text { - Existen queques, biscochos, pastelitos y tortas que pueden sustituir al cupcake, en } \\
\text { cuanto a darse un gusto. }\end{array}$ \\
\hline $\begin{array}{l}\text { F5: Rivalidad } \\
\text { entre los } \\
\text { competidores. }\end{array}$ & Bajo & $\begin{array}{l}\text { - SI bien la industria del cupcake en el mercado de la pastelería está en crecimiento, } \\
\text { para poder tener un nivel de competencia frente a otras empresas, es necesario tener } \\
\text { ciertas ventajas competitivas que le permita diferenciarse del resto. } \\
\text { - Si es que se establece bien ésta ventaja competitiva, los clientes verán difícil pasarse } \\
\text { a la competencia (costo de oportunidad). } \\
\text { - Actualmente, en el mercado hay muchas empresas e, incluso personas, que producen } \\
\text { cupcakes domésticos que tienen también parte del mercado, pero esto es mínimo, por } \\
\text { lo que la rivalidad no se ve muy reflejada. }\end{array}$ \\
\hline \multicolumn{2}{|c|}{$\begin{array}{r}\text { Evaluación General de la } \\
\text { Industria: }\end{array}$} & Moderado \\
\hline
\end{tabular}


Según el análisis presentado, encontramos que la industria de pastelería, en particular, la de los cupcakes, tiene un panorama favorable para el crecimiento de la empresa lo cual va de la mano con las mejoras que puedan proponerse en el presente trabajo. En el anexo 1, se presentará el detalle de este análisis.

\subsection{Cuadro General de Indicadores de la Empresa}

Como premisa para toda propuesta de mejora que se quiera plantear durante el desarrollo del presente trabajo, se debe tener un sustento numérico que nos muestre una situación actual versus una situación deseada, lo cual debe ir de la mano también en función a las estrategias que tenga la empresa de acuerdo a su visión, misión y según el análisis del entorno al cual está expuesto.

Dicho esto, a continuación mostramos los indicadores principales en aspectos económicos, internos, productivos y de cara al cliente, a fin de poder entender cuál es la situación actual y, en base al análisis a desarrollar, poder determinar cuál podrían ser los niveles deseados a alcanzar en la empresa: 


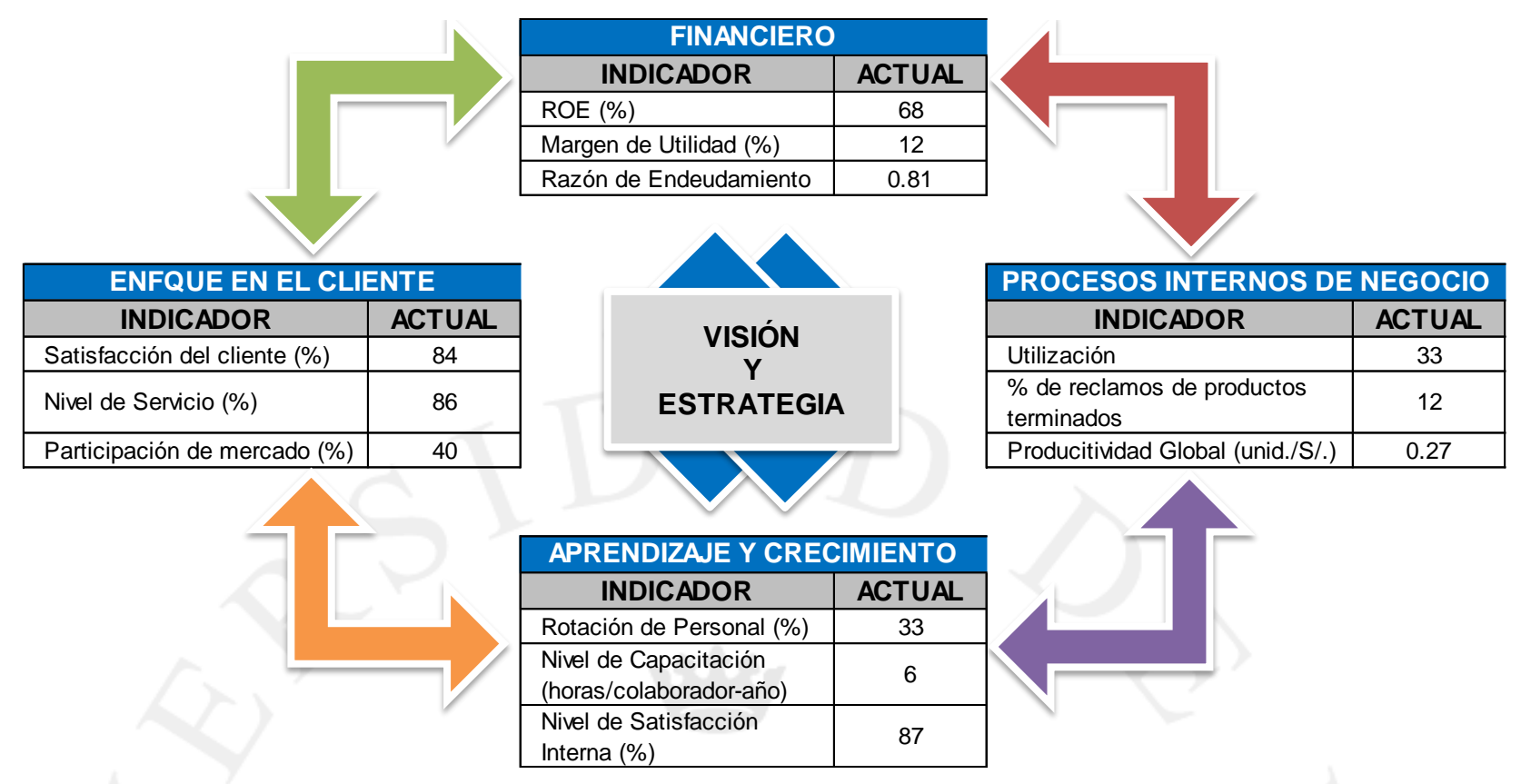

Figura 2. 11: Tablero de control de Indicadores principales de la empresa Claudia Cupcakes.

Fuente: Elaboración Propia. 


\section{CAPÍTULO III: MERCADO Y COMERCIALIZACIÓN DE LOS PRODUCTOS}

\subsection{Mercado}

\subsubsection{Estudio del producto}

Tal como se mencionó anteriormente, la empresa comercializa cupcakes, tortas y pre mezcla envasada, los cuales son ofrecidos, en su mayoría, a la cadena Cencosud como principal cliente.

Para el análisis de éste punto, nos centraremos básicamente en las tortas y el cupcake, considerando que son éstos los productos que representan el mayor porcentaje de ingreso en ventas para la empresa:

\section{a. Como tipo de producto}

Productos o bienes de consumo No Duraderos, ya que son alimentos y son consumidos de manera inmediata. Por otro lado, podrían considerarse también, por el nivel de detalle y calidad que requieren estos productos, como Bienes de Especialidad, dado que no está determinado a un mercado muy amplio, sino más bien, a uno que demanda productos de éste tipo según sus necesidades.

\section{b. Por el nivel de Tangibilidad}

Los cupcakes y tortas se clasifican como un Bien Tangible Puro, ya que la venta y comercialización de éstos no lleva consigo un servicio asociado el cual sea parte del producto en sí para su consumo final. 
Como atributos de éstos productos tenemos:

\section{a. Formulación e Ingredientes}

Satín (pre-mezcla), aceite, agua, huevos, esencia de sabores al gusto, entre otros aditamentos.

\section{b. Componentes y funciones}

La pre-mezcla, aceite, agua y los huevos son la base en la preparación del queque, mientras que la esencia de sabores que se le adiciona es para poder darle el gusto y sabor que el producto requiere y que generalmente es a solicitud del cliente, aunque en su mayoría de veces éste es de vainilla con pequeñas chispas de chocolate. Para mayor detalle, se verá esto en la descripción del producto.

\section{c. Dimensiones y características físicas}

Los cupcakes son de tamaño pequeño, con detalles atractivos al gusto del consumidor. Tienen una cobertura de masa elástica (masa fondant), el cual lleva adornos o detalles solicitados por el cliente. Lo mismo sucede con la torta, lo cual demanda aún más un nivel de especialización en cuanto a acabados y diseños.

\section{d. Envase y empaque}

Por lo general, los cupcakes están colocados en pirotines de papel y agrupados en 6 unidades, los cuales son colocados en un blíster de plástico especial. Además, lleva las etiquetas con el nombre de la marca (o en el caso de Cencosud, el nombre del supermercado pero haciendo 
referencia a la marca Claudia Cupcakes) y la información necesaria para conocimiento del cliente, como ingredientes, registro sanitario, etc. En cuanto a las tortas, éstas están colocadas en moldes o bases de tecnopor, y al momento de ser trasladadas son colocadas en cajas diseñadas especialmente para cada torta dependiendo del tamaño, evitando así también que se dañe o deteriore durante el trayecto al consumidor final.

Para los beneficios del producto, éstos se pueden orientar no sólo al hecho de consumir un producto agradable al sentido del gusto en sabor, sino también, al detalle sensorial que brinda al tener el cliente entre sus manos un producto agradable a la vista y con los diseños que él mismo solicita, teniendo así entonces una opción de personalización del producto ante situaciones particulares. Es decir, en el caso de estos productos, generalmente el cliente busca tener entre sus manos este producto más por los beneficios brindados que por los atributos.

En cuanto a los niveles del producto tenemos: 


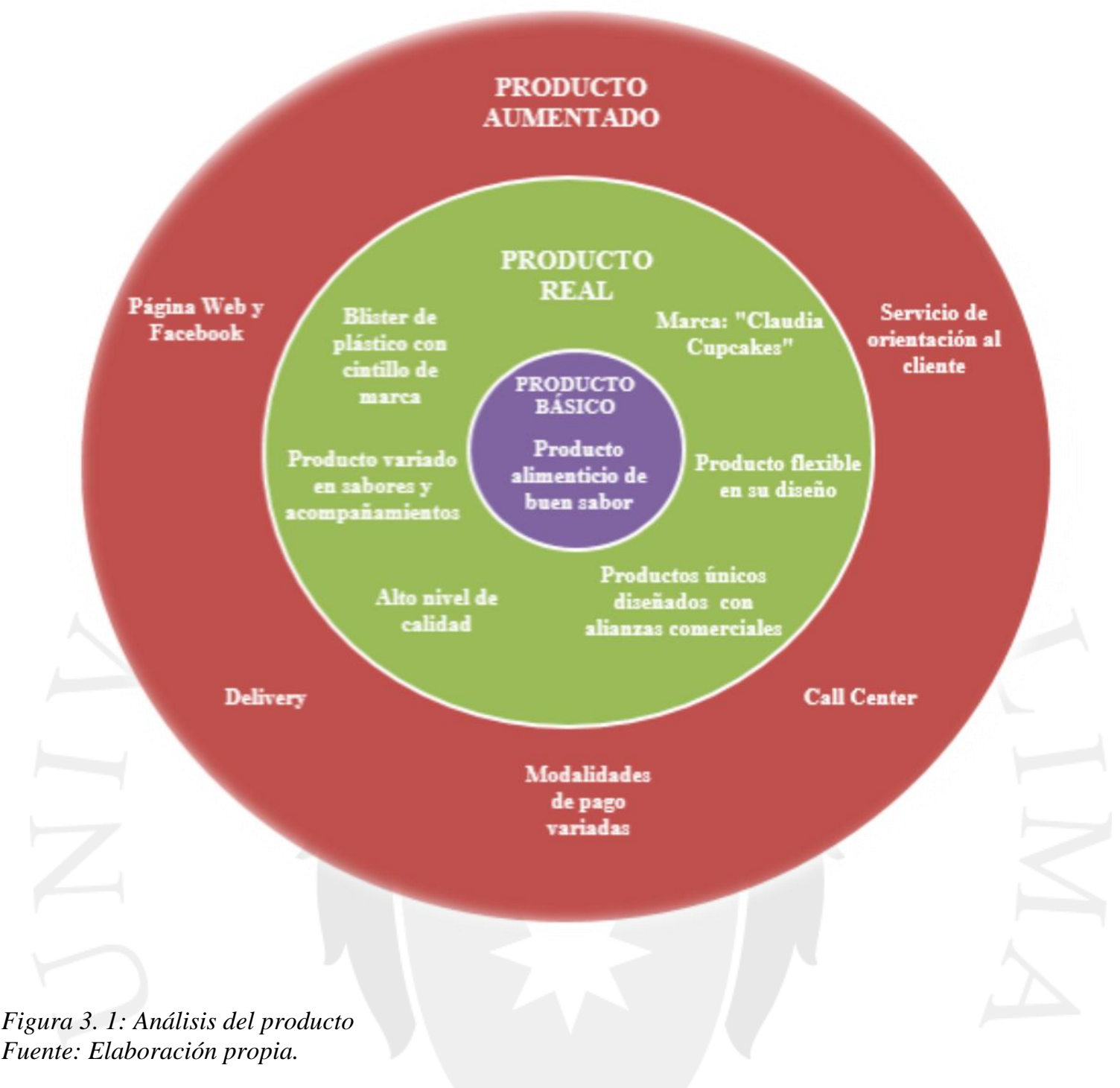

Fuente: Elaboración propia.

Como comentarios al gráfico mostrado, tenemos:

\section{a. Producto básico}

Los cupcakes esencialmente son alimentos que buscan cumplir con la necesidad de consumir un producto de buen sabor y que el cliente pueda darse un gusto con un postre agradable al paladar. 


\section{b. Producto real}

Los cupcakes llevan la marca registrada de Claudia Cupcakes ${ }^{\circledR}$ E.I.R.L, además son un producto flexible en diseños a elección del cliente y con una variada gama de sabores y acompañamientos. Los cupcakes son producidos con un alto nivel de calidad, cuidando minuciosamente cada detalle. Asimismo, la empresa Claudia Cupcakes cuenta con alianzas comerciales con otras compañías como Nestlé y Nutella, creando cupcakes únicos en el mercado con productos como Triangulo Donofrio, Kit-kat, galletas Oreo, leche condensada Nestlé, etc. Por último, en cuanto al empaque, los cupcakes generalmente se presentan en un blíster de 6 unidades, con un cintillo que lleva la marca de Cupcakes ${ }^{\circledR}$ E.I.R.L.

\section{c. Producto aumentado}

Los cupcakes, así como los demás productos comercializados por la empresa, se ofrecen en la página web de Claudia Cupcakes. En la página se pueden realizar los pedidos así como encontrar recetas, recientes noticias de la empresa y contacto. También cuentan con la red social Facebook para mantener una mayor cercanía con los actuales y potenciales clientes. La empresa tiene un número de Call Center en el cual se le orienta al cliente y se recepcionan los pedidos. Las modalidades de pago son variadas, se pueden realizar transferencias a las cuentas de la empresa o cancelar con tarjeta de crédito o débito. Para 
la entrega de los pedidos se cuenta con el servicio de delivery, existe un tarifario de acuerdo al distrito de entrega.

Finalmente, cabe resaltar que en el caso de la empresa en análisis, ésta maneja su línea productos con una misma marca, por lo que todos ellos estarían dentro del grupo que se conoce como marca de familia. La longitud o el mix de sus productos, como ya se mencionó antes, consta de los cupcakes, las tortas y las pre-mezclas, que si bien son producidas por su empresa proveedora de éste insumo, son comercializadas también con la marca Claudia Cupcakes.

\subsubsection{Estudio de la demanda}

El acceso a la información de la industria de panadería y pastelería en el Perú es muy limitado, lo cual dificulta determinar con exactitud la demanda actual de los productos; en particular, del cupcake. Esto debido a que el consumo es en su mayoría doméstico y ello hace difícil poder determinar el tipo y la cantidad de producto que se consume en mayor o menor medida; sin embargo, existen algunos datos que fueron estimados por ASPAN en el 2008 (Asociación Peruana de Empresarios de la Panadería y Pastelería) en este rubro: 
Tabla 3. 1: Consumo per cápita de productos de panadería y pastelería del Perú

\begin{tabular}{|c|c|c|c|c|c|c|c|c|}
\hline \multirow{2}{*}{ Producto } & \multirow{2}{*}{ Perú } & \multirow{2}{*}{$\begin{array}{c}\text { Lima } \\
\text { Metropolitana }\end{array}$} & \multirow{2}{*}{$\begin{array}{l}\text { Resto del } \\
\text { País }\end{array}$} & \multicolumn{2}{|c|}{ Área } & \multicolumn{3}{|c|}{ Región Natural } \\
\hline & & & & Urbana & Rural & Costa & Sierra & Selva \\
\hline Galletas & 1.8 & 1.9 & 1.7 & 1.8 & 1.5 & 1.8 & 1.6 & 1.6 \\
\hline Pan & 24 & 23.6 & 24.1 & 26.5 & 15.3 & 25.4 & 25.6 & 13.8 \\
\hline Pasteles y Tortas & 1.2 & 1.8 & 0.9 & 1.5 & 0.3 & 1.5 & 0.8 & 0.8 \\
\hline
\end{tabular}

Sin embargo, según Pío Pantoja ${ }^{1}$, actualmente el consumo per cápita habría alcanzado los $35 \mathrm{~kg}$ de productos de panadería y pastelería en el Perú; no obstante, este ratio está aún muy por debajo del consumo recomendado por la OMS que es de $55 \mathrm{~kg}$ per cápita y más lejos aún del consumo en Chile que asciende a $80 \mathrm{~kg}$ per cápita. Esto debido probablemente a una falta de costumbre de consumo de estos productos, ya que la cultura peruana considera la mayoría de veces su consumo sólo en el desayuno o en la cena. Con esto concluimos que la demanda en este sector tiene un crecimiento "vegetativo" al ritmo del crecimiento de la población, tal como lo describió Alejandro Daly² en el 2013.

Sin embargo, a pesar de lo expuesto, viendo el crecimiento de las ventas de Claudia Cupcakes y del mercado en general en éste producto, vemos que es un crecimiento sostenido y que, de a pocos, va tomando gran relevancia. Es así, por ejemplo, que en el caso de la empresa en análisis, al iniciar sus

\footnotetext{
${ }^{1}$ Presidente de Asociación Peruana de Empresarios de la Panadería y Pastelería (ASPAN).

${ }^{2}$ Miembro de la Sociedad Nacional de Industrias.
} 
operaciones en el año 2008 facturó un aproximado de S/.80,000.00 y, al cierre del 2014, se registró una facturación de más de S/.14400,000.00, por lo que el crecimiento en poco más de 4 años ha sido sustancial.

\subsubsection{Estudio de la oferta, competidores}

Actualmente es muy complicado poder ubicar o determinar claramente a la competencia formal, esto dado que ante la practicidad de la elaboración de estos productos, gran parte de los cupcakes son comercializados de forma casera y al menudeo sin tener rastro de ésta venta.

No obstante, al haber crecido este mercado a lo largo del tiempo, ha habido empresas que ante la popularidad y crecimiento de Claudia Cupcakes, han ido entrando al mercado con propuestas también novedosas para los clientes, en muchos casos incluso más accesibles para el bolsillo de los consumidores, aunque sin el mismo nivel de Calidad.

Entre los principales competidores de la empresa en análisis está Miss Cupcakes, Dolce Cuore, Haylli, entre otros. Para mayor detalle al respecto, revisar el anexo 02.

\subsubsection{Precios de mercado}

En éste mercado existe una amplia variedad de productos, desde los panes más comunes, hasta chocolatería y pasteles bien elaborados, cuyos precios dependen de ciertos factores, tales como el tipo de producto, tamaño, calidad y cantidad, entre los principales. Si nos enfocamos en los productos de 
cupcakes y tortas, el precio además depende del nivel de personalización requerida y los ingredientes.

Tomando el caso de la empresa en análisis y otras empresas que mantienen la formalidad en el rubro, el precio promedio por una unidad de cupcake fluctúa entre los $\mathrm{S} / .5 .00-\mathrm{S} / .6 .00$, siendo así un producto con un alto margen de ganancia puesto se estima un costo de producción unitario aproximado de $\mathrm{S} / .1 .50-\mathrm{S} / .2 .00$.

A continuación podemos apreciar un cuadro comparativo de precios de cupcakes por unidad:

Tabla 3. 2: Precios de cupcakes en el mercado Peruano

\begin{tabular}{|c|c|c|c|c|}
\hline & Claudia Cupcakes & Miss Cupcakes & Dolce Cuore & Haylli \\
\hline $\begin{array}{l}\text { Precio por } \\
\text { unidad }\end{array}$ & S/. 6.00 & S/. 6.00 & S/. 5.00 & S/. 6.00 \\
\hline
\end{tabular}

Cabe mencionar que generalmente éste producto se vende en paquete de 6 unidades, lo cual es comercializado en el mercado en un precio aproximado de S/.35.00. 


\subsubsection{Participación de mercado}

El mercado de los cupcakes y de las tortas con diseños personalizados se encuentra actualmente en crecimiento y las empresas se van repartiendo de a pocos el total de los consumidores de acuerdo a la necesidad de cada uno. Lamentablemente, para esta industria la información del mercado es muy limitada, razón por la cual no es posible poder mostrar cómo es el 'market share' actual en este rubro, consultando incluso en fuentes de información como produce, INEI, entre otras y en donde es muy limitada la información exacta con respecto a la empresa y a competidores directos. Sin embargo, de acuerdo a la experiencia con la que cuenta la Gerente General de la empresa, estima que actualmente la participación de la empresa estaría por encima del orden del $40 \%$ del mercado y, posiblemente, una participación muy cercana a ella por parte de la competencia directa, como Miss Cupcakes aunque, como se mencionó anteriormente, no habría manera de poder calcular con precisión y con metodología científica.

\subsubsection{Proyección de la demanda}

El negocio del Cupcake en el Perú está en auge. Por ejemplo, en el caso de Claudia, un índice de crecimiento anual promedio aproximadamente de $38.50 \%$ en los últimos 2 años y se estima que los índices de venta de éste producto está sobrepasando al nivel de venta de las tortas. Se espera que esta tendencia se mantenga y, con la diversificación de nuevos productos, pueda incrementarse aún más. Esto, de la mano con lo descrito en el punto 3.1.2, 
en donde se estima que el crecimiento del consumo de productos de panadería tenga también un crecimiento en el país.

Como datos de la evolución de las ventas en la empresa en análisis, tenemos:

\section{EVOLUCIÓN DE LAS VENTAS EN LA EMPRESA CLAUDIA CUPCAKES}

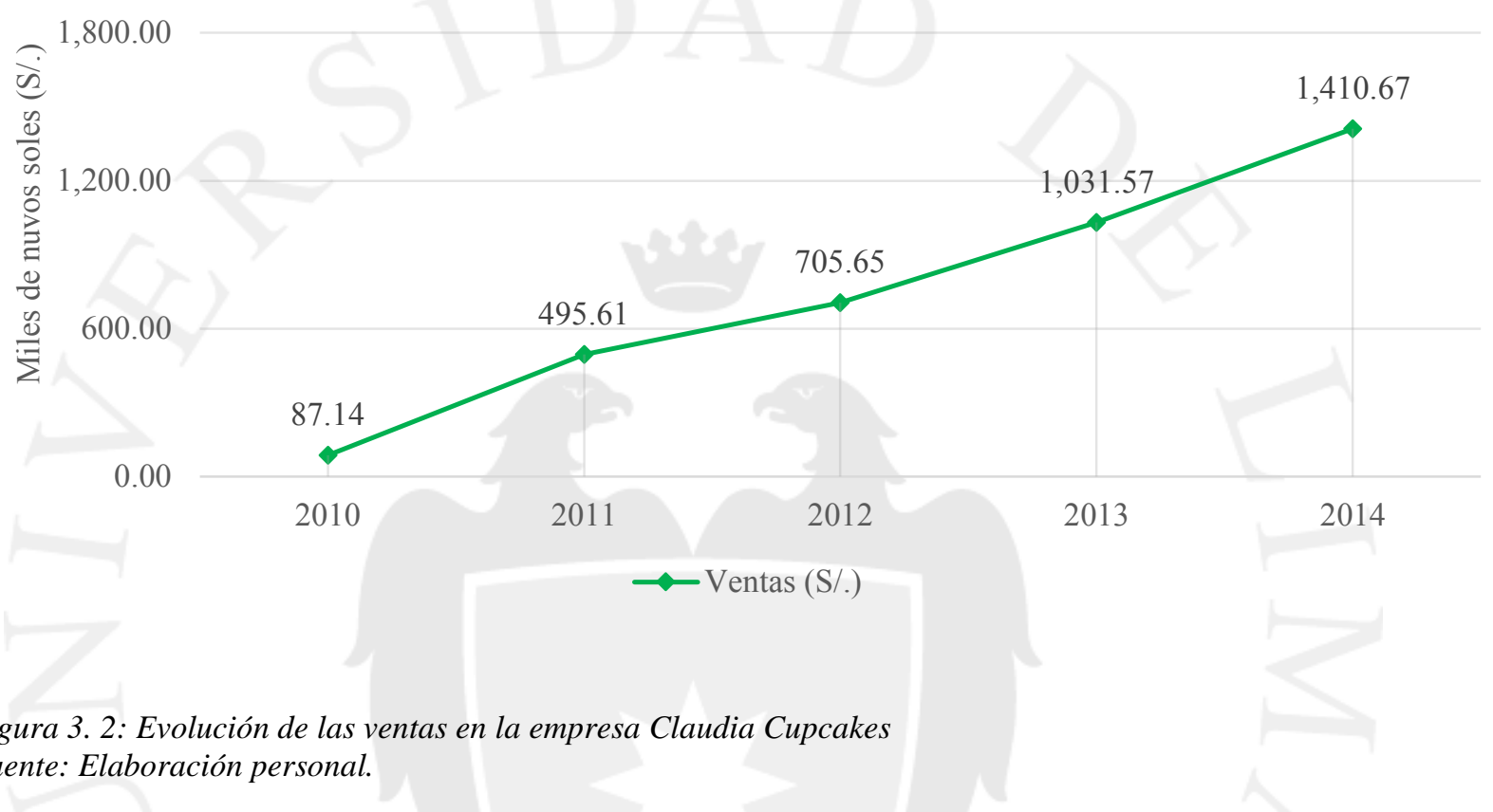

Figura 3. 2: Evolución de las ventas en la empresa Claudia Cupcakes Fuente: Elaboración personal.

Ésta evolución positiva estaría sustentada en algunos factores que a continuación se describen:

a. El crecimiento de la Economía Peruana, que va de la mano con la mejora en la capacidad adquisitiva, conlleva a un gasto mayor en productos no fundamentales.

b. Las nuevas tendencias que se van acentuando en el mercado debido a gustos y/o tradiciones "importadas" de otros países y que de a pocos son del gusto del consumidor peruano. 
c. La búsqueda de alternativas novedosas y creativas para ocasiones especiales y que puedan ser cubiertas fácilmente por productos como el cupcake o las tortas con diseños variados.

Posteriormente haremos un análisis más profundo con respecto a ésta data para que podamos tener una proyección de la demanda para los próximos 5 años.

\subsubsection{Productos o servicios sustitutos y complementarios}

De acuerdo a características descritas anteriormente, el cupcake es un producto caro, con precios por encima de otros productos alimenticios parecidos y con la finalidad de ir reemplazando a las tortas de mayor tamaño; sin embargo, estos productos son bastante aceptados en el mercado debido a su peculiaridad e innovación en los diseños, característica que lo diferencian de otros similares.

A pesar de lo mencionado anteriormente, entre los productos que podrían considerarse sustitutos, tomando en cuenta la finalidad alimenticia como tal, no como satisfacción en el diseño, tendríamos: 


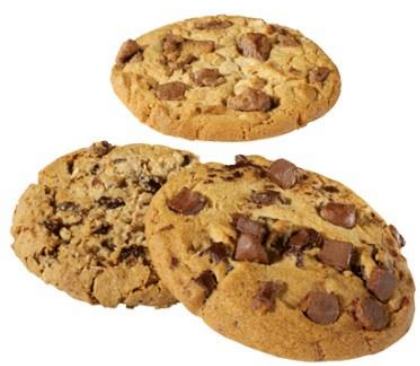

Galletas
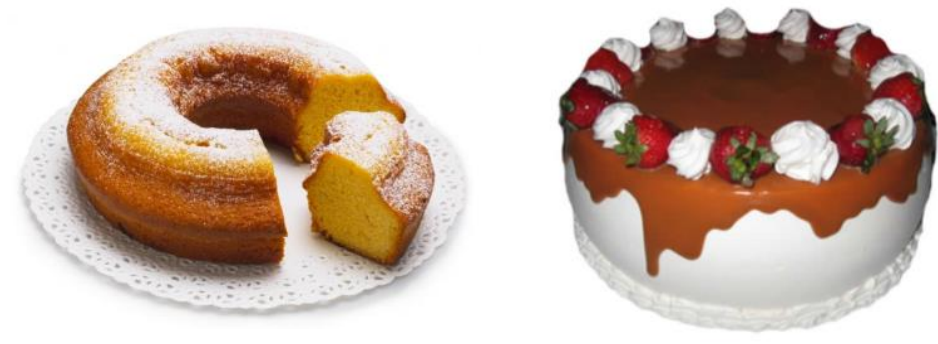

Tortas clásicas

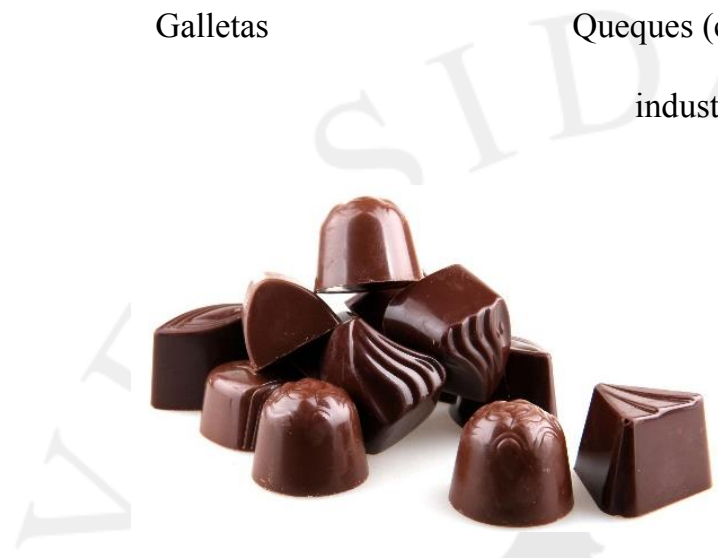

Chocolatería en General

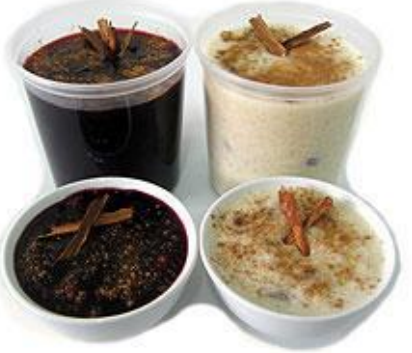

Dulcería clásica

Figura 3. 3: Productos sustitutos

Fuente: Imágenes extraídas de Google, 2015.

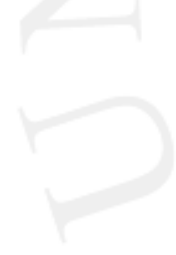


Por otro lado, existe una gran variedad de productos complementarios, entre los que tenemos:

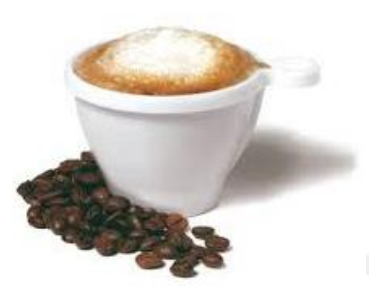

Café caliente/frío

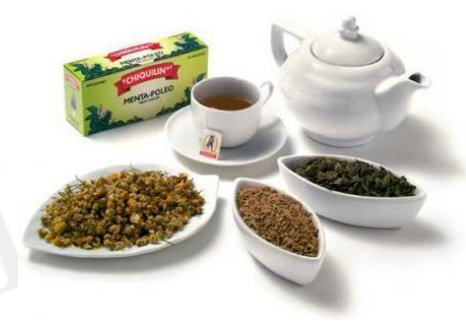

Infusiones

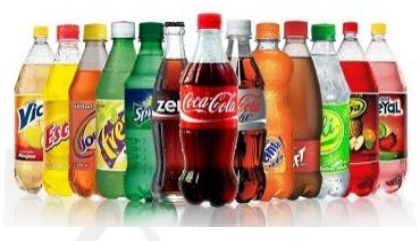

Gaseosas

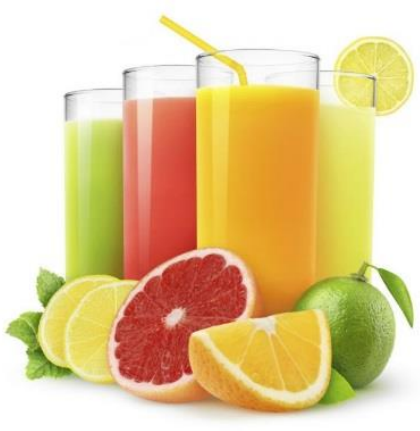

Jugos naturales

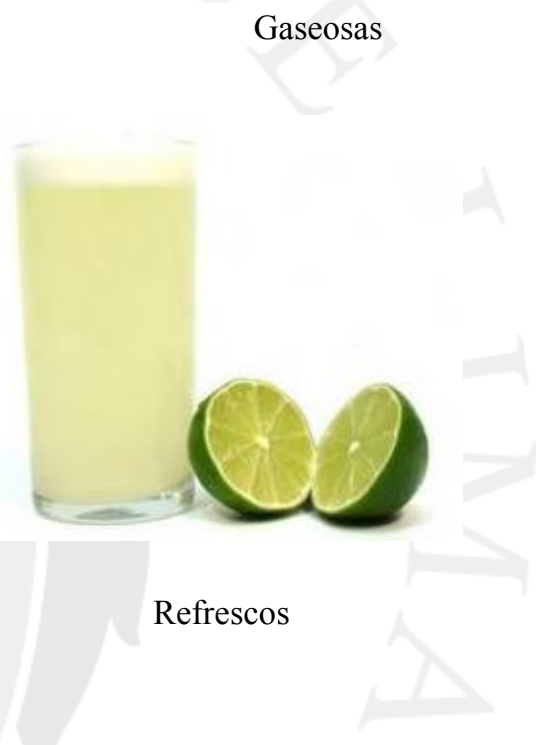

Figura 3. 4: Productos complementarios

Fuente: Imágenes extraídas de Google, 2015.

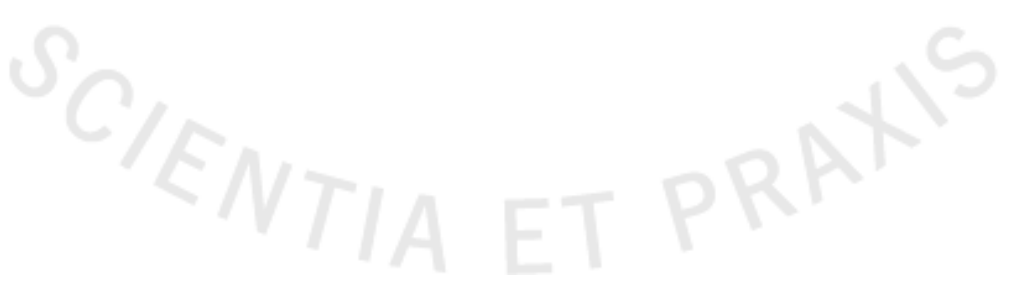




\subsection{Comercialización}

\subsubsection{Políticas y estrategias de comercialización de la empresa}

La empresa tiene diferenciado sus políticas de comercialización según el cliente que atienda. Estas son:

\section{a. Políticas para Cencosud}

- Los pedidos son ingresados diariamente para ser entregados en un plazo de 2 días. El pedido ingresa de acuerdo al tipo de producto y las características requeridas.

- Se mantiene un acuerdo de pago a 15 días, aunque en la práctica es, en promedio, a 20 días.

\section{b. Políticas para clientes particulares (personas naturales y/o} empresas)

- Los clientes hacen las consultas a la empresa, ya sea vía web (Facebook), correo o telefónicamente, a fin de conocer el plazo de entrega, precio y características generales.

- Si el cliente está de acuerdo a lo ofrecido, se ingresa el pedido. Esto es de manera esporádica de acuerdo a la necesidad del cliente y de acuerdo a la evaluación por parte de la empresa en cuanto a factibilidad de producción y tiempos (se prioriza los pedidos de Cencosud). 
- El pedido una vez ingresado se trabaja de acuerdo al plazo ofrecido por la empresa, siendo en promedio entre 1 a 2 semanas, dependiendo de la complejidad del pedido. Éste se trabaja en paralelo con los pedidos de Cencosud.

- Una vez culminado con la producción del pedido, éste se entrega al cliente de acuerdo a las condiciones acordadas previamente, pudiendo ser mediante el envío a una dirección solicitada o mediante el recojo en el taller.

- El pago es a contra entrega, aunque dependiendo de la complejidad del pedido, podría haber un adelanto mediante una transferencia o depósito bancario en la cuenta de la empresa.

Asimismo, algunas de las Estrategias de Comercialización adoptadas por Claudia Cupcakes:

a. Dar una buena atención y servicio al público en general, ya sea mediante la interacción con ellos en las redes sociales, así como en las entregas de pedidos en el taller o a domicilio.

b. Brindar ofertas especiales en ocasiones particulares o fechas festivas, de modo que permita una mayor llegada al público objetivo y su consumo.

c. Concretar alianzas con otras grandes marcas en el mercado de dulces, a fin de poder generar un mayor valor a su producto y una mayor satisfacción en el consumo del cliente. 
d. Manejar una flexibilidad en los precios ofrecidos, de acuerdo al volumen y/o características del pedido.

e. Utilizar el Facebook como medio principal de llegada a sus clientes finales, tanto para hacer conocer la marca presente en Cencosud como para comercializar sus productos (enfocada en el consumidor final: Estrategia "Pull").

\subsubsection{Principales clientes}

Los clientes de la empresa pueden dividirse en 3 segmentos o grupos bien marcados:

\section{DISTRIBUCIÓN DE LAS VENTAS 2014 POR TIPO DE CLIENTES DE CLAUDIA CUPCAKES}

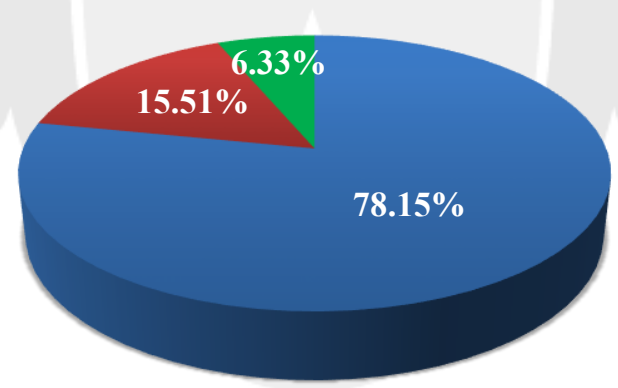

- Cencosud Retail Perú S.A. —Clientes Particulares — Corporativos

Figura 3. 5: Participación de clientes atendidos por la empresa Claudia Cupcakes.

Fuente: Elaboración propia. 


\section{a. Cadena de Supermercados Cencosud}

Mediante un acuerdo de exclusividad, actualmente Claudia Cupcakes es el único proveedor de cupcakes y pre mezclas, así como uno de los principales proveedores en la línea de pastelería de esta cadena de supermercados. Dada esta exclusividad, el mayor porcentaje en ventas de la empresa se centra en ésta cadena y, en consecuencia, los mayores esfuerzos de cumplimiento en la producción está destinado a éste segmento. Claro está, que ante éste cliente tiene una mayor exigencia en cuanto a los estándares de calidad para poder mantener la línea de sus demás proveedores, sobretodo, en alimentos.

En cifras de ventas a éste segmento tenemos:

Tabla 3. 3: Ventas 2014 a Cencosud

\section{b. Clientes individuales}

La empresa se inició con la venta de sus productos al público en general de manera directa. Hoy en día se mantiene ésta venta pero en menor cantidad considerando que la mayoría de clientes optan por comprar sus productos mediante Cencosud; sin embargo algunos de ellos mantienen pedidos directos por la necesidad particular que requieren, sobre todo en las características y/o diseño del producto.

Las ventas que representan este segmento de clientes son: 
Tabla 3. 4: Ventas 2014 a clientes individuales

NOMBRE DEL CLIENTE

Clientes Varios (Particulares / Individuales)
MONTO TOTAL

FACTURADO 2014 (S/.)

$218,860.81$

\section{c. Clientes corporativos}

Algunas empresas solicitan pedidos a Claudia Cupcakes, especialmente de cupcakes, para algunos eventos especiales o incluso como Merchandising. Si bien estas cantidades no representan un número considerable en el global de ventas de la empresa, también la consideramos dentro del universo de clientes.

En cifras aproximadas de los pedidos realizados por estos clientes, tenemos:

Tabla 3. 5: Ventas 2014 a clientes corporativos

\begin{tabular}{|l|c|}
\hline \multicolumn{1}{|c|}{ NOMBRE DEL CLIENTE } & $\begin{array}{c}\text { MONTO TOTAL } \\
\text { FACTURADO 2014 (S/.) }\end{array}$ \\
\hline ALICORP S.A.A & $19,613.96$ \\
\hline MICROSOFT PERU SRL & $7,384.44$ \\
\hline EDUPARQUES PERU SAC & $5,852.80$ \\
\hline BANCO INTERNACIONAL DEL PERU SA & $5,290.40$ \\
\hline COOPERATIVA DE AHORRO Y CREDITO ABACON & $4,462.50$ \\
\hline VEINTE SOBRE VEINTE PRODUCCIONES SRL & $4,300.00$ \\
\hline DELICIAS CATERING SAC & $4,119.00$ \\
\hline TRES PALMERAS SA & $3,896.36$ \\
\hline BOEHRINGER INGELHEIM PERU SAC & $3,648.79$ \\
\hline OTRAS EMPRESAS & $30,740.00$ \\
\hline TOTAL FACTURADO CORPORATIVOS 2014 & $\mathbf{8 9 , 3 0 8 . 2 5}$ \\
\hline
\end{tabular}


Cabe mencionar que si bien para la empresa es importante mantener a estos dos últimos tipos de clientes, la prioridad de atención y cumplimiento es con Cencosud, por lo que si hubiera pedidos que posiblemente pudieran interferir con la producción principal, es mejor no tomarlos a fin de no fallar en la fecha solicitada.

\subsubsection{Estrategia de precios}

Actualmente, dependiendo de los competidores con que se le compare, la empresa podría tener una estrategia de Alineamiento comparada con otras marcas conocidas y fuertes en cupcakes, puesto que sus precios ingresan relativamente al mismo nivel que las demás; sin embargo, comparado frente a otras empresas o productores pequeños, la estrategia podría considerarse como de Selección, debido a que los precios son elevados frente a los ofrecidos por éstos últimos ya que el mercado al cual apunta es de los segmentos A y B, en donde es aceptado debido al nivel de calidad de sus productos.

Por otro lado, de cara a los clientes que la empresa cuenta, se aplica dos estrategias de fijación de precios:

\section{a. Fijación de precios basada en el valor para el cliente}

Esta estrategia aplica tanto para los clientes individuales como para los corporativos y ofrece la combinación perfecta de calidad a precio justo. Mediante esta estrategia se logra que el cliente valore el producto por 
los beneficios que reciben de este y se fija un precio para dicho valor. Lo que realiza Claudia Cupcakes es evaluar las necesidades y percepciones de valor de los clientes y fija un precio meta que se ajuste al valor percibido. Para ello la empresa determina los costos asociados que permita diseñar y elaborar el producto que entregue el valor deseado.

\section{b. Fijación de precios alto-bajo}

Aplicado para los clientes individuales en algunos casos, en donde los pedidos diarios tienen establecidos un precio alto $\mathrm{y}$ en ocasiones especiales realiza promociones con precios bajos temporales en algunos productos.

\section{c. Fijación de precio basada en costos}

Aplicada para la cadena de supermercados Cencosud teniendo un convenio de pedidos con productos específicamente diseñados bajo sus requerimientos. La estrategia consiste en fijar precios en base a costos de producción, distribución y venta del producto, a estos costos se le adiciona las utilidades por esfuerzo y los riesgos a lo que se puede enfrentar la empresa.

Ahora, podría considerarse también que la empresa aplica la estrategia de precios de Prestigio. Esta estrategia se basa en establecer un precio alto para el producto, atrayendo a los clientes que desean un producto de buena calidad con características innovadoras, que le pueda dar cierto status al 
cliente. Asimismo, esta estrategia va dirigida hacia clientes que no escatimen en precios, con el fin de poder captar clientes exclusivos con mayor poder adquisitivo.

Como recomendación particular, sería adecuado establecer un buen sistema de fijación de precios aunque éste pueda tomar bastante tiempo en poder ser bien estructurado; sin embargo, el beneficio estaría en poder lograr una efectiva segmentación de sus clientes de acuerdo a su sensibilidad al precio y que esté acorde al entorno y al mercado en el que participa actualmente (nacional), considerando que ante situaciones en las que se vea que la estrategia establecida no funcione como se espera, se pueda hacer una revisión detallada de esto a fin de poder ajustarlas para hacer frente a la competencia en el mercado, tomando en cuenta las variables necesarias para esto, como las cantidades, tipos de cliente, formas de pago, antigüedad del cliente, costos asociados, etc.

\subsubsection{Promoción y publicidad}

La mezcla de Promoción que aplica para la empresa se explica a continuación:

\section{a. Promoción de Ventas}

En algunas ocasiones, como por ejemplo, ante el lanzamiento de nuevos diseños y tipo de cupcakes que la empresa produce, ésta genera algún tipo de oferta en particular que permita al cliente poder tener la facilidad 
de conocer el producto, así como también, poder crear algún incentivo adicional, como por ejemplo, cupcakes de regalo adicional o algún otro producto "gratis". Esto también aplica en situaciones o fechas especiales, como el día de la Madre, Navidad, etc.

\section{b. Ventas Personales}

En este caso, la empresa no aplica ésta modalidad para los clientes individuales o corporativos, pues son ellos los que solicitan a la empresa un pedido en particular de manera proactiva; esto es más que nada para cuando la empresa desea presentar un nuevo producto a la cadena

Cencosud con la idea de poder ingresar con algo novedoso a ésta cadena, incluyendo esto incluso la degustación del producto, etc.

\section{c. Relaciones Públicas}

Para esto, la empresa cuenta con una página web en donde no sólo se conoce un poco más de la empresa, si no también, es una ventana para poder mostrar al público con respecto a algunos de los productos que se ofrece y poder generar pedidos online (vía correo electrónico).

\section{d. Marketing Directo}

Esto lo realiza a la par con la publicidad que la empresa realiza mediante el Facebook, pues es por éste canal en donde tiene una mayor interacción con sus consumidores finales y donde de alguna manera genera lazos de lealtad y cercanía con ellos. 


\section{e. Publicidad}

La empresa usa distintos medios para poder hacer publicidad a sus productos y ofrecerlos al mercado. Entre estos, tenemos:

\section{- Facebook}

Se tiene una cuenta en la cual publica diariamente novedades en productos, recetas, promociones, etc. En esta plataforma hay numerosa cantidad de seguidores de la marca los cuales, a su vez, se convierten en potenciales clientes, entre individuales $\mathrm{y}$ corporativos, superando a la fecha más de 112,000 seguidores (al 16/09/2015):

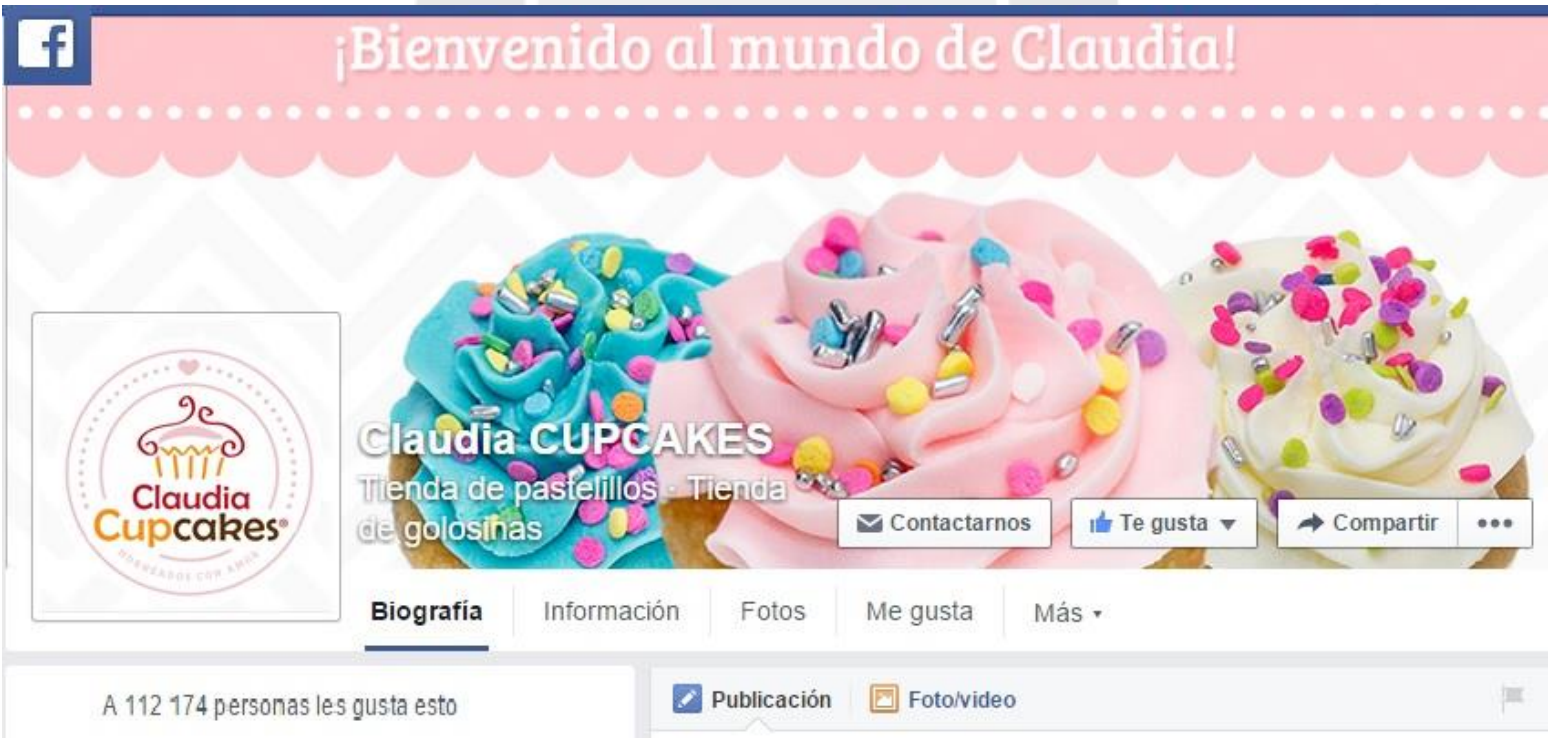

Figura 3. 6: Portada de la página de Facebook de Claudia Cupcakes Fuente: Facebook Claudia Cupcakes 
- Radio y Televisión

Si bien la empresa no ha invertido ni está en sus planes por ahora invertir en éste medio, ha sido invitada a algunos programas de radio y televisión con la finalidad de contar un poco acerca de la empresa, teniendo así también un espacio para poder hacer publicidad a la marca y a los productos que ofrece. Esto debido al gran éxito por el que pasa actualmente con sus ventas y aceptación en el mercado.

\section{- Periódicos y revistas}

Como una historia más de emprendimiento con grandes éxitos en la actualidad, la empresa ha sido parte de entrevistas y reportajes en éstos medios en donde, además de ser inspiración para otras ideas de negocio parecidas, puede también al igual que en el medio anterior, poder hacer publicidad de la marca.

\subsubsection{Canales de distribución / atención}

Los canales de atención y/o distribución aplicados por la empresa son:

\section{a. Venta Directa}

Tal como se mencionó en capítulos anteriores, en el caso de los pedidos hechos por clientes particulares o corporativos, los productos son vendidos directamente a ellos mediante alguno de canales de venta: Facebook, correo, teléfono, etc., y éstos son entregados directamente en 
el taller de producción de la empresa, puesto aún no se cuenta con un puesto o tienda de atención directa.

\section{b. Venta a Intermediarios}

Esto es aplicable para el caso de las ventas que se realiza a Cencosud, puesto que si bien ellos como o cadena de supermercados le compran a la empresa y en grandes volúmenes, no son los consumidores finales, quienes son los que finalmente se espera crear la afinidad con la marca.

\section{c. Servicio de Delivery}

Igual que en el caso de las ventas directas, esto únicamente se diferencia que, de acuerdo a algún trato ya pactado con el cliente como condición de venta, el pedido es entregado en su domicilio o lugar especificado, haciendo uso de alguna de las 2 unidades de transporte con los que cuenta la empresa.

De acuerdo a los datos proporcionados por la empresa, durante el 2014 la distribución de las ventas por cada tipo de canal de atención fue distribuida de esta manera: 
\% DE VENTAS POR CADA CANAL DE ATENCIÓN

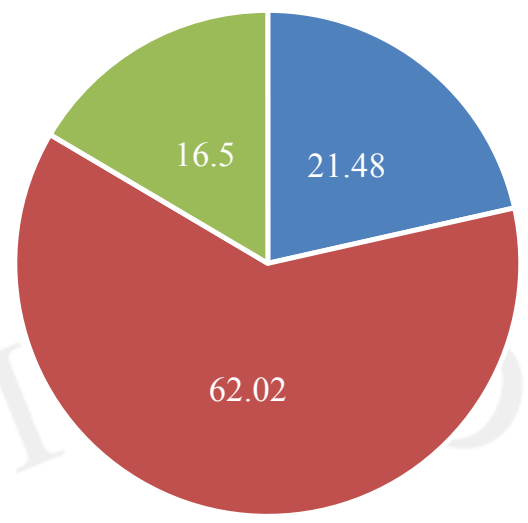

- Venta Directa - Venta Intermediarios - Servicio Delivery

Figura 3. 7: Porcentaje de ventas según canal de atención Fuente: Claudia Cupcakes, 2015.

Del gráfico anterior observamos que, como ya se había mencionado anteriormente, el mayor porcentaje de ventas se concentra en las que se realiza al canal intermediario, que en este caso pertenece a Cencosud, puesto es con quien se hace el mayor volumen de producción y ventas durante el año, por lo que sería adecuado enfocar mejor las estrategias de ventas a éste canal con la finalidad de afianzar y hacer crecer aún más el público consumidor.

A continuación, mostramos el flujo actual para la solicitud y atención de pedidos por parte de la empresa: 


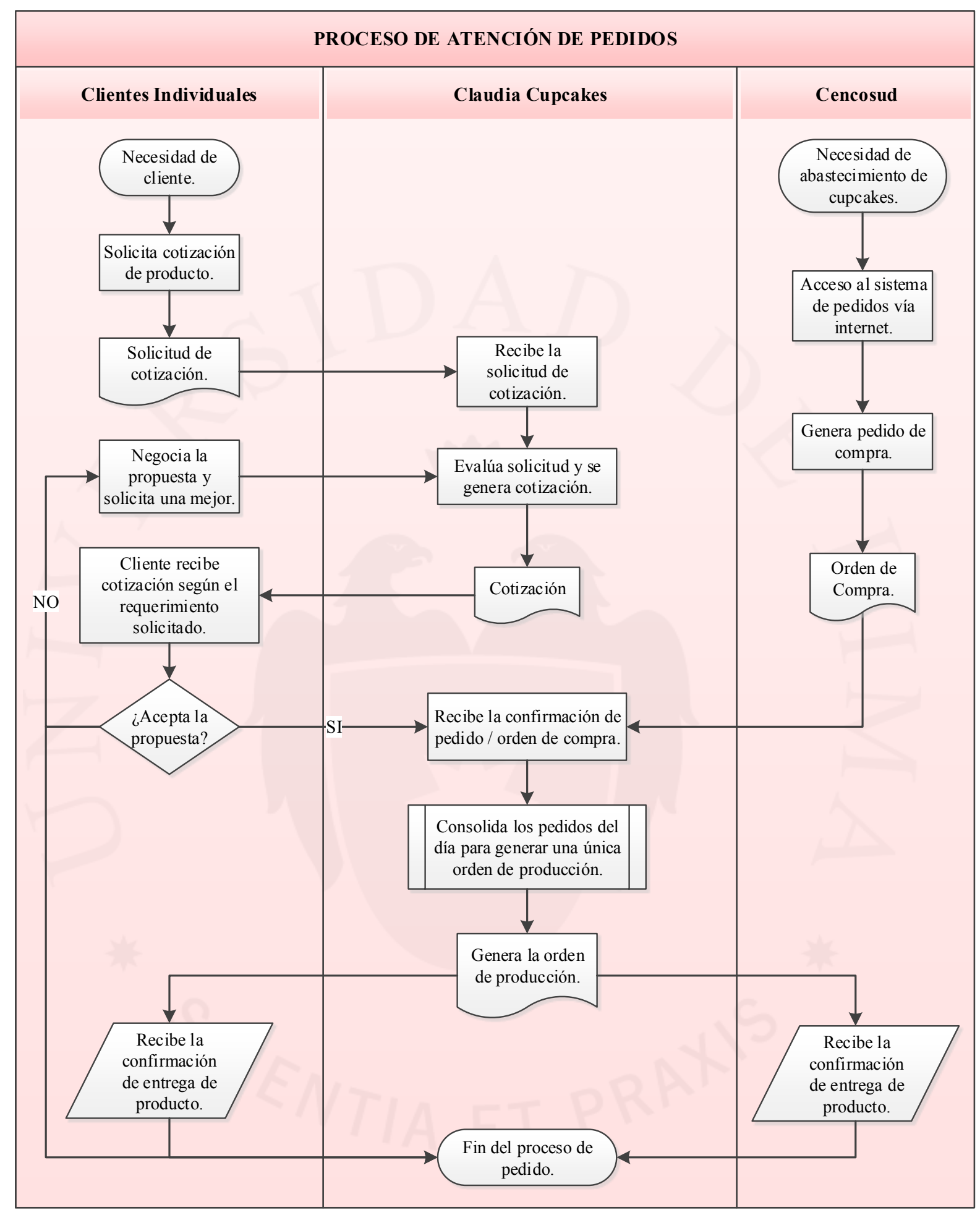

Figura 3. 8: Diagrama de flujo para la atención de pedidos

Fuente: Elaboración propia. 


\subsubsection{Comportamiento de las ventas}

El negocio de los cupcakes suele mantener un comportamiento de ventas predecible, tomando en cuenta que de acuerdo a las diversas temporadas o fechas especiales, estas pueden sufrir incrementos considerables, siendo esto más probable que el pronóstico en las caídas de las ventas. Dicho esto, a continuación se presenta el comportamiento de las ventas al cierre del año 2014:

\section{COMPORTAMIENTO DE LAS VENTAS 2014}

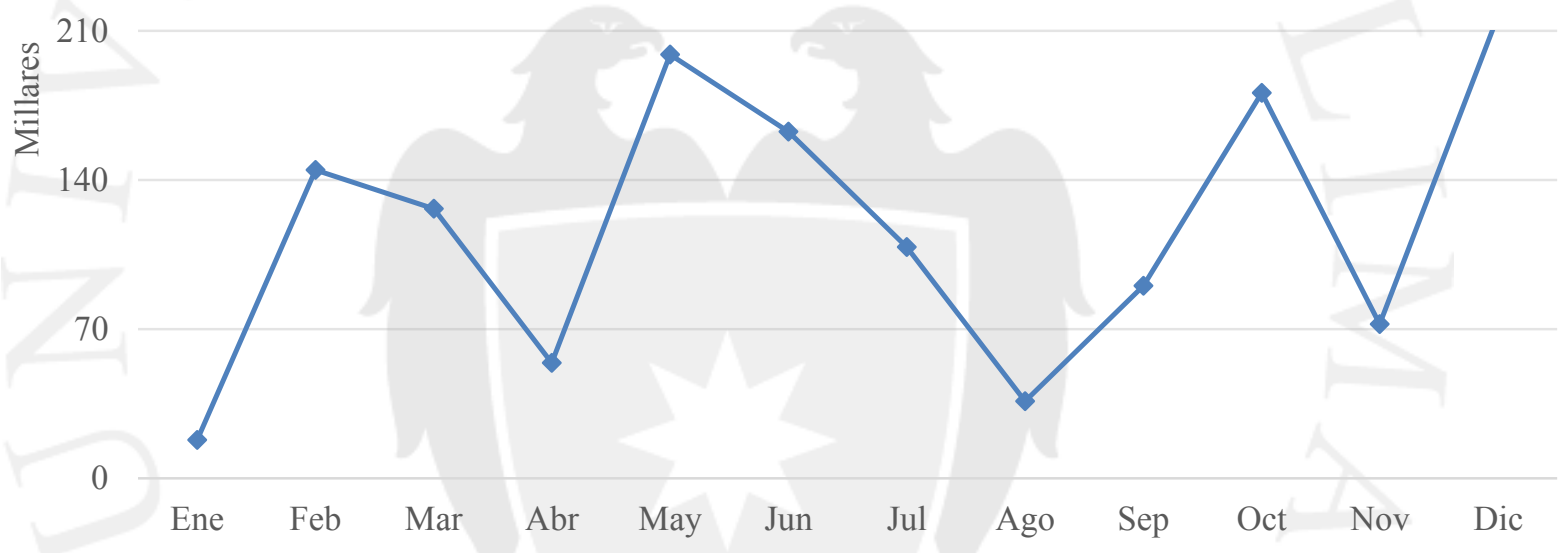

Figura 3. 9: Comportamiento de las ventas 2014 de la empresa Claudia Cupcakes Fuente: Claudia Cupcakes, 2015.

Como se puede apreciar en el gráfico anterior, éste comportamiento fluctuante responde a las diversas temporadas o fechas especiales que se presentan durante el año; sin embargo, sería adecuado poder revisar cómo ha sido el comportamiento en los últimos años y así poder entender si existe algún tipo de estacionalidad en las ventas ya acentuada en el mercado: 
COMPORTAMIENTO DE LAS VENTAS ANUALES 2010 - 2014

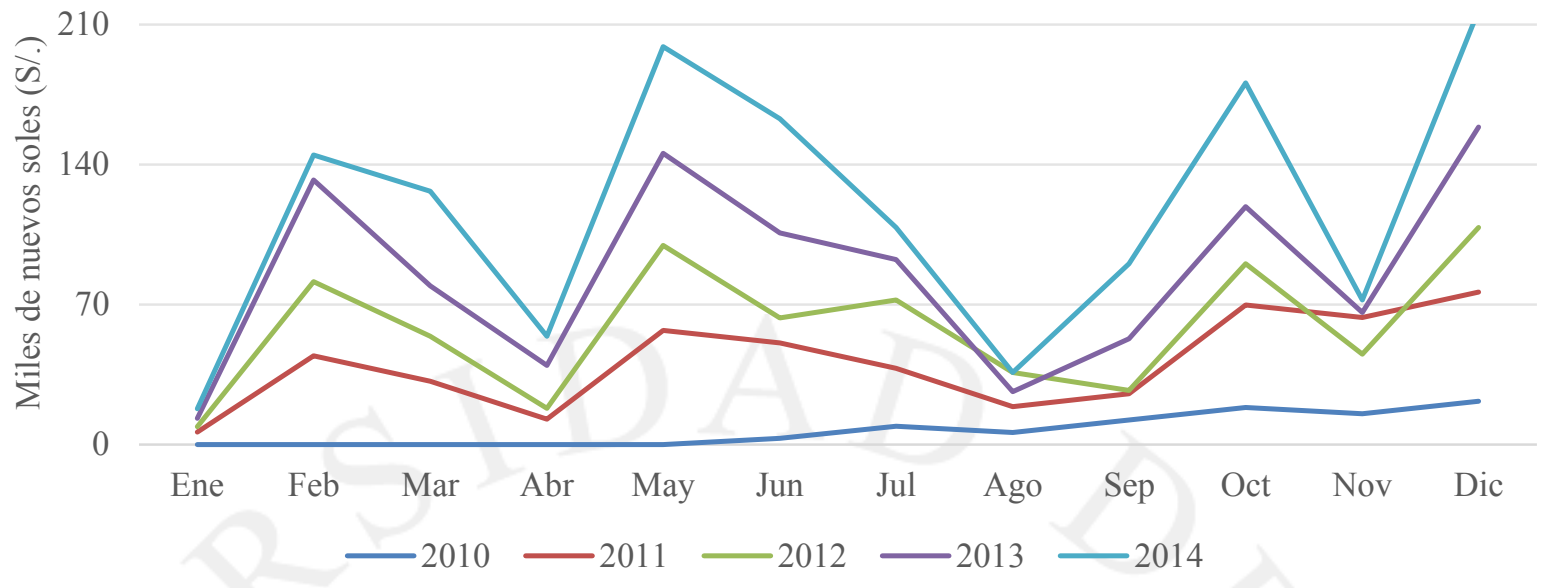

Figura 3. 10: Comportamiento de las ventas anuales 2010 - 2014

Fuente: Claudia Cupcakes, 2015.

Como vemos, son los meses de Diciembre y Mayo los que presentan un mayor número de ventas con respecto al resto del año por las ocasiones de la temporada Navideña y el Día de la Madre respectivamente, siendo el primero el mes con mayor venta debido a que esta tendencia se mantiene durante todo el mes. Así mismo, observamos que son los meses de Enero, Abril y Agosto los que menor venta presentan, probablemente debido al gasto realizado por el mercado durante los meses previos. Cabe mencionar que, en el caso de Setiembre del 2014, hubo un ligero crecimiento a comparación de años anteriores, puesto por primera vez la marca entró a la feria gastronómica Mistura.

Para entrar un poco al detalle, a continuación se presenta el comportamiento de las ventas durante el año 2014 para los distintos productos que la empresa comercializa: 
COMPORTAMIENTO DE LAS VENTAS 2014 DE CUPCAKES

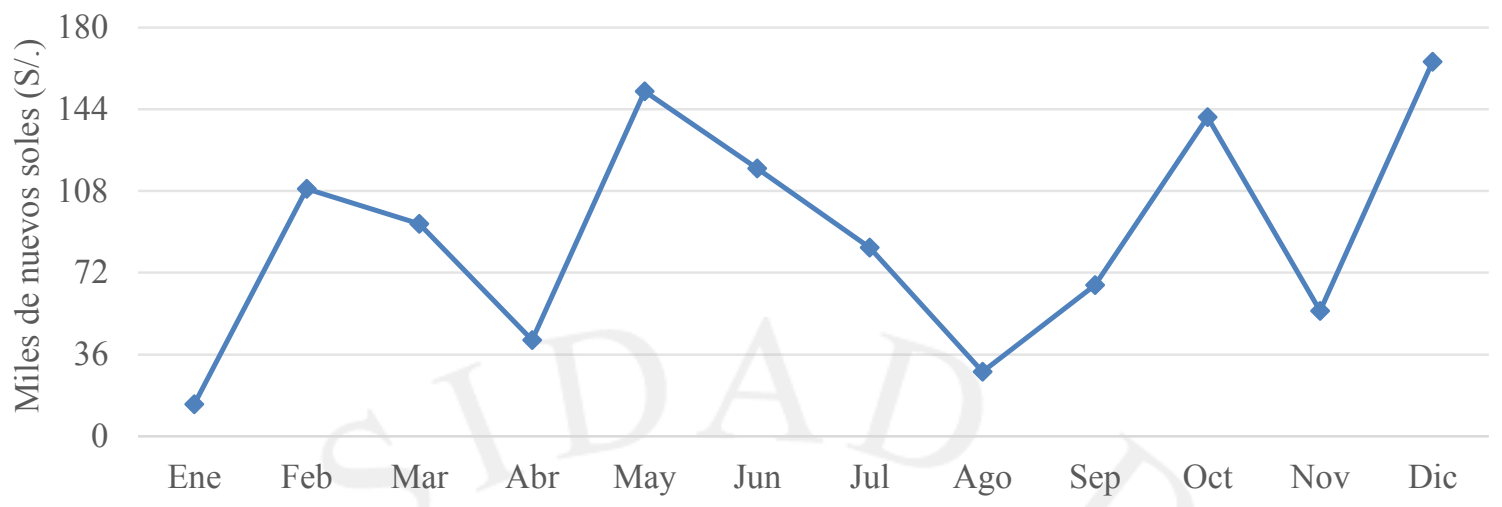

Figura 3. 11: Ventas de cupcakes 2014

Fuente: Claudia Cupcakes, 2015.

COMPORTAMIENTO DE LAS VENTAS 2014 DE TORTAS

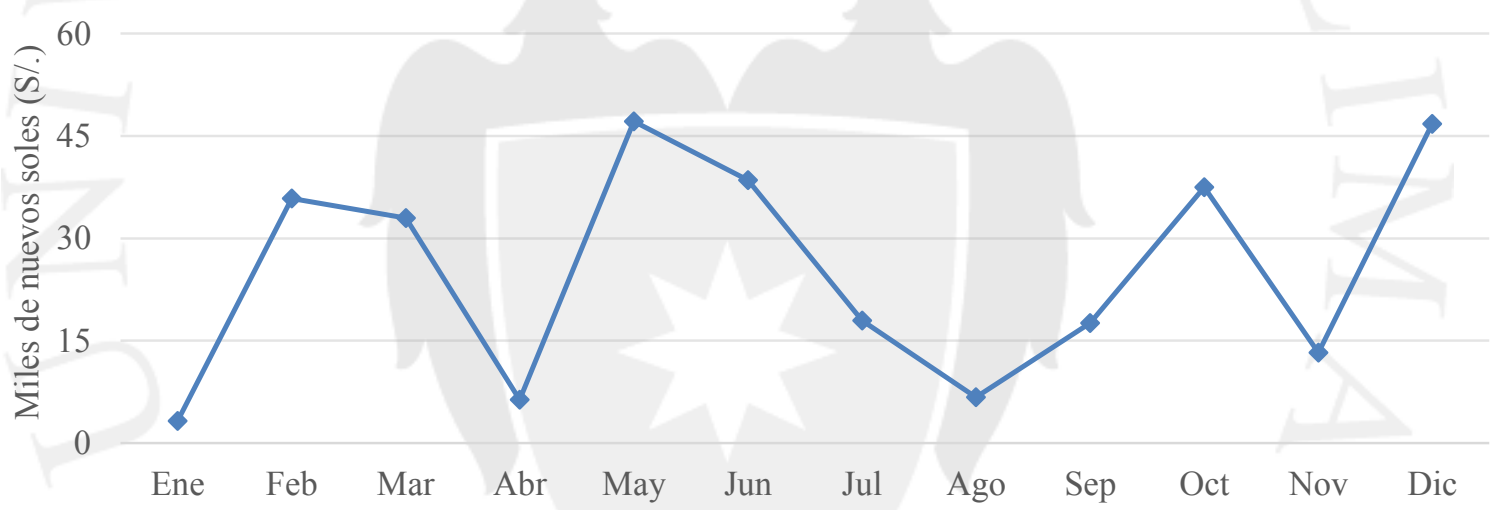

Figura 3. 12: Ventas de tortas 2014

Fuente: Claudia Cupcakes, 2015. 


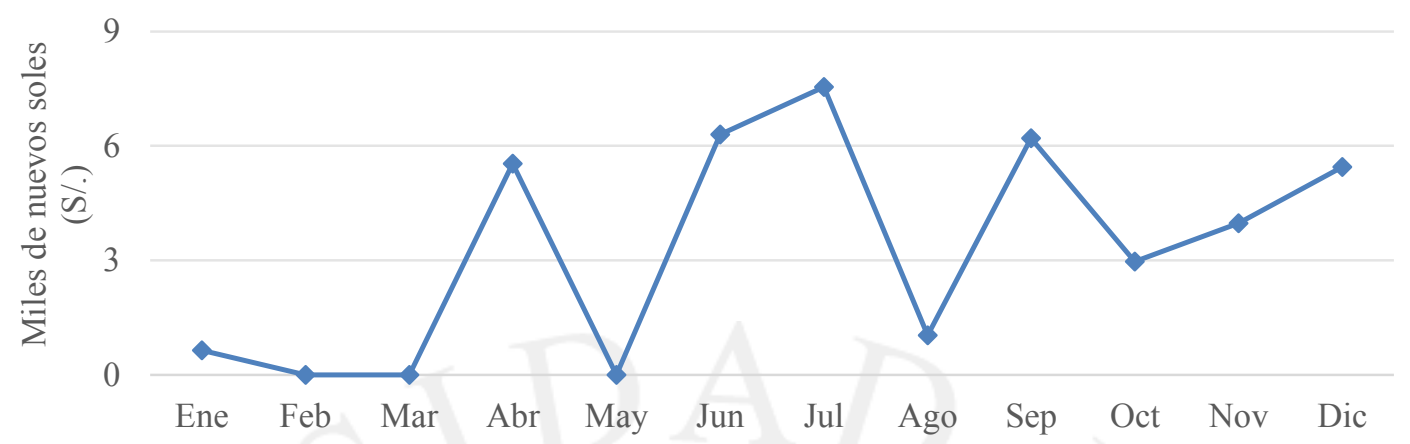

Figura 3. 13: Ventas de pre mezclas 2014

Fuente: Claudia Cupcakes, 2015.

De los cuadros anteriores, observamos en primera instancia que el mayor porcentaje de ventas se concentra en el cupcake, en un promedio aproximado cercano al $80 \%$, seguido de las tortas en un 15 a $17 \%$ en promedio. Además, vemos también que el comportamiento en las ventas de ambos productos es muy similar, a comparación de las ventas de la pre mezcla en donde, incluso, se reflejan meses en donde no hay venta. Esto último va de la mano con que éste es el producto que representa el menor porcentaje de ventas para la empresa.

Dicho esto, encontramos posibles oportunidades de mejora para que los meses valle no sean tan pronunciados y, quizá de la mano con alguna estrategia de ventas, se pueda generar que las ventas no caigan tan profundamente de un mes a otro según las temporadas. 


\subsubsection{Satisfacción de los clientes / usuarios locales e internacionales}

La satisfacción de los clientes de la empresa podría ser medida de diversas maneras. Por ejemplo, de una manera bastante subjetiva, tendríamos el número de seguidores con los que cuenta a través de las redes sociales, los cuales como se observó anteriormente, son a la fecha más de 112,000 y que cada vez más va en aumento. Sin embargo, entre otras formas de poder medir la satisfacción, consideramos las que se describe a continuación:

a. La primera, es mediante una encuesta vía online que realizamos a los clientes a través de la página de Facebook. Mediante ella, tratamos no sólo de ver la satisfacción en general que tienen con la empresa, si no también, qué aspectos son los que más aprecian y aquellos en los que de alguna manera sería adecuado apuntar alguna estrategia para poder mejorar aún más. A continuación, se muestran los resultados de ésta encuesta, de acuerdo a la leyenda adjunta: 
$\square$ NS / NO Nada Satisfecho $\square$ Poco Satisfecho $\square$ Satisfecho $\square$ Muy Satisfecho
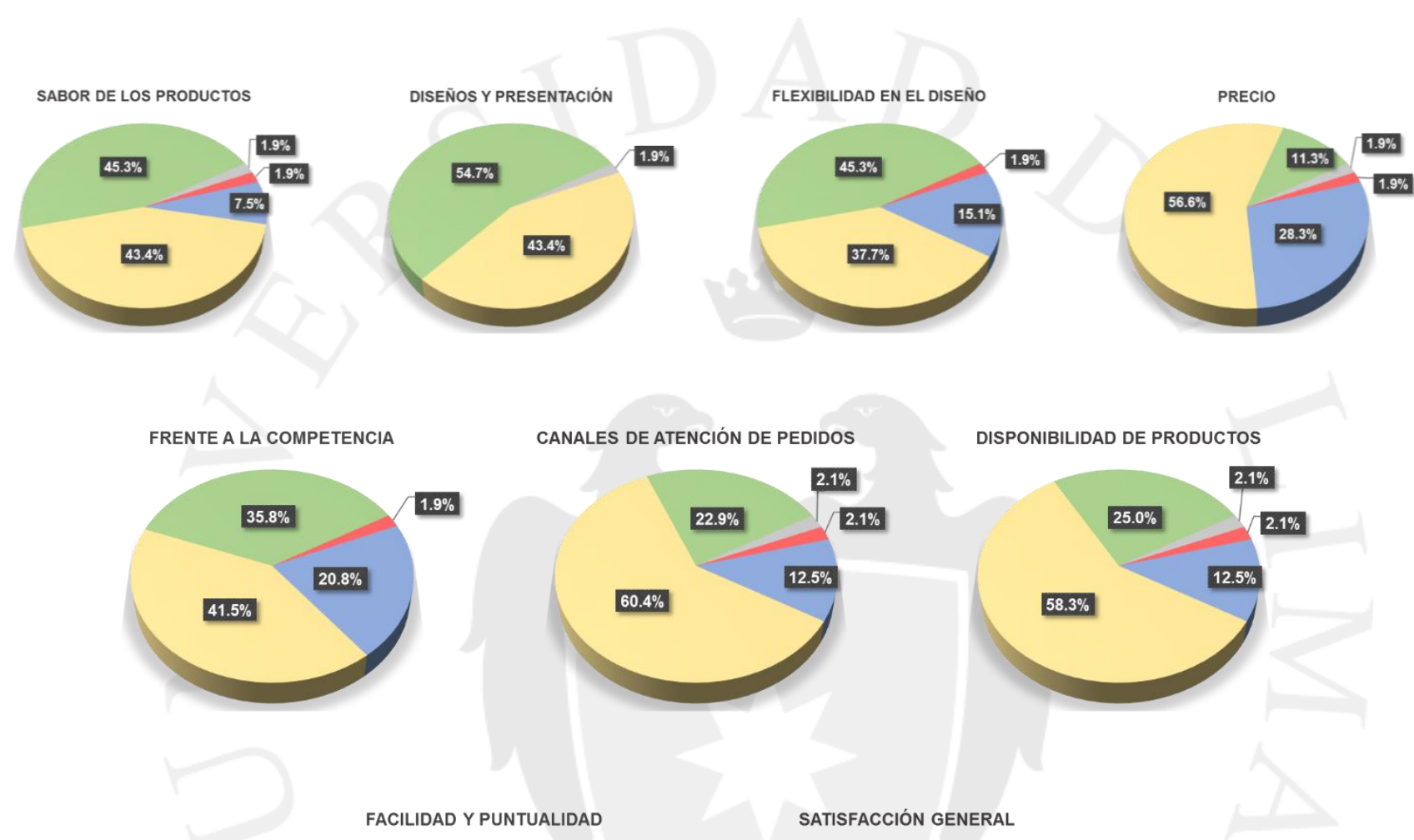

Figura 3.14: Resultados de encuesta de satisfacción al cliente

Fuente: Elaboración propia.
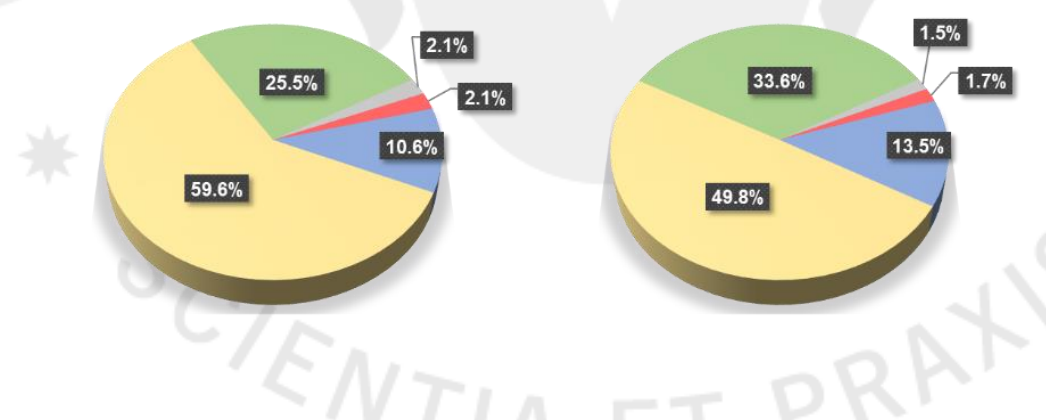
Tal como se observa en los gráficos presentados, cerca del $84 \%$ del total de encuestados se encuentran, al menos, satisfechos con la empresa en líneas generales, así como en cada uno de los aspectos evaluados. Si bien éstos resultados son bastante positivos, creemos que estos podrían ser aún mejores si se consideran aquellos aspectos en donde hay un porcentaje considerable como "no satisfecho", como lo es en el precio y en la comparación con otros productos de la competencia, en donde los valores que se presentan nos indican que sería conveniente diseñar estrategias que permitan a éstos consumidores poder incrementar su satisfacción con la empresa y así también crecer la empresa en conjunto, como por ejemplo, tener más promociones que le permita al público objetivo acceder a los productos ofrecidos con mayor frecuencia. En éste aspecto, que es más que nada de opinión más que de algo tangible, podríamos tener un resultado bastante bueno.

b. Por otro lado, como una manera de poder tener un resultado más cercano a la satisfacción de los clientes de una manera un poco más medible, consideramos también tomar un indicador que va ligado al nivel de servicio ofrecido por la empresa; en este caso, a través del cumplimiento en la entrega de pedidos a tiempo según lo solicitado por el cliente, ya se Cencosud, clientes particular o corporativos. Así, entonces, tendríamos: 


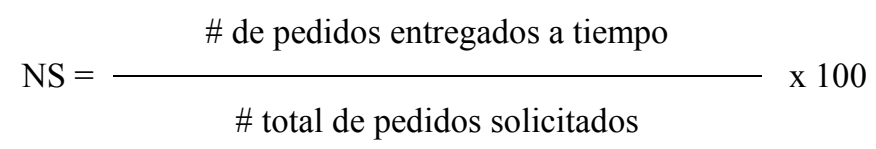

Considerando el ratio mencionado, y de acuerdo al histórico de la empresa durante el 2014, tenemos:

$$
\mathrm{NS}=\frac{4088}{4760} \times 100=\mathbf{8 6} \%
$$

Vemos que el resultado de este indicado va de la mano con la encuesta de satisfacción al cliente realizada como parte del análisis de la empresa, la cual arrojó un $85.1 \%$ de satisfacción en lo que corresponde a puntualidad y facilidad en el servicio/producto brindado. Éste resultado, si bien no es malo, puede ser mejor considerando las oportunidades de mejora que podamos encontrar en el desarrollo del análisis de la empresa.

c. Finalmente, como parte de nuestro análisis, tomamos en cuenta el dato con respecto al tiempo promedio que le toma a la empresa poder reponer los productos que puedan ser entregados con algún tipo de defecto en particular. Según detalles brindados por la Gerencia General, el tiempo promedio de reposición es muy cercano a las 2 horas, dependiendo del lugar al cual haya que volver a entregar el pedido. Cabe mencionar que, casi en la totalidad de los casos, estos problemas se presentan por 
detalles externos más que del producto mismo, como por ejemplo, un etiquetado del envase inadecuado, etc.

Del análisis realizado correspondiente al impacto económico estimado por la reposición de pedidos defectuosos, tenemos como resultado un valor de S/.35.12 / semana (Ver anexo 03 para detalles de cálculo).

\subsection{Resumen de los principales indicadores del capítulo}

A continuación, un resumen de los indicadores hallados en este capítulo:

\section{Tabla 3. 6: Indicadores principales del capítulo 3}

\begin{tabular}{|l|c|c|}
\hline \multicolumn{1}{|c|}{ INDICADOR } & VALOR ACTUAL & META \\
\hline Participación de mercado & $40 \%$ & $75 \%$ \\
\hline Satisfacción de clientes & $83 \%$ & $90 \%$ \\
\hline Nivel de servicio & $86 \%$ & $90 \%$ \\
\hline Tiempo de reposición de pedidos & 2 horas & 1 hora \\
\hline
\end{tabular}




\section{CAPÍTULO IV: ASPECTOS TÉCNICOS Y OPERACIONES}

\subsection{De la planta / centro de operaciones y sus instalaciones}

Claudia Cupcakes es una empresa cuyos procesos no tienen un nivel de complejidad muy alto, pues estos pueden ser hechos de manera doméstica sin mayor problema; sin embargo, uno de los aspectos claves de éxito de la empresa es, sin duda, la creatividad e innovación que aplica en su producción, lo que hace que la mano de obra, más que las máquinas propiamente, sea su gran ventaja competitiva en el mercado.

A continuación, haremos un análisis de todos los aspectos productivos involucrados en la cadena de valor de la empresa, a fin de identificar oportunidades de mejora que le permita seguir con un crecimiento sostenido.

\subsubsection{Características principales de la maquinaria y/o equipos para el} servicio

La empresa cuenta con las siguientes máquinas y equipos: 
Tabla 4. 1: Principales equipos en el taller de la empresa

\begin{tabular}{|c|c|c|c|c|c|}
\hline $\mathbf{N}^{\circ}$ & MÁQUINA & $\begin{array}{l}\text { CANTIDAD } \\
\text { (Und.) }\end{array}$ & $\begin{array}{l}\text { ANTIGÜEDAD } \\
\text { (Años) }\end{array}$ & $\begin{array}{l}\text { VALOR } \\
\text { (S/./und.) }\end{array}$ & FUNCIÓN \\
\hline 1 & $\begin{array}{l}\text { Batidora } \\
\text { Industrial }\end{array}$ & 1 & 1 & $3,342.86$ & $\begin{array}{l}\text { Mezclar los ingredientes básicos para la } \\
\text { elaboración del queque para los } \\
\text { cupcakes y tortas para las producciones } \\
\text { en grandes cantidades. }\end{array}$ \\
\hline 2 & $\begin{array}{l}\text { Batidora } \\
\text { Doméstica }\end{array}$ & 1 & 1 & $1,575.84$ & $\begin{array}{l}\text { Sirve de "alivio" para las mezclas que se } \\
\text { realizan en la producción de grandes } \\
\text { cantidades o para pedidos pequeños. }\end{array}$ \\
\hline 3 & Dosificadora & 1 & 1 & $38,097.71$ & $\begin{array}{l}\text { Verter sobre los pirotines la mezcla ya } \\
\text { preparada en las cantidades necesarias } \\
\text { para ser horneada. }\end{array}$ \\
\hline 4 & $\begin{array}{l}\text { Horno } \\
\text { industrial }\end{array}$ & 1 & 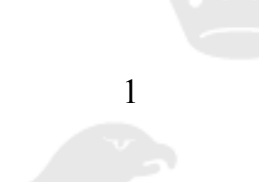 & $8,379.84$ & $\begin{array}{l}\text { Tiene la función de hornear la mezcla ya } \\
\text { preparada para producir el queque que } \\
\text { sirve como base para el cupcake o las } \\
\text { tortas. }\end{array}$ \\
\hline 5 & $\begin{array}{l}\text { Balanza } \\
\text { Electrónica }\end{array}$ & 1 & 1 & 157.84 & $\begin{array}{l}\text { Realizar el pesado de algunos } \\
\text { ingredientes que se necesiten durante el } \\
\text { proceso de mezclado o algún otro. }\end{array}$ \\
\hline 6 & $\begin{array}{l}\text { Horno } \\
\text { Microondas }\end{array}$ & 1 & 1 & 224.18 & $\begin{array}{l}\text { Derretir algunas barras de chocolate } \\
\text { para el proceso de decoración. }\end{array}$ \\
\hline 7 & $\begin{array}{l}\text { Rack de } \\
\text { Pastelería }\end{array}$ & 5 & 1 & - & $\begin{array}{l}\text { Aquí se colocan los queques que se } \\
\text { encuentran en producción (producto en } \\
\text { proceso), sobre todo cuando ya fueron } \\
\text { horneados y están a la espera de ser } \\
\text { decorados. }\end{array}$ \\
\hline 8 & Refrigeradora & 1 & 1 & $2,800.00$ & $\begin{array}{l}\text { Enfriar los cupcakes una vez que éstos } \\
\text { han sido ya decorados con la finalidad } \\
\text { de que el producto quede bien } \\
\text { moldeado, más aún cuando éste contiene } \\
\text { chocolate como cobertura. }\end{array}$ \\
\hline
\end{tabular}




\subsubsection{Disposición de planta}

Actualmente, el taller no cuenta con una disposición adecuada para la finalidad que tiene la empresa. Funciona en un espacio adecuado en el garaje de una vivienda familiar, observándose que el espacio no pueda ser adecuado de la manera más óptima posible. Esto, re afirmado al tener la medida del espacio que actualmente ocupa: $69.82 \mathrm{~m}^{2}$.

A continuación, en la siguiente página, se tiene una vista actual del taller y la disposición con la que cuenta para sus operaciones: 


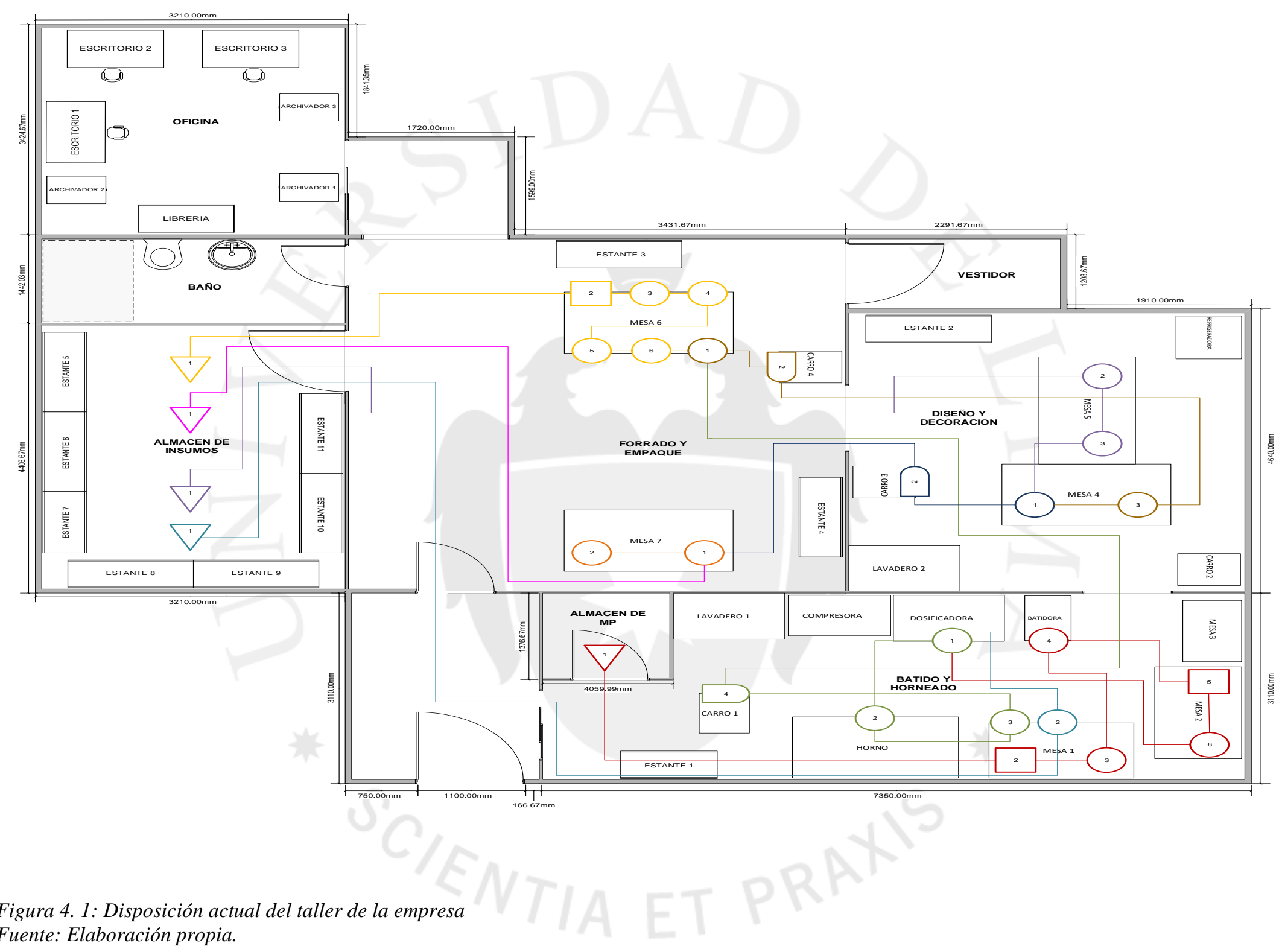


Con la finalidad de sustentar los requerimientos de espacio, se procede a estimar el área total necesitada para la empresa según el análisis de Guerchet y así poder determinar los espacios necesarios para la empresa, con lo que obtenemos:

Tabla 4. 2: Análisis de Guerchet para el área de batido y horneado.

\begin{tabular}{|c|c|c|c|c|c|c|c|c|c|}
\hline \multicolumn{10}{|c|}{$\mathrm{hm}=1.63 / / \mathrm{hf}=1.14 / / \mathrm{k}=0.72$} \\
\hline \multicolumn{10}{|c|}{ ÁREA DE BATIDO Y HORNEADO } \\
\hline \multirow{2}{*}{ Elementos } & \multicolumn{5}{|c|}{ Dimensiones } & \multicolumn{4}{|c|}{ Solución } \\
\hline & $\mathrm{n}$ & $\mathrm{N}$ & $1(\mathrm{~m})$ & $\mathrm{a}(\mathrm{m})$ & $\mathrm{h}(\mathrm{m})$ & Ss & $\mathrm{Sg}$ & $\mathrm{Se}$ & St \\
\hline Horno industrial & 1 & 1 & 1.72 & 1.00 & 1.78 & 1.72 & 1.72 & 2.46 & 5.90 \\
\hline Batidora industrial & 1 & 1 & 0.48 & 0.73 & 1.00 & 0.35 & 0.35 & 0.50 & 1.20 \\
\hline Dosificadora & 1 & 3 & 1.15 & 0.75 & 1.35 & 0.86 & 2.59 & 2.47 & 5.92 \\
\hline Compresora & 1 & 1 & 1.06 & 0.66 & 0.75 & 0.70 & 0.70 & 1.00 & 2.40 \\
\hline Carro de pasteleria & 1 & 2 & 0.65 & 0.52 & 1.60 & 0.34 & 0.68 & 0.73 & 1.74 \\
\hline Mesa de soporte (TG) & 2 & 3 & 0.98 & 0.43 & 0.90 & 0.42 & 1.26 & 1.21 & 5.78 \\
\hline Mesa de soporte (TP) & 1 & 3 & 0.75 & 0.43 & 0.90 & 0.32 & 0.97 & 0.92 & 2.21 \\
\hline Estantes/Anaqueles & 1 & 3 & 1.00 & 0.45 & 2.40 & 0.45 & 1.35 & 1.29 & 3.09 \\
\hline Operarios & 1 & & 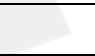 & 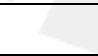 & 1.65 & 0.50 & & & \\
\hline \multicolumn{9}{|c|}{ Área requerida } & 28.25 \\
\hline
\end{tabular}


Tabla 4. 3: Análisis de Guerchet para el área de diseño y decoración.

\begin{tabular}{|l|c|c|c|c|c|c|c|c|c|}
\hline \multicolumn{7}{|c|}{$\mathrm{hm}=1.64 / / \mathrm{hf}=1.70 / / \mathrm{k}=0.48$} \\
ÁREA DE DISEÑO Y DECORACIÓN \\
\cline { 2 - 12 } \multicolumn{1}{|c|}{ Elementos } & $\mathrm{n}$ & $\mathrm{N}$ & $1(\mathrm{~m})$ & $\mathrm{a}(\mathrm{m})$ & $\mathrm{h}(\mathrm{m})$ & $\mathrm{Ss}$ & $\mathrm{Sg}$ & $\mathrm{Se}$ & $\mathrm{St}$ \\
\hline Carro de pastelería & 2 & 2 & 0.65 & 0.52 & 1.60 & 0.34 & 0.68 & 0.49 & 3.00 \\
\hline Mesa de trabajo & 2 & 4 & 1.50 & 0.70 & 0.90 & 1.05 & 4.20 & 2.52 & 15.55 \\
\hline Estantes/Anaqueles & 1 & 3 & 1.30 & 0.45 & 2.40 & 0.59 & 1.76 & 1.12 & 3.46 \\
\hline Refrigeradora & 1 & 1 & 0.60 & 0.68 & 1.81 & 0.41 & 0.41 & 0.39 & 1.21 \\
\hline Operarios & 4 & & & & 1.65 & 0.50 & & & \\
\hline Limpieza & 1 & & & & 1.65 & 0.50 & & & \\
\hline Coord. de producción & 1 & & & & 1.65 & 0.50 & & & \\
\hline \multicolumn{3}{|c|}{ Área requerida } & & & & & $\mathbf{2 3 . 2 2}$ \\
\hline
\end{tabular}

Tabla 4. 4: Análisis de Guerchet para el área de forrado y empaque.

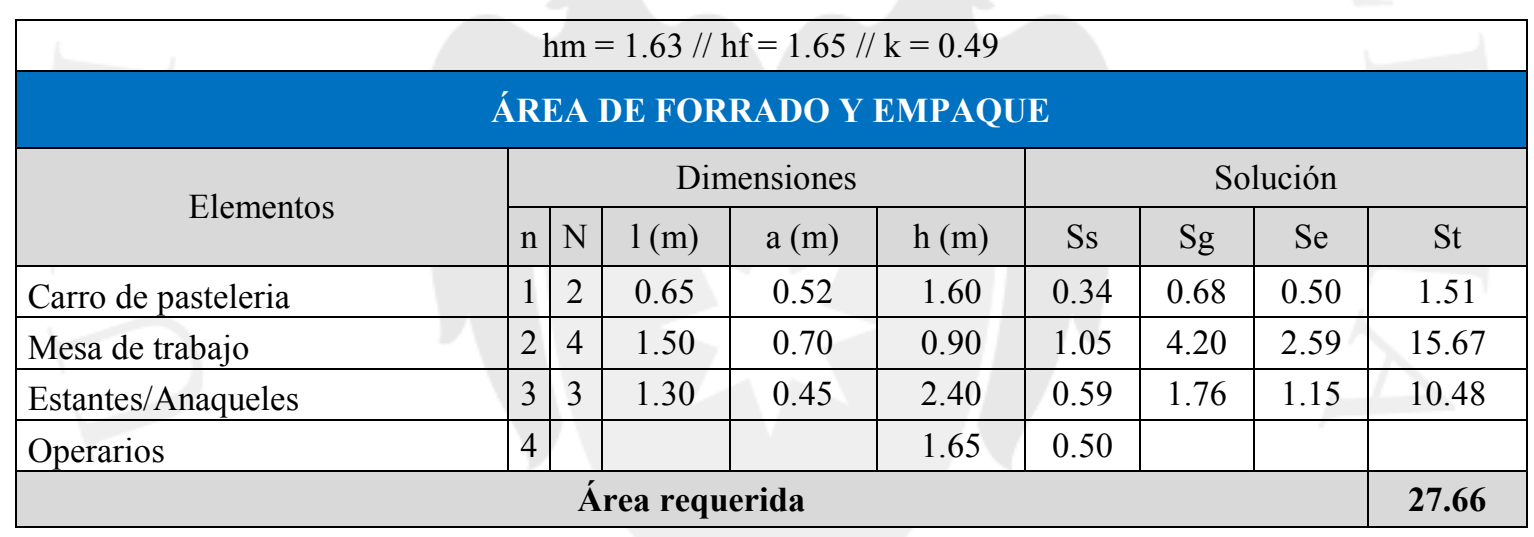


Tabla 4. 5: Análisis de Guerchet para el área oficinas administrativas.

\begin{tabular}{|c|c|c|c|c|c|c|c|c|c|}
\hline \multicolumn{10}{|c|}{$\mathrm{hm}=1.65 / / \mathrm{hf}=1.78 / / \mathrm{k}=0.46$} \\
\hline \multicolumn{10}{|c|}{ ÁREA DE OFICINA ADMINISTRATIVA } \\
\hline \multirow{2}{*}{ Elementos } & \multicolumn{5}{|c|}{ Dimensiones } & \multicolumn{4}{|c|}{ Solución } \\
\hline & $\mathrm{n}$ & $\mathrm{N}$ & $1(\mathrm{~m})$ & $\mathrm{a}(\mathrm{m})$ & $\mathrm{h}(\mathrm{m})$ & Ss & $\mathrm{Sg}$ & $\mathrm{Se}$ & St \\
\hline Escritorio & 3 & 1 & 1.00 & 0.61 & 1.35 & 0.61 & 0.61 & 0.57 & 5.36 \\
\hline Librería & 1 & 1 & 1.00 & 0.45 & 1.80 & 0.45 & 0.45 & 0.42 & 1.32 \\
\hline Baño & 1 & 1 & 2.47 & 1.36 & 2.45 & 3.36 & 3.36 & 3.12 & 9.84 \\
\hline Archivador & 3 & 1 & 0.45 & 0.61 & 1.50 & 0.27 & 0.27 & 0.26 & 2.41 \\
\hline Operarios & 3 & & 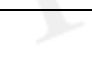 & & 1.65 & 0.50 & 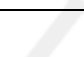 & & \\
\hline \multicolumn{9}{|c|}{ Área requerida } & 18.93 \\
\hline
\end{tabular}

Tabla 4. 6: Análisis de Guerchet para el área de almacén de materias primas.

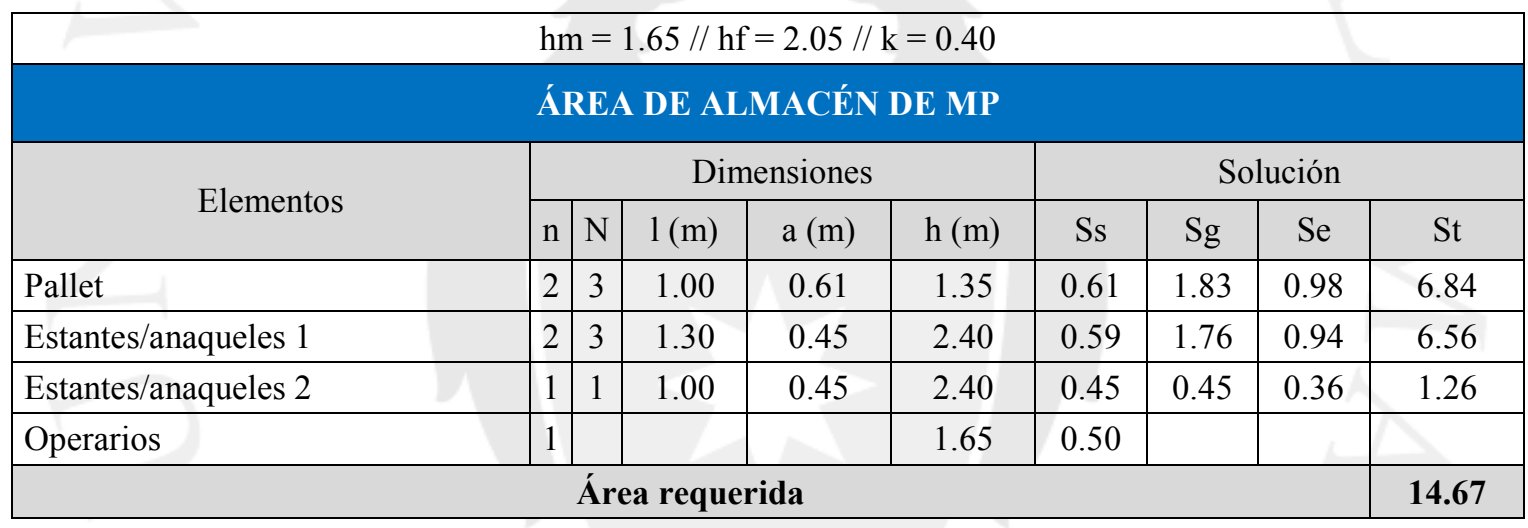

Tabla 4. 7: Análisis de Guerchet para el área de almacén de insumos.

\begin{tabular}{|c|c|c|c|c|c|c|c|c|c|}
\hline \multicolumn{10}{|c|}{$\mathrm{hm}=1.65 / / \mathrm{hf}=2.40 / / \mathrm{k}=0.34$} \\
\hline \multicolumn{10}{|c|}{ ÁREA DE ALMACÉN DE INSUMOS } \\
\hline \multirow{2}{*}{ Elementos } & \multicolumn{5}{|c|}{ Dimensiones } & \multicolumn{4}{|c|}{ Solución } \\
\hline & $\mathrm{n}$ & $\mathrm{N}$ & $1(\mathrm{~m})$ & $a(m)$ & $\mathrm{h}(\mathrm{m})$ & Ss & $\mathrm{Sg}$ & $\mathrm{Se}$ & St \\
\hline Estantes/anaqueles 1 & 5 & 3 & 1.30 & 0.45 & 2.40 & 0.59 & 1.76 & 0.94 & 16.41 \\
\hline Operarios & 1 & & & & 1.65 & 0.50 & & & \\
\hline \multicolumn{9}{|c|}{ Área requerida } & 16.41 \\
\hline
\end{tabular}


Finalmente, sumando cada una de las áreas obtenidas, tenemos como resultado final:

\section{ÁREA TOTAL REQUERIDA: $129.15(*)$ metros cuadrados}

(*) Sin considerar el área de vestidores, área de baño de operarios y patio.

Luego, hacemos un análisis de 3 situaciones: el área actual, el área requerida y un área propuesta de mejora al corto plazo:

Tabla 4. 8: Escenarios para la disposición del taller de la empresa

\begin{tabular}{|l|c|c|c|}
\hline \multicolumn{4}{|c|}{ ESCENARIOS PARA EL ÁREA DE PLANTA } \\
\hline \multicolumn{1}{|c|}{ Área } & Área actual $(\mathrm{m} 2)$ & $\begin{array}{c}\text { Área requerida } \\
(\mathrm{m} 2)\end{array}$ & $\begin{array}{c}\text { Área propuesta } \\
(\mathrm{m} 2)\end{array}$ \\
\hline ÁREA DE BATIDO Y HORNEADO & 17.33 & 28.25 & 25.61 \\
\hline ÁREA DE DISEÑO Y DECORACIÓN & 19.19 & 23.22 & 19.19 \\
\hline ÁREA DE FORRADO Y EMPAQUE & 30.33 & 27.66 & 30.33 \\
\hline $\begin{array}{c}\text { ÁREA DE OFICINA } \\
\text { ADMINISTRATIVA }\end{array}$ & 10.99 & 18.93 & 19.51 \\
\hline ÁREA DE ALMACÉN DE MP & 1.86 & 14.67 & 10.99 \\
\hline ÁREA DE ALMACÉN DE INSUMOS & 14.15 & 16.41 & 14.15 \\
\hline VESTIDOR & 2.77 & 2.77 & 2.77 \\
\hline ÁREA DE BAÑO OPERARIOS & 4.63 & 4.63 & 4.63 \\
\hline ÁREA DE BAÑO ADMINISTRACIÓN & 0.00 & 0.00 & 3.41 \\
\hline ÁREA DE PATIO & 6.27 & 6.27 & 6.27 \\
\hline \hline & $\mathbf{1 0 7 . 5 2}$ & $\mathbf{1 4 2 . 8 2}$ & $\mathbf{1 3 6 . 8 5}$ \\
\hline ÁREA TOTAL & & & \\
\hline
\end{tabular}


Con este resultado confirmamos que desde el momento en que se ingresa al taller, el espacio actual es muy limitado, existiendo una brecha aproximada de $35 \mathrm{~m} 2$. En la actualidad sólo se cuenta con un $75 \%$ del área total requerida.

Debido a que no se ha encontrado un local por la zona con el tamaño del espacio requerido, se está optando por alquilar un espacio contiguo de aproximadamente $25 \mathrm{~m} 2$. Considerando esta mejora a corto plazo, se estaría cumpliendo con el $90 \%$ del área total requerida.

En cuanto al reajuste del espacio de las áreas, el estudio se ha complementado con las relaciones que tienen las áreas entre sí, reubicando algunos de acuerdo a la proximidad necesaria y al espacio requerido.

Por lo tanto, nos damos cuenta que una posibilidad de mejora podría ser la ampliación de los espacios, ya que para la cantidad de máquinas o equipos, mobiliario y trabajadores con los que cuenta actualmente la empresa, el espacio es insuficiente. Otra opción sería buscar ampliaciones de espacio en el garaje contiguo al taller actual.

\subsubsection{Capacidad instalada y su utilización}

Para hallar la capacidad instalada actual, primero se ha realizado un balance de materia prima para el proceso de conversión a producto terminado (PT), en este caso estamos tomando al cupcake horneado como el PT. A continuación se presenta un esquema simplificado del proceso con las respectivas capacidades de cada máquina en las operaciones: 


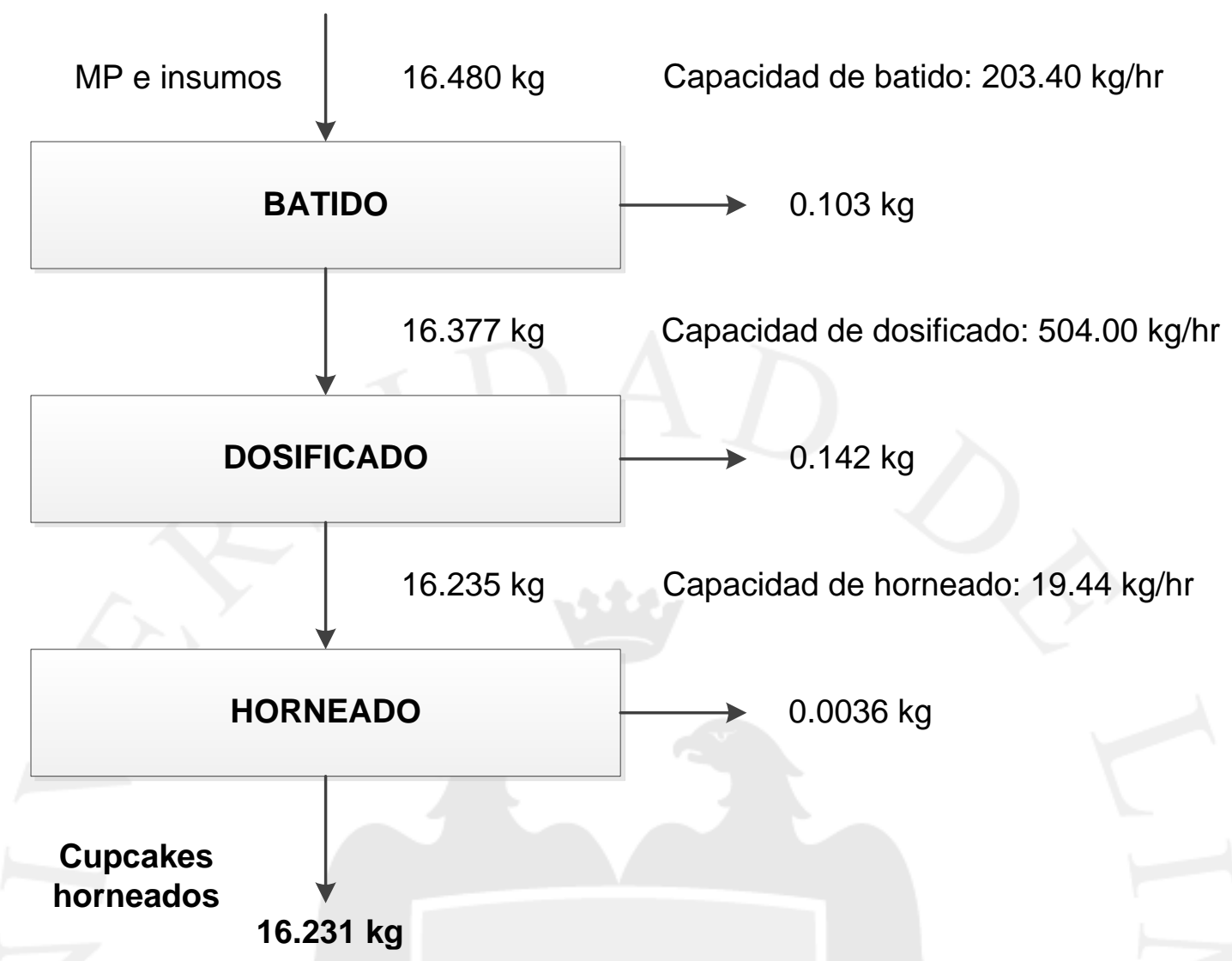

Figura 4. 2: Diagrama de balance de materia para la producción de cupcakes Fuente: Elaboración propia.

Asimismo, se está considerando lo siguiente:

a. Para todas las operaciones: 5.5 días por semana, 9 horas reales por turno, 1 turno por día.

b. En cuanto al factor de eficiencia, se consideraron distintos factores para cada máquina, esto debido a que solo la dosificadora necesita al trabajador para poder operar. En el resto de las máquinas, la intervención del operario es mínima. 
c. El factor de utilización (U) se halló de la siguiente manera:

Tabla 4. 9: Cálculo del factor de utilización de las máquinas en cada área.

\begin{tabular}{|l|c|c|c|c|c|c|c|}
\hline \multicolumn{1}{|c|}{ Operación } & $\begin{array}{c}\text { T. Refrigerio } \\
\text { (hr.) }\end{array}$ & $\begin{array}{c}\text { T. Prep. } \\
\text { (hr.) }\end{array}$ & $\begin{array}{c}\text { T. Limpieza } \\
\text { (hr.) }\end{array}$ & $\begin{array}{c}\text { T. Total } \\
\text { (hr.) }\end{array}$ & NHP & NHR & $\begin{array}{c}\text { U } \\
\text { (NHP/NHR) }\end{array}$ \\
\hline BATIDO & 1.00 & 0.01 & 0.25 & 1.26 & 7.74 & 9.00 & $\mathbf{0 . 8 6}$ \\
\hline DOSIFICADO & 1.00 & 0.04 & 0.33 & 1.38 & 7.63 & 9.00 & $\mathbf{0 . 8 5}$ \\
\hline HORNEADO & 1.00 & 0.34 & 0.25 & 1.59 & 7.41 & 9.00 & $\mathbf{0 . 8 2}$ \\
\hline
\end{tabular}

d. Mientras que los valores de factor de eficiencia de máquina utilizados son los siguientes:

Tabla 4. 10: Cálculo del factor de eficiencia para cada área.

\begin{tabular}{|l|c|}
\hline \multicolumn{1}{|c|}{ Operación } & $\begin{array}{c}\mathbf{E} \\
\text { (Factor de } \\
\text { eficiencia) }\end{array}$ \\
\hline BATIDO & 0.90 \\
\hline DOSIFICADO & 0.85 \\
\hline HORNEADO & 0.90 \\
\hline
\end{tabular}


e. Con estos datos hallados, hacemos el cálculo de la capacidad de planta actual con el que cuenta la empresa:

Tabla 4. 11: Cálculo de la capacidad de planta actual de la empresa.

\begin{tabular}{|l|c|c|c|c|c|c|c|c|c|c|c|}
\hline \multicolumn{1}{|c|}{ PROCESO } & QE & $\mathbf{P}$ & $\mathbf{M}$ & $\mathbf{H} / \mathbf{T}$ & $\mathbf{T}$ & $\mathbf{D} / \mathbf{A}$ & $\mathbf{U}$ & $\mathbf{E}$ & $\mathbf{C O}$ & $\mathbf{F} / \mathbf{Q}$ & $\mathbf{C O} \times \mathbf{F} / \mathbf{Q}$ \\
\hline BATIDO & 16.48 & 203.40 & 1 & 9 & 1 & 285.5 & 0.86 & 0.90 & $404,607.60$ & 0.98 & $398,494.30$ \\
\hline DOSIFICADO & 16.38 & 504.00 & 1 & 9 & 1 & 285.5 & 0.85 & 0.85 & $932,600.03$ & 0.98 & $918,509.16$ \\
\hline HORNEADO & 16.24 & 19.44 & 1 & 9 & 1 & 285.5 & 0.82 & 0.90 & $37,005.43$ & 0.98 & $36,446.30$ \\
\hline $\begin{array}{c}\text { F } \\
\text { (Producto terminado en } \\
\text { kg finales) }\end{array}$ & $\mathbf{1 6 . 2 3}$ & \multicolumn{10}{|c|}{} \\
\hline
\end{tabular}

Siendo:

- QE: Cantidad entrante según balance de materia (en kg).

- $\quad$ P: Producción/hora de máquina $(\mathrm{kr} / \mathrm{hr})$.

- $\quad$ M: Número de máquinas.

- $\quad \mathrm{H} / \mathrm{T}$ : Horas reales por turno.

- T: Número de turnos al día.

- D/A: Días al año.

- U: Factor de utilización.

- $\quad$ E: Factor de eficiencia.

- $\mathrm{CO}=\operatorname{PxMx}(\mathrm{D} / \mathrm{A}) \mathrm{x}(\mathrm{H} / \mathrm{T}) \mathrm{xUxT}$ : Capacidad de producción en unidades según balance de materia por cada operación $(\mathrm{kg})$.

- F/Q: Factor de conversión 
- $\mathrm{CO}$ x FQ: Capacidad de producción en unidades de producto terminado para cada operación.

f. Finalmente, tenemos la capacidad de planta hallada:

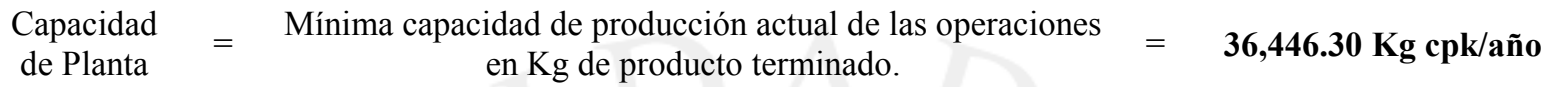

De acuerdo al resultado obtenido, nuestra capacidad de planta se rige a partir del cuello de botella, en este caso, el horno. La capacidad de planta actual es de $36,446.30 \mathrm{~kg}$ de cupcakes/año.

Luego, para poder hallar la utilización de la capacidad en la empresa, nos hemos basado en la demanda del año 2014 y la capacidad de planta actual, ambos datos expresados en $\mathrm{kg}$ :

$$
\text { Utilización }=\frac{\text { Demanda }}{\text { Capacidad de planta }}
$$

$$
\text { Utilización }=\frac{11,950.34}{36,446.30}=32.79 \%
$$

Este indicador nos muestra que actualmente la empresa está utilizando sólo un 33\% de su capacidad de planta. Esto es debido a que las máquinas solo trabajan medio turno y con esto es suficiente para satisfacer la demanda actual. Otro punto es que se han comprado máquinas de una capacidad mayor a la que se necesita actualmente, con miras a crecer en e futuro. 
Si tomamos como referencia la demanda proyectada (que se halla en el punto 4.5.1 del presente trabajo), la utilización futura de la planta, con la capacidad que se cuenta actualmente, sería:

Tabla 4. 12: Cálculo de la utilización de planta de acuerdo a la demanda proyectada.

UTILIZACIÓN DE PLANTA EN FUNCIÓN A LA DEMANDA PROYECTADA

\begin{tabular}{|l|c|c|c|c|c|}
\hline Año & 2015 & 2016 & 2017 & 2018 & 2019 \\
\hline Demanda (und) & 243,030 & 288,390 & 333,750 & 379,110 & 424,470 \\
\hline Demanda (kg de cpk) & 14,582 & 17,303 & 20,025 & 22,747 & 25,468 \\
\hline Capacidad actual & 36,446 & 36,446 & 36,446 & 36,446 & 36,446 \\
\hline Utilización & $40.01 \%$ & $47.48 \%$ & $54.94 \%$ & $62.41 \%$ & $69.88 \%$ \\
\hline
\end{tabular}

Con lo mostrado, podemos observar que al 2019 la empresa estaría utilizando un $69.88 \%$ del total de su capacidad instalada de planta, trabajando bajo las condiciones actuales, por lo que la empresa se puede mantener sin ningún problemas durante, al menos, 5 años más de operación.

\subsubsection{Sistema de mantenimiento}

La empresa cuenta con varias máquinas y equipos para la administración, producción y despacho de los productos. Actualmente no se ha implementado un sistema de mantenimiento para todos ellos. En la mayoría de estas máquinas y equipos se realiza un mantenimiento reactivo.

Esto no sólo genera el riesgo de poder parar la operación ante la falla de alguna de las máquinas, si no también, genera un riesgo aún mayor en la seguridad e integridad de los trabajadores, sobre todo en aquellos equipos 
de mayor tamaño o importancia, como lo es la batidora industrial o el horno; asimismo, puede ser esto también un factor de generar productos con fallas en calidad y sobre costos.

Entre algunos de los mantenimientos realizados durante el 2014 tenemos:

Tabla 4. 13: Registro de mantenimientos a equipos 2014.

\begin{tabular}{|c|c|c|}
\hline EQUIPO / MÁQUINA & $\begin{array}{c}\text { FECHA DE ÚLTIMO } \\
\text { MANTENIMIENTO }\end{array}$ & $\begin{array}{c}\text { COSTO DE } \\
\text { MANTENIMIENTO } \\
(\text { S/.) }\end{array}$ \\
\hline Horno Industrial Salva & $12 / 09 / 2015$ & 743.40 \\
\hline Dosificadora Industrial & Nunca & Nunca \\
\hline Batidora Industrial Nova & $13 / 12 / 2014$ & Nunca \\
\hline Batidora Kitchen Aid & $24 / 10 / 2014$ & 540.00 \\
\hline Refrigeradora & Nunca & Nunca \\
\hline Balanza & $17 / 10 / 2014$ & 590.00 \\
\hline Microondas & Nunca & Nunca \\
\hline Camioneta 1 & Noviembre 2014 & 961.91 \\
\hline Camioneta 2 & Octubre 2014 & 1075.85 \\
\hline Auto Toyota de Gerencia & Julio 2014 & 973.75 \\
\hline
\end{tabular}

\subsection{Del proceso}

\subsubsection{Situación tecnológica de los procesos}

La empresa Claudia Cupcakes tiene 3 principales procesos, en cada uno de estos procesos se aplican algunas tecnologías bases para el funcionamiento adecuado de la empresa. 


\section{a. Recepción de pedidos}

En este proceso existen 4 vías para el ingreso de pedidos: Facebook, página web, correo y central telefónica. En el caso de Cencosud, se trabaja con un software especial para el ingreso de sus requerimientos. Una vez recibidos por la empresa, estos se consolidan por día y se genera una orden de producción. Para este último proceso no se hace uso de ningún programa que analice y optimice la orden de los pedidos, más bien es a criterio del trabajador encargado; es decir, es un proceso semi - automático, puesto la parte inicial del ingreso de pedido está en sistemas, mientras que el procesamiento del pedido es manual.

\section{b. Producción}

El proceso de producción se inicia con la preparación del queque, el cual es estándar para todos los productos, ya sean cupcakes o tortas. La única variación que podría haber, es en el sabor o aditivos (toppings) que podría tener el producto. Para esto, en el área de Mezclado, se prepara la mezcla base que consiste en la combinación de la pre-mezcla, el agua, aceite y huevos en el recipiente que va colocado en la batidora, el cual lo realiza un operario ya que es un proceso totalmente manual. Luego, ésta mezcla es colocada en la batidora industrial, en donde finalmente se procesa para obtener la masa. Éste último proceso es automático puesto durante el mezclado no hay intervención de algún operario. Posteriormente, ésta masa es distribuida a través de la dosificadora en los pirotines colocados en los moldes respectivos, el cual es un proceso 
semi automático puesto que inicialmente el operario vierte la masa obtenida en la dosificadora pero luego ésta es programada para que vierta en los pirotines la cantidad exacta para producir el queque. Luego, éstos moldes conteniendo la masa ya vertida sobre ellos son ingresados al horno para el proceso de horneado respectivamente con el fin de obtener el queque. Durante el proceso de horneado la única intervención del operario es para ver el avance de la cocción y esto es de manera visual a través de los vidrios del horno.

Una vez obtenido el queque, se procede a retirarlos del horno y pasan a un proceso de enfriamiento, el cual no se requiere de algún equipo en particular, puesto que éste proceso se hace con la temperatura ambiente. Ya enfriados, pasan al área de forrado, en donde un operario se encarga de cubrir el cupcake con una ligera plancha de masa fondant para que sirva como base para los elementos de decorado. Posterior a esto, el cupcake ya forrado pasa a decoración, el cual es un proceso completamente manual debido al nivel de detalles que requiere y que no puede ser automatizado ya que es conocimiento del operario propiamente.

Finalmente, terminado el decorado del cupcake, pasa al área de clasificado y empaquetado, el cual es un proceso también manual. Aquí, los cupcakes son colocados en los blíster que corresponda según la presentación que se requiere, para luego ser sellados y envueltos en cintas de la marca para ser finalmente despachados. 


\section{c. Despacho de pedidos}

La empresa cuenta con 2 unidades de reparto. Para los pedidos realizados por Cencosud, éstos son colocados dentro de la unidad de transporte de tal manera que el producto no sea vea afectado durante el trayecto hacia su destino. El reparto hacia las sedes se realiza mediante los criterios de tiempo y distancia el cual es determinado por la persona encargada de ventas, puesto de momento no está automatizado.

En cuanto al reparto de los pedidos particulares, el proceso es el mismo, solo que también se considera el criterio de prioridad de pedido. En este proceso la empresa no hace uso de ningún software para optimizar el tiempo de reparto, así como el rastreo de las unidades.

Para poder tener una idea más conceptualizada de los procesos descritos previamente, en el capítulo 4.2.3

\subsubsection{Normas técnicas de fabricación}

En la actualidad, no existe una Norma Técnica Peruana (NTP) específica para la fabricación de productos de Pastelería en general (sólo para algunos tipos de panes); sin embargo, existe la siguiente Norma Sanitara:

Tabla 4. 14: Detalle de la Norma Sanitaria aplicable al sector de Pastelería.

\begin{tabular}{|c|c|c|}
\hline CÓDIGO & NOMBRE & PUBLICACIÓN \\
\hline RM N $1020-2010 /$ MINSA & $\begin{array}{c}\text { Norma Sanitaria para la Fabricación, } \\
\text { Elaboración y Expendio de Productos de } \\
\text { Panificación, Galletería y Pastelería. }\end{array}$ & $30 / 12 / 2010$ \\
\hline
\end{tabular}


Esta norma tiene el propósito de brindar los lineamientos necesarios para proteger la salud de los consumidores, disponiendo los requisitos sanitarios que deben cumplir los productos de panificación, galletería y pastelería y los establecimientos que los fabrican, elaboran y expenden.

En ella también se dan las pautas que debe tener el establecimiento en donde se produce estos alimentos y las características necesarias que debe tener el proceso de producción en general para cumplir los requisitos mínimos sanitarios.

En el caso de la empresa en estudio, se tiene claro estos lineamientos y los aplica en gran medida; sin embargo, quedan aún algunos aspectos por ser considerados, como por ejemplo, el análisis periódico de los alimentos producidos por un tema de costos elevados, los cuales no pueden ser afrontados con la frecuencia que se necesita.

\subsubsection{Análisis de los métodos de trabajo}

Para poder analizar los procesos involucrados en la empresa, a continuación mostramos el DAP (Diagrama de Actividades del Proceso) y el DOP (Diagrama de Operaciones del Proceso) con la finalidad de encontrar en ellos también oportunidades de mejora: 


\begin{tabular}{|c|c|c|c|c|c|c|c|c|c|c|}
\hline \multicolumn{4}{|l|}{ CURSOGRAMA ANALÍTICO } & \multicolumn{7}{|c|}{ Oporavio-/ Material / Equipo- } \\
\hline Diagrama No. 1 & de & 1 & & \multirow{2}{*}{\multicolumn{4}{|c|}{ Actividad }} & \multicolumn{3}{|c|}{ Resumen } \\
\hline \multirow{2}{*}{\multicolumn{4}{|c|}{ Producto: Six pack de cupcakes modelo Avengers (45 unidades) }} & & & & & Actual & Propuesto & Economía \\
\hline & & & & \multirow{2}{*}{\multicolumn{4}{|c|}{$\begin{array}{l}\text { Operación } \\
\text { Inspección } \\
\text { Espera } \\
\text { Transporte } \\
\text { Almacenamiento }\end{array}$}} & $\begin{array}{c}18 \\
2\end{array}$ & & \\
\hline \multirow{2}{*}{\multicolumn{4}{|c|}{$\begin{array}{l}\text { Actividad: BATIR, MANGUEAR, HORNEAR, FORRAR, DECORAR } \\
\text { Método: actual / propuooto- }\end{array}$}} & & & & & $\begin{array}{l}4 \\
5 \\
4\end{array}$ & & \\
\hline & & & & \multicolumn{4}{|c|}{ Distancia (mts.) } & & & \\
\hline \multicolumn{4}{|l|}{ Lugar: CLAUDIA CUPCAKES } & \multicolumn{4}{|c|}{ Tiempo (hrs.-hom.) } & $317.67^{\prime}$ & & \\
\hline Operario (s): & \multicolumn{3}{|c|}{ Ficha no. } & \multirow{2}{*}{\multicolumn{4}{|c|}{$\begin{array}{l}\text { Costo } \\
\text { Mano de obra Material }\end{array}$}} & & & \\
\hline Compuesto por: & \multirow{2}{*}{\multicolumn{2}{|c|}{$\begin{array}{l}\text { Fecha: } \\
\text { Fecha: }\end{array}$}} & & & & & & & & \\
\hline \multirow{2}{*}{\begin{tabular}{|} 
Aprobado por: \\
DESCRIPCIÓN
\end{tabular}} & & & & \multicolumn{4}{|c|}{$\begin{array}{c}\text { TOTAL } \\
\text { Actividad }\end{array}$} & & & \\
\hline & Cantidad & Distancia & Tiempo & \multicolumn{3}{|c|}{ Actividad } & $\nabla$ & \multicolumn{3}{|c|}{ OBSERVACIONES } \\
\hline \multicolumn{11}{|l|}{$\begin{array}{l}\text { En almacén de MP: pre mezcla, huevo, aceite, } \\
\text { agua y chispas de chocolate }\end{array}$} \\
\hline Transp. Al área de horneado & & & $1.01^{\prime}$ & & & & & & 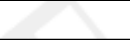 & \\
\hline Pesado & & & $2.02^{\prime}$ & & & & & $\begin{array}{l}8 \mathrm{~kg} \text { de pre } \\
1.84 \mathrm{~kg} \mathrm{de}\end{array}$ & $\begin{array}{l}\text { ezcla, } 2.8 \mathrm{kc} \\
\text { ua, } 2.64 \mathrm{~kg} \mathrm{c}\end{array}$ & $\begin{array}{l}\text { de huevo, } \\
\text { aceite }\end{array}$ \\
\hline Mezclado manualmente & & & $4.74^{\prime}$ & & & & & Con espát & de batidora & \\
\hline Batido & & & $5.44^{\prime}$ & & & & & Por 5 minu & & \\
\hline Pesado & & & $1.12^{\prime}$ & D & & & & $1.20 \mathrm{~kg} \mathrm{de}$ & ispas de cho & olate \\
\hline Mezclado manualmente & & & $2.09^{\prime}$ & & & & & Con espát & de madera & \\
\hline Colocado de pirotines en moldes & & & $5.21^{\prime}$ & & & & & & & \\
\hline Mangueado (Dosificado) & & & $9.21^{\prime}$ & & & & & $\begin{array}{l}\text { Regular do } \\
\text { mezcla }\end{array}$ & cador al 35\% & $=60 \mathrm{gr} \mathrm{de}$ \\
\hline Horneado & & & $53.73^{\prime}$ & & & & & $\begin{array}{l}\text { Precanlent } \\
\mathrm{T}=160^{\circ} \mathrm{C}, 5\end{array}$ & $\begin{array}{l}20 \text { minutos a } \\
\text { minutos }\end{array}$ & \\
\hline Desmoldado & & & $1.88^{\prime}$ & 8 & & & & & & \\
\hline Enfriado & & & $49.68^{\prime}$ & & & & & $\mathrm{T}=\mathrm{ambient}$ & 50 minutos & \\
\hline Transp. Al área de forrado & & & $0.18^{\prime}$ & & & & & & & 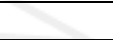 \\
\hline $\begin{array}{l}\text { En almacén de insumos: masa fondant, tintes } \\
\text { de colores }\end{array}$ & & & & & & & & & & \\
\hline Transp. Al área de forrado & & & $0.78^{\prime}$ & & & & & & & \\
\hline Pesado & & & $0.93^{\prime}$ & & & & & $4.6 \mathrm{~kg} \mathrm{de} \mathrm{r}$ & sa fondant & \\
\hline Teñido & & & $2.85^{\prime}$ & & & & & De acuerd & diseño & \\
\hline Estirado & & & $7.12^{\prime}$ & 8 & & & & $1.5-2 \mathrm{~mm}$ & espesor & \\
\hline Cortado & & & $9.28^{\prime}$ & & & & & Cortador $\mathrm{d}$ & $\mathrm{cm}$ de diám & \\
\hline \begin{tabular}{|l|} 
Untado en cupcakes \\
\end{tabular} & & & $7.21^{\prime}$ & 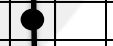 & & & & Con manja & anco & \\
\hline Pegado de forros & & & 9.39 & & & & & & 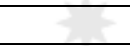 & \\
\hline Transp. Al área de decorado & & & $0.20^{\prime}$ & & & & & & & \\
\hline $\begin{array}{l}\text { En almacén de insumos: masa fondant, tintes } \\
\text { de colores, etiquetas }\end{array}$ & & & & & & & & & & \\
\hline Transp. Al área de decorado & & & $0.84^{\prime}$ & & & & & +2 & & \\
\hline 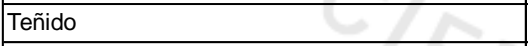 & & & $5.05^{\prime}$ & & & & 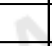 & De acuerd & diseño & \\
\hline Diseño de adornos & 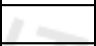 & & $80.91^{\prime}$ & 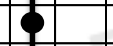 & & & - & 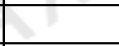 & & \\
\hline Etiquetado de cupcakes & t & 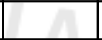 & 8.11 & $\phi$ & - & & + & F. producc & y F. de venc & niento \\
\hline Pegado de adornos & 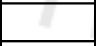 & 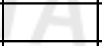 & 22.43 & & & & & Con clara & huevo & \\
\hline En almacén de insumos: envases, cintillos & & & & & & & 2 & & & \\
\hline Transp. Al área de empacado & & & $0.98^{\prime}$ & & & 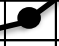 & & & & \\
\hline Empacado & & & $15.84^{\prime}$ & & & & & 6 cupcake & or envase & \\
\hline Colocado de cintillo & & & $9.46^{\prime}$ & 5 & & & & & & \\
\hline TOTAL & & & 317.67 & \begin{tabular}{|l|l|}
19 & 2 \\
\end{tabular} & 4 & 5 & 4 & & & \\
\hline
\end{tabular}

Figura 4. 3: Diagrama de Actividades del Proceso de producción de cupcakes Fuente: Elaboración propia. 


\section{DIAGRAMA DE OPERACIONES Y PROCESOS PARA LA ELABORACIÓN DE CUPCAKES}

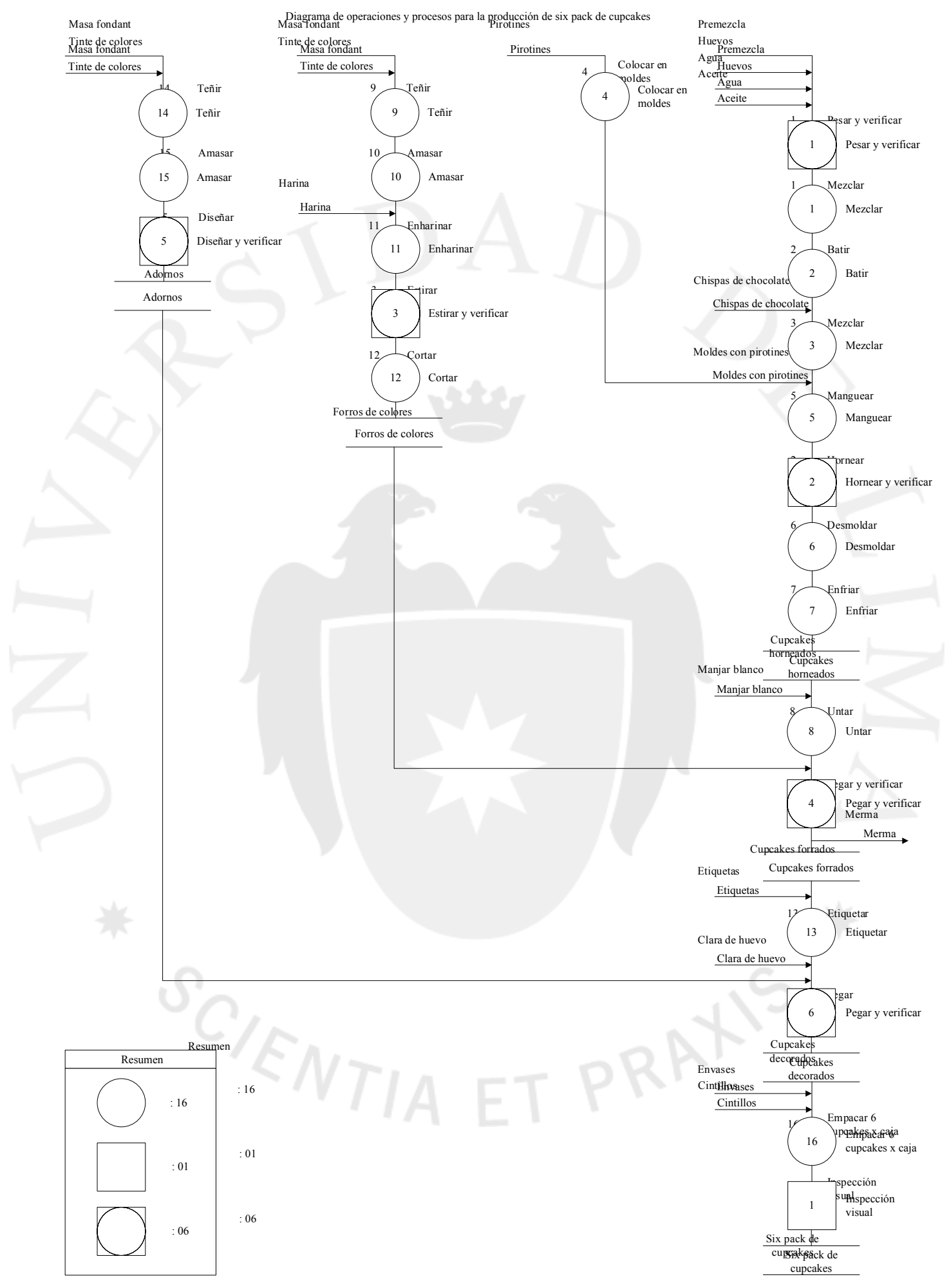

Figura 4. 4: Diagrama de Operaciones y Procesos para la producción de cupcakes Fuente: Elaboración propia. 
Para mayor detalle con respecto a las características de las actividades y procesos descritos, consultar el anexo 04 al final de éste trabajo.

\subsubsection{Control del proceso y aseguramiento de la calidad}

La empresa Claudia Cupcakes se preocupa por vender un producto, que además de ajustarse a las necesidades del cliente, cumpla con características de alta calidad.

En la actualidad cuenta con un con una persona responsable en temas de aseguramiento de calidad, quien, entre otros temas administrativos afines, controla que se cumplan las buenas prácticas de manufactura en los procesos de producción y verifica que, tanto la materia prima que se adquiere, como el producto en proceso y finalmente el producto terminado cumplan con los estándares mínimos requeridos.

Adicionalmente, tal como se mencionó en el capítulo 4.2.2, la normativa existente actual que regula los procesos productivos en alimentos es la "Norma Sanitaria para la Fabricación, Elaboración y Expendio de Productos de Panificación, Galletería y Pastelería", la cual es aplicada por la empresa, puesto es requisito indispensable para que pueda operar; asimismo, existe también un proceso sistemático preventivo para poder garantizar la inocuidad alimentaria de forma lógica y objetiva denominado HACCP (Por su siglas en inglés: "Análisis de Peligros y Puntos Críticos de Control”), el cual permite identificar, evaluar y prevenir todos los riesgos de contaminación de los productos a nivel físico, químico y biológico a lo largo 
de todos los procesos de la cadena de suministro, estableciendo medidas preventivas y correctivas para su control para asegurar esta inocuidad.

Actualmente la empresa hace los esfuerzos necesarios para poder implementar éstas medidas que permitan poder alcanzar todos los requisitos para poder optar, en un período determinado, a una certificación HACCP, a fin de que sea ésta una oportunidad de seguir creciendo en el mercado. Al finalizar este sub capítulo encontraremos el análisis realizado en los aspectos HACCP para la empresa en análisis. Previamente, hacemos un repaso de algunas de las actividades de control que se realizan dentro de los procesos involucrados en la cadena de valor de la empresa:

\section{a. Materias primas:}

- Control visual del producto que ingresa y que esté conforme a lo solicitado.

- Peso del contenido del producto.

- Colocar adecuadamente en los espacios asignados las materias primas según su característica y/o uso en el proceso.

- Controlar periódicamente que éstos se encuentren en las condiciones adecuadas que permitan su cuidado y conservación.

\section{b. Producto en proceso:}

- Asegurar que la manipulación de alimentos sea la adecuada y no exista contaminación cruzada una vez que el producto está en proceso de producción. 
- Controlar visualmente del proceso durante el proceso de mezclado y posterior al horneado.

- Controlar la textura del producto escogiendo al azar algunas muestras.

- Tomar nota de las diversas situaciones que podrían presentarse y que puedan afectar al producto.

- Determinar qué producto o lote está conforme a lo solicitado para su continuidad en el proceso.

\section{c. Producto terminado:}

- Inspeccionar al producto una vez terminado todos los procesos productivos.

- Cuidar que el producto ya empacado y listo para despacho sea almacenado hasta su salida en las condiciones necesarias para cuidar no sólo su aspecto físico externo, sino sobre todo, su condición interna para evitar cualquier tipo de contaminación.

- Generar el registro necesario de salida del producto a fin de poder tener una rastreabilidad necesaria del producto una vez despachado. 
Previo al análisis HACCP, se considera éste esquema:
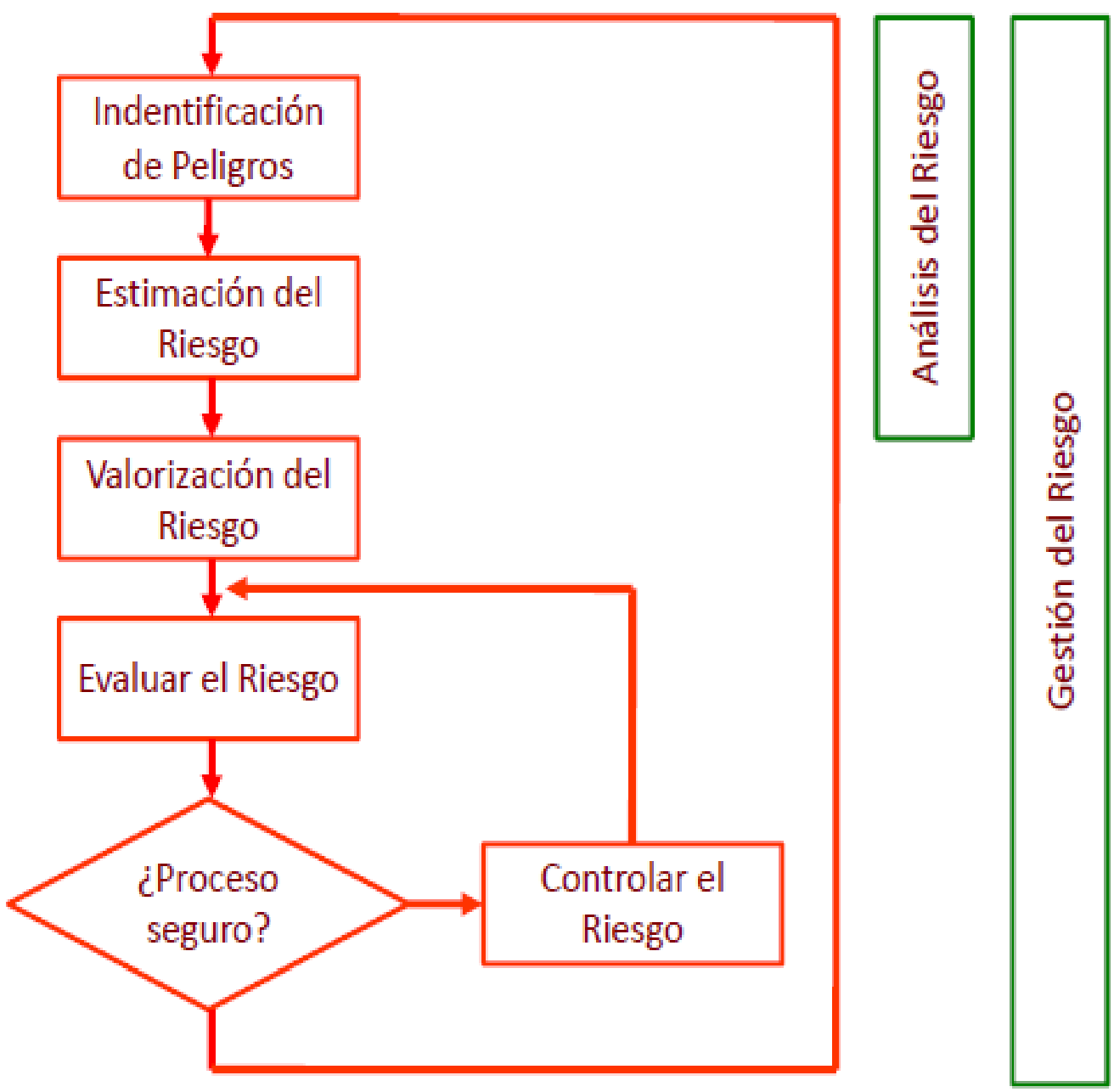

Figura 4. 5: Esquema para la elaboración de un plan HACCP Fuente: FAO, 2012.

Como parte de las propuestas de mejoras, desarrollaremos detalladamente el correspondiente plan HACCP en el capítulo 8 del presente trabajo. 


\subsection{De los productos}

\subsubsection{Descripción técnica}

Tomando como base los lineamientos brindados por la $\mathrm{RM} \mathrm{N}^{\circ} 1020$ 2010/MINSA mencionada anteriormente, los aspectos físico-químicos requeridos para la elaboración de estos productos son los siguientes:

Tabla 4. 15: Parámetros para la producción de cupcakes

\begin{tabular}{|c|c|c|}
\hline PRODUCTO & PARÁMETRO & $\begin{array}{c}\text { LÍMITES MÁXIMOS } \\
\text { PERMISIBLES (\%) }\end{array}$ \\
\hline \multirow{2}{*}{$\begin{array}{c}\text { Bizcochos y similares con y sin relleno } \\
\text { (panetón, chancay, panes de dulce, pan de } \\
\text { pasas, pan de camote, pan de papa, tartas, } \\
\text { tortas, pasteles y otros similares) }\end{array}$} & Humedad & 40 \\
\cline { 2 - 3 } & $\begin{array}{c}\text { Acidez (expresada en Ácido } \\
\text { Láctico) }\end{array}$ & 0.70 \\
\cline { 2 - 3 } & Cenizas & 3 \\
\hline
\end{tabular}

Asimismo, considerando la misma fuente, tenemos también los criterios microbiológicos a considerar en la elaboración del producto: 
Tabla 4. 16: Criterios microbiológicos para productos de panadería y pastelería

Productos que no requieren refrigeración, con o sin relleno y/o cobertura (pan, galletas, panes
enriquecidos o fortificados, tostadas, bizcochos, panetón, queques, obleas, pre-pizzas, otros).

Todos estos aspectos son analizados y evaluados al menos una vez al año en

la producción de la empresa. Si bien la ley requiere que se haga esta evaluación sea realizada al menos 2 veces al año, la empresa no logra cumplir las especificadas debido al costo que implica poder hacerlo. Esto podría convertirse en una traba en su búsqueda de ingresar en nuevos nichos u oportunidades en el mercado.

Por otro lado, tomando los aspectos externos o técnicos propiamente del cupcake tamaño estándar elaborado por la empresa tenemos: 
Tabla 4. 17: Especificaciones externas del cupcake

\begin{tabular}{|c|c|c|}
\hline Parámetro & Medición & Unidad \\
\hline Altura & 40 & Milímetros $(\mathrm{mm})$ \\
\hline Peso & 65 & Gramos $(\mathrm{gr})$ \\
\hline Diámetro & 50 & Milímetros $(\mathrm{mm})$ \\
\hline
\end{tabular}

Y en lo que corresponde a los detalles de producción de cupcakes:

$1 \mathrm{~L}$. masa preparada $=1.130 \mathrm{~kg}$. Masa preparada

Densidad de la masa $=1.130 \mathrm{~kg} / \mathrm{L}$.

Considerando éstos parámetros utilizados por la empresa, para la preparación de la mezcla se usan los siguientes ingredientes y en las cantidades especificadas a continuación, en un bowl de 15 litros (no necesariamente el bowl lleno):

- $\quad 7.50 \mathrm{~kg}$ de satín (pre mezcla).

- $\quad 2.50 \mathrm{~kg}$ de huevo.

- $2.33 \mathrm{~kg}$ de aceite

- $\quad 1.61 \mathrm{~kg}$ de agua (1.61 lt.)

- 800 gr. de chispas chocolate 
Posteriormente, para el proceso de horneado, los parámetros de cocción son:

- Temperatura de horneado: $150^{\circ} \mathrm{C}$

- Tiempo de horneado: 50 minutos (aprox.).

Una vez cocido el queque, cada cupcake es recubierto por una capa hecha a base de masa fondant (masa elástica). El rendimiento aproximado de éste insumo es:

- $\quad 1 \mathrm{~kg}$ masa fondant $=61$ cupcakes (aprox.)

El tiempo utilizado para la cobertura del queque con la masa fondant es en promedio 30 min por cada 50 cupcakes; sin embargo, usualmente la masa pasa por un proceso de coloración de acuerdo al diseño final que se desea del producto, por lo cual, paralelamente al horneado del queque, ésta masa puede pasar por éste proceso el cual podría tomar más tiempo incluso que el de cubrir el queque con dicha masa propiamente.

Como características finales del producto, tendríamos:

Tabla 4. 18: Especificaciones físicas finales del cupcake.

\begin{tabular}{|c|l|}
\hline Factor & \multicolumn{1}{|c|}{ Descripción } \\
\hline Aspecto & $\begin{array}{l}\text { Queque: color canela con puntos de color marrón (chispas de chocolate). } \\
\text { Cupcake final (ya decorado): Color blanco y rosado con figuras de } \\
\text { decoración. Tamaño pequeño como un queque personal, con forma de un } \\
\text { pentágono sin la punta superior. }\end{array}$ \\
\hline Físico & $\begin{array}{l}\text { Queque: rugoso al tacto. } \\
\text { Cupcake final: liso al tacto, con textura esponjosa y un poco húmeda, } \\
\text { consistencia media y suave, con un peso ligero }\end{array}$ \\
\hline Aroma & Olor a vainilla, sabor dulce y agradable. \\
\hline
\end{tabular}


Para el caso de las tortas, el procedimiento es muy similar al de la elaboración del cupcake, con la diferencia en el aspecto físico ya que sus características dependerán de cada pedido; pero, en nuestro caso de análisis, considerando que el cupcake es el producto más vendido, nos enfocamos en él.

\subsubsection{Normas técnicas del producto}

De la misma manera que para el Proceso de fabricación en sí de los productos de pastelería, actualmente no existe una Norma Técnica Peruana (NTP) orientada a la fabricación de tortas, pasteles o cupcakes en general; sin embargo, siguiente la misma línea que en el punto 4.2.2, para la producción de la empresa se rige mediante la $\mathrm{RM} \mathrm{N}^{\circ}$ 1020-2010/MINSA "Norma Sanitaria para la Fabricación, Elaboración y Expendio de Productos de Panificación, Galletería y Pastelería", donde de la misma manera se dan las pautas necesarias para la producción de éste alimento.

\subsubsection{Indicadores de cumplimiento de estándares de calidad}

El cumplimiento de los estándares de calidad por parte de la empresa en estudio, puede ser analizado desde muchas aristas, las cuales cohesionan una adecuada gestión de la calidad y satisfacción en el cliente final.

Así, tenemos por ejemplo: 


\section{a. Nivel de Satisfacción de los clientes con el producto}

\section{SATISFACCIÓN GENERAL}

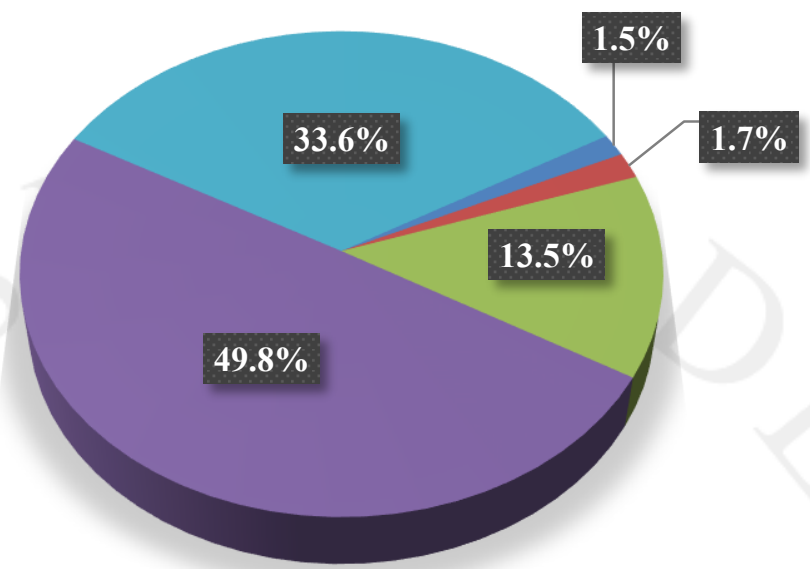

$\square$ NS / NO $\square$ Nada Satisfecho $\square$ Poco Satisfecho $\square$ Satisfecho $\square$ Muy Satisfecho

Figura 4. 6: Satisfacción de los clientes con el producto

Fuente: Elaboración propia.

Entre "Muy Satisfecho" y "Satisfecho" tenemos un nivel de satisfacción general de $83.4 \%$ por parte de los clientes, lo cual es un indicador muy bueno, aunque es más importante analizar qué sucede con el 17\% de clientes restantes que no están en este grupo.

\section{b. Nivel de rechazos de productos en proceso}

$$
\mathrm{NRPP}=\frac{\# \text { de productos rechazados }}{\# \text { total de producidos }} \times 100
$$




$$
\mathrm{NRPP}=\frac{16800}{202,415} \times 100=\mathbf{8 . 3} \%
$$

El indicador anterior mostrado nos muestra un bajo índice de rechazo de productos en proceso, lo cual nos da a entender que los controles visuales aplicados actualmente serían adecuados para el proceso productivo.

\section{c. Nivel de pedidos/productos defectuosos (observados y/o rechazados}

\section{al ser despachados)}

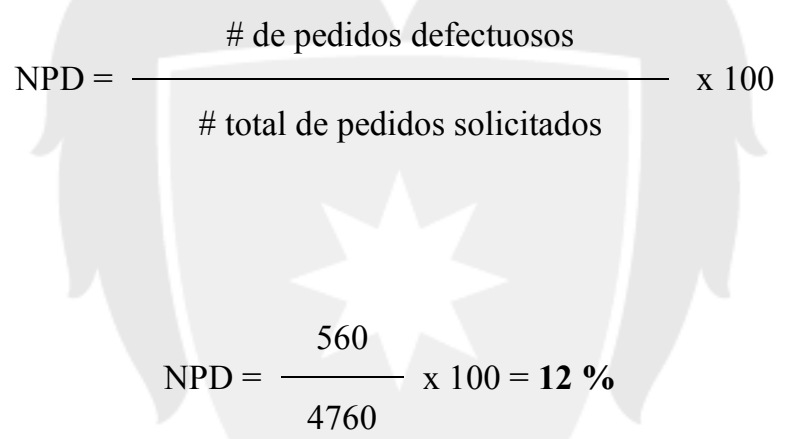

Como comentario al indicador anterior, tenemos el dato de que los casos presentados en el rechazo de pedidos se presentan, en su mayoría, por algunas fallas detectadas en el etiquetado de algunos productos $\mathrm{y}$, en otros casos, porque el producto presentaba ligeras imperfecciones por una mala manipulación en el proceso de despacho. Cabe acotar que estas fallas son en gran medida en la atención de pedidos de Cencosud. 


\subsection{De las materias primas}

\subsubsection{Descripción de las materias primas}

Como se mencionó anteriormente, el cupcake y las tortas, principales

productos de la empresa, tienen como base esencial del producto el queque.

Para su preparación, las materias primas utilizadas son:

Tabla 4. 19: Descripción de las materias primas.

\begin{tabular}{|c|c|c|}
\hline INGREDIENTE & DESCRIPCIÓN & IMAGEN \\
\hline Pre mezcla (Satín) & $\begin{array}{l}\text { Combinación de harina con otros aditamentos: polvo de } \\
\text { hornear, polvo de vainilla, entre otros. El único proveedor para } \\
\text { éste insumo es la empresa Puratos, cuyo producto tiene } \\
\text { diversas presentaciones: "Tegral Torta de Chocolate", "Satín } \\
\text { Creme Cake", etc.; Debido a la cercanía con éste proveedor y } \\
\text { ante la venta de productos en gran volumen a Cencosud, se ha } \\
\text { desarrollado productos exclusivos para la producción de } \\
\text { queques, que llevan nombres de "Cake Wong". }\end{array}$ & Purat \\
\hline Aceite & $\begin{array}{l}\text { Elemento importante en la mezcla para la preparación del } \\
\text { queque. Se usa el que se utiliza comúnmente en la cocina, } \\
\text { pudiendo ser de cualquier marca siempre y cuando cumpla con } \\
\text { las especificaciones de salubridad mínimas. }\end{array}$ & \\
\hline Agua & $\begin{array}{l}\text { El agua es obtenida directamente del suministro de agua } \\
\text { potable y es vertida tal cual en la mezcla, puesto que durante el } \\
\text { proceso de horneado, debido a la temperatura a la cual es } \\
\text { procesada la masa, las impurezas presentes son eliminadas. } \\
\text { Cabe mencionar que la única excepción para el uso de agua } \\
\text { envasada es para las tortas de chocolate una vez que han sido } \\
\text { horneadas, con la finalidad de remojar el queque. }\end{array}$ & \\
\hline Huevos & $\begin{array}{l}\text { Como en cualquier mezcla casera para preparar un queque, los } \\
\text { huevos son también parte importante en éste proceso de } \\
\text { mezclado, ya que gracias a su textura y componentes, éste } \\
\text { permite poder crear una masa más consistente y un producto } \\
\text { con las características deseadas. Estos insumos son adquiridos } \\
\text { como compra al por mayor en tiendas mayoristas, ya que la } \\
\text { compra directa al productor resulta siendo más costosa que la } \\
\text { opción actual. }\end{array}$ & \\
\hline
\end{tabular}




\begin{tabular}{|c|l|c|}
\hline INGREDIENTE & \multicolumn{1}{|c|}{ DESCRIPCIÓN } \\
\hline $\begin{array}{l}\text { Chispas de } \\
\text { Chocolate }\end{array}$ & $\begin{array}{l}\text { Ingrediente opciones de acuerdo al requerimiento del cliente. } \\
\text { Éstas chispas de chocolates, o "toppings", son agregadas a la } \\
\text { mezcla y, en conjunto con los demás ingredientes, se hornea } \\
\text { para producir el queque. }\end{array}$ \\
\hline $\begin{array}{c}\text { Cobertura de } \\
\text { Chocolate }\end{array}$ & $\begin{array}{l}\text { Se utiliza para poder hacer la cobertura de un tipo específico de } \\
\text { cupcake: "Cupcake zambito", el cual ha tenido una gran } \\
\text { acogida en el público y por ende tiene una producción } \\
\text { importante. }\end{array}$ \\
\hline
\end{tabular}

Una vez obtenido el queque ya horneado, se procede a la cobertura del mismo. Para esto, la materia prima es:

Tabla 4. 20: Descripción de otros insumos.

\begin{tabular}{|c|l|c|}
\hline INGREDIENTE & \multicolumn{1}{|c|}{ DESCRIPCIÓN } \\
\hline Masa Fondant & $\begin{array}{l}\text { La masa fondant es quizá la razón principal por la que } \\
\text { el cupcake es preferido, ya que, al margen de tener un } \\
\text { buen sabor, es con éste ingrediente con el que se } \\
\text { pueden hacer todos los diseños deseados y que le dan } \\
\text { la ventaja competitiva. }\end{array}$ \\
\hline Colorantes & $\begin{array}{l}\text { Los colorantes son el complemente de la Masa } \\
\text { Fondant, ya que ésta última viene sin coloración } \\
\text { (blanco) y es con éste ingrediente con el que puede } \\
\text { tenerse cualquier color deseado para el diseño que se } \\
\text { quiera realizar. }\end{array}$ \\
\hline
\end{tabular}


Finalmente, hay implementos adicionales que no son parte de la producción del producto propiamente; sin embargo, son parte de la cadena de preparación del producto hasta que éste se encuentre listo para ser despachado. Entre éstos, tenemos:

a. Moldes para el queque: Utilizados para colocar la masa antes de ingresar al horno.

b. Pirotines: es el envase en el cual se coloca la masa y, posteriormente, en el molde para ingresarlo al horno.

c. Blíster: Una vez terminado el producto ya decorado, éste se empaca en blísteres de distintas presentaciones $(1,3,6$, etc,).

d. Etiquetas: Son las que se colocan debajo del producto en donde se indica la fecha de vencimiento, número de lote, etc.

e. Moños: Están para dar los detalles de decoración finales del producto.

\subsubsection{Relaciones con los proveedores}

La empresa mantiene una muy buena relación con sus proveedores ya que éstos cumplen a tiempo con las órdenes de compra que se ingresa y en el nivel de servicio deseado por la empresa; sin embargo tiene una relación más cercana con 3 proveedores: "Puratos", "Fratello" y "Negusa".

En el caso del primero, éste se ha convertido incluso en una alianza comercial, puesto no sólo le suministra la pre mezcla para la producción de cupcakes y tortas, si no también, ahora mediante un proceso de "trasvase", 
se vierte la pre mezcla en otros empaques en donde luego se comercializa directamente al público pero con la marca de Claudia Cupcakes. Esto se vende en las tiendas Cencosud. Es por eso que, para éste proveedor, la relación comercial con la empresa en estudio es muy importante al punto de convertirse prácticamente como un nuevo canal de venta al público.

Por otro lado, Fratello y Negusa suministran la masa fondant y los ingredientes de chocolate, respectivamente. En el caso del primero, adicionalmente suministra también el colorante en gel para poder dar color a la masa de acuerdo a la necesidad, mientras que los aditamentos de chocolate que suministra Negusa, consiste en los toppings los cuales contienen la mayoría de cupcakes y la cobertura para producir el cupcake "Zambito". Para éstos 2, si bien Claudia Cupcakes no es una empresa grande, la relación comercial que se ha cultivado hasta ahora es importante $\mathrm{y}$, de alguna manera, es muy considerada para ellos.

Citamos a los principales proveedores mencionados anteriormente, cada uno con un estimado del nivel de calidad y servicio actual hacia la empresa, en base a las fórmulas:

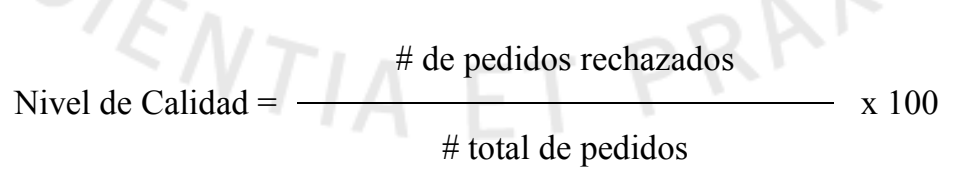

\footnotetext{
\# de productos entregados a tiempo

Nivel de Servicio $=\longrightarrow \times 100$

\# total de pedidos entregados
} 
Tabla 4. 21: Niveles de servicio de proveedores

\begin{tabular}{|c|c|c|c|c|}
\hline PROVEEDOR & $\begin{array}{c}\text { MATERIA PRIMA } \\
\text { QUE SUMINISTRA }\end{array}$ & FRECUENCIA & $\begin{array}{c}\text { NIVEL DE } \\
\text { CALIDAD } \\
(\%)\end{array}$ & $\begin{array}{c}\text { NIVEL DE } \\
\text { SERVICIO } \\
(\%)\end{array}$ \\
\hline Puratos & Pre-mezcla & Semanal & 99 & 99 \\
\hline Fratello & Masa Fondant & Semanal & 98 & 99 \\
\hline Negusa & Chocolates & Semanal & 98 & 97 \\
\hline
\end{tabular}

Puratos es el proveedor exclusivo de Claudia Cupcakes, habiendo creado, incluso, una relación de productor intermediario, ya que si bien Claudia utiliza sus pre mezclas como ingrediente clave para la producción del queque, dentro de la línea de productos que ofrece la empresa está también la Pre-mezcla para preparar cupcakes en casa, lo cual no es sino una distribución de la pre mezcla producido por Puratos pero con la marca de Claudia Cupcakes. Obviamente, al ser ésta última la marca más comercial por sus cupcakes propiamente, como sus tortas, la pre mezcla tiene un alto potencial de venta considerando lo anterior.

En el caso de los demás insumos, como el aceite y huevos, éstos son comprados directamente en tiendas mayoristas, puesto según se tiene información, por alguna razón los precios que se tienen aquí son más competitivos que comprarlos directamente al productor. 


\subsubsection{Sistema de control y reposición de existencias}

Actualmente la empresa no tiene un sistema implementado para el control y la reposición de sus existencias de materia prima e insumos. Si bien es cierto que usualmente no hay rotura de stock o desabastecimiento de éstos elementos, la gestión actual no elabora un adecuado plan de compras acorde a la demanda y ésta se genera únicamente de manera visual, es decir, cuando se percibe una posible falta de suministros para la producción, lo que activa la necesidad de compra. Cabe mencionar que el nivel de inventario de la empresa no es fijo puesto su producción es a pedido; sin embargo, si bien podría haber funcionado hasta ahora, podría ser aún mucho mejor si es que se consideran las variables necesarias para un planeamiento adecuado de la compra y abastecimiento de suministros y stock, como principalmente, la proyección de demanda según la data histórica de períodos anteriores.

Por otro lado, actualmente el ingreso y salida de materiales y suministros es manejado a través de un kárdex muy sencillo, en el cual se trata de llevar un poco el control de lo que se adquiere y lo que se utiliza en la producción. Para poder tener una idea más clara de las ideas mencionadas, revisamos algunos índices y/o datos al respecto tomados durante el año 2014 - 2015 (indicadores anuales): 


\section{a. Nivel de servicio del abastecimiento de materiales}

Éste valor se considera en un 100\%, puesto en el transcurso del 2014 no se presentó alguna situación que en la que el suministro de materiales haya afectado a la producción o, peor aún, la haya parado.

$=\frac{\text { Total de solicitudes atendidas }}{\text { Total de solicitudes }} \times 100=\quad \mathbf{1 0 0} \%$

\section{b. Ruptura de Stock}

La ruptura de stock podría perjudicar fuertemente a la empresa, debido a que ante una situación así la producción se vería afectada y el producto no llegaría al mercado, con lo que hasta se podrían perder a los clientes. Sin embargo, a la fecha no se tiene un registro de una situación así puesto que, en cuanto a las materias primas siempre se cuenta debido a la compra periódica (no planificada) que se hace y, por otro lado, la empresa no produce para generar stock de productos terminados ya que todo es a pedido y hasta ahora no ha dejado de entregar un pedido por una ruptura del inventario de materias primas o el producto solicitado.

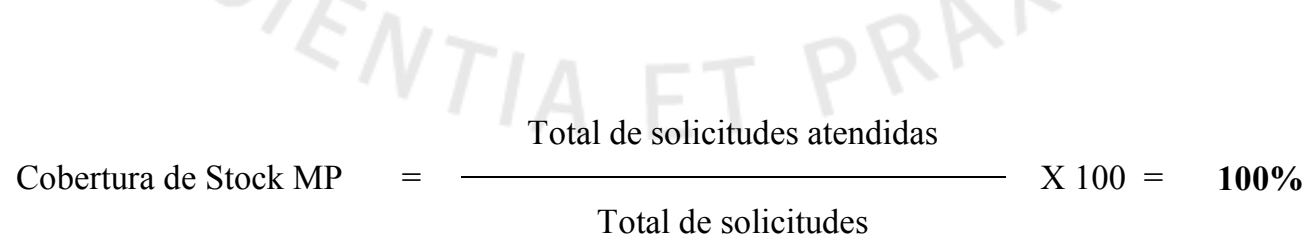




\section{c. Rotación de Inventarios}

Tal como se indicó en los puntos anteriores, la empresa no genera inventarios de productos terminados debido a que la producción es a pedido y la entrega es al día siguiente de producido (durante la noche la producción pernocta de manera apilada sobre las mesas de trabajo); sin embargo, podría medirse la rotación del inventario que se tiene en materias primas e insumos:

Rotación de Inventarios
$=$ $\frac{\text { Costo de ventas }}{\text { Inventario Promedio }}=$ $=\frac{\mathrm{S} / .5850 .20}{\mathrm{~S} / .342 .75}=\mathbf{1 7 . 0 7}$ veces

Con el dato obtenido observamos que este dato va de la mano con el número de veces en que rota el inventario de materias primas e insumos en almacén, considerando que estas compras no son planificadas y simplemente se dan a "simple vista" por parte de la gerencia ante situaciones previsibles de falta de materiales. Éste número podría mejorarse considerando una mayor capacidad de almacenamiento en los almacenes y, por otro lado, logrando quizá menores precios con los proveedores comprando en mayor volumen, ya que comprar en lotes 
más pequeños es probablemente un impedimento para ofrecer precios mejores por parte del proveedor.

\section{d. Stock de Seguridad}

Actualmente la empresa no maneja un valor de stock de seguridad por las razones antes explicadas. El principal limitante ahora es la poca disponibilidad de espacio y, por otro lado, dado a que usualmente la compra que realizan les permite poder cubrir la necesidad que tienen para la producción.

\section{e. Deterioro de productos}

Como se mencionó anteriormente, la empresa produce a pedido, por lo que no se genera un stock de productos terminados que puedan correr el riesgo de malograrse; sin embargo, los productos que podrían si quizá deteriorarse debido al almacenamiento son las materias primas e insumos, pero ésta situación no se ha presentado al día de hoy considerando en principio que lo que la empresa compra es usado en un plazo máximo de 2 semanas (tiempo promedio de inventario de MP en almacén: Pre mezcla, aceite y huevos), por lo que éste riesgo es muy bajo. 
Para poder tener una idea más clara al respecto, lo cuantificamos así:

$\begin{gathered}\text { Deterioro de } \\ \text { productos }\end{gathered}=\frac{\text { Productos deteriorados en almacén }}{\text { Total de productos almacenados }}=\frac{0}{\mathrm{~S} / .342 .75}=\mathbf{0} \%$

Es por ello que planteamos, como oportunidad de mejora, el implementar un sistema adecuado para el control y la reposición de las existencias que permita un adecuado manejo logístico y que esto conlleve a un mejor manejo en costos de una manera más eficiente.

\subsubsection{Gestión de almacenes}

La gestión de almacenes en la empresa en análisis se presenta de una manera inadecuada, puesto a pesar de que actualmente existen 2 espacios destinados como almacenes de materias primas e insumos con un área total de 16.01 $\mathrm{m}^{2}$, se observa que la organización de dicho espacio no es el correcto para la conservación de los elementos y con la facilidad necesaria de acceso para un flujo de materiales sencillo en el proceso productivo, tal como se observa en éstas imágenes: 

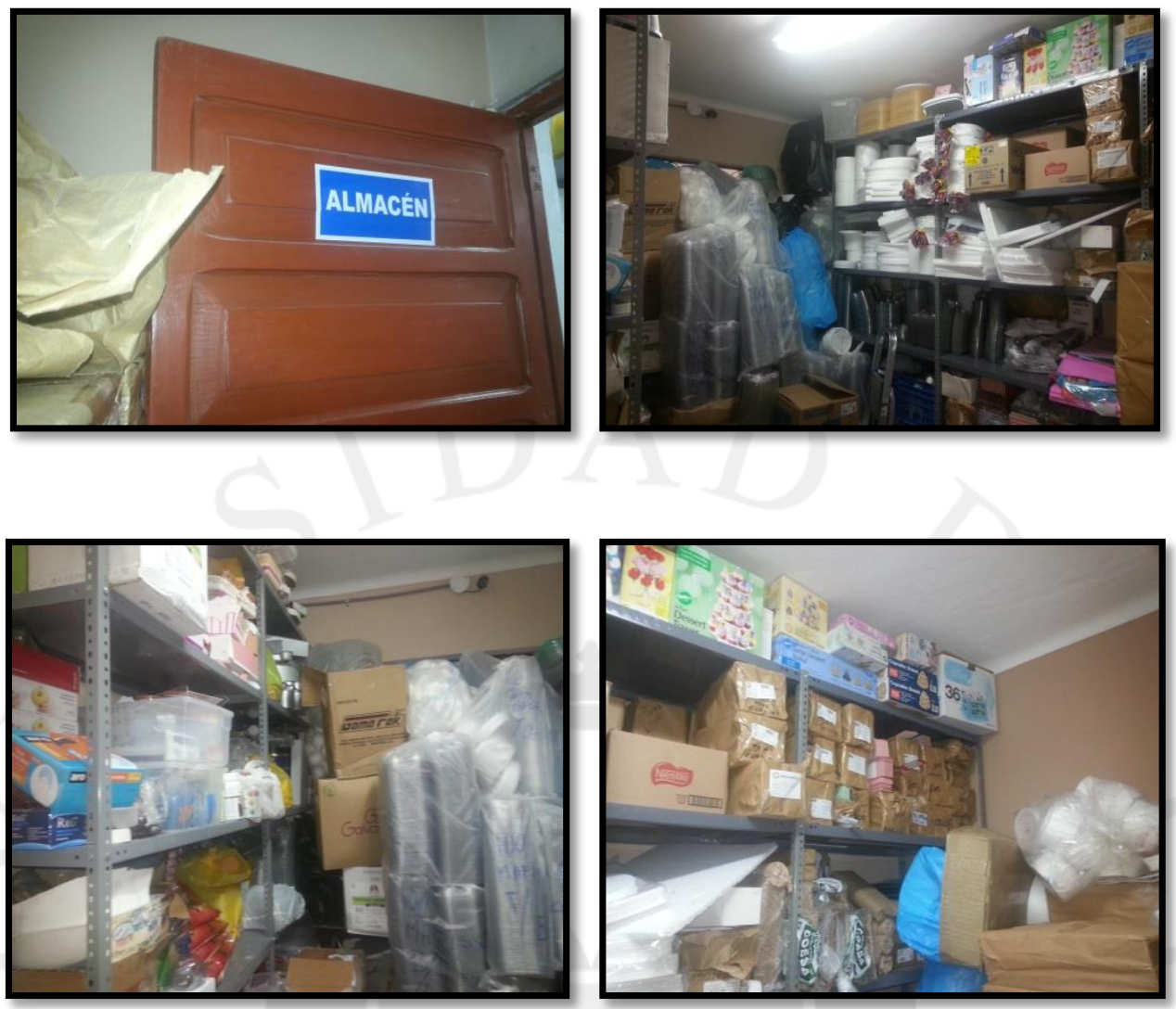

Figura 4. 7: Imágenes del almacén de insumos. Fuente: Claudia Cupcakes, 2015.

Además, existen lugares en el taller en donde están distribuidos también otros insumos, como la pre mezcla y el aceite, los cuales tienen espacios únicos destinados distintos al almacén principal y que son cercanos a la zona de mezclado y horneado, así como andamios que tienen los materiales necesarios para el proceso de forrado y decorado, como se aprecia en las imágenes: 

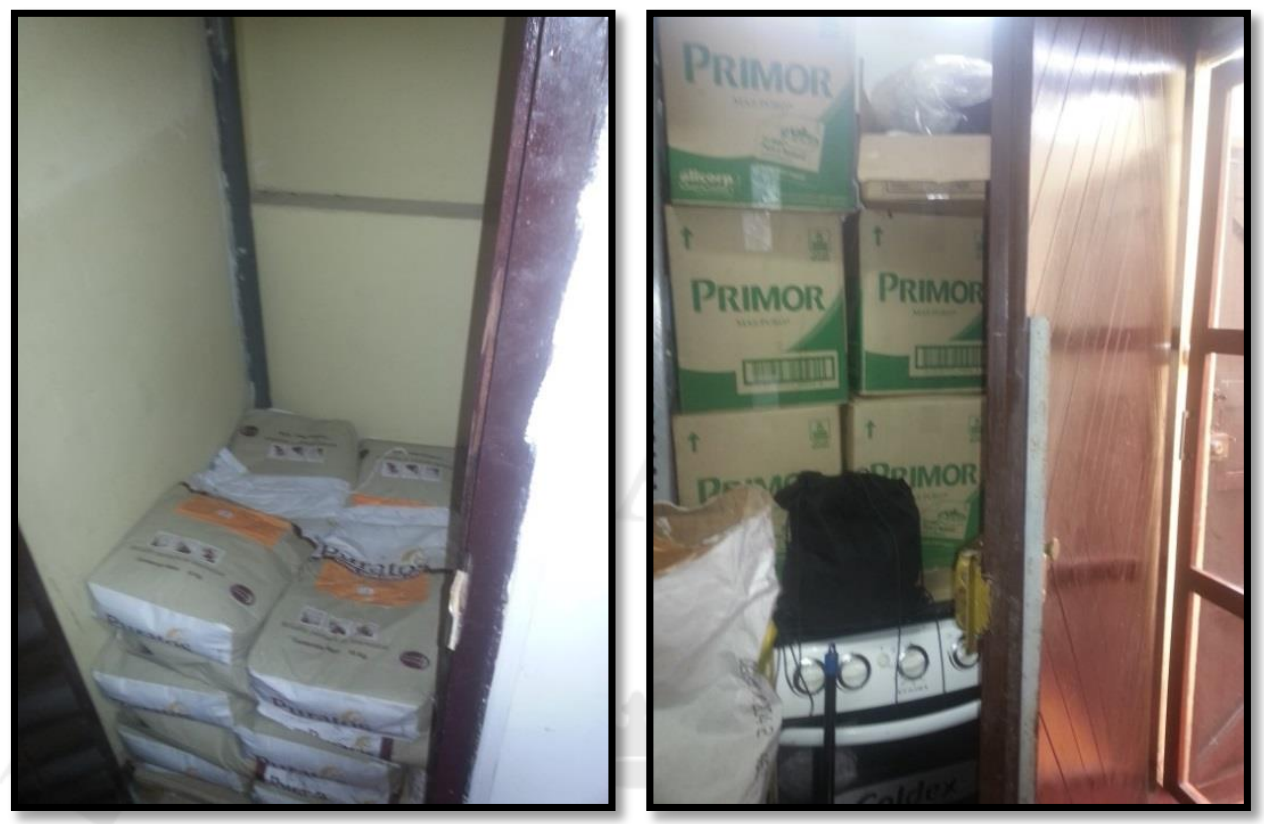

Figura 4. 8: Imágenes del almacén de materia prima. Fuente: Claudia Cupcakes, 2015.

Cabe mencionar que todos estos espacios descritos no tienen restricción de acceso al personal para su libre disposición durante el proceso; sin embargo, esto puede convertirse también en un riesgo para la seguridad de los insumos.

Por otro lado, la descripción del proceso de recepción y posterior almacenaje de los insumos es como a continuación se describe:

a. Recepción de materiales adquiridos y selección de cada uno de ellos.

b. Registro de los materiales recibidos para el control y posterior seguimiento.

c. Distribución en los espacios determinados y almacenamiento.

d. Despacho de materiales a producción de acuerdo a la necesidad. 
Con lo descrito, vemos que todo el proceso, desde la distribución de los espacios de almacenes hasta el despacho de insumos para la producción puede ser mejorado a fin de poder generar mayores eficiencias.

Para hallar el área de almacén necesario, se ha tomado en cuenta la demanda proyectada del 2019, que son 424,470 cupcakes. Asimismo, hemos considerado la reposición de MP cada 2 semanas. A continuación veremos la presentación de cada producto y la cantidad requerida.

Tabla 4. 22: Pesos de materias primas para cálculo de área de almacén.

\begin{tabular}{|c|c|c|}
\hline \multicolumn{2}{|c|}{ Presentación de MP } & kg \\
\hline Pre mezcla & $20 \mathrm{~kg}$ & 20.00 \\
\hline Aceite & $5 \mathrm{lt}$ & 4.63 \\
\hline Huevo & 30 huevos & 1.80 \\
\hline
\end{tabular}

Tabla 4. 23: Medidas que ocupan las principales materias primas.

\begin{tabular}{|c|c|c|c|}
\hline \multicolumn{3}{|c|}{ Tamaño (m) } & \multirow{2}{*}{$\begin{array}{c}\text { Volumen } \\
(\mathbf{m} 3)\end{array}$} \\
\cline { 1 - 3 } Alto & Largo & Ancho & 0.04 \\
\hline 0.1 & 1 & 0.4 & 0.01 \\
\hline 0.35 & 0.2 & 0.2 & 0.01 \\
\hline 0.08 & 0.35 & 0.3 & \\
\hline
\end{tabular}


Tabla 4. 24: Cantidad requerida en unidades de materias primas.

\begin{tabular}{|c|c|c|c|c|}
\hline MP & $\begin{array}{c}\text { Q anual } \\
(\mathbf{k g})\end{array}$ & $\begin{array}{c}\text { Q x 2 semanas } \\
(\mathbf{k g})\end{array}$ & \multicolumn{2}{|c|}{$\begin{array}{c}\text { Q requerida } \\
\text { (unidades) }\end{array}$} \\
\hline Pre mezcla & $12,576.89$ & 483.73 & 24.19 & $\mathbf{2 5 . 0 0}$ \\
\hline Aceite & $4,401.91$ & 169.30 & 36.57 & $\mathbf{3 7 . 0 0}$ \\
\hline Huevo & $4,150.37$ & 159.63 & 88.68 & $\mathbf{8 9 . 0 0}$ \\
\hline
\end{tabular}

Para almacenar la pre mezcla se usaran pallets de $1.20 \mathrm{~m}$ x $1.00 \mathrm{~m}$. Por piso se colocaran 3 bolsas de pre mezcla, hasta un máximo de 13 pisos. Solo será necesario un pallet para almacenar esta MP.

En cuanto a los huevos, también se hará uso de pallets, bajo las mismas condiciones. Por piso se colocaran 9 cajas de huevos, hasta un máximo de 10 pisos. Para almacenar esta MP, solo será necesario 1 pallet.

Para almacenar las galoneras de aceite, usaremos los estantes/anaqueles con dimensiones de $1.30 \mathrm{~m} \times 0.45 \mathrm{~m} \times 2.40 \mathrm{~m}$. Se usaran los 4 primeros pisos del estante/anaquel, debido a que puede ser peligroso colocarlos en niveles superiores. Se colocaran 4 galoneras por piso, solo serán necesarios 2 estantes/anaqueles para almacenar esta MP.

Adicionalmente, se está considerando un estante/anaquel para almacenar productos pequeños que no ocupan mucho espacio. El estante/anaquel tiene las siguientes dimensiones: $1.00 \mathrm{~m} \times 0.45 \mathrm{~m} \times 2.40 \mathrm{~m}$.

Por otro lado, hallamos el área necesaria para el almacén de insumos. Para ello, hemos tomado como base la misma cantidad proyectada de demanda para el 2019; asimismo, hemos considerado la reposición de MP cada 2 
semanas. A continuación veremos la presentación de cada producto y la cantidad requerida:

Tabla 4. 25: Cálculo de unidades de insumos necesarias para el área de almacén.

\begin{tabular}{|c|c|c|}
\hline \multicolumn{2}{|c|}{ Presentación } & Unid. \\
\hline Blister & 25 & unid. \\
\hline Cintilllo & 25 & unid. \\
\hline Etiquetas & 1000 & unid. \\
\hline Fondant F. & 1 & $\mathrm{~kg}$ \\
\hline Pirotin & 50 & unid. \\
\hline Fondant D. & 1 & $\mathrm{~kg}$ \\
\hline
\end{tabular}

Tabla 4. 26: Cantidad de unidades requeridas de insumos para el almacén.

\begin{tabular}{|l|r|r|r|r|r|}
\hline \multicolumn{1}{|c|}{ MP } & Q & Unid. & Q x 2 semanas & \multicolumn{2}{c|}{$\begin{array}{c}\text { Q requerida } \\
\text { (unidades) }\end{array}$} \\
\hline Blister & $70,745.00$ & unid. & $2,720.96$ & $\mathbf{1 0 8 . 8 4}$ & $\mathbf{1 0 9 . 0 0}$ \\
\hline Cintilllo & $424,470.00$ & unid. & $16,325.77$ & $\mathbf{6 5 3 . 0 3}$ & $\mathbf{6 5 4 . 0 0}$ \\
\hline Etiquetas & $424,470.00$ & unid. & $16,325.77$ & $\mathbf{1 6 . 3 3}$ & $\mathbf{1 7 . 0 0}$ \\
\hline Fondant F & $7,231.71$ & $\mathrm{~kg}$ & 278.14 & $\mathbf{2 7 8 . 1 4}$ & $\mathbf{2 7 9 . 0 0}$ \\
\hline pirotin & $424,470.00$ & unid. & $16,325.77$ & $\mathbf{3 2 6 . 5 2}$ & $\mathbf{3 2 7 . 0 0}$ \\
\hline Fondant D & $7,860.56$ & $\mathrm{~kg}$ & 302.33 & $\mathbf{3 0 2 . 3 3}$ & $\mathbf{3 0 3 . 0 0}$ \\
\hline
\end{tabular}

Estos insumos se almacenarán en estantes/anaqueles de $1.30 \mathrm{~m}$ x $0.45 \mathrm{~m}$ x $2.40 \mathrm{~m}$.

En el caso de los blíster, se colocaran en cajas de cartón de $50 \mathrm{~cm} \mathrm{x} 40 \mathrm{~cm} \mathrm{x}$ $50 \mathrm{~cm}$, para mantener un orden. Colocaremos 4 paquetes de blíster por caja, por lo que en total tendríamos 28 cajas llenas de blíster. Haremos uso de casi 3 estantes/anaqueles, la mitad del tercer estante/anaquel estará libre. 
En el caso de los cintillos, se colocaran en cajas de $0.4 \mathrm{~cm} \times 0.4 \mathrm{~cm} \times 0.4 \mathrm{~cm}$. Colocaremos 40 paquetes de cintillos por caja, en total necesitaremos 17 cajas. En total necesitaremos un estante/anaquel, dejando un pequeño espacio.

En el caso de las etiquetas, se colocaran en cajas de $20 \mathrm{~cm} \times 20 \mathrm{~cm} \times 20 \mathrm{~cm}$. Para guardar las etiquetas, será necesaria solo 1 caja. Esta caja puede colocarse en el pequeño espacio que sobro en el estante/anaquel de los cintillos.

En cuanto a los 02 tipos de masa fondant, se almacenaran en cajas de $40 \mathrm{~cm}$ x $40 \mathrm{~cm}$ x $40 \mathrm{~cm}$. En cada caja se guardaran $45 \mathrm{~kg}$ de masa, que equivalen a 14 cajas. En total necesitaremos 1 estante/anaquel para guardar este insumo. Para almacenar los pirotines, se usaran cajas de $0.40 \mathrm{~cm}$ x $0.40 \mathrm{cmx} 0.40 \mathrm{~cm}$. Se guardaran 30 paquetes de pirotines por caja, en total 11 cajas. Se necesitara 1 estante/anaquel para almacenar este insumo.

Adicionalmente, se está considerando un estante/anaquel para almacenar productos pequeños que no ocupan mucho espacio. El estante/anaquel tiene las siguientes dimensiones: $1.00 \mathrm{~m} \times 0.45 \mathrm{~m} \times 2.40 \mathrm{~m}$.

En ambos almacenes se está considerando el recorrido de 1 operario.

Con el análisis realizado, concluimos que actualmente el área que se cuenta para los almacenes de materia prima e insumos es insuficientes pero, sin embargo, proponemos un área un poco más amplia que pueda acercarse a lo que realmente se requiere. 


\subsection{Planeamiento y control de la producción}

\subsubsection{Pronóstico de la producción}

La empresa actualmente no cuenta con un pronóstico de su producción a futuro, por lo que como parte de nuestra propuesta de valor para tener claro el panorama, planteamos la elaboración de éste pronóstico de acuerdo a la metodología que pueda corresponder.

Cabe mencionar que en vista de que la empresa también produce tortas y comercializa pre mezclas, se está estandarizando los otros productos de acuerdo a las horas-hombre invertidas para posteriormente, mediante el ratio de producción de cupcake/hora-hombre poder tener una misma unidad; en nuestro caso, unidades de cupcakes. En nuestro análisis, utilizamos el modelo de series de tiempo el cual toma como base los datos históricos de la producción de la empresa para la proyección anual por los próximos 5 años: 
Tabla 4. 27: Demanda histórica de la empresa.

\begin{tabular}{|c|c|c|c|c|c|c|c|c|}
\hline \multirow{2}{*}{ MES } & \multicolumn{5}{|c|}{$\begin{array}{c}\text { DEMANDA } \\
\text { (Unidades de cupcakes) }\end{array}$} & \multirow{2}{*}{$\begin{array}{c}\text { DEMANDA } \\
\text { PROMEDIO } \\
\text { (1) }\end{array}$} & \multirow{2}{*}{$\begin{array}{l}\text { DEMANDA } \\
\text { PROMEDIO } \\
\text { MENSUAL (2) }\end{array}$} & \multirow{2}{*}{$\begin{array}{c}\text { ÍNDICE } \\
\text { ESTACIONAL } \\
(1) /(2)\end{array}$} \\
\hline & 2010 & 2011 & 2012 & 2013 & 2014 & & & \\
\hline Ene & - & 939 & 1,306 & 1,877 & 2,651 & 1,693 & 9,727 & 0.17 \\
\hline Feb & - & 6,341 & 11,915 & 18,999 & 20,653 & 14,477 & 9,727 & 1.49 \\
\hline Mar & - & 4,589 & 7,703 & 11,045 & 17,915 & 10,313 & 9,727 & 1.06 \\
\hline Abr & - & 1,783 & 2,543 & 5,738 & 7,964 & 4,507 & 9,727 & 0.46 \\
\hline May & - & 8,077 & 14,260 & 20,682 & 28,599 & 17,904 & 9,727 & 1.84 \\
\hline Jun & 486 & 7,226 & 9,309 & 14,935 & 22,870 & 10,965 & 9,727 & 1.13 \\
\hline Jul & 1,430 & 5,532 & 10,221 & 12,766 & 15,716 & 9,133 & 9,727 & 0.94 \\
\hline Ago & 945 & 2,807 & 5,222 & 3,752 & 5,295 & 3,604 & 9,727 & 0.37 \\
\hline Sep & 1,896 & 3,712 & 3,821 & 7,350 & 12,846 & 5,925 & 9,727 & 0.61 \\
\hline Oct & 2,810 & 10,189 & 12,909 & 17,316 & 26,273 & 13,899 & 9,727 & 1.43 \\
\hline Nov & 2,328 & 9,279 & 6,326 & 9,313 & 10,444 & 7,538 & 9,727 & 0.77 \\
\hline Dic & 3,195 & 11,005 & 15,805 & 22,658 & 31,188 & 16,770 & 9,727 & 1.72 \\
\hline \multicolumn{6}{|c|}{ Promedio total de la demanda anual } & 116,729 & & \\
\hline
\end{tabular}

De acuerdo a lo anterior, observamos que el índice de estacionalidad en algunos meses es bastante marcado, tal cual lo pudimos analizar en el capítulo 3.2.6.

Previamente, para poder haber hallado la demanda promedio mensual, se realizó el siguiente cálculo:

Demanda promedio Promedio total de la demanda anual mensual

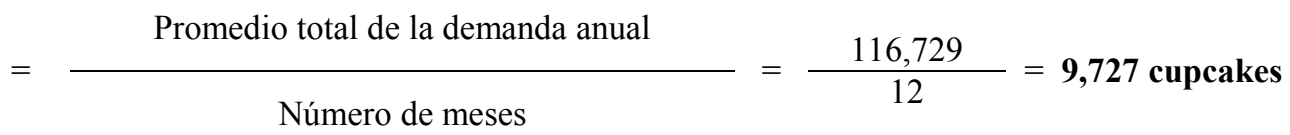


Posteriormente, considerando ahora las cantidades históricas anuales, hacemos el pronóstico de la producción con estacionalidad anual, mediante una regresión lineal considerando como variable dependiente para nuestro análisis, el comportamiento del PBI per cápita en los últimos años y de las proyecciones que se tiene para los siguientes años:

Tabla 4. 28: Producción histórica de Claudia Cupcakes y PBI per cápita Perú.

\begin{tabular}{|c|c|c|c|c|}
\hline \multicolumn{5}{|c|}{ PRODUCCIÓN HISTÓRICA ANUAL } \\
(UND) \\
\hline $\mathbf{2 0 1 0}$ & $\mathbf{2 0 1 1}$ & $\mathbf{2 0 1 2}$ & $\mathbf{2 0 1 3}$ & $\mathbf{2 0 1 4}$ \\
\hline $\mathbf{1 2 . 9 8}$ & $\mathbf{1 3 . 6 6}$ & $\mathbf{1 4 . 3 1}$ & $\mathbf{1 4 . 9 7}$ & $\mathbf{1 5 . 6 2}$ \\
\hline 13,090 & 71,478 & 101,338 & 146,431 & 202,415 \\
\hline
\end{tabular}

Obteniendo la siguiente ecuación para la recta de tendencia:

$$
\begin{aligned}
\mathbf{Y}= & 68,803 * \mathrm{X}-877,510 \\
\mathbf{R 2}= & 0.9911 \\
\mathbf{R}= & 0.9955
\end{aligned}
$$

Observamos que el coeficiente de correlación (R) es aceptable porque es mayor a 0.70 y muy próximo a 1 , por lo que tendríamos una relación bastante cerca en cuanto al avance de los años y al crecimiento de la demanda, obteniendo así la siguiente proyección anual para los próximos 5 años: 
Tabla 4. 29: Producción proyectada de Claudia Cupcakes acorde al PBI per cápita Perú.

\begin{tabular}{|c|c|c|c|c|}
\hline \multicolumn{5}{|c|}{ PROYECCIÓN DE LA PRODUCCIÓN ANUAL } \\
(UND) \\
\hline $\mathbf{2 0 1 5}$ & $\mathbf{2 0 1 6}$ & $\mathbf{2 0 1 7}$ & $\mathbf{2 0 1 8}$ & $\mathbf{2 0 1 9}$ \\
\hline $\mathbf{1 6 . 4 3}$ & $\mathbf{1 7 . 3 2}$ & $\mathbf{1 8 . 1 8}$ & $\mathbf{1 9 . 1 8}$ & $\mathbf{2 0 . 2 3}$ \\
\hline 253,050 & 314.312 & 373,125 & 442,401 & 514,346 \\
\hline
\end{tabular}

Finalmente, tomando en cuenta el pronóstico anual y considerando el índice de estacionalidad hallado inicialmente, obtenemos la proyección de la producción mensual para los siguientes 5 años, también:

Tabla 4. 30: Proyección de la demanda de la empresa Claudia Cupcakes.

\begin{tabular}{|c|c|c|c|c|c|c|}
\hline \multirow{2}{*}{ MES } & \multicolumn{5}{|c|}{$\begin{array}{c}\text { DEMANDA PROYECTADA } \\
\text { (Unidades de cupcakes) }\end{array}$} \\
\cline { 2 - 6 } & $\mathbf{2 0 1 5}$ & $\mathbf{2 0 1 6}$ & $\mathbf{2 0 1 7}$ & $\mathbf{2 0 1 8}$ & $\mathbf{2 0 1 9}$ & ÍNDICE \\
ESTACIONAL \\
\cline { 2 - 6 } Ene & 3,523 & 4,181 & 4,839 & 5,496 & 6,154 & 0.17 \\
\hline Feb & 29,872 & 35,447 & 41,022 & 46,598 & 52,173 & 1.47 \\
\hline Mar & 21,406 & 25,401 & 29,396 & 33,391 & 37,387 & 1.06 \\
\hline Abr & 9,560 & 11,344 & 13,128 & 14,912 & 16,697 & 0.47 \\
\hline May & 37,012 & 43,920 & 50,828 & 57,736 & 64,643 & 1.83 \\
\hline Jun & 22,966 & 27,253 & 31,539 & 35,826 & 40,112 & 1.13 \\
\hline Jul & 19,211 & 22,796 & 26,382 & 29,967 & 33,553 & 0.95 \\
\hline Ago & 7,455 & 8,847 & 10,239 & 11,630 & 13,022 & 0.37 \\
\hline Sep & 12,542 & 14,883 & 17,224 & 19,565 & 21,906 & 0.62 \\
\hline Oct & 28,762 & 34,130 & 39,499 & 44,867 & 50,235 & 1.42 \\
\hline Nov & 15,813 & 18,764 & 21,716 & 24,667 & 27,618 & 0.78 \\
\hline Dic & 34,908 & 41,424 & 47,939 & 54,455 & 60,970 & 1.72 \\
\hline TOTAL & $\mathbf{2 5 3 , 0 5 0}$ & $\mathbf{3 1 4 . 3 1 2}$ & $\mathbf{3 7 3 , 1 2 5}$ & $\mathbf{4 4 2 , 4 0 1}$ & $\mathbf{5 1 4 , 3 4 6}$ & \\
\hline
\end{tabular}


En base a la proyección mostrada, vemos que la tendencia de crecimiento en las ventas en los próximos años es sumamente fuerte pero que, debido a la capacidad instalado con la que cuenta actualmente la empresa, podrá afrontar sin mayor problema; sin embargo, es necesario proyectar para futuro la cantidad Operarios y/o Mano de Obra que necesitará para poder cumplir la demanda estimada y no generar insatisfacción. 


\section{CAPÍTULO V: ASPECTOS DE GESTIÓN}

\subsection{Gestión de recursos humanos}

\subsubsection{Sistema de trabajo}

Claudia cupcakes es una empresa pequeña pero formalmente constituida.

Para poder tener una idea un poco más clara del esquema que maneja la empresa actualmente, presentamos el organigrama:

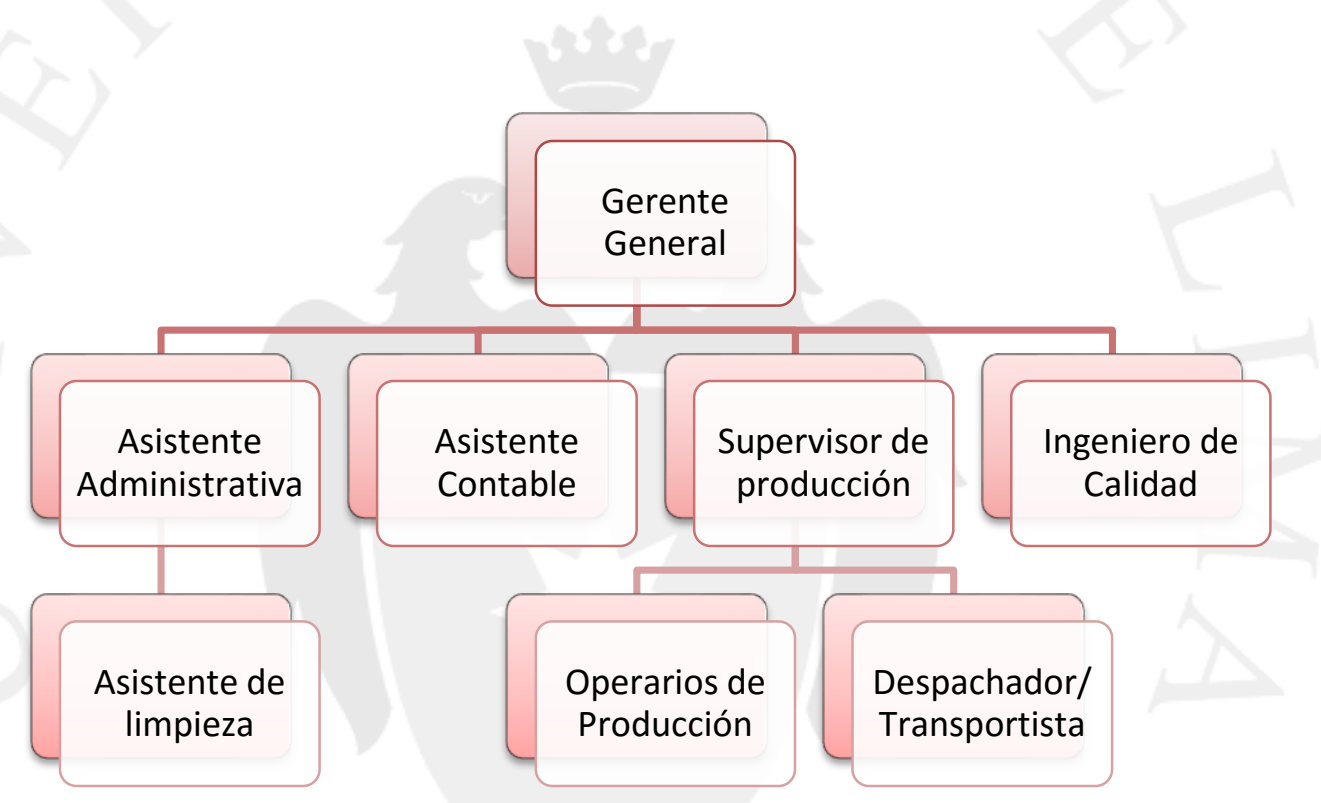

Figura 5. 1: Organigrama de la empresa Claudia Cupcakes

Fuente: Elaboración propia.

La Gerencia General está a cargo de la dueña de la empresa, cuyo rol fundamentalmente está en buscar continuamente nuevas oportunidades de negocio en el mercado que permitan desarrollarse a la empresa de una manera innovadora y clara; sin embargo, se percibe actualmente una participación un poco limitada en los procesos, situación que podría ser 
mejorada con la finalidad de poder incrementar el clima laboral de la empresa.

En cuanto al sistema de trabajo que maneja para la gestión del recurso humano, actualmente se cuenta con 22 trabajadores en total, distribuidos de la siguiente manera:

Tabla 5. 1: Esquema de trabajo en la empresa Claudia Cupcakes.

\begin{tabular}{|c|c|c|}
\hline & Régimen Laboral en Planilla & $\begin{array}{l}\text { Régimen Laboral de Recibos por } \\
\text { Honorarios y/o practicantes }\end{array}$ \\
\hline Nro. de trabajadores & 11 & 6 (en promedio) \\
\hline Horario de Trabajo & \multicolumn{2}{|c|}{$\begin{array}{l}9 \text { horas diarias de Lun a Vie (9:00 a.m. }-6: 00 \text { p.m. con una hora de refrigerio) } \\
\text { Sab } 6 \text { horas (9:00 a.m. }-2: 00 \text { p.m. sin refrigerio) }\end{array}$} \\
\hline Horas Extras & $\begin{array}{c}\text { Aplicables hasta terminar la } \\
\text { producción del día, las cuales no son } \\
\text { remunerables. }\end{array}$ & No aplicables. \\
\hline Período de prueba & \multicolumn{2}{|c|}{3 meses (Aprox.). } \\
\hline $\begin{array}{l}\text { Tipo de trabajo } \\
\text { realizado }\end{array}$ & \multicolumn{2}{|c|}{ De acuerdo a la especialidad y según la programación diaria. } \\
\hline
\end{tabular}

En lo que corresponde a los niveles de salarios, la empresa los tiene diferencia de la siguiente manera: 


\section{a. Con mayor antigüedad y experiencia}

Ingreso promedio S/.1800.00 y todos los beneficios de ley, como CTS, ESSALUD, gratificaciones, etc.

\section{b. Practicantes y nuevos ingresos}

Inician con un salario de $\mathrm{S} / .800 .00$.

Cabe mencionar que actualmente no hay una persona encargada exclusivamente a la Gestión de Recursos Humanos. Esto, básicamente considerando que la empresa es aún pequeña; sin embargo, en algunas ocasiones contrata los servicios de empresas que brindan consultoría en este tema. Entre algunos de los procesos afines que ve la consultora están:

\section{a. Reclutamiento y Selección de personal}

Ante la necesidad de contar con una nueva persona en la empresa, la Gerencia General hace la convocatoria a través de los diversos portales de empleo, de donde recibe posteriormente las postulaciones.

\section{b. Administración de Personal}

Aplicable para la contratación del personal, aspectos legales, pagos, vacaciones etc., es también gestionado desde la Gerencia General en conjunto con el asistente contable y la asistente administrativa. 
Por otro lado, de manera interna se gestionan algunos procesos afines, como por ejemplo:

\section{a. Capacitación}

El ingresante inicialmente capacitada por el mismo personal de la empresa de acuerdo al puesto que ingresa, quienes mediante el traspaso oral de la información, así como a través de instructivos y manuales ya establecidos, alimentan su conocimiento.

\section{b. Integración}

Es parte del equipo el trabajo en conjunto para poder integrar en el grupo al nuevo ingresante y que de esa forma pueda adaptarse más rápido al ambiente.

Lo descrito es aplicable para el personal operario y administrativo, aunque son éstos últimos en menor cantidad que el personal productivo y con menor necesidad de captación.

Finalmente, si bien todo el personal que ingresa a trabajar a la parte de producción cuenta con nociones generales de pastelería, se considera la especialización con la que cuenta cada uno de ellos para repartir la carga y tipo de trabajo, con el fin de obtener el beneficio de avanzar con la producción de una manera más rápida y con los mejores estándares de calidad. 
Dentro de las mediciones que podemos realizar como un aspecto en la gestión del personal, tenemos el nivel de rotación interno que actualmente existe en la empresa, mediante la fórmula:

$$
\text { Rotación del personal }=\frac{(\mathrm{A}+\mathrm{D}) / 2}{(\mathrm{~F} 1+\mathrm{F} 2) / 2} \times 100
$$

Donde:

- A: Número de personas contratadas durante el período considerado.

- D: Personas desvinculadas durante el mismo período.

- F1: Número de trabajadores al comienzo del período considerado.

- F2: Número de trabajadores al final del período.

Para nuestro análisis, tomaremos como referencia los datos del período 2014; asimismo, los datos a considerar corresponden al personal en planilla durante el mismo período. Siendo así, tenemos:

$$
\text { Rotación del personal }=\frac{(4+2) / 2}{(8+10) / 2} \times 100=\mathbf{3 3 . 3 3 \%}
$$

Esta situación podría deberse básicamente a que el personal siente que su trabajo es bastante satisfactorio y ven cómo va creciendo en el mercado, a pesar de que la empresa no da mayores beneficios que los requeridos por ley a ellos, sin embargo, sienten un apego hacia la empresa. 
Al tratarse de una empresa con esquema familiar, las funciones principales, partiendo desde la gerencia hasta la supervisión general de la producción (alta gerencia y mandos medios), es realizado por miembros de la familia, por lo que en éste aspecto no hay mayor problema en cuanto a la gestión de su sistema de trabajo; sin embargo, creemos que podría ser mejor gestionado desde la Gerencia General teniendo un mayor nivel de involucramiento en todos sus procesos.

Como parte de nuestra evaluación en los aspectos de Gestión del Recurso Humano, realizamos por primera vez en la empresa una encuesta de satisfacción interna para poder medir el clima laboral actual. A continuación, presentamos los resultados a nivel general (los detalles y mediciones al detalle, se podrán encontrar en el anexo 05):

Satisfacción General Interna en la empresa Claudia Cupcakes

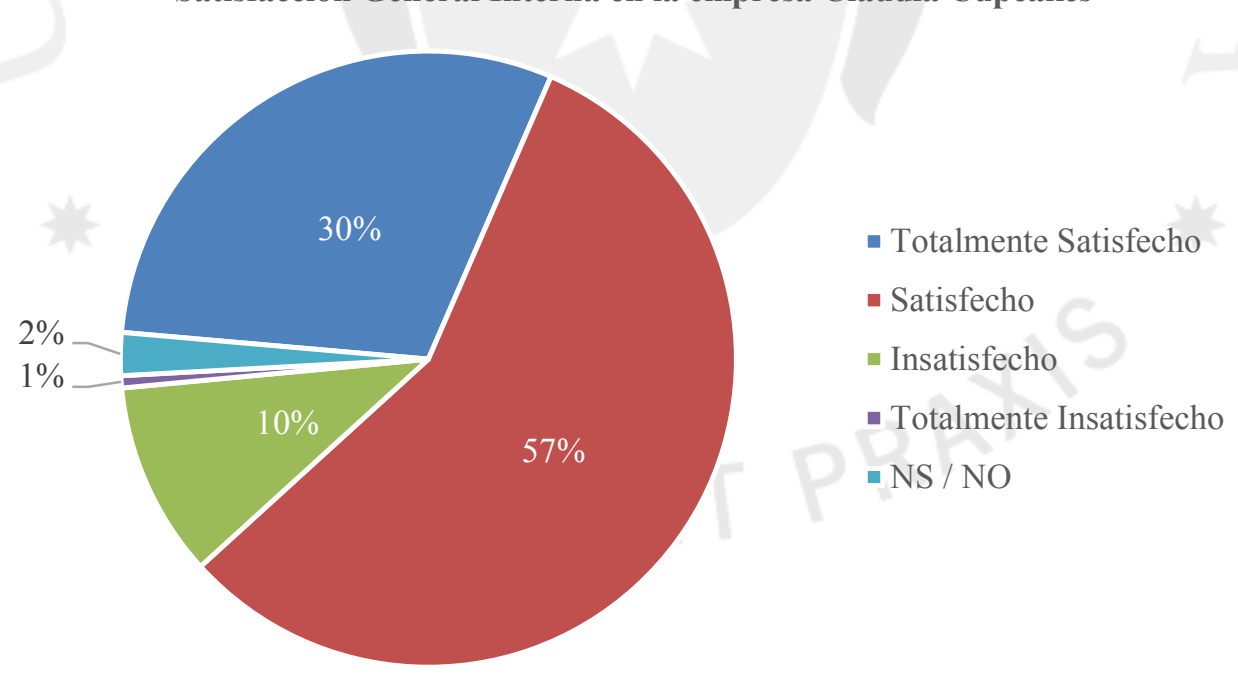

Figura 5. 2: Satisfacción interna en la empresa Claudia Cupcakes.

Fuente: Elaboración propia. 
Del total de trabajadores encuestados, tenemos como resultado que en conjunto, existe un aproximado de $87 \%$ de satisfacción en la empresa, aunque hay un $13 \%$ que, al menos, se encuentra insatisfecho con su permanencia, debido a diversos factores los cuales podremos revisar en el anexo indicado; no obstante, dentro de los aspectos más relevantes evaluados, tenemos:

Tabla 5. 2: Resultados de la encuesta de satisfacción interna en la empresa Claudia Cupcakes.

\begin{tabular}{|l|c|c|c|c|c|}
\hline \multicolumn{7}{|c|}{ SATISFACCIÓN INTERNA POR ASPECTOS (\%) } \\
\hline \multicolumn{1}{|c|}{ Aspecto Evaluado } & $\begin{array}{c}\text { Totalmente } \\
\text { Satisfecho }\end{array}$ & Satisfecho & Insatisfecho & $\begin{array}{c}\text { Totalmente } \\
\text { Insatisfecho }\end{array}$ & NS / NO \\
\hline La Organización. & 23.08 & 63.46 & 9.62 & 1.92 & 1.92 \\
\hline $\begin{array}{l}\text { Relaciones con la dirección de la } \\
\text { organización. }\end{array}$ & 24.18 & 58.24 & 14.29 & 1.10 & 2.20 \\
\hline Compañeros de trabajo. & 58.97 & 35.90 & 5.13 & 0.00 & 0.00 \\
\hline Creatividad e Iniciativa. & 25.64 & 66.67 & 2.56 & 0.00 & 5.13 \\
\hline Condiciones Ambientales. & 29.67 & 56.04 & 12.09 & 0.00 & 2.20 \\
\hline Satisfacción General. & 30.13 & 56.73 & 10.26 & 0.64 & 2.24 \\
\hline
\end{tabular}

Tal como se aprecia en los resultados por aspectos mostrados en el cuadro anterior, se puede concluir que existe un grado importante de satisfacción entre las relaciones interpersonales que existen en la empresa, lo cual indica 
que el ambiente de cooperación es bastante bueno. Sin embargo, un aspecto qué resaltar como aspecto de mejora es en cuanto a las relaciones con la dirección de la organización, puesto que si bien el nivel de satisfacción es bueno (aprox. 83\%), hay un 15\% del total de colaboradores que están insatisfechos en este aspecto con la organización.

Finalmente, de la misma encuesta realizada vemos que un buen porcentaje de los encuestados (al menos un aprox. 65\% del total) siente que sus opiniones y sugerencias son escuchadas y tomadas en cuenta por la gerencia; sin embargo, hay un $31 \%$ de los colaboradores que no sienten esto. $Y$ es en esta línea que tenemos algunas de las sugerencias planteadas por los colaboradores:

a. Mejorar el trato con los trabajadores.

b. Que cada compañero se haga responsable de su propio trabajo.

c. Mejorar el reconocimiento a las horas extras sin presentar "peros" a fin de mes.

d. Mayor comunicación y liderazgo. Apoyo constante hacia los colaboradores.

e. Realizar reuniones periódicas para comunicar las inquietudes y mejorar el clima laboral.

f. Cumplir con los horarios establecidos de trabajo. 
En base a éstas sugerencias pueden plantearse debidas opciones de mejoramiento del clima interno en la empresa, por lo cual serán tomadas en cuenta al momento del análisis de éste aspecto de gestión.

\subsubsection{Perfiles y nivel de profesionalización}

Debido a la creciente demanda de los productos de la empresa, en la parte operativa se procura contar con personal con las nociones suficientes en pastelería y repostería e, incluso, con la experiencia necesaria para que puedan aportar lo mayor posible en la producción y que provengan de instituciones de prestigio en la enseñanza de cocina y pastelería en el país. En las temporadas de mayor demanda podría requerirse personal de apoyo para mantener los estándares establecidos y requeridos por la empresa.

En el anexo 8 del presente trabajo, presentamos nuestra propuesta para los perfiles de puesto en una ficha correspondiente para cada uno. No obstante, a continuación mostramos un resumen de los puestos actualmente vigentes en la empresa considerando las funciones que realiza cada uno de ellos: 
Tabla 5. 3: Descripción de puestos en la empresa Claudia Cupcakes.

\begin{tabular}{|c|c|}
\hline PUES & FUNCIONES PRINCIPALES \\
\hline Gerente General & $\begin{array}{l}\text { - Establecer los lineamientos y plan de Marketing de la empresa en los medios. } \\
\text { - Controlar los procesos de la empresa y proponer mejoras en la eficiencia. } \\
\text { - Buscar nuevos proyectos que permita incrementar el mercado objetivo. } \\
\text { - Gestionar adecuadamente la cartera de productos de la empresa. } \\
\text { - Gestionar la gestión de los Recursos Humanos de la compañía de manera adecuada. } \\
\text { - Establecer las políticas necesarias para maximizar la rentabilidad de la empresa. } \\
\text { - Establecer las metas adecuadas para alcanzar los objetivos generales de la empresa. }\end{array}$ \\
\hline & $\begin{array}{l}\text { - Controlar los estados financieros de la empresa, así como el balance general y la } \\
\text { facturación. } \\
\text { - Apoyo en gestiones diversas con la Gerencia General. } \\
\text { - Recopila y ordena la información contable de la empresa para presentar al } \\
\text { Outsoursing (que maneja la contabilidad general). }\end{array}$ \\
\hline $\begin{array}{l}\text { nte } \\
\text { rativa }\end{array}$ & $\begin{array}{l}\text { - Atender los pedidos ingresados por los clientes en los diversos canales de venta. } \\
\text { - Generar las cotizaciones y confirmación de pedido según lo solicitado. } \\
\text { - Responder todas las consultas que ingresan por el correo electrónico. } \\
\text { - Apoyar en las diversas tareas solicitadas por la Gerencia General en aspectos de } \\
\text { Marketing. }\end{array}$ \\
\hline $\begin{array}{l}\text { Practicante de } \\
\text { Calidad }\end{array}$ & $\begin{array}{l}\text { - Controlar los certificados y/o fichas de calidad de las materias primas suministradas } \\
\text { por proveedores. } \\
\text { - Llevar un adecuado control de los registros de producción. } \\
\text { - Tener el registro de los productos despachados a fin de controlar el rastro de cada } \\
\text { uno. } \\
\text { - Responder las consultas enviadas al correo de Calidad de la empresa con respecto a } \\
\text { los productos. } \\
\text { - Brindar oportunidades de mejora y/o sugerencias en el proceso productivo para } \\
\text { preservar la inocuidad alimenticia del producto. }\end{array}$ \\
\hline $\begin{array}{l}\text { Supervisor de } \\
\text { Producción }\end{array}$ & $\begin{array}{l}\text { - Verificar y controlar el proceso de producción en la empresa. } \\
\text { - Apoyar en la operación a los operarios con menor experiencia para su pronta } \\
\text { adaptación. }\end{array}$ \\
\hline $\begin{array}{l}\text { Operario de } \\
\text { Producción }\end{array}$ & $\begin{array}{l}\text { - Realizar diversas tareas asignadas durante el proceso de producción en la empresa. } \\
\text { - Apoyar en el proceso de empaquetado y despacho de productos según se requiera. } \\
\text { - Proponer ideas creativas para nuevos e innovadores diseños en los productos de la } \\
\text { empresa. }\end{array}$ \\
\hline $\begin{array}{l}\text { Despachador / } \\
\text { Transportista }\end{array}$ & $\begin{array}{l}\text { - Apoyar en el proceso de despacho de productos desde el taller de producción al } \\
\text { vehículo de transporte. } \\
\text { - Realizar el traslado y entrega de los pedidos en las tiendas (Cencosud), domicilios } \\
\text { (personales) y/o empresas. }\end{array}$ \\
\hline
\end{tabular}


Actualmente la empresa no tiene establecido el tiempo determinado de la curva de aprendizaje, aunque se tiene muy en cuenta que la rapidez en la realización de los trabajos asignados se gana con la experiencia y con la enseñanza brindada por el personal que tiene mayor tiempo en la empresa.; sin embargo, de acuerdo a un determinado tiempo transcurrido se evalúa al personal para decidir su continuidad y permanencia en la empresa, considerando principalmente su eficiencia en el trabajo, traducido en los tiempos empleados y en la calidad del trabajo final entregado. Usualmente, éste tiempo de evaluación es de 3 meses, aunque ésta medición del tiempo de aprendizaje podría ser medido mejor aún mediante una revisión y análisis de la data histórica a fin de determinar una correcta curva de aprendizaje para futuros colaboradores.

\subsubsection{Línea de carrera y capacitación}

Para poder mantenerse actualizado en las nuevas tendencias del mercado de pastelería, los colaboradores deben capacitarse; sin embargo, de acuerdo a información brindada por la empresa, durante el año sólo se dictan 2 capacitaciones. Estas son enfocadas en temas generales, como en calidad de alimentos, etc.; aunque, cabe mencionar, que dependiendo de la importancia de algún taller o feria que pudiera presentarse, podría enviarse a algún colaborador en particular para que pueda participar y así incrementar sus conocimientos en el tema. Creemos que éstos niveles son bajos para un mercado que necesita constante innovación de cara al público objetivo, y 
además que con esto se podría obtener un "win to win", ya que por un lado la empresa logra fidelizar al personal, logra un mayor "know how" para aplicar esos conocimientos en su producción y, por otro lado, el empleado obtiene mayor capacitación y experiencia en éste rubro.

Para poder medir el nivel de capacitación que actualmente tiene la empresa, mostramos el indicador que nos muestra ésta situación:

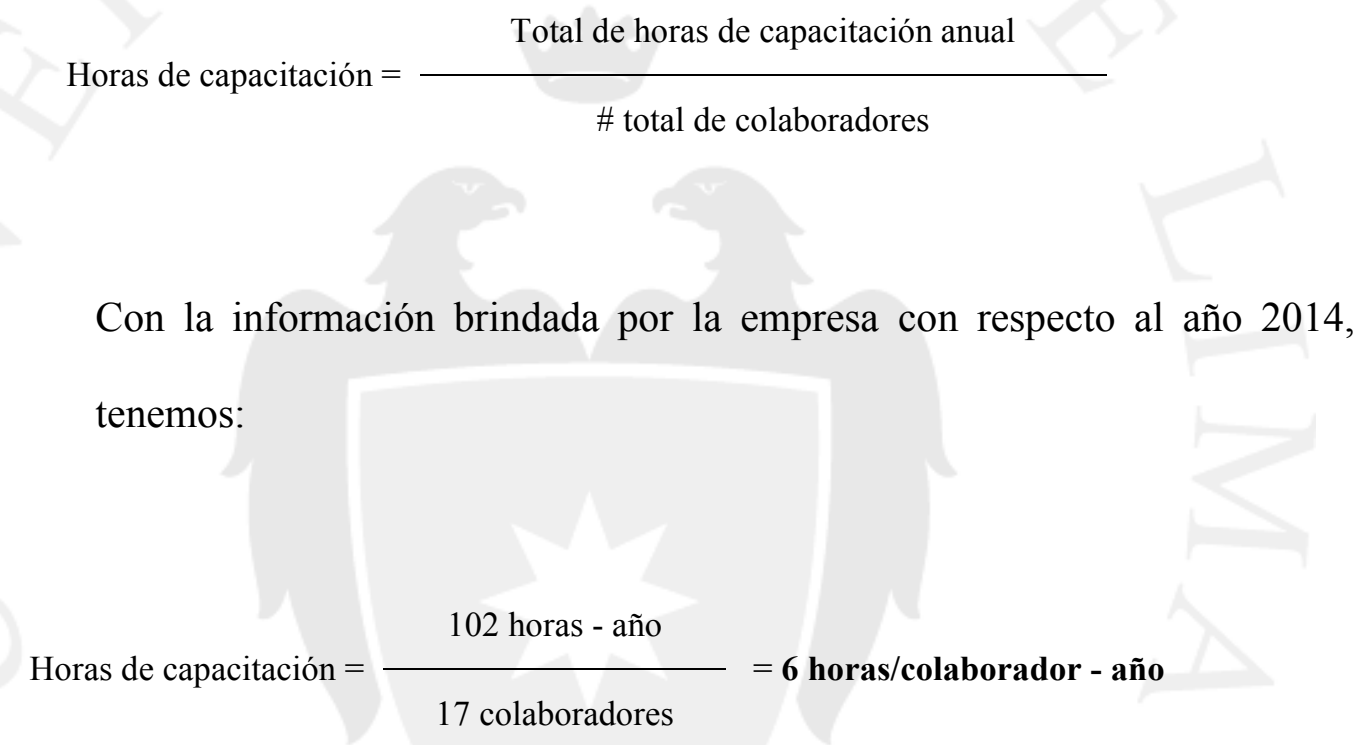

Vemos que el indicador de horas de capacitación actual no es malo; sin embargo, creemos que éste ratio podría ser mayor, (dependiendo del nivel de especialización que se quiera tener en cada operario) considerando sobretodo su nivel de adaptación al puesto durante la etapa de aprendizaje, la cual puede ser enriquecida con capacitaciones y/o cualquier tipo de enseñanza que le permita crecer profesionalmente $y$, a la vez, sea un beneficio para la empresa. 
De momento no hay un esquema de línea de carrera establecido, ya que por ahora la estructura organizacional contempla, en su mayoría, al personal de producción los cuales todos están en un mismo nivel, a excepción del supervisor de los procesos. Por otro lado, en la parte administrativa el esquema es más pequeño aún, considerando algunos puestos de asistente, contador, etc. Se espera que, con el tiempo y de acuerdo a nivel de especialización de sus empleados, puedan generarse nuevas oportunidades para ellos y, en consecuencia, la empresa sea aún más atractiva para su desarrollo.

\subsection{Gestión de calidad}

La industria de alimentos no podría funcionar (no sólo adecuadamente, si no legalmente), si es que no tuviera un correcto y adecuado manejo de un sistema de calidad que permita tener una producción que cumpla con los parámetros mínimos para el consumo humano. Es así que la empresa cuenta con los certificados de ley que le permiten poder operar legalmente y, sobretodo, poder brindar productos de alta calidad a sus clientes.

Para lograr esto, la empresa cuenta con un sistema de calidad que si bien no es muy complejo, tiene lo básico para poder apuntar a seguir creciendo y consolidando su sistema. Así bien, cuenta con ésta estructura: 

a. Manual de Calidad
b. Procedimientos
c. Instructivos

Además, cuenta con una persona responsable en el área de calidad que, aparte de velar por el control de éstos documentos, se encarga también de crear las bases y lineamientos para que, a un futuro cercano, se pueda lograr una certificación HACCP que le permita, incluso, poder tener más oportunidades de crecimiento en el mercado; Además, también, sería ideal conseguir en un futuro una certificación ISO 9001:2015 que garantice una adecuada gestión de su sistema de Calidad. Por ahora, estos lineamientos ya aplicados le permiten poder ingresar a un mercado grande como lo es la cadena Cencosud.

Para los indicadores aplicables en este capítulo podríamos tomar en cuenta a los descritos en el desarrollo del capítulo 4.3.3, los cuales están ligados al cumplimiento de las normativas aplicables a los productos; sin embargo, serviría también considerar el indicador del nivel de reclamos presentados a la empresa durante el 2014:

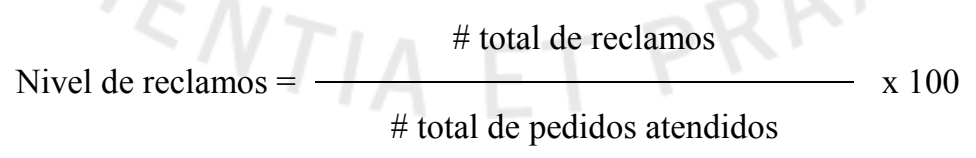


Así, de acuerdo a la información obtenida de la empresa, tenemos:

$$
\text { Nivel de reclamos }=\frac{560}{4760} \times 100=\mathbf{1 2} \%
$$

Observamos que el índice de reclamos es bastante bajo y esto es debido a que fueron situaciones muy fortuitas las presentadas durante el 2014; como por ejemplo, algunos detalles en el diseño del producto que no estuvieron acorde a lo solicitado por el cliente, lo cual puede ser traducido en cuestión de gustos particulares y, en otros casos, por alguna demora presentada en la atención de un pedido; sin embargo, fueron situaciones que la empresa supo manejar de manera adecuada de cara a la satisfacción del cliente.

\subsection{Seguridad y salud ocupacional}

La empresa no tiene implementado un sistema de Seguridad y Salud Ocupacional acorde a lo que indica la norma; y ante una posible inspección de cumplimiento de la Ley 29783 Ley de SST y su reglamento, la empresa estaría en falta grave, ya que por más de ser PYME, la ley obliga a cumplir con ciertos lineamientos en cuanto a la seguridad y salud de los trabajadores.

Es así que de acuerdo a la situación actual que se observa en la empresa, particularmente en el taller de producción en donde se realizan todos los procesos principales, encontramos algunas fortalezas: 
a. 5 extintores con certificados de mantenimiento.

b. Señalización de emergencia.

c. Se realiza un examen de manos periódicamente antes del inicio de las operaciones.

El número de debilidades en cuanto a seguridad y salud ocupacional refiere, son bastante menos importantes que las fortalezas y debilidades que mencionaremos más adelante en el resumen de las fortalezas y debilidades halladas en la empresa, entre las que tenemos:

a. No hay simulacros de evacuación, sismos o incendios.

b. No hay una adecuada señalización, sobre todo en almacén, en aspectos de seguridad.

c. Algunos estantes no están debidamente colocados, lo que incremente el peligro para el personal.

d. No hay certificados médicos antes de la incorporación y antes de la salida del personal de la empresa.

e. No hay procedimientos adecuados para las medidas de seguridad.

Los mencionados anteriormente son sólo algunos aspectos que tenemos como deficiente en lo que corresponde a Seguridad Laboral, por lo que nos servirán de input para nuestro análisis de posibles oportunidades de mejora. 
Algunos de los índices que actualmente tenemos en la empresa en materia de Seguridad y Salud Ocupaciones tenemos:

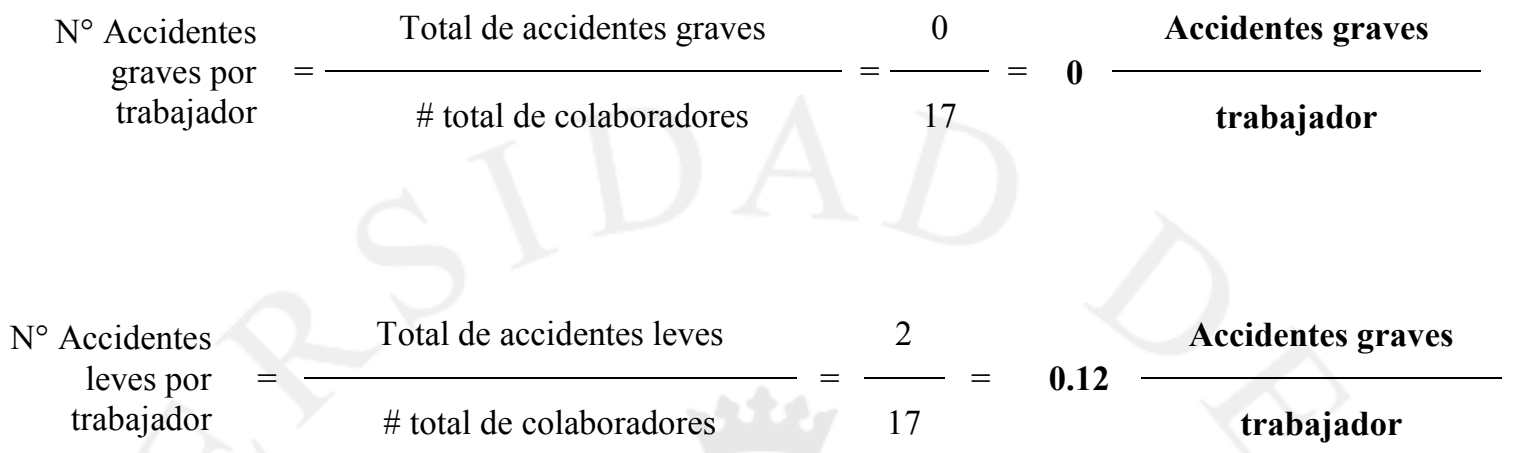

Éstos indicadores son muy buenos a efectos de poder medir el nivel de cuidado por el personal que existe en la empresa a pesar de las deficiencias mencionadas anteriormente, puesto quiere decir que a pesar de la limitada gestión en aspectos de seguridad laboral, los accidentes son casi nulos y el riesgo del trabajador está controlado.

\subsection{Gestión ambiental}

De la misma manera que en el aspecto de la Seguridad y Salud Ocupacional, la empresa no tiene implementado actualmente un sistema de control ambiental de acuerdo a la normativa para poder alcanzar alguna certificación en éste aspecto; Sin embargo, cumple con las mínimas disposiciones legales para el desecho de sus residuos orgánicos producidos en la empresa. Esto mediante un almacenaje de los residuos en contenedores de basura que posteriormente son desechados con el servicio de recojo municipal de basura. 
Usualmente los residuos sólidos que emite la empresa está compuesto por los empaques y envases de la materia prima utilizado, por lo que se podría medir en cuanto al total de desechos generados al año:

$\begin{gathered}\text { Total Residuos } \\ \text { Sólidos al año }\end{gathered}=\frac{\text { Ton total Residuos Sólidos }}{\text { Año } 2014=360 \text { días }}=\mathbf{0 . 7 6 8} \frac{\text { Ton residuos Sólidos }}{\text { Año }}$

Tal como se mencionó previamente, éstos residuos son dispuestos de manera doméstica mediante el servicio de recojo de basura del distrito en donde opera la empresa. Cabe mencionar, además, que estos residuos no son peligrosos.

Por otro lado, la empresa hace uso del servicio de agua potable para la preparación de sus cupcakes. Considerando el balance de éste elemento en la preparación de sus productos, así como también para el uso diario en los servicios higiénicos, entre otros. Como dato al 2014 tenemos:

$\begin{array}{r}\text { Total agua } \\ \text { utilizada al año }\end{array}=\frac{\text { Lts. Agua utilizada }}{\text { Año } 2014=360 \text { días }}=\mathbf{3 , 7 6 0 . 4 9} \frac{\text { Lts. agua }}{\text { Año }}$

Finalmente, la empresa no emite algún tipo de emisión gaseosa al medio ambiente, por lo que su impacto al aire es prácticamente nulo.

\subsection{Gestión de la información}


En la empresa Claudia Cupcakes la información es un tema sensible. Es así, que las recetas, secretos de sus productos, diseños, etc., se mantienen en reserva. Asimismo, con el tiempo que tiene la empresa, han podido generar una base de datos de clientes a los que han atendido anteriormente y les permite poder mantener una fidelidad con ellos mediante promociones u ofertas especiales.

Por otro lado, una ventana que tiene la empresa para dar a conocer las novedades de sus productos a sus clientes, es su página de Facebook, en donde también se puede lograr ingresar los pedidos de los clientes, para luego generar una coordinación "1 to $1 "$ con ellos.

Sin embargo, hay algunos aspectos que de momento aún está un tanto débil si de manejo de información interna se trata:

a. Actualmente no hay un sistema de back up de información que se genere periódicamente, y que pueda permitir contar con esa data ante alguna contingencia que pudiera presentarse a futuro.

b. Ante nuevos ingresos de colaboradores a la empresa, actualmente no existe algún tipo de procedimiento establecido que pueda permitir transmitir el "know how" al nuevo integrante, sólo una enseñanza visual.

c. Aún no se tiene un control establecido que pueda restringir el flujo de información hacia el exterior una vez que alguno de los trabajadores pudiera salir de la empresa, lo cual podría convertirse en un riesgo para la empresa. 
Con lo anteriormente expuesto, podrían plantearse algunas oportunidades de mejora que posteriormente podremos analizar y proponer. 


\section{CAPÍTULO VI: ASPECTOS ECONÓMICOS Y FINANCIEROS}

\subsection{Costos, Gastos e Inversiones}

\subsubsection{Costos y Gastos}

Para el desarrollo del siguiente capítulo, tomaremos como base toda la información que se tiene de la empresa al cierre del año 2014 y analizaremos los costos de producción, (directos e indirectos), los gastos administrativos, los gastos de ventas, gastos financieras, etc. El detalle de cada uno de éstos costos se encuentran al final del presente trabajo en el Anexo 07.

A continuación, presentamos el esquema de costos y gastos de la empresa:

Tabla 6. 1: Resumen de costos de la empresa.

RESUMEN DE COSTOS,

GASTOS E INVERSIONES
COSTO ANUAL

$(\mathrm{S} /$.

$695,183.39$

$46,581.91$

$741,765.30$

$224,320.64$

$137,505.73$

$8,845.34$

989,879.99
PARTICIPACIÓN

SUB COSTO (\%)
PARTICIPACIÓN

GLOBAL(\%)

- Costos directos

- Costos indirectos

COSTOS DE PRODUCCIÓN

GASTOS ADMINISTRATIVOS

GASTOS DE VENTAS

GASTOS GENERALES

INVERSIONES

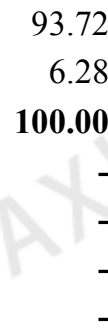

6.28

33.07

2.22

35.28

10.67

6.54

0.42

47.09 
Del cuadro anterior podemos concluir que los costos de representan el $35.28 \%$ del total; aunque, cabe señalar además, que dicho costo representa un poco más del $50 \%$ de las ventas totales.

Finalmente, en cuanto a la estructura de los costos de producción, sólo la Materia Prima representa el 49\% de los costos totales, lo cual ya es elevado.

\subsection{Situación económica financiera de la empresa}

A continuación, presentamos los principales ratios financieros de la empresa a 31 de Diciembre del 2014:

\section{a. RATIOS DE LIQUIDEZ}

- $\quad$ LIQUIDEZ

$$
\mathrm{RL}=\frac{\text { Activo corriente }}{\text { Pasivo Corriente }}=\frac{147,036.00}{108,638.00}=\mathbf{1 . 3 5} \text { veces }
$$

Este ratio de Liquidez nos muestra que la empresa cuenta con una buena capacidad de pago. 
- PRUEBA DEFENSIVA

$\mathrm{PD}=\frac{\text { Efectivo y Equivalentes }}{\text { Pasivo Corriente }}=\frac{18,752.00}{108,638.00}=\mathbf{0 . 1 7 3}$ veces

Este indicador nos muestra que por cada sol de deuda a corto plazo, hay 0.173 en efectivo para pagar dicha deuda. Pagar ésta deuda, por ahora, sería imposible.

\section{- $\quad$ CAPITAL DE TRABAJO}

$\mathrm{CT}=$ Activo Corriente - Pasivo Corriente $=147,036.00-108,638.00=\mathbf{S} / \mathbf{3 8 , 3 9 8 . 0 0}$

Este indicador nos muestra que la empresa contaría con S/.38,398.00 de excedente luego de cumplir sus compromisos con terceros. Dicho excedente podría ser usado para el cumplimiento de otras deudas al largo plazo y/o inversiones en la empresa que permitan seguir generando ingresos para la empresa. 


\section{b. RATIOS DE RENTABILIDAD}

- RENTABILIDAD DE PATRIMONIO

$$
\mathrm{ROE}=\frac{\text { Utilidad Neta }}{\text { Patrimonio }}=\frac{166,833.09}{245,488.09}=\mathbf{6 7 . 9 6 \%}
$$

Este ratio nos indica que actualmente es rentable poder invertir en la empresa debido al retorno que se espera por cada sol invertido.

- MARGEN DE UTILIDAD NETA

$$
\text { MUN }=\frac{\text { Utilidad Neta }}{\text { Ventas Netas }}=\frac{166,838.09}{1^{\prime} 410,670.00}=\mathbf{1 1 . 8 3} \%
$$

Éste indicador nos muestra que del total de las ventas registradas durante el 2014, el $11.83 \%$ representa la utilidad alcanzada por la empresa después de los impuestos aplicados a la venta. 


\section{c. RATIOS DE SOLVENCIA}

- ENDEUDAMIENTO PATRIMONIAL

$$
\mathrm{EP}=\frac{\text { Pasivo Total }}{\text { Patrimonio }}=\frac{299,024.00}{245,488.09}=\mathbf{1 . 2 2}
$$

Si la empresa deseara pagar sus deudas con el patrimonio con el cual cuenta, no tendría la capacidad de pago suficiente para poder hacerlo. Esto refleja un mediano endeudamiento, lo que hace que algunos costos de deuda sean altos e implica un riesgo para la empresa; es decir, no es lo suficientemente solvente.

- RAZÓN DE ENDEUDAMIENTO

$$
\mathrm{RE}=\frac{\text { Pasivo Total }}{\text { Activo Total }}=\frac{299,024.00}{370,310.00}=\mathbf{0 . 8 1} \text { veces }
$$

Éste indicador nos da a entender que el $81 \%$ del activo total de la empresa está financiado por terceros y el 19\% por dueños y otros componentes del patrimonio. Por lo tanto, un financiamiento alto por terceros significa un alto apalancamiento. 


\section{d. RATIOS DE GESTIÓN}

- PERIODO PROMEDIO DE COBRO

$\mathrm{PPC}=\frac{\text { Días año }}{\text { Rotación ctas. } \mathrm{x} \text { cobrar }}=\frac{360}{8.59}=\mathbf{4 1 . 8 9}$ días

Este indicador nos muestra que la empresa realiza sus cobranzas

promedio a 42 días aproximadamente. Cabe señalar que mientras menos sea la cantidad de días, la empresa rota el dinero más veces al año; es decir, tiene mayor circulación.

- PERIODO PROMEDIO DE PAGO

$$
\text { PPC }=\frac{\text { Días año }}{\text { Rotación ctas. } x \text { pagar }}=\frac{360}{3.27}=\mathbf{1 1 0 . 1} \text { días }
$$

Éste ratio nos indica que la empresa realiza los pagos a sus proveedores principales a los 110 días aproximadamente. Es recomendable que el período promedio de pago sea mayor al de cobro. 


\section{CAPÍTULO VII: DESCRIPCIÓN DE LAS PRINCIPALES FORTALEZAS Y DEBILIDADES DE LA EMPRESA}

\subsection{Mercado y comercialización de los productos o servicios}

Las fortalezas identificadas son:

a. La empresa cuenta con una marca registrada y con un $40 \%$ de participación de mercado, lo que le permite tener una mejor llegada a su público.

b. Tiene una importante relación y cercanía con sus principales proveedores, lo cual le permite asegurar el cumplimiento y poder formar alianzas estratégicas a fin de poder ampliar sus mercados. Esto se refleja en el nivel de calidad y servicio del proveedor, los cuales ascienden al $98 \%$.

c. Maneja una importante cartera de clientes entre los cuales destaca la cadena de supermercados Cencosud, la cual debido a su gran relevancia en el mercado Peruano, le permite tener mayores oportunidades de crecimiento no sólo dentro, si no también fuera del país. Esto se sustenta mediante el nivel de satisfacción del cliente, el cual es $84 \%$.

d. Buen control de las condiciones de pagos con clientes mediante el establecimiento de cláusulas específicas en los contratos. 
Las debilidades identificadas son:

a. La empresa no hace uso de indicadores de gestión para dar seguimiento a la participación de mercado o nivel de servicio.

b. La empresa no se compara con los resultados obtenidos por el mejor competidor que tiene en el mercado actualmente.

c. No existe una estrategia de ventas agresiva para captar una mayor participación en el mercado. Por ejemplo, ampliar la línea de productos light, abrir un local comercial, alquiler de espacios publicitarios, etc.

\subsection{Aspectos técnicos y de operaciones}

Las fortalezas identificadas son:

a. La empresa se va modernizando tecnológicamente en su maquinaria, lo que le permite poder estar a la vanguardia del mercado de pastelería. Como prueba de esto, las mejoras tecnológicas permiten que la capacidad instalada de la planta ascienda a 36,446.30 kg-cupcakes al año.

b. Los productos cuentan con una presentación agradable, vistosa y con diseños variados. La preferencia de su público se debe al exquisito sabor de los productos, lo que se ve reflejado en la fidelización de sus clientes. A la fecha, cuentan con más de 200 diseños creados para los cupcakes y una variedad de más de 15 sabores, tanto para cupcakes como tortas. 
Las debilidades identificadas son:

a. La actual disposición de planta no permite que el flujo del proceso y los espacios sean los adecuados como para poder contar con una certificación HACCP. El área actual es de $107.52 \mathrm{~m} 2$, mientras que el área requerida es de 142.82 m2. Además, el flujo del proceso no es adecuado, actualmente el tiempo estándar del mismo es de 317.67 minutos por la producción de 270 cupcakes, pudiéndose reducir en un $10 \%$, con el nuevo flujo.

b. No hay un sistema de aseguramiento de la calidad e inocuidad alimentaria en la empresa que permita poder mantener un buen desempeño de sus procesos y, sobretodo, tener la claridad del cumplimiento de los mínimos estándares requeridos por la ley (Norma Sanitaria). Esto se puede medir mediante el nivel de reclamos de Producto Terminado, el cual asciende al 4.59\%. Asimismo, hemos encontrado 3 puntos críticos de control en las operaciones, los cuales no están siendo controlados mediante parámetros y revisiones.

c. Si bien la empresa va contando de a pocos con maquinaria nueva y moderna, no se está haciendo uso de su máxima capacidad de planta, esto se justifica mediante el indicador de utilización con un 33\%, explicado por la baja demanda y por la alta capacidad de producción de las máquinas adquiridas. 


\subsection{Aspectos de gestión}

Las fortalezas identificadas son:

a. En cuanto a la gestión de recursos humanos, existe un buen clima laboral, debido a que un $87 \%$ de los trabajadores, se encuentran satisfechos en aspectos generales con la empresa.

b. En cuanto a la gestión de la calidad, se mantiene un bajo nivel de reclamos, siendo este $2.29 \%$. Los motivos se basan en aspectos más externos que internos del producto.

Las debilidades identificadas son:

a. No hay un manual de Organización y Funciones establecido que permita tener clara todas las funciones y responsabilidades del personal que labora en la empresa.

b. No hay capacitaciones y/o talleres programados a los colaboradores en temas afines de la empresa y que permita ampliar su panorama de conocimientos. Esto se mide mediante el nivel de capacitación por colaborador, siendo 6 horas/año, un resultado no muy alto, de acuerdo del nivel de especialización requerida.

c. No se ha implementado un sistema de gestión de seguridad y salud en el trabajo de acuerdo a las exigencias de la Ley $\mathrm{N}^{\circ} 27983$ y su reglamento aprobado con D.S. 005-2012 TR. 
d. No se cuenta con un sistema para puntos de Medio Ambiente. Este se encuentra actualmente en proceso desarrollo. El total de residuos sólidos emitidos al año ascienden a 0.768 toneladas de residuos/año.

\subsection{Aspectos económicos y financieros}

Las fortalezas identificadas son:

a. La empresa cuenta con una alta rentabilidad financiera. En el caso de que Claudia Cupcakes desee vender acciones, el retorno para los accionistas seria del $68 \%$, por lo que es una buena propuesta de inversión.

Las debilidades halladas tenemos:

- La empresa tiene un mediano endeudamiento patrimonial, debido a que si actualmente quisieran pagar la deuda con el patrimonio, no tendrían la capacidad. Por cada sol de patrimonio, hay 1.22 soles de deuda.

- El margen de utilidad neta (utilidad sobre las ventas) tiene un nivel bajo del $11 \%$ en promedio, que si bien no es malo, podría ser mayor optimizando algunos costos y/o generando mayores ingresos.

- La empresa presenta un alto nivel de endeudamiento por terceros en activos, lo cual significa un alto apalancamiento, que en caso se presenten perdidas en los resultados, puede terminar empeorando la situación. El $81 \%$ de la deuda es financiada por terceros. 
- La empresa no cuenta con liquidez suficiente para pagar la deuda a corto plazo, ya que por cada sol de deuda, existe 0.173 en efectivo para hacer frente, lo cual no es suficiente. 


\section{CAPÍTULO VIII: ESTRATEGIAS Y PROPUESTAS DE MEJORA}

\subsection{Análisis FODA}

\subsubsection{Determinación de los principales indicadores de gestión y definición de}

metas

Antes de proponer algunas estrategias y proyectos de mejora para la empresa, presentaremos el estado de los principales indicadores estratégicos de gestión y las conclusiones del análisis FODA. Para ello mostramos a continuación el Cuadro de Mando de Control Integral o "Balance Scorecard", por sus siglas en inglés, en donde se aprecian los principales indicadores de Gestión de la empresa y las metas establecidas en conjunto con la Gerencia General:

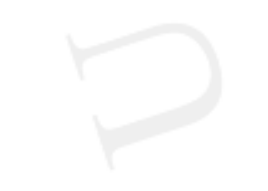

\section{FINANCIERO}

\begin{tabular}{|l|c|c|}
\hline \multicolumn{3}{|c|}{ FINANCIERO } \\
\hline \multicolumn{1}{|c|}{ INDICADOR } & ACTUAL & META \\
\hline ROE (\%) & 68 & 72 \\
\hline Margen de Utilidad (\%) & 12 & 17 \\
\hline Razón de Endeudamiento & 0.81 & 0.65 \\
\hline \multicolumn{2}{|c}{} \\
\hline
\end{tabular}

ENFQUE EN EL CLIENTE INDICADOR

\begin{tabular}{|l|c|c|}
\hline \multicolumn{1}{|c|}{ Satisfacción del cliente (\%) } & ACTUL & META \\
\hline Nivel de Servicio (\%) & 86 & 90 \\
\hline Participación de mercado (\%) & 40 & 55 \\
\hline
\end{tabular}

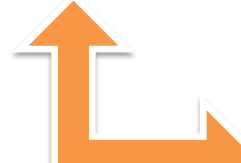

Razón de Endeudamiento

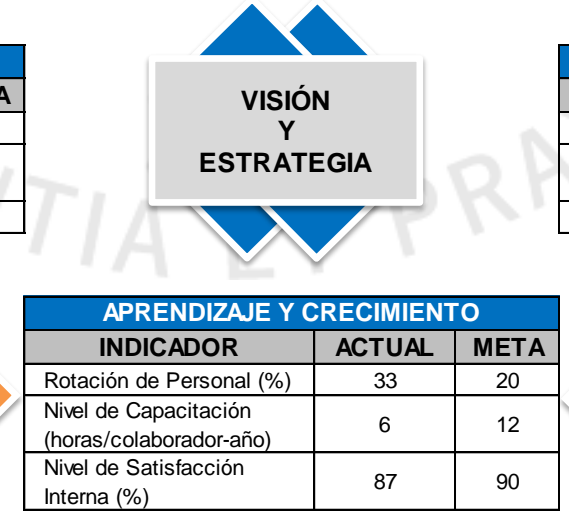

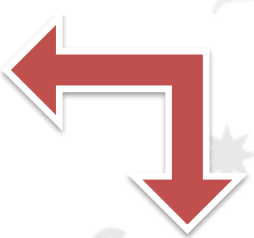

PROCESOS INTERNOS DE NEGOCIO \begin{tabular}{|l|l|l|}
\hline INDICADOR & ACTUAL & META \\
\hline
\end{tabular}

\begin{tabular}{|l|c|c|}
\hline \multicolumn{1}{|c|}{ Utilización } & ACT & M \\
\hline $\begin{array}{l}\text { \% de reclamos de productos } \\
\text { terminados }\end{array}$ & 12 & 5 \\
\hline Producitividad Global (unid./S/.) & 0.27 & 0.5 \\
\hline
\end{tabular}

Figura 8. 1: Tablero de indicadores principales de la empresa Claudia Cupcakes Fuente: Elaboración propia. 
Del gráfico anterior mostrado podemos observar, por ejemplo, que la tasa de rotación del personal (33\%) y la baja cantidad de horas de capacitación por trabajador año (6h), estaría afectando la calidad (5\% reclamo) y productividad del proceso (0.27); asimismo tales resultados tienen influencia en la satisfacción del cliente y en la participación de mercado y todo ello se refleja en los resultados financieros.

\subsubsection{Factores FODA}

\section{a. FACTORES INTERNOS}

De acuerdo al análisis realizado en el capítulo anterior al determinar todos los factores internos de la empresa, para poder acotar nuestro siguiente análisis haremos uso de la herramienta Pareto, a fin de determinar las fortalezas y debilidades que puedan tener una mayor relevancia para la empresa de acuerdo a nuestro propio punto de vista y por parte de la Gerencia General: 
Tabla 8. 1: Análisis de las Fortalezas de la empresa Claudia Cupcakes

\begin{tabular}{|c|c|c|c|c|c|c|}
\hline \multirow{2}{*}{ FORTALEZAS IDENTIFICADAS } & \multicolumn{4}{|c|}{ EVALUACIÓN (*) } & \multirow{2}{*}{$\%$} & \multirow{2}{*}{$\begin{array}{c}\% \\
\text { ACUM. }\end{array}$} \\
\hline & DM & $\mathbf{E P}$ & GG & Total & & \\
\hline 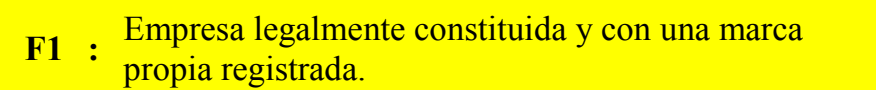 & 5 & 5 & 5 & 15 & 14 & 14 \\
\hline 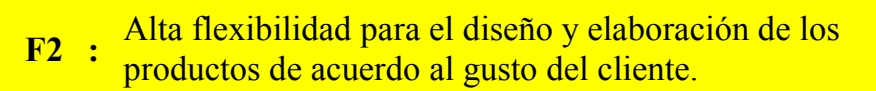 & 5 & 5 & 5 & 15 & 14 & 27 \\
\hline F3 : Buena presentación, diseño y sabor de sus productos. & 5 & 5 & 5 & 15 & 14 & 41 \\
\hline F4 : Muy buena relación con sus principales proveedores. & 5 & 3 & 5 & 13 & 12 & 53 \\
\hline F5 : Muy buena relación con sus principales clientes. & 3 & 3 & 5 & 11 & 10 & 63 \\
\hline $\begin{array}{l}\text { F6 : Cuenta con personal competente con estudios } \\
\text { técnicos en panadería y pastelería. }\end{array}$ & 5 & 3 & 3 & 11 & 10 & 73 \\
\hline 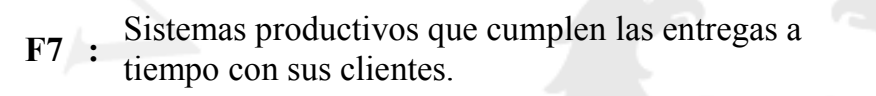 & 3 & 1 & 5 & 9 & 8 & 81 \\
\hline F8 : Buen nivel de rentabilidad financiera (ROE) & 3 & 1 & 3 & 7 & 6 & 87 \\
\hline F9 : Maquinaria moderna. & 3 & 1 & 3 & 7 & 6 & 94 \\
\hline F10 : Buen clima laboral. & 3 & 1 & 3 & 7 & 6 & 100 \\
\hline & & & & 110 & 100 & \\
\hline
\end{tabular}

Leyenda:

\begin{tabular}{|c|c|}
\hline Nivel de Fortaleza & Puntaje \\
\hline Alta Fortaleza & 5 \\
\hline Fortaleza Media & 3 \\
\hline Baja Fortaleza & 1 \\
\hline
\end{tabular}

(*) DM: Daniela Martínez / EP: Elio Pérez / GG: Gerencia General Claudia Cupcakes. 


\section{ANÁLISIS DE PARETO PARA IDENTIFICAR LAS PRINCIPALES FORTALEZAS DE LA EMPRESA}

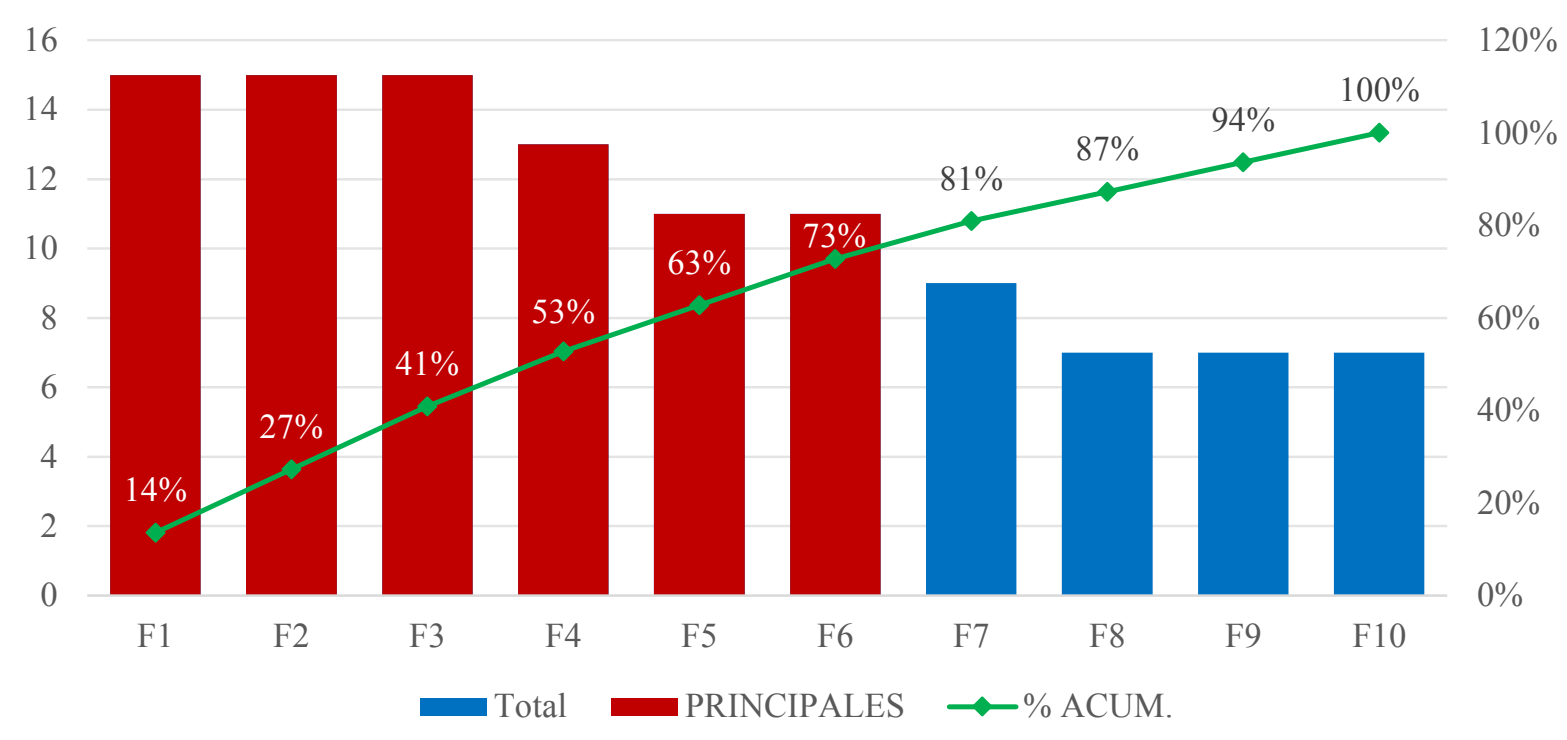

Figura 8. 2: Diagrama de Pareto de las Fortalezas de la empresa Claudia Cupcakes Fuente: Elaboración propia. 
Tabla 8. 2: Análisis de las Debilidades de la empresa Claudia Cupcakes.

\begin{tabular}{|c|c|c|c|c|c|c|}
\hline \multirow{2}{*}{ DEBILIDADES IDENTIFICADAS } & \multicolumn{4}{|c|}{ EVALUACIÓN (*) } & \multirow{2}{*}{$\%$} & \multirow{2}{*}{$\begin{array}{c}\% \\
\text { ACUM. }\end{array}$} \\
\hline & DM & EP & GG & PROM. & & \\
\hline $\begin{array}{l}\text { D1 : Ausencia de un sistema de Aseguramiento de la Calidad e } \\
\text { Inocuidad Alimentaria. }\end{array}$ & 20 & 20 & 20 & 20 & $11 \%$ & $11 \%$ \\
\hline D2 : Carencia de un Plan Estratégico. & 20 & 20 & 20 & 20 & $11 \%$ & $22 \%$ \\
\hline $\begin{array}{l}\text { D3 : Áreas reducidas e inadecuada distribución del taller para el } \\
\text { desarrollo del proceso. }\end{array}$ & 20 & 20 & 20 & 20 & $11 \%$ & $33 \%$ \\
\hline $\begin{array}{l}\text { D4 : Bajo compromiso de la gerencia en los procesos internos de la } \\
\text { empresa. }\end{array}$ & 20 & 20 & 15 & 18 & $10 \%$ & $44 \%$ \\
\hline $\begin{array}{l}\text { D5 : No existe un sistema adecuado para la compra y reposición de } \\
\text { suministros y manejo de inventarios. }\end{array}$ & 20 & 20 & 15 & 18 & $10 \%$ & $54 \%$ \\
\hline D6 : Ineficiente utilización de la capacidad instalada. & 20 & 15 & 15 & 17 & $9 \%$ & $63 \%$ \\
\hline D7 : Bajo nivel de margen de utilidad neta. & 10 & 15 & 15 & 13 & $7 \%$ & $70 \%$ \\
\hline $\begin{array}{l}\text { D8 : Ausencia de Indicadores de Gestión correctamente establecidos } \\
\text { para el control de sus procesos. }\end{array}$ & 15 & 10 & 10 & 12 & $6 \%$ & $77 \%$ \\
\hline $\begin{array}{l}\text { Do se ha implementado un Sistema de Gestión de Seguridad y } \\
\text { Salud en el Trabajo. }\end{array}$ & 15 & 10 & 10 & 12 & $6 \%$ & $83 \%$ \\
\hline $\begin{array}{l}\text { D10 : Falta de personal competente que permita un diseño de una } \\
\text { estrategia de ventas adecuada. }\end{array}$ & 10 & 15 & 5 & 10 & $6 \%$ & $89 \%$ \\
\hline D11 : Inadecuada políticas de financiamiento con terceros. & 10 & 5 & 10 & 8 & $5 \%$ & $94 \%$ \\
\hline $\begin{array}{l}\text { D12 : No existe un programa de capacitación continuo para sus } \\
\text { trabajadores. }\end{array}$ & 10 & 5 & 5 & 7 & $4 \%$ & $97 \%$ \\
\hline $\begin{array}{l}\text { D13 : No se han implementado mecanismos de control para minimizar el } \\
\text { impacto de los factores de riesgo medioambientales. }\end{array}$ & 5 & 5 & 5 & 5 & $3 \%$ & $100 \%$ \\
\hline & & & & 1 & $100 \%$ & \\
\hline
\end{tabular}

Leyenda:

\begin{tabular}{|c|c|}
\hline Criticidad & Puntaje \\
\hline Muy Crítico & 20 \\
\hline Crítico & 15 \\
\hline Regular & 10 \\
\hline Bajo & 5 \\
\hline Muy Bajo & 1 \\
\hline
\end{tabular}




\section{ANÁLISIS DE PARETO PARA IDENTIFICAR LAS PRINCIPALES DEBILIDADES DE LA EMPRESA}

25

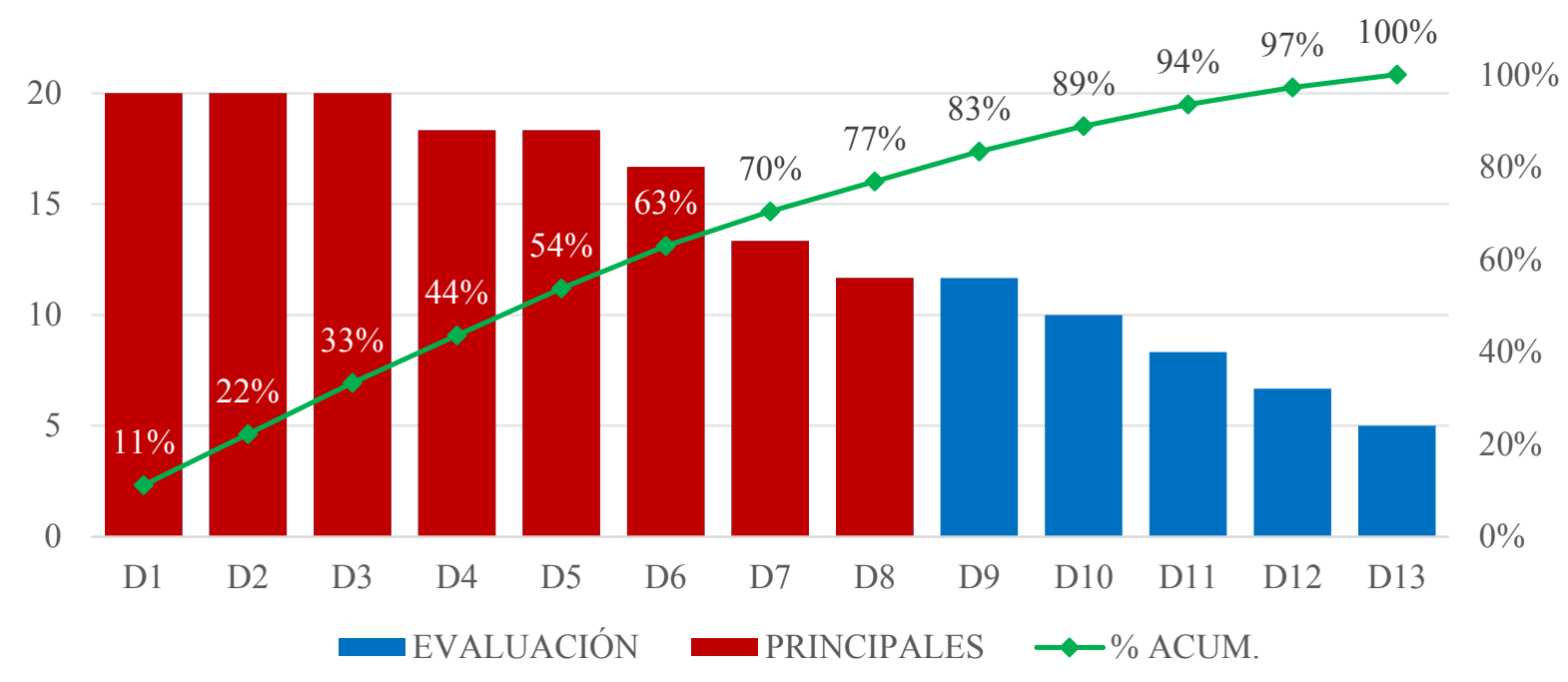

Figura 8. 3: Diagrama de Pareto de las Debilidades de la empresa Claudia Cupcakes Fuente: Elaboración propia.

$120 \%$

\section{$00 \%$ \\ $0 \%$ \\ $60 \%$ \\ $0 \%$ \\ $0 \%$ $\%$}




\begin{tabular}{|c|c|c|c|}
\hline FACTORES CRÍTICOS DE ÉXITO & PESO & CALIF. & $\begin{array}{l}\text { TOTAL } \\
\text { POND. }\end{array}$ \\
\hline $\begin{array}{l}\text { FORTALEZAS } \\
\text { F1: Empresa legalmente constituida y con una marca propia registrada. }\end{array}$ & 0.10 & 4 & 0.40 \\
\hline F2: Alta flexibilidad para el diseño y elaboración de los productos de acuerdo al gusto del cliente. & 0.08 & 4 & 0.32 \\
\hline F3: Buena presentación, calidad y sabor de sus productos. & 0.09 & 4 & 0.36 \\
\hline F4: Muy buena relación con sus principales proveedores. & 0.07 & 3 & 0.21 \\
\hline F5: Muy buena relación con sus principales clientes. & 0.07 & 3 & 0.21 \\
\hline F6: Cuenta con personal competente con estudios técnicos en pastelería. & 0.08 & 4 & 0.32 \\
\hline \multicolumn{4}{|l|}{ DEBILIDADES } \\
\hline D1: Ausencia de un sistema de Aseguramiento de la Calidad e Inocuidad Alimentaria. & 0.05 & 1 & 0.05 \\
\hline D2: Carencia de un Plan Estratégico. & 0.07 & 1 & 0.07 \\
\hline D3: Áreas reducidas e inadecuada distribución del taller para el desarrollo del proceso. & 0.07 & 2 & 0.14 \\
\hline D4: Bajo compromiso de la gerencia en los procesos internos de la empresa. & 0.05 & 1 & 0.05 \\
\hline D5: No existe un sistema adecuado para la compra y reposición de suministros y manejo de inventarios. & 0.08 & 2 & 0.16 \\
\hline D6: Ineficiente utilización de la capacidad instalada. & 0.04 & 2 & 0.08 \\
\hline D7: Bajo nivel de margen de utilidad neta. & 0.06 & 1 & 0.06 \\
\hline D8: Ausencia de Indicadores de Gestión correctamente establecidos para el control de sus procesos. & 0.09 & 2 & 0.18 \\
\hline TOTAL & 1.00 & & 2.61 \\
\hline
\end{tabular}

\begin{tabular}{|c|c|c|c|c|}
\hline & & \multicolumn{2}{|c|}{$\begin{array}{c}\text { Nivel de relevancia del factor en la } \\
\text { empresa (CALIFICACIÓN) }\end{array}$} & \\
\hline \multirow{2}{*}{\multicolumn{2}{|c|}{$\begin{array}{l}\text { Importancia del factor en la } \\
\text { Industria (PESO) }\end{array}$}} & 1 & Debilidad Mayor & \multirow{3}{*}{$\begin{array}{c}\begin{array}{c}\text { Criterio puntaje Total } \\
\text { Ponderado }\end{array} \\
\text { Rango [1.00 - 4.00] }\end{array}$} \\
\hline & & 2 & Debilidad Menor & \\
\hline 0.0 & Sin importancia & 3 & Fortaleza Menor & \\
\hline 1.0 & Muy importante & 4 & Fortaleza Mayor & Promedio 2.50 \\
\hline
\end{tabular}

Tabla 8. 3: Matriz EFI aplicado a la empresa Claudia Cupcakes 
De la matriz EFI evaluada, obtenemos un resultado global ponderado de 2.61, lo cual indica que la empresa en estudio es una organización sólida, considerando que está por encima de la media que es $\mathbf{2 . 5}$.

\section{b. FACTORES EXTERNOS}

De la misma manera que en la descripción de los factores internos de la empresa, ahora detallamos los factores externos identificados para la organización:

Tabla 8. 4: Oportunidades y Debilidades principales halladas en la empresa.

\section{OPORTUNIDADES}

- Crecimiento del mercado interno y externo de pastelería.

- Posibilidad de alianzas comerciales con grandes empresas.

- Facilidad de acceso a la tecnología de máquina y equipos.

- Estabilidad en los precios de mercado.

- Facilidad de acceso a medios de comunicación para publicidad.

- Ferias Gastronómicas en el país.

- Desarrollo del comercio electrónico.

\section{AMENAZAS}

- Crecimiento de la competencia.

- Facilidad de ingreso en el negocio de cupcakes.

- Competidores con menores costos.

- Alta variedad de productos sustitutos.

- Dificultad de acceso a personal capacitado y/o calificado en el rubro.

- Acceso al crédito con altas tasas de interés.

- Leyes y normas cada vez más exigentes para la industria en general.

Del mismo modo, procederemos con el análisis que corresponde a éstos

factores mediante la matriz EFE (Evaluación de Factores Externos). 
Tabla 8. 5: Matriz EFE aplicado a la empresa Claudia Cupcakes.

\begin{tabular}{|l|l|l|l|}
\hline \multicolumn{1}{|c|}{ FACTORES DETERMINANTES DE ÉXITO } & PESO & CALIF. & $\begin{array}{c}\text { TOTAL } \\
\text { POND. }\end{array}$ \\
\hline $\begin{array}{l}\text { OPORTUNIDADES } \\
\text { O1: Crecimiento del mercado interno y externo de pastelería. }\end{array}$ & 0.12 & 4 & 0.52 \\
\hline O2: Posibilidad de alianzas comerciales con grandes empresas. & 0.11 & 4 & 0.48 \\
\hline O3: Facilidad de acceso a la tecnología de máquina y equipos. & 0.06 & 3 & 0.18 \\
\hline O4: Estabilidad en los precios de mercado. & 0.05 & 3 & 0.15 \\
\hline O5: Facilidad de acceso a medios de comunicación para publicidad. & 0.04 & 2 & 0.10 \\
\hline O6: Ferias gastronómicas en el país. & 0.08 & 4 & 0.32 \\
\hline O7: Crecimiento y desarrollo del comercio electrónico & 0.05 & 3 & 0.12 \\
\hline AMENAZAS & & & \\
A1: Crecimiento de la competencia. & 0.10 & 2 & 0.22 \\
\hline A2: Facilidad de ingreso en el negocio de cupcakes. & 0.08 & 3 & 0.24 \\
\hline A3: Competidores con menores costos. & 0.06 & 3 & 0.21 \\
\hline A4: Alta variedad de productos sustitutos. & 0.07 & 2 & 0.16 \\
\hline A5: Dificultad de acceso a personal capacitado y/o calificado en el rubro. & 0.10 & 3 & 0.30 \\
\hline A6: Dificultad de acceso a créditos por altas tasas de interés. & 0.03 & 1 & 0.03 \\
\hline A7: Leyes y normas cada vez más exigentes para la industria en general. & 0.05 & 2 & 0.10 \\
\hline \multicolumn{1}{|c|}{ TOTAL } & $\mathbf{1 . 0 0}$ & & $\mathbf{3 . 1 3}$ \\
\hline
\end{tabular}

\begin{tabular}{|c|c|c|c|}
\cline { 3 - 4 } \multicolumn{1}{c|}{} & \multicolumn{2}{c|}{$\begin{array}{c}\text { Eficiencia de respuesta de la } \\
\text { empresa al factor (CALIFICACIÓN) }\end{array}$} \\
\hline $\begin{array}{c}\text { Importancia del factor en la } \\
\text { Industria (PESO) }\end{array}$ & 1 & Respuesta mala \\
\cline { 2 - 4 } & 2 & Respuesta media \\
\hline 0.0 & Sin importancia & 3 & Respuesta superior a la media \\
\hline 1.0 & Muy importante & 4 & Respuesta superior \\
\hline
\end{tabular}

CRITERIO PUNTAJE TOTAL

Rango [1.00 - 4.00]

Promedio 2.50 
De la matriz EFE evaluada obtenemos un resultado global ponderado de 3.03, lo cual indica que la empresa en estudio es una organización que está respondiendo de manera adecuada y oportuna ante las oportunidades y amenazas que se presentan, lo cual indicaría que estaría aprovechando eficazmente dichas oportunidades existentes y minimizando los posibles efectos negativos de las amenazas presentes o potenciales a las que podría estar expuesta. 


\subsubsection{Determinación de Estrategias FODA}

Tabla 8. 6: Matriz FODA de la empresa Claudia Cupcakes

\begin{tabular}{|c|c|c|}
\hline & $\begin{array}{l}\text { FORTALEZAS } \\
\text { (F) }\end{array}$ & $\begin{array}{l}\text { DEBILIDADES } \\
\text { (D) }\end{array}$ \\
\hline 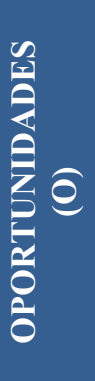 & $\begin{array}{l}\text { ESTRATEGIAS OFENSIVAS (FO) } \\
\text { - Acentuar la marca mediante más alianzas estratégicas con } \\
\text { grandes empresas para expandir aún más el mercado objetivo. } \\
\text { - Ampliar los canales de venta al público para brindar facilidades } \\
\text { de acceso a sus productos, como el e-commerce (comercio } \\
\text { electrónico). }\end{array}$ & $\begin{array}{l}\text { ESTRATEGIAS DE ORIENTACIÓN (DO) } \\
\text { - Re-disponer la planta para tener una mejor distribución de } \\
\text { espacios para las operaciones. } \\
\text { - Implementar un adecuado sistema de producción y gestión de la } \\
\text { cadena de suministros (control de la producción, materias } \\
\text { primas, inventarios, etc). } \\
\text { - Implementar un adecuado Sistema de Aseguramiento de la } \\
\text { Calidad. }\end{array}$ \\
\hline$\sum_{i=1}^{\infty} \mathbb{4}$ & $\begin{array}{l}\text { ESTRATEGIAS DEFENSIVAS (FA) } \\
\text { - Estrechar la cercanía y lazos comerciales con los proveedores y } \\
\text { clientes actuales. } \\
\text { - Implementar controles y/o Normas Técnicas de Seguridad, Salud } \\
\text { Ocupacional y Gestión Ambiental. }\end{array}$ & $\begin{array}{l}\text { ESTRATEGIAS DE SOBREVIVENCIA (DA) } \\
\text { - } \quad \text { Elaborar un plan estratégico para la empresa. }\end{array}$ \\
\hline
\end{tabular}




\subsection{Propuestas de mejora}

En base del estado de los indicadores estratégicos, el análisis FODA y las políticas sugeridas por la dirección de la empresa, se pasará a proponer un conjunto de propuestas de mejora para la compañía.

\subsubsection{Descripción detallada de las propuestas de mejora}

Para nuestro análisis de las oportunidades de mejora a plantear para la empresa, primero haremos un resumen general de ellas mediante la matriz $5 \mathrm{~W}-1 \mathrm{H}$ (de las siglas en inglés: “What?” = ¿Qué?; “Where?” = ¿Dónde?; “When?” = ¿Cuándo?; "Why?” = ¿Por qué?; "Who?”= ¿Quién? y "How?” $=$ ¿Cómo?), para que, tomando como input para nuestro análisis las estrategias FODA planteadas previamente, podamos identificar estas oportunidades de la manera más adecuada.

A continuación, la matriz planteada con las estrategias principales a adoptar por la empresa y que nos darán las opciones de oportunidades de mejora para poder implementar:

A continuación, presentamos la matriz con la lista de mejoras a implementar: 
Tabla 8. 7: Matriz 5W1H para las propuestas de mejora.

\begin{tabular}{|c|c|c|c|c|c|}
\hline $\begin{array}{l}\text { ¿Qué? } \\
\text { WHAT }\end{array}$ & $\begin{array}{l}\text { ¿Por qué? } \\
\text { WHY }\end{array}$ & $\begin{array}{l}\text { ¿Cómo? } \\
\text { HOW }\end{array}$ & $\begin{array}{l}\text { ¿Cuándo? } \\
\text { WHEN }\end{array}$ & $\begin{array}{l}\text { ¿Dónde? } \\
\text { WHERE }\end{array}$ & $\begin{array}{l}\text { ¿Quién? } \\
\text { WHO }\end{array}$ \\
\hline Definición & Objetivo a alcanzar & Acciones a realizar & $\begin{array}{c}\text { Fecha / } \\
\text { Hora }\end{array}$ & $\begin{array}{l}\text { Ubicación } \\
\text { geográfica }\end{array}$ & Responsable \\
\hline $\begin{array}{l}\text { Elaborar un plan estratégico } \\
\text { integrado en toda la } \\
\text { empresa. }\end{array}$ & $\begin{array}{l}\text { Definir hacia dónde quiere } \\
\text { llegar la empresa y cuáles } \\
\text { serán las metas que tendrá } \\
\text { que cumplir para lograr sus } \\
\text { objetivos. }\end{array}$ & $\begin{array}{l}\text { - Elaborar un Plan } \\
\text { Estratégico. }\end{array}$ & Por Definir & $\begin{array}{l}\text { Taller } \\
\text { (Lima) }\end{array}$ & $\begin{array}{l}\text { Jefe de } \\
\text { Proyecto }\end{array}$ \\
\hline $\begin{array}{l}\text { Re-disponer la planta para } \\
\text { tener una mejor distribución } \\
\text { de espacios para las } \\
\text { operaciones. }\end{array}$ & Incrementar la productividad & $\begin{array}{l}\text { - Nueva disposición } \\
\text { de planta (taller). } \\
\text { - Plan 5S. }\end{array}$ & Por Definir & $\begin{array}{l}\text { Taller } \\
\text { (Lima) }\end{array}$ & $\begin{array}{l}\text { Jefe de } \\
\text { Proyecto }\end{array}$ \\
\hline $\begin{array}{l}\text { Implementar un Sistema de } \\
\text { Aseguramiento de la } \\
\text { Calidad. }\end{array}$ & $\begin{array}{l}\text { Preservar la inocuidad en la } \\
\text { cadena de producción de los } \\
\text { alimentos. }\end{array}$ & $\begin{array}{l}\text { - Elaboración de un } \\
\text { plan HACCP. }\end{array}$ & Por Definir & $\begin{array}{l}\text { Taller } \\
\text { (Lima) }\end{array}$ & $\begin{array}{c}\text { Jefe de } \\
\text { Proyecto }\end{array}$ \\
\hline $\begin{array}{l}\text { Implementar un sistema de } \\
\text { Planeamiento y Control de } \\
\text { la Producción e Inventarios. }\end{array}$ & $\begin{array}{l}\text { Asegurar un adecuado } \\
\text { manejo de la producción y el } \\
\text { suministro de Materia Prima. }\end{array}$ & $\begin{array}{l}\text { - Implementar un } \\
\text { sistema de PCP de la } \\
\text { mano con un sistema } \\
\text { MRP. }\end{array}$ & Por Definir & $\begin{array}{l}\text { Taller } \\
\text { (Lima) }\end{array}$ & $\begin{array}{c}\text { Jefe de } \\
\text { Proyecto }\end{array}$ \\
\hline $\begin{array}{l}\text { Implementar controles en } \\
\text { materia de Seguridad y } \\
\text { Salud Ocupacional. }\end{array}$ & $\begin{array}{l}\text { Cultura de prevención en } \\
\text { riesgos de SST y Medio } \\
\text { Ambiente. }\end{array}$ & $\begin{array}{l}\text { - Establecer las } \\
\text { bases para un } \\
\text { Sistema de SST. }\end{array}$ & Por Definir & $\begin{array}{l}\text { Taller } \\
\text { (Lima) }\end{array}$ & $\begin{array}{l}\text { Jefe de } \\
\text { Proyecto }\end{array}$ \\
\hline
\end{tabular}

A continuación, detallamos las propuestas de mejora planteadas en el cuadro anterior:

\section{a. Elaboración de un Plan Estratégico}

Planteamos que la empresa pueda implemente un adecuado Plan Estratégico que esté acorde a su situación actual y a lo que quiere llegar en un determinado período. 


\section{- Desarrollo}

- Primero comunicamos a la Gerencia la importancia de tener un plan estratégico establecido en la empresa que permita llevar a cabo todas las tareas necesarias para alcanzar las metas y objetivos que encaminen a la organización hacia un camino que nos lleve hacia un objetivo final.

- Luego de haber transmitido el objetivo de establecer un Plan Estratégico a la Gerencia, es necesario saber y entender cuál es la situación actual de la empresa, a fin de poder establecer el camino más adecuado acorde a las necesidades y posibilidades de la empresa.

- Así, haciendo uso inicialmente de una matriz BCG, determinamos cuál es la posición actual del producto clave de la empresa: el cupcake. 


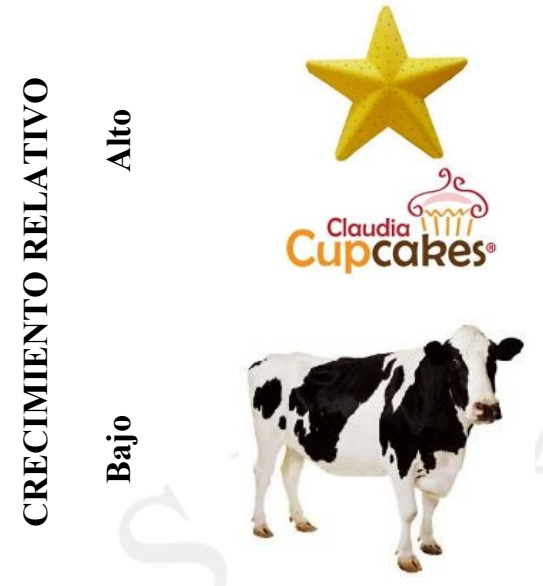

Alta

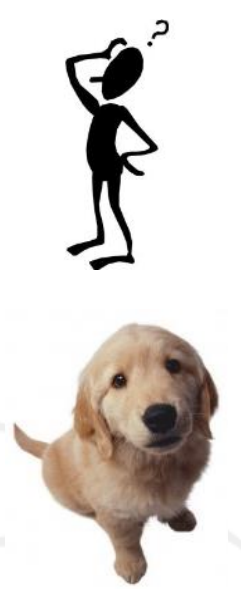

Baja

PARTICIPACIÓN RELATIVA EN EL MERCADO

Figura 8. 4: Matriz BCG para el análisis del Cupcake

Fuente: Elaboración propia.

Del análisis anterior, vemos que el cupcake es el producto estrella de la empresa, puesto a lo largo de los últimos años ha demostrado un comportamiento ascendente en las ventas, así como también una participación alta en el mercado de acuerdo a la experiencia de la Gerencia General de la empresa.

- Luego, a fin de poder tener más clara la situación de la empresa de manera medible, revisamos nuestro tablero de indicadores obtenido como resultado del análisis realizado, el cual fue revisado anteriormente, según el esquema del "Balance Scorecard".

- Finalmente, es adecuado revisar todos los aspectos internos y externos analizados en el FODA de la empresa, puesto nos dará 
también una vista general de cuál es la situación de la empresa de manera interna y externa, considerando también la posibilidad de hacer un benchmarking frente a la competencia, de modo que sepamos la manera en cómo podemos estar como ellos o mejor.

Una vez establecida la revisión de la situación actual de la empresa, nos hacemos en conjunto con la empresa las siguientes preguntas para establecer nuestra visión, misión y objetivos organizacionales:

- ¿Cuál es nuestra razón de ser? ¿Qué nos da vida y sentido como empresa?

Evaluamos en conjunto con la empresa éstas preguntas y como respuesta tuvimos que la razón principal de la empresa es de ofrecer los mejores productos de pastelería al mercado para satisfacer la necesidad del cliente. De aquí obtenemos nuestra misión de la empresa.

\section{- ¿Hacia dónde deseamos ir o llegar a ser?}

Hecha esta pregunta internamente, llegamos a la conclusión que la empresa quiere ser líder no sólo en el Perú, si no también fuera de él, en la producción e innovación de cupcakes y productos de pastelería. He aquí nuestra visión de negocio. 
- ¿Qué hacemos bien y/o qué deseamos hacer para llegar a hacer realidad esa visión?

De esta pregunta que hacemos en conjunto con la empresa, determinamos cuáles son los objetivos estratégicos que la empresa deberá tener en cuenta e ir cumpliendo para que, de ese modo, se logre alcanzar la visión estratégica planteada.

Finalmente, como respuesta a las preguntas planteadas y teniendo en claro la situación actual de la empresa y hacia dónde desea caminar, establecemos la misión, la visión y los objetivos de la Organización: 


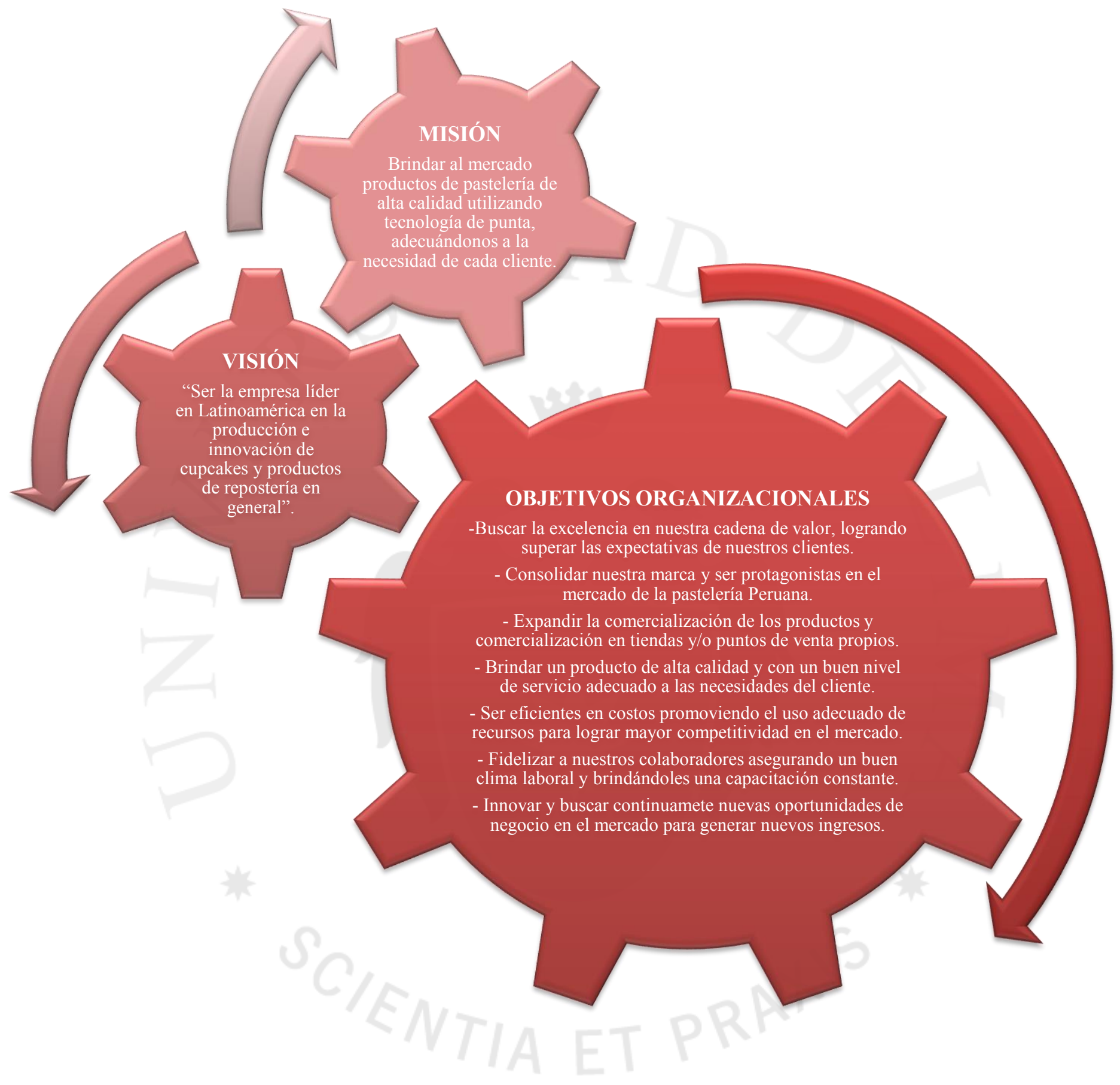

Figura 8. 5: Propuesta de Misión, Visión y Objetivos Estratégicos para Claudia Cupcakes.

Fuente: Elaboración propia. 
Una vez establecido el Plan Estratégico, continúa la etapa de difusión en toda la empresa a fin de que lo propuesto no quede sólo en eso, si no que se transmita a cada uno de los colaboradores y, de ese modo, se logre su compromiso con cada uno de los objetivos trazados. Para ello, elaboramos un plan de difusión mediante:

- Presentación formal de la misión, visión y objetivos por parte de la Gerencia.

- Afiches colocados en el taller que sean recordatorios para los colaboradores.

- Seguimiento y medición: Hay un dicho que reza: "No se puede mejorar o gestionar lo que no se puede medir". Siendo así, se establece un plan de seguimiento y/o medición de cada uno de los indicadores establecidos para alcanzar los objetivos trazados y la misión y visión propuesta. Esto nos permitirá obtener información fiable del estado de avance de nuestro Plan propuesto, así como poder determinar qué nuevos objetivos trazar ante nuevos escenarios.

De cara a la propuesta que planteamos a la empresa, establecemos el siguiente seguimiento anual: 
Tabla 8. 8: Implementación y seguimiento al Plan Estratégico.

\begin{tabular}{|l|l|l|l|l|l|l|l|l|l|l|l|l|}
\hline \multirow{2}{*}{ Actividad } & \multicolumn{9}{c|}{2015} & \multicolumn{7}{c|}{2016} & Jul \\
\hline & Sep & Oct & Nov & Dic & Ene & Feb & Mar & Abr & May & Jun & Jul & Ago \\
\hline Establecer Plan Estratégico & & & & & & & & & & & & \\
\hline Difusión del Plan en la empresa & & & & & & & & & & & & \\
\hline Primera medición de Indicadores & & & & & & & & & & & & \\
\hline $1^{\circ}$ Revisión de avance en objetivos & & & & & & & & & & & & \\
\hline $2^{\circ}$ Revisión de avance en objetivos & & & & & & & & & & & & \\
\hline $3^{\circ}$ Revisión de avance en objetivos & & & & & & & & & & & & \\
\hline $4^{\circ}$ Revisión de avance en objetivos & & & & & & & & & & & & \\
\hline $5^{\circ}$ Revisión de avance en objetivos & & & & & & & & & & & & \\
\hline
\end{tabular}

\section{- Beneficios}

Al establecer un Plan Estratégico adecuado a la empresa, obtendremos éstos beneficios:

- Incrementaremos la participación de mercado.

- Conoceremos de mejor manera la realidad de la organización.

- Pensaremos al largo plazo y establecer metas y objetivos al corto y mediano plazo.

- Mejoraremos el manejo de los recursos de la empresa.

- Implementaremos mejoras continuas en los procesos involucrados en las metas y objetivos.

- Pensaremos de manera sistemática para la planificación de los procesos. 
- Inversión

Si es que se optara por los servicios de un profesional especializado en temas de Planeamiento Estratégico o una empresa consultora en el tema, se estima una inversión aproximada de S/.25,000.00.

\section{b. Re - disposición de planta}

Al realizar una re disposición del taller se busca aumentar la productividad, minimizando los recursos. Lo que planteamos es reducir el tiempo estándar del procesamiento de un lote de producción.

\section{- Desarrollo}

- Realizamos un análisis de Guerchet

Con este análisis verificamos si el tamaño de las áreas con las que cuenta el taller actualmente, son las correctas. Este análisis ya fue realizado en el Capítulo IV: 4.1.2., con lo que obtenemos el siguiente cuadro resumen: 
Tabla 8. 9: Escenarios propuestos para la nueva distribución de planta.

\begin{tabular}{|l|c|c|c|}
\hline \multicolumn{1}{|c|}{ ESCENARIOS PARA EL ÁREA DE PLANTA } \\
\hline Área & Área actual (m2) & $\begin{array}{c}\text { Área requerida } \\
(\mathrm{m} 2)\end{array}$ & $\begin{array}{c}\text { Área propuesta } \\
(\mathrm{m} 2)\end{array}$ \\
\hline ÁREA DE BATIDO Y HORNEADO & 17.33 & 28.25 & 25.61 \\
\hline ÁREA DE DISEÑO Y DECORACIÓN & 19.19 & 23.22 & 19.19 \\
\hline ÁREA DE FORRADO Y EMPAQUE & 30.33 & 27.66 & 30.33 \\
\hline ÁREA DE OFICINA ADMINISTRATIVA & 10.99 & 18.93 & 19.51 \\
\hline ÁREA DE ALMACÉN DE MP & 1.86 & 14.67 & 10.99 \\
\hline ÁREA DE ALMACÉN DE INSUMOS & 14.15 & 16.41 & 14.15 \\
\hline VESTIDOR & 2.77 & 2.77 & 2.77 \\
\hline ÁREA DE BAÑO OPERARIOS & 4.63 & 4.63 & 4.63 \\
\hline ÁREA DE BAÑO ADMINISTRACIÓN & 0.00 & 0.00 & 3.41 \\
\hline ÁREA DE PATIO & 6.27 & 6.27 & 6.27 \\
\hline \hline \multicolumn{1}{|c|}{ ÁREA TOTAL } & $\mathbf{1 0 7 . 5 2}$ & $\mathbf{1 4 2 . 8 2}$ & $\mathbf{1 3 6 . 8 5}$ \\
\hline
\end{tabular}

Con este resultado confirmamos que el espacio actual es muy limitado, existiendo una brecha aproximada de $35 \mathrm{~m} 2$. En la actualidad sólo se cuenta con un $75 \%$ del área total requerida.

El área propuesta se ha incrementado en un $20 \%$ más a lo que existía en la actualidad. Esto debido a que se alquiló un espacio contiguo de aproximadamente $25 \mathrm{~m} 2$, llegando al 90\% del área total requerida, esto con el fin de realizar una mejora a corto plazo.

En cuanto al reajuste del espacio de las áreas, el estudio se ha complementado con las relaciones que tienen las áreas entre sí, reubicando algunos de acuerdo a la proximidad necesaria y al espacio requerido. 
- Diagramamos el proceso

Para asegurarnos que el flujo del proceso sea el correcto, primero trazaremos el diagrama de análisis de procesos, mediante el cual sabremos el tiempo estándar consumido por cada lote producido. Previo a este paso, se realizará el diagrama de operaciones del proceso y la toma de tiempos de las actividades.

Tanto el diagrama de operaciones del proceso (DOP) como el diagrama de análisis de procesos (DAP), fueron realizados en el Capítulo IV 4.2.3.

Como conclusión obtenemos que para la producción de un lote de 270 cupcakes tenemos un tiempo estándar de 317.67 minutos.

- Realizamos el Diagrama Relacional

Para definir la ubicación de las áreas en el taller, utilizaremos el diagrama relacional de actividades. Luego trazaremos el flujo de las operaciones en un mapa del taller.

A continuación, el desarrollo del diagrama: 


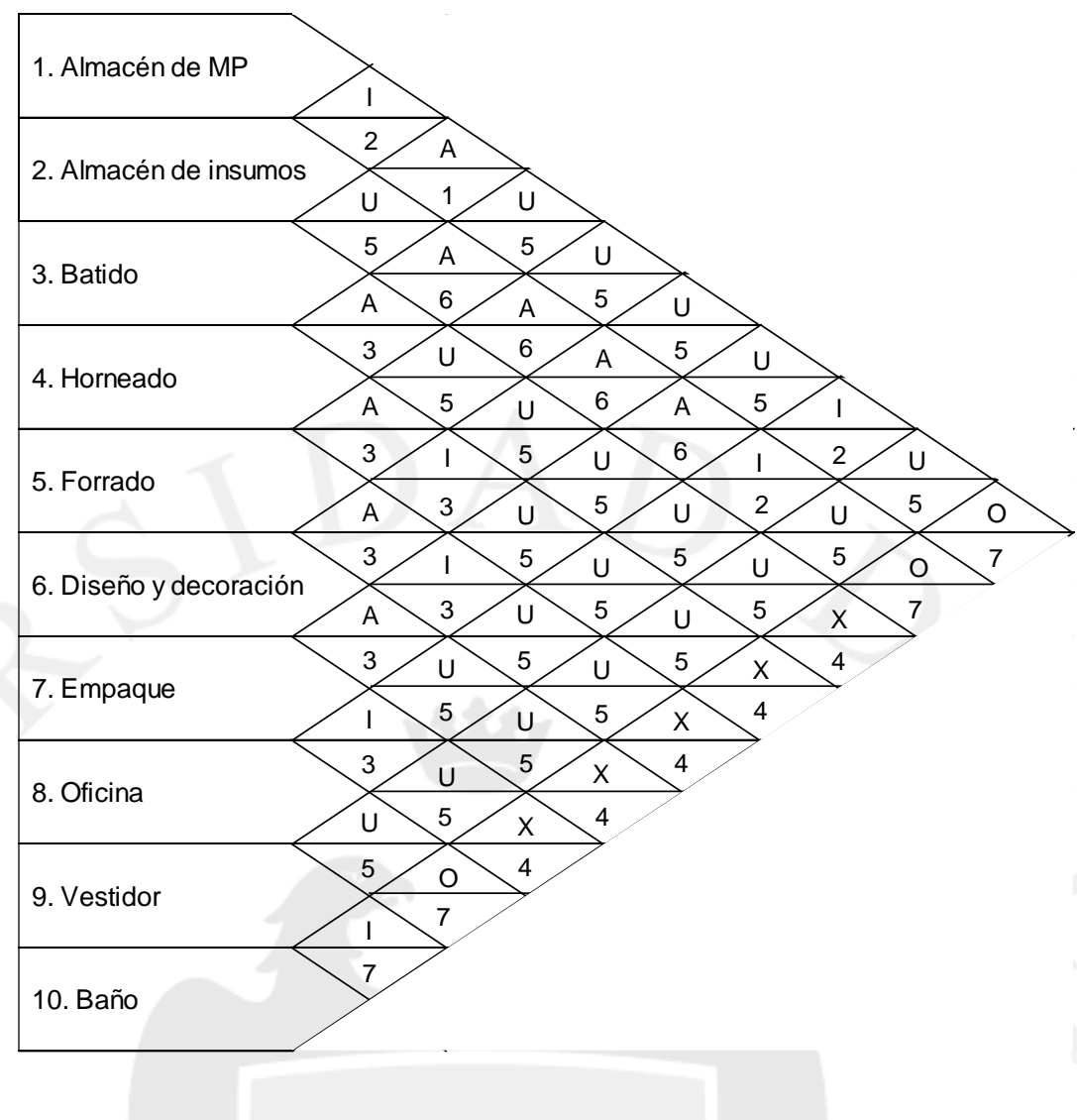

\begin{tabular}{|c|l|}
\hline CÓDIGO & \multicolumn{1}{c|}{ MOTIVOS } \\
\hline 1 & No se desea el manipuleo ni la contaminación de la materia prima. \\
\hline 2 & Para facilitar el control e inventario en el almacén. \\
\hline 3 & Por el seguimiento del proceso. \\
\hline 4 & Por el olor y posible contaminación. \\
\hline 5 & Por no ser necesario. \\
\hline 6 & Para facilitar la cercanía de los insumos necesarios. \\
\hline 7 & Por mantener orden. \\
\hline
\end{tabular}

Figura 8. 6: Análisis relacional para la distribución de planta

Fuente: Elaboración propia 
Tomando como base la tabla relacional, tenemos los siguientes valores de proximidad:

Tabla 8. 10: Valores de proximidad para el análisis relacional de planta.

\begin{tabular}{r|l|} 
A: & $(3,4)(4,5)(5,6)(6,7)(1,3)(2,4)(2,5)(2,6)(2,7)$ \\
\hline I: & $(1,2)(7,8)(9,10)(4,6)(5,7)(2,8)(1,8)$ \\
\hline O: & $(2,10)(1,10)(8,10)$ \\
\hline X: & $(7,10)(6,10)(5,10)(4,10)(3,10)$ \\
\hline
\end{tabular}

El diagrama relacional para la nueva disposición de planta quedaría como a continuación se muestra:

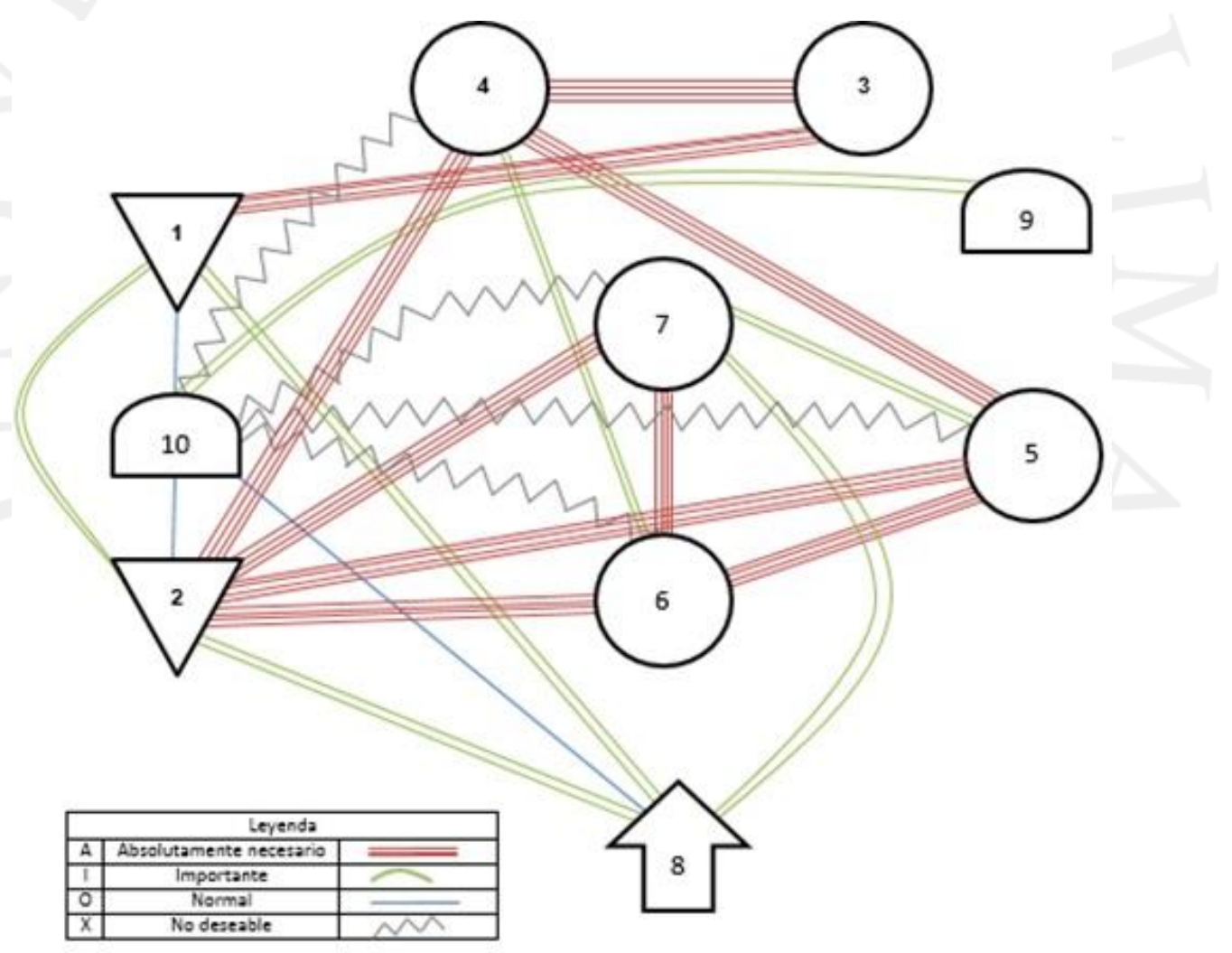

Figura 8. 7: Diagrama relacional para la distribución de planta propuesta.

Fuente: Elaboración propia 
De acuerdo a lo obtenido, la nueva disposición de planta quedaría como a continuación se muestra:

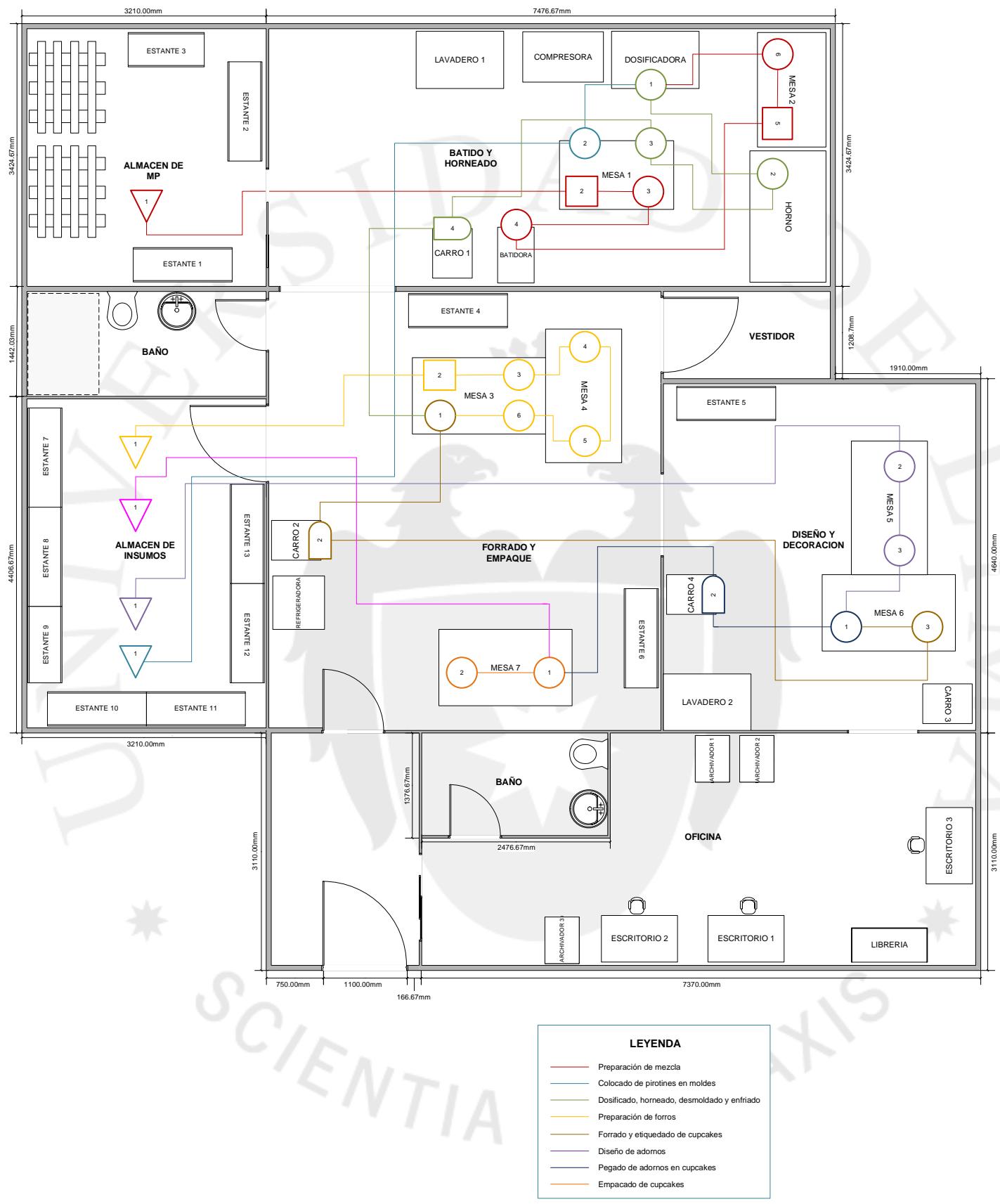

Figura 8. 8: Nueva distribución de planta propuesta.

Fuente: Elaboración propia. 
- Verificamos el nuevo tiempo estándar

Con la nueva disposición de planta se realizará una nueva toma de tiempos para verificar el tiempo estándar con el nuevo flujo. Así, con la nueva disposición propuesta, el tiempo estándar del proceso de reducirá en un $10 \%$.

Finalmente, el beneficio que encontramos para esta propuesta lo plasmamos como una mejora en la productividad, lo cual detallamos a continuación:

\section{- Mejora en la productividad}

Con la nueva disposición de planta se realizará una nueva toma de tiempos para verificar el tiempo estándar para un lote con el nuevo flujo de recorrido. Así, con la nueva disposición propuesta, la productividad por operario incrementará aproximadamente en un $10 \%$, tal como lo detallamos:

Tabla 8. 11: Beneficios de implementar la nueva distribución de planta.

\begin{tabular}{|c|c|c|c|c|}
\cline { 2 - 5 } & Tiempo (min) & $\begin{array}{c}\text { Distancia } \\
\text { recorrida } \\
(\mathbf{m})\end{array}$ & $\begin{array}{c}\text { Producción } \\
\text { (cupcakes/año) }\end{array}$ & $\begin{array}{c}\text { Productividad } \\
\text { operario } \\
\text { (cupcakes/día) }\end{array}$ \\
\hline Actual & 317.67 & 66.87 & 202,415 & 71 \\
\hline Con mejora & 288.52 & 60.73 & 222,880 & 79 \\
\hline
\end{tabular}


Con la nueva productividad por operario se podrá cubrir una gran parte de la demanda insatisfecha que actualmente es del $14 \%$ de la producción anual. Dicho esto, se tendrá un mayor ingreso tal como se detalla a continuación:

Tabla 8. 12: Beneficio económico de la nueva propuesta de distribución de planta.

\begin{tabular}{|c|c|}
\cline { 2 - 2 } \multicolumn{1}{c|}{} & $\begin{array}{c}\text { Ingreso anual } \\
(\mathrm{S} / \text {.) }\end{array}$ \\
\hline Actual & 1 '`410,671.11 \\
\hline Con mejora & $1{ }^{\prime} 553,294.54$ \\
\hline Beneficio & $\mathbf{1 4 2 , 6 2 3 . 4 3}$ \\
\hline
\end{tabular}

Asimismo, este incremento de productividad permitirá tener la capacidad suficiente para poder buscar nuevos productos para ingresar al mercado, los cuales se convertirán en una nueva fuente de ingresos.

El presupuesto para la adecuación de ambientes y el re disposición de la planta se muestra en el siguiente cuadro: 
Tabla 8. 13: Inversión económica de la nueva propuesta de distribución de planta.

\begin{tabular}{|l|c|r|r|}
\cline { 2 - 4 } \multicolumn{1}{c|}{} & $\begin{array}{c}\text { Cantidad } \\
\text { (und.) }\end{array}$ & $\begin{array}{c}\text { Costo } \\
\text { unitario (S/.) }\end{array}$ & $\begin{array}{c}\text { Costo total anual } \\
\text { (S/.) }\end{array}$ \\
\hline Desplazamiento de maquinaria & 2 & 150.00 & 300.00 \\
\hline Alquiler de espacio adicional & 1 & $1,300.00$ & $1,300.00$ \\
\hline Unificación de ambientes & 1 & 569.00 & 569.00 \\
\hline Acarreo y eliminación de desmonte & 1 & 150.00 & 150.00 \\
\hline Pallets & 2 & 30.00 & 60.00 \\
\hline Mesa de trabajo & 1 & $1,670.00$ & $1,670.00$ \\
\hline Estantes/anaqueles & 2 & 250.00 & 500.00 \\
\hline Adecuación de sistema eléctrico & 1 & 300.00 & 300.00 \\
\hline Nuevo baño & 1 & $7,500.00$ & $7,500.00$ \\
\hline \multicolumn{2}{|c|}{ INVERSIÓN TOTAL } & $\mathbf{1 2 , 3 4 9 . 0 0}$ \\
\hline
\end{tabular}

Adicionalmente, como parte del ordenamiento del taller, implementamos como propuesta de mejora, la elaboración y descripción de las máquinas mediante las fichas de máquinas correspondientes, las cuales mostramos en los anexos de este trabajo.

Para complementar la re disposición de planta, consideramos necesario implementar la metodología de las $5 \mathrm{~S}$ para asegurar que los tiempos logrados con las mejoras propuestas se mantengan en el tiempo. 


\section{c. Aplicación de la metodología 5's}

Aplicaremos esta metodología japonesa en la empresa a fin de poder ordenar y estandarizar los procesos a fin de tener una mejor eficiencia en su desarrollo; asimismo, para complementar la re disposición de planta, consideramos necesario implementarla para asegurar que los tiempos logrados con las mejoras propuestas se mantengan en el tiempo. A continuación, mostraremos el desarrollo de ésta propuesta en la empresa:

\section{- Capacitación del personal}

Consideramos de suma importancia que en esta etapa de la implementación se programen capacitaciones al personal a fin de brindarles los conocimientos y técnicas necesarias para el buen funcionamiento de un programa $5 \mathrm{~S}$ en la empresa. Se tocara la importancia de cada fase de implementación y los protocolos establecidos para cada una.

Una vez capacitado el personal en la parte teórica de esta metodología, iniciamos con el despliegue de cada una de las " $\mathrm{S}$ ": 


\section{- Seiri (Clasificar)}

Se seleccionará todo lo que no es necesario y ocupa espacio y se eliminará del área de trabajo todos los elementos innecesarios para la tarea que se realiza, de forma que se pueda controlar el flujo de las cosas evitando estorbos y despilfarros. Dentro de esta etapa usaremos el sistema de la Tarjeta Roja, el cual consiste en colocar tarjetas rojas en los objetos innecesarios o de poco uso con el propósito de deshacerse de ellos posteriormente. Para ellos se implementa una "Zona Roja”, la cual será ubicada en un estante/anaquel del almacén de insumos. Dichos objetos serán almacenados durante un tiempo para comprobar si efectivamente no se van a utilizar. En el cuadro adjunto, podemos observar el criterio de trabajo que se aplicara en la clasificación de objetos.

Se implementara el siguiente formato para la clasificación de objetos: 


\begin{tabular}{|l|c|l|l|}
\hline \multicolumn{3}{|c|}{ TARJETA ROJA } \\
\hline Categoría: & \multicolumn{2}{|l|}{ Nombre del artículo: } \\
\hline Fecha: & Localización: \\
\hline Cantidad: & Valor (S/.): \\
\hline \multirow{3}{*}{ Razones } & No se necesitan & Uso desconocido & Contaminante \\
\cline { 2 - 4 } & No se necesitan pronto & Excedente & Otro: \\
\cline { 2 - 4 } & Material de desperdicio & Obsoleto & \\
\hline \multirow{3}{*}{$\begin{array}{c}\text { Método de } \\
\text { eliminación }\end{array}$} & Tirar & \multicolumn{2}{|c|}{ Desecho completo } \\
\cline { 2 - 4 } & Vender & Autoridad & \\
\cline { 2 - 4 } & Otros & Firma & \\
\hline
\end{tabular}

Figura 8. 9: Propuesta de formato para la clasificación de objetos.

Fuente: Elaboración propia.

Como se observó en la figura anterior, el formato de las tarjetas rojas cuenta con la siguiente información:

Categoría: Describe el tipo de artículo en el que está colocada la tarjeta. En este caso el trabajador va a llenar la categoría del artículo, si es insumo, si es chatarra, equipo de oficina, instrumentos de medición, etc.

$>$ Nombre del artículo: Identifica el artículo que está siendo clasificado.

Fecha: Cuando se realizó la clasificación del artículo.

Localización: El lugar donde se encuentra ubicado el artículo dentro del área de almacén, para poder ser encontrado fácilmente. 
$>$ Cantidad: Cuando se trata de varios artículos de un mismo tipo, para evitar el exceso de tarjetas en una zona.

$>$ Razones: Motivos por lo que se requiere eliminar este artículo. Por ejemplo:

- No se necesitan (ahora o pronto)

- Material de desperdicio

- Uso desconocido

- Excedente

- Obsoleto

- Contaminante

- Otro

$>\quad$ Modo de eliminación.- Tipo de acción que se tomará para poder eliminar el artículo. Entre los cuales se encuentran:

- Tirar

- Vender

- Otros

$>$ Desecho completo: Colocamos el nombre de la persona encargada y su firma.

Hemos realizado una posible evaluación y análisis de los objetos innecesarios o de poco uso en todas las áreas del taller, tomando en cuenta los criterios de la Tarjeta Roja. Como resultado se evidencio la presencia de recursos innecesarios 
como material de acarreo, utensilios, papelería, insumos, producto en proceso y equipos de oficina.

Los beneficios que obtendremos al aplicar "Seiri" en el taller serán:

$>$ Liberaremos espacio útil en planta y oficinas, espacio al que se puede brindar un mejor uso.

$>$ Mejoraremos la calidad del producto previniendo errores. Buena visualización.

$>$ Incrementaremos la productividad en trabajadores. Mejor facilidad y rapidez realizando el trabajo.

$>$ Eliminaremos pérdidas en materiales. Materiales expuestos a un ambiente no favorable.

\section{- Seiton (ordenar)}

Organizaremos todos los objetos clasificados como necesarios para que se puedan encontrar con facilidad y no perder tiempo. Dentro de este paso, tendremos las siguientes actividades:

Definiremos un lugar de ubicación para estos objetos, de acuerdo a límites marcados por áreas de trabajo, almacenaje y zonas de paso. Los elementos utilizados deben colocarse lo más cercano del lugar donde se usan. 
$>$ Eliminaremos la suciedad, polvo, etc. Se colocaran los objetos en sobres, cajas de plástico, cajas de cartón, bolsas, etc. para mantener un mejor orden.

$>$ Los estantes/anaqueles, mesas de trabajo, muebles de oficina y maquinaria/equipo tendrán lugares específicos. Lo limitaremos con marcas en el suelo definiendo su ubicación en el taller.

$>$ Etiquetaremos y asignaremos números en cada categoría de objeto colocado en los almacenes de MP e insumos, para la fácil localización de los mismos.

Los beneficios que obtendremos al usar "Seiton" en el taller serán:

Eliminaremos movimientos innecesarios, mayor productividad.

$>$ Mejoraremos visualización de objetos.

$>$ Lograremos un ambiente de trabajo más seguro y con menor riesgo de accidentes.

$>$ Eliminaremos perdidas en materiales. Materiales expuestos a un ambiente no favorable. 


\section{- $\quad$ Seiso (limpiar)}

Impulsaremos la limpieza en el entorno de trabajo, incluidas máquinas y herramientas, pisos, paredes, etc. Para poder inspeccionar el funcionamiento de máquinas, detectar $\mathrm{y}$ corregir posibles fallas. Asimismo, ayudara a mantener un ambiente salubre.

Para esto implementaremos un programa de limpieza, el cual consistirá en realizar labores de limpieza por 9 horas diarias. Se organizaran los tiempos de limpieza por áreas, diferenciando las productivas de las administrativas, a fin de no interrumpir las labores diarias. El trabajo de limpieza iniciará a las 7 a.m. y concluirá a las 4 p.m., considerando una hora de refrigerio.

Las oficinas administrativas y las máquinas principales tales como el horno, batidora, dosificadora se limpiarán antes de que se inicien las labores.

Al finalizar las labores de limpieza de áreas y pasillos, se realizará una inspección visual a fin de asegurar que no existan condiciones sub estándares en las instalaciones que puedan generar algún incidentes o accidente. El personal de limpieza será capacitado para que pueda evidenciar estas situaciones.

Los beneficios que obtendremos de usar "Seiso" en el taller serán los siguientes: 
Mejoraremos el bienestar físico y emocional del trabajador.

Mejoraremos la calidad, evitando productos contaminados.

$>$ Incrementaremos la vida útil de maquinarias/equipos.

$>$ Detectaremos las averías con mayor facilidad.

\section{- Seiketsu (estandarizar)}

Para poder mantener los logros de las 3 primeras 5's, estandarizaremos lo realizado hasta este momento fijando lugares donde deben estar las cosas, así como el lugar en donde deben de desarrollarse las actividades y la limpieza. Esto se observará mediante documentos, fotografías o dibujos que ayuden a seguir lo estipulado.

Para la implementación de esta metodología de mejora, no es necesaria la utilización de muchos recursos, principalmente económicos, ya que es una opción en la que lo más importante para su realización es la planificación adecuada de los tiempos en que se usará al personal para poder hacer todo el proceso de clasificación, orden y limpieza, ya que es lo que demanda hacer en el corto plazo o en el "momento", y la parte de normalización y disciplina se mantendrá en el tiempo. 
En esta etapa de la metodología, se usará una técnica con la que los trabajadores, así como la gerencia, se encuentren concientizados con fomentar una cultura de orden y limpieza. Para esto se propone el establecimiento de una política, la cual mostramos a continuación:

\section{POLITÍCA DEL PROGRAMA 5's}

Con el fin de mantener los lugares de trabajo limpios y ordenados y así conseguir un mejor aprovechamiento del espacio, una mejora en la efectividad, seguridad del trabajo y, en general, un entorno más seguro y agradable, Claudia Cupcakes se comprometerá con las siguientes normas de clasificación, orden y limpieza a todas las unidades de la organización.

1. Es tarea de todos mantener el ambiente de trabajo excelentemente limpio y ordenado de acuerdo a la metodología de 5's. Las tareas relacionadas con organización, orden y limpieza deben ser integradas como parte de las actividades regulares y no como actividades extraordinarias.

2. Todos somos responsables por mantener la metodología 5's, siendo el coordinador de producción quien fungirá de garante, para lo cual estará permanentemente vigilante y compartiendo con todos los colaboradores a fin de conseguir el éxito en el proceso.

3. Se debe entrenar al personal nuevo en la metodología 5's a través de la charla de inducción. Es decir, se fusiona la inducción a trabajadores nuevos con la metodología implementada.

4. Teniendo en cuenta uno de los principios de la prevención, como es de evitar los riesgos desde el origen, deben descubrirse las causas que originan la desorganización, desorden y suciedad con el fin de adoptar las medidas necesarias para su eliminación de raíz.

5. Es obligación de cada trabajador, dejar y entregar su lugar de trabajo limpio y ordenado antes de finalizar el turno.

6. Los colaboradores deberán tener en su puesto de trabajo solo los implementos necesarios y mantenerlos ordenados y limpios. Asimismo, mantendrán los utensilios ordenados y en perfecto estado de conservación.

7. Los suelos deberán estar en excelentes condiciones y limpios de grasas y otro materiales deslizantes con el fin de evitar riesgos de caída a igual nivel y choque contra objetos móviles e inmóviles.

8. Los recipientes para el contenido de desperdicios y útiles con riesgo biológico deberán encontrarse señalizados y se procederá a la gestión de los residuos de la forma más segura.

\section{GERENCIA GENERAL}

Figura 8. 10: Propuesta de Política del programa 5S.

Fuente: Elaboración propia. 


\section{- Shitsuke (mantener disciplina)}

Al culminar con toda la implementación de las 5's, se requiere conservar todas las técnicas en óptimas condiciones, esto quiere decir que no se regrese al estado en que se encontraba antes el área. Para alcanzar este nivel de mejora continua, revisaremos de manera frecuente los protocolos para cada técnica implementada para así lograr la disciplina entre los operarios.

Estas verificaciones de la implementación deben realizarse en reuniones periódicas con la participación activa del gerente. Se realizaran inspecciones y controles visuales que forman parte de las revisiones periódicas para no permitir que ningún tipo de anomalía afecte al funcionamiento de las 5's.

Además se nombrará a un supervisor líder para la implantación en toda la planta.

La frecuencia y responsables de las actividades descritas se detallan en el siguiente cuadro:

Tabla 8. 14: Frecuencia de actividades de seguimiento a la implementación de 5S.

\begin{tabular}{|c|c|c|}
\hline Actividad & Frecuencia & Responsable \\
\hline Revisión de protocolos & Semestral & Jefe de producción \\
\hline Inspección visual & Semanal & Supervisor $5 \mathrm{~s}$ \\
\hline Reunión & Mensual & $\begin{array}{l}\text { Jefe de producción / Supervisor 5s } \\
\text { / Gerente general }\end{array}$ \\
\hline Capacitación $(*)$ & Trimestral & Gerente general \\
\hline Auditoria & Semestral & Supervisor $5 \mathrm{~s}$ \\
\hline
\end{tabular}




\section{d. Elaboración de un Plan HACCP}

La implementación de un sistema HACCP como punto de inicio para la implementación de un Sistema de gestión de la Calidad e inocuidad alimentaria es un aspecto clave que la empresa debe tomar en consideración en su búsqueda de crecimiento en el mercado. Así pues, considerando que el objetivo principal de la empresa es evitar las devoluciones y pérdidas por producto en mal estado, para poder asegurar la calidad de los alimentos, es necesario cumplir con los siguientes requisitos de inocuidad alimentaria:

- Ausencia de contaminantes

- Ausencia de adulterantes

- Ausencia de toxinas

- Otras sustancias que puedan hacer nocivo el alimento para la salud A continuación los pasos para aplicar el plan HACCP:

- Descripción del producto y del proceso, descrito en el punto 4.3.1 del Capítulo IV. 
- Luego, identificamos los agentes de riesgos y determinar los puntos críticos de control (PCC), según se muestra a continuación:

\begin{tabular}{|c|c|c|c|c|c|}
\hline \multicolumn{6}{|c|}{ PUNTOS CRÍTICOS DE CONTROL DEL PROCESO } \\
\hline $\begin{array}{l}\text { Etapa de proceso } \\
\text { (1) }\end{array}$ & $\begin{array}{l}\text { Peligros } \\
\text { (2) }\end{array}$ & $\begin{array}{l}\text { ¿El peligro es } \\
\text { significativo? } \\
\text { (3) }\end{array}$ & $\begin{array}{l}\text { Justifique decisión } \\
\text { (4) }\end{array}$ & $\begin{array}{c}\text { ¿Qué medidas } \\
\text { preventivas pueden ser } \\
\text { aplicadas? } \\
\text { (5) }\end{array}$ & $\begin{array}{c}\text { Es un PPC? (SI/NO) } \\
(6)\end{array}$ \\
\hline $\begin{array}{l}\text { RECEPCIÓN DE MP E } \\
\text { INSUMOS (pre mezcla, } \\
\text { huevos, chispas de } \\
\text { chocolate, etc.) }\end{array}$ & $\begin{array}{l}\begin{array}{l}\text { Biológico } \\
\text { bacterias Presencia de } \\
\text { patógenas }\end{array} \\
\text { (salmonelas) } \\
\text { provenientes del huevo. } \\
\text { Físico Residuos propios } \\
\text { del área o ambiente. } \\
\text { Físico químico } \\
\begin{array}{l}\text { Composición y uso de } \\
\text { los envases. }\end{array}\end{array}$ & SI & $\begin{array}{l}\text { Infección a los } \\
\text { consumidores. } \\
\text { Falta de higiene en el } \\
\text { área de batido y } \\
\text { horneado. } \\
\text { MP expuesta. } \\
\text { Reacciones alérgicas o } \\
\text { posible intoxicación en } \\
\text { usuarios consumidores. }\end{array}$ & \begin{tabular}{|lr} 
Selección & de \\
proveedores y & análisis \\
microbiológico. & \\
Mayor frecuencia de \\
limpieza y orden. \\
Análisis fisico químico \\
de los envases. \\
Asegurarse que los \\
envases & \multicolumn{2}{c}{ usados } \\
únicamente & para \\
contener alimentos.
\end{tabular} & SI \\
\hline BATIDO & $\begin{array}{l}\text { Biológico } \\
\text { Contaminación cruzada } \\
\text { por presencia de } \\
\text { bacterias patógenas. } \\
\text { Físico Residuos propios } \\
\text { de la MP a usar. }\end{array}$ & $\mathrm{NO}$ & $\begin{array}{l}\text { Falta de higiene en la } \\
\text { batidora, mesa de } \\
\text { trabajo, utensilios u } \\
\text { operario. } \\
\text { Distracción del operario } \\
\text { y la no aplicación de las } \\
\text { BPM. }\end{array}$ & $\begin{array}{l}\text { POES (Procedimientos } \\
\text { operacionales de } \\
\text { sanitación } \\
\text { estandarizados). } \\
\begin{array}{l}\text { Capacitación en BPM y } \\
\text { control al operario. }\end{array} \\
\end{array}$ & NO \\
\hline DOSIFICADO & \begin{tabular}{ll}
\multicolumn{3}{l}{ Biológico } \\
Contaminación cruzada \\
por presencia $\quad$ de \\
bacterias patógenas $\mathrm{u}$ \\
otras mezclas en \\
proceso.
\end{tabular} & NO & $\begin{array}{l}\text { Falta de higiene en } \\
\text { moldes, manguera de } \\
\text { dosificado o mesa de } \\
\text { trabajo. } \\
\text { Distracción del operario. } \\
\text { Preparación de varias } \\
\text { mezclas a la vez. }\end{array}$ & $\begin{array}{l}\text { POES y BPM. } \\
\text { Preparar una mezcla a la } \\
\text { vez. } \\
\text { Concentración. }\end{array}$ & NO \\
\hline
\end{tabular}




\section{PUNTOS CRÍTICOS DE CONTROL DEL PROCESO}

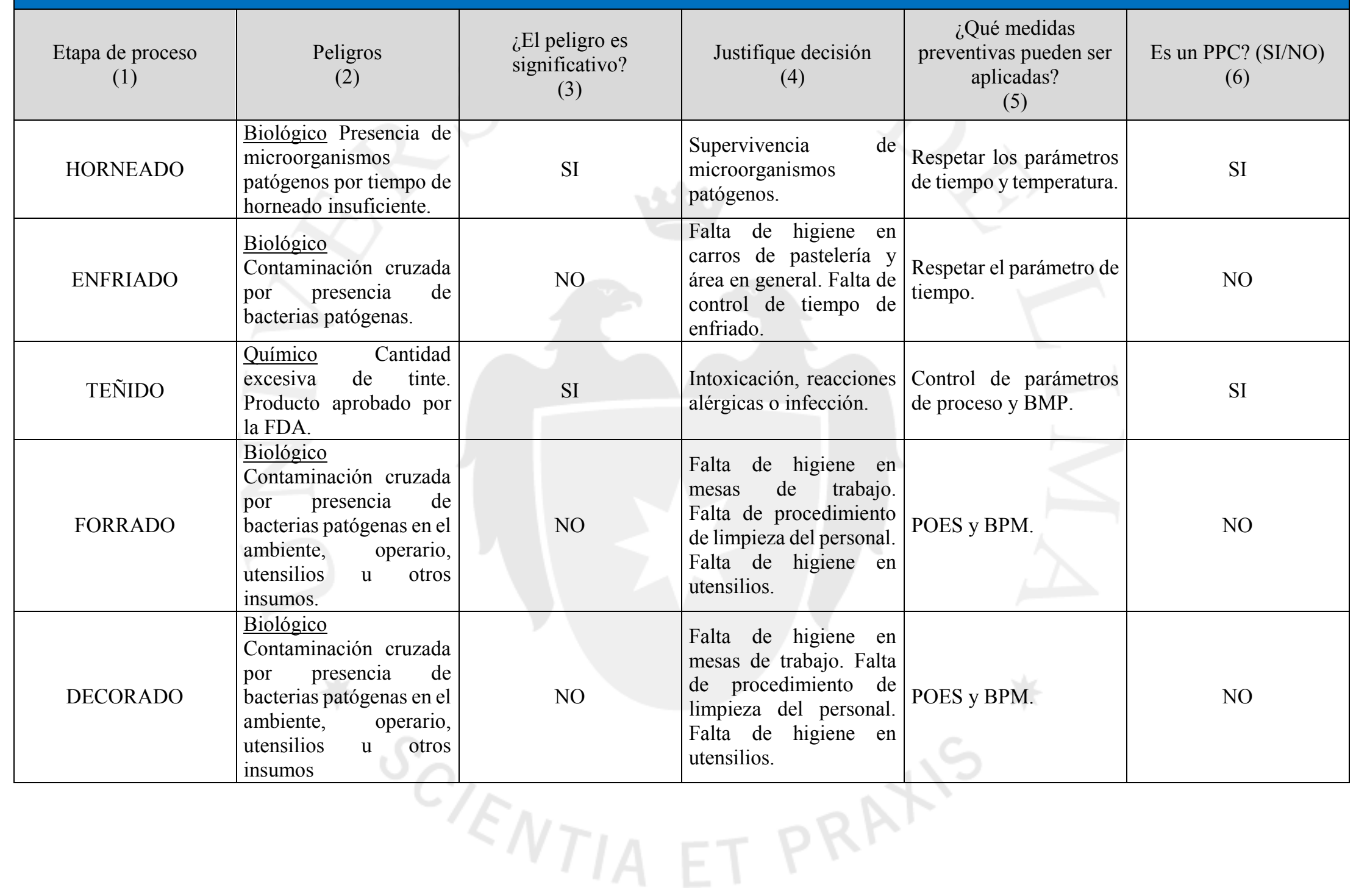




\section{PUNTOS CRÍTICOS DE CONTROL DEL PROCESO}

\begin{tabular}{|c|c|c|c|c|c|}
\hline $\begin{array}{c}\text { Etapa de proceso } \\
\text { (1) }\end{array}$ & $\begin{array}{l}\text { Peligros } \\
\text { (2) }\end{array}$ & $\begin{array}{c}\text { ¿El peligro es } \\
\text { significativo? } \\
\text { (3) }\end{array}$ & $\begin{array}{l}\text { Justifique decisión } \\
\text { (4) }\end{array}$ & $\begin{array}{c}\text { ¿Qué medidas } \\
\text { preventivas pueden ser } \\
\text { aplicadas? } \\
\text { (5) }\end{array}$ & $\begin{array}{c}\text { Es un PPC? (SI/NO) } \\
(6)\end{array}$ \\
\hline ENVASADO & $\begin{array}{l}\text { Biológico } \\
\text { Contaminación cruzada } \\
\text { por presencia de } \\
\text { bacterias patógenas en el } \\
\text { ambiente y operario. } \\
\text { Físico químico } \\
\text { Composición y uso de } \\
\text { los envases. }\end{array}$ & NO & $\begin{array}{l}\text { Falta de higiene en } \\
\text { mesas de trabajo. } \\
\text { Falta de procedimiento } \\
\text { de limpieza del personal. } \\
\text { Reacciones alérgicas o } \\
\text { posible intoxicación en } \\
\text { usuarios consumidores. }\end{array}$ & $\begin{array}{lrr}\text { POES y } & \text { BPM. } \\
\text { Análisis físico } & \text { químico } \\
\text { de los } & \text { envases. } \\
\text { Envases } & \text { usados } \\
\text { únicamente } & \text { para } \\
\text { contener alimentos. }\end{array}$ & NO \\
\hline
\end{tabular}

Tabla 8. 15: Análisis HACCP de la empresa Claudia Cupcakes.

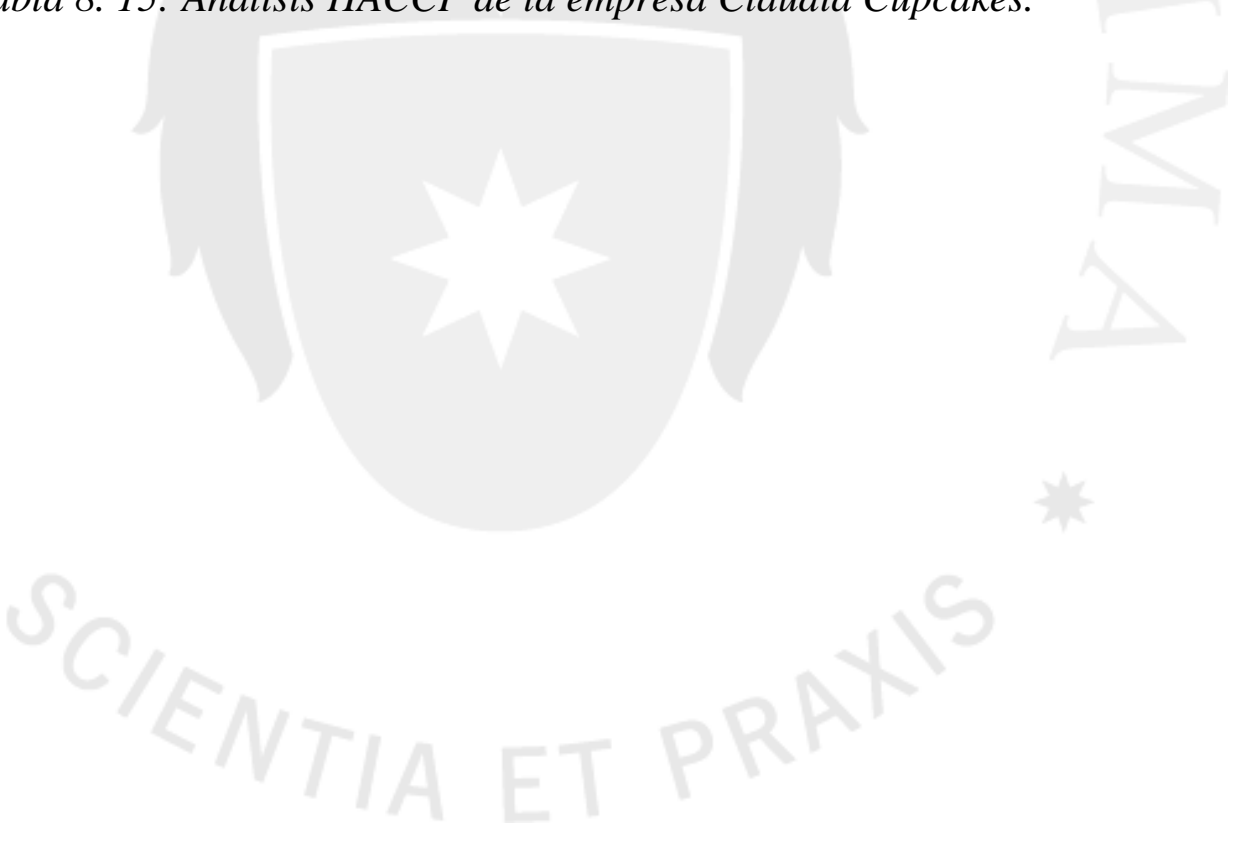


- Finalmente, determinamos los límites críticos de seguridad para los PCC, control de los PCC, proponer acciones correctivas, registrar los datos y verificar que el sistema esté funcionando.

\begin{tabular}{|c|c|c|c|c|c|c|c|c|c|}
\hline \multirow{2}{*}{$\begin{array}{l}\text { Puntos críticos } \\
\text { de control } \\
\text { (1) }\end{array}$} & \multirow{2}{*}{$\begin{array}{c}\text { Peligros } \\
\text { significativos } \\
\text { (2) }\end{array}$} & \multirow{2}{*}{$\begin{array}{c}\text { Límites para } \\
\text { cada medida } \\
\text { preventiva } \\
\text { (3) }\end{array}$} & \multicolumn{4}{|c|}{ Monitoreo } & \multirow{2}{*}{$\begin{array}{l}\text { Acciones } \\
\text { correctivas } \\
\quad(8)\end{array}$} & \multirow{2}{*}{$\begin{array}{l}\text { Registros } \\
\text { (9) }\end{array}$} & \multirow{2}{*}{$\begin{array}{l}\text { Verificación } \\
\quad(10)\end{array}$} \\
\hline & & & $\begin{array}{l}\text { Qué } \\
\text { (4) }\end{array}$ & $\begin{array}{l}\text { Cómo } \\
\text { (5) }\end{array}$ & $\begin{array}{l}\text { Frecuencia } \\
\text { (6) }\end{array}$ & $\begin{array}{l}\text { Quién } \\
\text { (7) }\end{array}$ & & & \\
\hline $\begin{array}{l}\text { RECEPCIÓN } \\
\text { DE MP E } \\
\text { INSUMOS (pre } \\
\text { mezcla, huevos, } \\
\text { chispas de } \\
\text { chocolate, etc.) }\end{array}$ & $\begin{array}{l}\text { Presencia r de } \\
\text { bacterias patógenas } \\
\text { (salmonelas) } \\
\text { provenientes del } \\
\text { huevo. Residuos } \\
\text { propios del área o } \\
\text { ambiente. } \\
\text { Composición y uso } \\
\text { de los envases. }\end{array}$ & $\begin{array}{l}\text { Criterio } \\
\text { selección } \\
\text { proveedores } \\
\text { limpieza. }\end{array}$ & \begin{tabular}{l|l} 
le & Parámetros \\
leiológicos. \\
y & Parámetros \\
físico \\
químicos.
\end{tabular} & \begin{tabular}{|lr} 
& \\
Solicitar & \\
certificado de \\
registro \\
sanitario del \\
proveedor de \\
MP e insumos. \\
Limpieza de \\
espacios.
\end{tabular} & \begin{tabular}{|l} 
En cada \\
recepción de \\
MP \\
insumos. \\
Limpieza \\
diaria.
\end{tabular} & $\begin{array}{l}\text { Asistente } \\
\text { administrativo }\end{array}$ & \begin{tabular}{|lr} 
Crear registros \\
de recepción de \\
MP e insumos. \\
Dedicar & 7 \\
minutos & de \\
limpieza. &
\end{tabular} & $\begin{array}{ll}\text { Registro } & \text { de } \\
\text { recepción } & \text { de } \\
\text { MP. } & \\
\text { Registro } & \text { de } \\
\text { limpieza } & \text { de } \\
\text { áreas. } & \end{array}$ & $\begin{array}{l}\text { Recuento } \\
\text { microbiológico } \\
\text { cada } 20 \text { días. }\end{array}$ \\
\hline HORNEADO & $\begin{array}{l}\text { Presencia de } \\
\text { microorganismos } \\
\text { patógenos por } \\
\text { tiempo de horneado } \\
\text { insuficiente. }\end{array}$ & $\begin{array}{l}\mathrm{T}: \quad 160 \\
\text { Tiempo: } \\
\text { minutos }\end{array}$ & $\begin{array}{l}\text { C } \\
0 \\
0\end{array}$ & $\begin{array}{l}\text { Mediciones con } \\
\text { termómetro y } \\
\text { refractómetro } \\
\text { de abbe. }\end{array}$ & Cada lote. & $\begin{array}{ll}\text { Supervisor } & \text { de } \\
\text { Calidad } & \\
\text { (Producción). } & \end{array}$ & 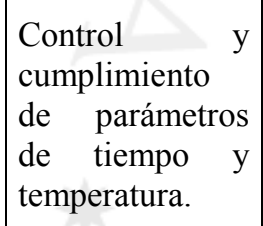 & $\begin{array}{lr}\text { Registros } & \text { de } \\
\text { tiempo } & \text { de } \\
\text { horneado } & y \\
\text { temperatura. }\end{array}$ & $\begin{array}{l}\text { Recuento } \\
\text { microbiológico } \\
\text { cada } 15 \text { días. }\end{array}$ \\
\hline
\end{tabular}




\section{LÍMITES DE CONTROL}

\begin{tabular}{|c|c|c|c|c|c|c|c|c|c|}
\hline \multirow{2}{*}{$\begin{array}{l}\text { Puntos críticos } \\
\text { de control } \\
\text { (1) }\end{array}$} & \multirow{2}{*}{$\begin{array}{c}\text { Peligros } \\
\text { significativos } \\
\text { (2) }\end{array}$} & \multirow{2}{*}{$\begin{array}{c}\text { Límites para } \\
\text { cada medida } \\
\text { preventiva } \\
\text { (3) }\end{array}$} & \multicolumn{4}{|c|}{ Monitoreo } & \multirow{2}{*}{$\begin{array}{c}\text { Acciones } \\
\text { correctivas } \\
(8)\end{array}$} & \multirow{2}{*}{$\begin{array}{l}\text { Registros } \\
\text { (9) }\end{array}$} & \multirow{2}{*}{$\begin{array}{l}\text { Verificación } \\
\quad(10)\end{array}$} \\
\hline & & & $\begin{array}{l}\text { Qué } \\
\text { (4) }\end{array}$ & $\begin{array}{l}\text { Cómo } \\
\text { (5) }\end{array}$ & $\begin{array}{c}\text { Frecuencia } \\
\text { (6) }\end{array}$ & $\begin{array}{l}\text { Quién } \\
\text { (7) }\end{array}$ & & & \\
\hline TEÑIDO & $\begin{array}{lr}\text { Cantidad } & \text { excesiva } \\
\text { de } & \text { tinte. } \\
\text { Producto } & \text { aprobado } \\
\text { por la FDA. }\end{array}$ & $\begin{array}{ll}\text { Criterio } & \text { de } \\
\text { selección } & \text { de } \\
\text { proveedores. } & \\
\text { Seguimiento del } & \text { del } \\
\text { procedimiento de } \\
\text { producción. }\end{array}$ & \begin{tabular}{|lr} 
& \\
Parámetros \\
físico & \\
químicos. & \\
Color & del \\
elemento & a \\
teñir & y \\
textura. & \\
\end{tabular} & \begin{tabular}{|ll} 
Certificado & del \\
proveedor & de \\
alimentos. & \\
Visual &
\end{tabular} & Cada lote. & $\begin{array}{l}\text { Supervisor de } \\
\text { Calidad } \\
\text { (Producción). } \\
\text { Asistente } \\
\text { administrativo. }\end{array}$ & $\begin{array}{ll}\text { Crear registros } \\
\text { de recepción de } \\
\text { insumos. } \\
\text { Control r de } \\
\text { parámetros } & \text { de } \\
\text { proceso y BMP. }\end{array}$ & $\begin{array}{ll}\text { Registro } & \text { de } \\
\text { recepción } & \text { de } \\
\text { insumos. } & \end{array}$ & $\begin{array}{l}\text { Recuento } \\
\text { microbiológico } \\
\text { cada } 15 \text { días. }\end{array}$ \\
\hline
\end{tabular}

Tabla 8. 16: Límites de control establecidos para la implementación del plan HACCP.

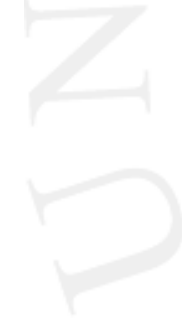


La implementación del plan HACCP busca asegurar inocuidad al 100\% del total de la producción de la empresa. De igual manera no se puede asegurar que no se tendrá ningún producto defectuoso, es por esto que se tomara una efectividad gradual del $25 \%$ anual de la solución propuesta.

El número de cupcakes rechazados en el proceso antes y después de la mejora se muestra a continuación:

Tabla 8. 17: Número de cupcakes rechazados en proceso.

\begin{tabular}{|c|c|c|c|c|c|}
\hline \multicolumn{7}{|c|}{ Número de cupcakes rechazados en proceso } \\
\hline Actual & Año 1 & Año 2 & Año 3 & Año 4 & Año 5 \\
\hline 16,800 & 12,600 & 9,450 & 7,088 & 5,316 & 3,987 \\
\hline
\end{tabular}

Ahora se muestran los cálculos del costo de reprocesamiento de cupcakes:

Tabla 8. 18: Cálculo de costo de reprocesamiento de cupcakes.

\begin{tabular}{|c|c|}
\hline Costo de producción anual (S/.) & $723,983.39$ \\
\hline Producción (cupcakes/año) & 202,415 \\
\hline Costo unitario (S/. / cupcake) & 3.58 \\
\hline
\end{tabular}

Con la implementación de la mejora los costos del reproceso irán disminuyendo anualmente, la empresa generaría un ahorro importante, tal cual se muestra en los cuadros siguientes: 
Tabla 8. 19: Costo anual de reprocesos.

\begin{tabular}{|l|c|c|c|c|c|}
\hline \multicolumn{7}{|c|}{ Costo anual de reproceso (S/.) } \\
\hline Actual & Año 1 & Año 2 & Año 3 & Año 4 & Año 5 \\
\hline 60,089 & 45,067 & 33,800 & 25,350 & 19,013 & 14,259 \\
\hline
\end{tabular}

Tabla 8. 20: Ahorro anual de reprocesos implementando HACCP.

\begin{tabular}{|c|c|c|c|c|}
\hline \multicolumn{5}{|c|}{ Ahorro anual de reproceso (S/.) } \\
\hline Año 1 & Año 2 & Año 3 & Año 4 & Año 5 \\
\hline 15,022 & 11,267 & 8,450 & 6,338 & 4,753 \\
\hline
\end{tabular}

Finalmente, con la mejora propuesta reducimos el indicador de Nivel de rechazos de productos en proceso. Dicho indicador se muestra en el cuadro que sigue:

Tabla 8. 21: Límites de control establecidos para la implementación del plan HACCP.

\begin{tabular}{|c|c|c|c|c|c|}
\hline \multicolumn{7}{|c|}{ Nivel de rechazos de productos en proceso } \\
\hline Actual & Año 1 & Año 2 & Año 3 & Año 4 & Año 5 \\
\hline $8.3 \%$ & $6.2 \%$ & $4.7 \%$ & $3.5 \%$ & $2.6 \%$ & $2.0 \%$ \\
\hline
\end{tabular}

\section{Mejora en el nivel de pedidos defectuosos}

De igual forma no se puede asegurar que no se tendrá ningún rechazo de producto terminado por parte del cliente, es por esto que se tomara una efectividad gradual del 25\% anual de la solución propuesta. 
El número de pedidos defectuosos antes y después de la mejora se muestran a continuación:

Tabla 8. 22: Proyección del impacto en número de pedidos defectuosos.

\begin{tabular}{|c|c|c|c|c|c|}
\hline \multicolumn{7}{|c|}{ Proyección de impacto en numero de pedidos defectuosos } \\
\hline Actual & Año 1 & Año 2 & Año 3 & Año 4 & Año 5 \\
\hline 560 & 420 & 315 & 236 & 177 & 133 \\
\hline
\end{tabular}

Ahora se muestran los cálculos del costo de reprocesamiento por pedido:

Tabla 8. 23: Costos de reprocesamiento de pedidos.

\begin{tabular}{|l|c|}
\hline Producción (cupcakes/año) & 202,415 \\
\hline Costo de producción anual (S/.) & $723,983.39$ \\
\hline Cantidad de pedidos (pedidos/año) & 4,760 \\
\hline Costo de producción por pedido (S/./ pedido) & 152.10 \\
\hline
\end{tabular}

Ahora se muestran los cálculos del costo de reposición por pedido, tomando en cuenta que en promedio se tienen que reponer un $16 \%$ del mismo y el tiempo de reposición promedio es de 2 horas por pedido:

Tabla 8. 24: Proyección de la cantidad de pedidos a reprocesar con la mejora.

\begin{tabular}{|c|c|c|c|c|c|}
\hline \multicolumn{7}{|c|}{ Proyección de la cantidad de pedidos a reprocesar con la mejora } \\
\hline Antes & Año 1 & Año 2 & Año 3 & Año 4 & Año 5 \\
\hline 90 & 67 & 50 & 38 & 28 & 21 \\
\hline
\end{tabular}


Tabla 8. 25: Proyección para los costos de reposición anual con la mejora.

\begin{tabular}{|l|c|c|c|c|c|c|}
\hline \multicolumn{1}{|c|}{ Costo anual (S/.) } & Actual & Año 1 & Año 2 & Año 3 & Año 4 & Año 5 \\
\hline $\begin{array}{l}\text { Reproceso de pedidos } \\
\text { defectuosos }\end{array}$ & 13,628 & 10,221 & 7,666 & 5,749 & 4,312 & 3,234 \\
\hline $\begin{array}{l}\text { Traslado para reposición } \\
\text { (combustible) }\end{array}$ & 527 & 395 & 296 & 222 & 167 & 125 \\
\hline Traslado para reposición (MO) & 1,057 & 793 & 595 & 446 & 334 & 251 \\
\hline Costo total anual de reposición & $\mathbf{1 5 , 2 1 2}$ & $\mathbf{1 1 , 4 0 9}$ & $\mathbf{8 , 5 5 7}$ & $\mathbf{6 , 4 1 7}$ & $\mathbf{4 , 8 1 3}$ & $\mathbf{3 , 6 1 0}$ \\
\hline
\end{tabular}

Tabla 8. 26: Proyección de ahorros anuales en pedidos defectuosos con la mejora.

\begin{tabular}{|c|c|c|c|c|}
\hline \multicolumn{5}{|c|}{ Proyección de ahorro anual de pedidos defectuosos (S/.) } \\
\hline Año 1 & Año 2 & Año 3 & Año 4 & Año 5 \\
\hline 3,803 & 2,852 & 2,139 & 1,604 & 1,203 \\
\hline
\end{tabular}

Finalmente, con la mejora propuesta reducimos el indicador de Nivel de pedidos defectuosos. Dicho indicador se muestra en el cuadro que sigue:

Tabla 8. 27: Proyección de la mejora en el indicador del nivel de pedidos defectuosos.

\section{Proyección de indicador de nivel de pedidos defectuosos}

\begin{tabular}{|c|c|c|c|c|c|}
\hline Actual & Año 1 & Año 2 & Año 3 & Año 4 & Año 5 \\
\hline $12 \%$ & $9 \%$ & $7 \%$ & $5 \%$ & $4 \%$ & $3 \%$ \\
\hline
\end{tabular}


Para la elaboración del plan se contratara una consultoría externa. La inversión anual para la contratación del proveedor se muestra a continuación:

Tabla 8. 28: Costos de implementación de HACCP.

\begin{tabular}{|l|c|c|c|}
\cline { 2 - 4 } \multicolumn{1}{c|}{} & $\begin{array}{c}\text { Cantidad } \\
\text { (unid.) }\end{array}$ & Costo unitario (S/.) & $\begin{array}{c}\text { Costo total anual } \\
\text { (S/.) }\end{array}$ \\
\hline Desarrollo del Plan HACCP & 1 & $12,000.00$ & $12,000.00$ \\
\hline Capacitación HACCP & 3 & 500.00 & $1,500.00$ \\
\hline $\begin{array}{l}\text { Costo de requisitos }- \text { análisis } \\
\text { microbiológico }\end{array}$ & 24 & 50.00 & $1,200.00$ \\
\hline \multicolumn{2}{|c|}{ INVERSIÓN TOTAL } & $\mathbf{1 4 , 7 0 0 . 0 0}$ \\
\hline
\end{tabular}




\section{e. Implementar un sistema de PCP}

Un sistema de PCP (Planeamiento y Control de la Producción) que incluya un sistema MRP, es hoy en día una herramienta muy poderosa de cara a una adecuada y eficiente gestión de la producción de la empresa y a la manera en cómo se va a suministrar los requerimientos de materias primas e insumos que permitan poden cumplir con la producción planificada y cubrir así la demanda de la empresa.

\section{- Desarrollo}

- Concientizar a la gerencia general de la importancia en la implementación de éste sistema y los beneficios que trae dentro de toda la cadena de producción y suministro para la cobertura de la necesidad de mercado. Esto incluye, también, el justificar la inversión que pudiera conllevar la implementación de este sistema.

- Se identificará cuál o cuáles son los productos principales de la empresa que serán incluidos en el sistema MRP. Para esto, en el diagnóstico general presentado durante el desarrollo de éste trabajo, determinamos que el producto principal es el cupcake seguido de las tortas, considerando su nivel de ventas a nivel general. A efectos de tener claro el requerimiento para 
la producción, tomaremos estos productos como referencia principal.

- Una vez tomada la decisión de implementar el sistema, comenzamos con el desarrollo correspondiente:

\section{$>$ Proyección de la demanda}

Es clave iniciar el planteamiento de un sistema PCP tomando en cuenta la proyección de la demanda para un determinado período, a fin de que se pueda considerar las cantidades más cercanas posibles de producción y sirva esto para el planeamiento de sus materiales e inventarios. Para este punto, tomamos como input la información proporcionada en el capítulo 4.5.1 (Pronóstico de la producción), en donde mostramos la manera en cómo hacer la proyección y la planteamos de acuerdo a la data histórica con la que contamos. A continuación, la mostramos: 
Tabla 8. 29: Demanda histórica de la empresa Claudia Cupcakes.

\begin{tabular}{|c|c|c|c|c|c|c|c|c|}
\hline \multirow{2}{*}{ MES } & \multicolumn{5}{|c|}{$\begin{array}{c}\text { DEMANDA } \\
\text { (Unidades de cupcakes) }\end{array}$} & \multirow{2}{*}{$\begin{array}{c}\text { DEMANDA } \\
\text { PROMEDIO } \\
\text { (1) }\end{array}$} & \multirow{2}{*}{$\begin{array}{c}\text { DEMANDA } \\
\text { PROMEDIO } \\
\text { MENSUAL (2) }\end{array}$} & \multirow{2}{*}{$\begin{array}{c}\text { ÍNDICE } \\
\text { ESTACIONAL } \\
(1) /(2)\end{array}$} \\
\hline & 2010 & 2011 & 2012 & 2013 & 2014 & & & \\
\hline Ene & - & 939 & 1,306 & 1,877 & 2,651 & 1,693 & 9,727 & 0.17 \\
\hline Feb & - & 6,341 & 11,915 & 18,999 & 20,653 & 14,477 & 9,727 & 1.49 \\
\hline Mar & - & 4,589 & 7,703 & 11,045 & 17,915 & 10,313 & 9,727 & 1.06 \\
\hline Abr & - & 1,783 & 2,543 & 5,738 & 7,964 & 4,507 & 9,727 & 0.46 \\
\hline May & - & 8,077 & 14,260 & 20,682 & 28,599 & 17,904 & 9,727 & 1.84 \\
\hline Jun & 486 & 7,226 & 9,309 & 14,935 & 22,870 & 10,965 & 9,727 & 1.13 \\
\hline Jul & 1,430 & 5,532 & 10,221 & 12,766 & 15,716 & 9,133 & 9,727 & 0.94 \\
\hline Ago & 945 & 2,807 & 5,222 & 3,752 & 5,295 & 3,604 & 9,727 & 0.37 \\
\hline Sep & 1,896 & 3,712 & 3,821 & 7,350 & 12,846 & 5,925 & 9,727 & 0.61 \\
\hline Oct & 2,810 & 10,189 & 12,909 & 17,316 & 26,273 & 13,899 & 9,727 & 1.43 \\
\hline Nov & 2,328 & 9,279 & 6,326 & 9,313 & 10,444 & 7,538 & 9,727 & 0.77 \\
\hline Dic & 3,195 & 11,005 & 15,805 & 22,658 & 31,188 & 16,770 & 9,727 & 1.72 \\
\hline \multicolumn{6}{|c|}{ Promedio total de la demanda anual } & 116,729 & & \\
\hline
\end{tabular}

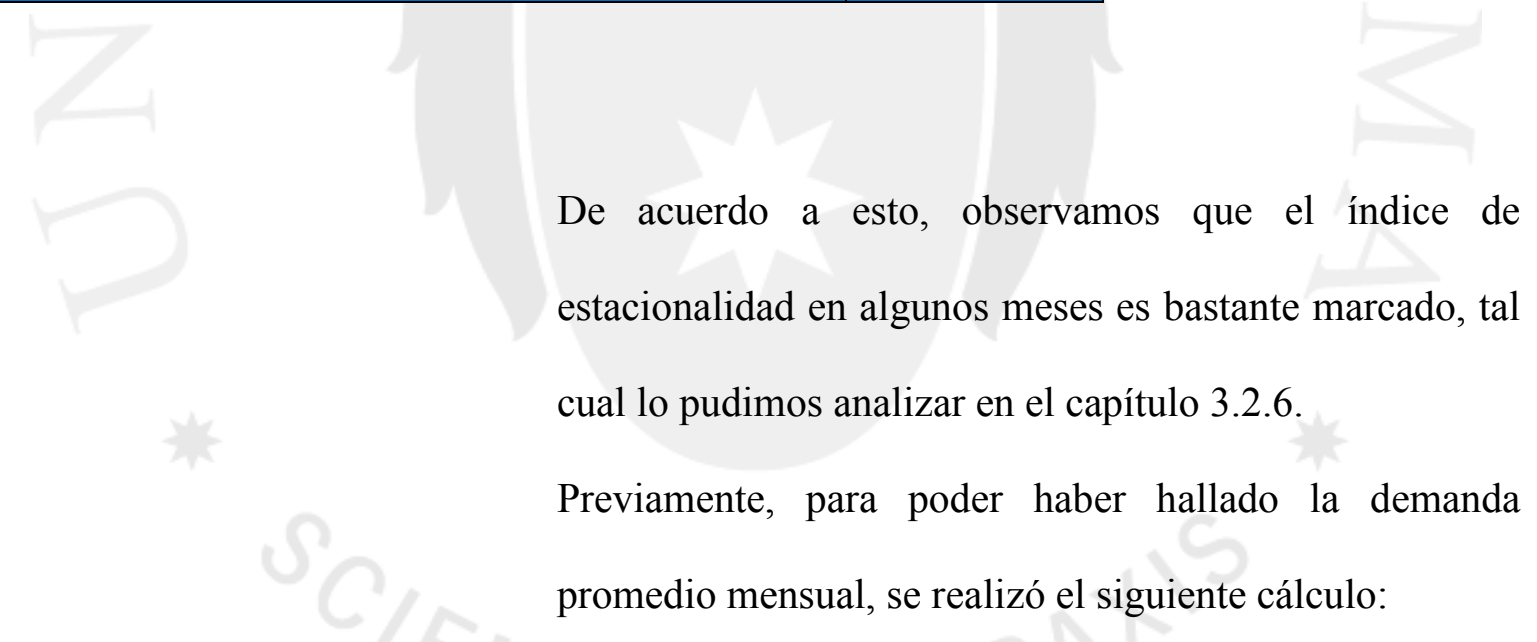

$\underset{\text { mensual }}{\underset{\text { Demanda promedio }}{\operatorname{man}}}=\frac{\text { Promedio total de la demanda anual }}{\text { Número de meses }}=\frac{116,729}{12}=\mathbf{9 , 7 2 7}$ cupcakes 
Posteriormente, considerando ahora las cantidades históricas anuales, hacemos el pronóstico de la producción con estacionalidad anual, mediante una regresión lineal, tomando en cuenta como nuestra variable dependiente a el comportamiento histórico y proyectado del PBI per cápita.

Tabla 8. 30: Producción histórica anual vs. PBI per cápita Perú.

\begin{tabular}{|c|c|c|c|c|}
\hline \multicolumn{5}{|c|}{ PRODUCCIÓN HISTÓRICA ANUAL } \\
(UND) \\
\hline $\mathbf{2 0 1 0}$ & $\mathbf{2 0 1 1}$ & $\mathbf{2 0 1 2}$ & $\mathbf{2 0 1 3}$ & $\mathbf{2 0 1 4}$ \\
\hline $\mathbf{1 2 . 9 8}$ & $\mathbf{1 3 . 6 6}$ & $\mathbf{1 4 . 3 1}$ & $\mathbf{1 4 . 9 7}$ & $\mathbf{1 5 . 6 2}$ \\
\hline 13,090 & 71,478 & 101,338 & 146,431 & 202,415 \\
\hline
\end{tabular}

Obteniendo la siguiente ecuación para la recta de tendencia:

$$
\begin{aligned}
\mathbf{Y}= & 68,803 * \mathrm{X}-877,510 \\
\mathbf{R 2}= & 0.9911 \\
\mathbf{R}= & 0.9955
\end{aligned}
$$

Observamos que el coeficiente de correlación (R) es aceptable porque es mayor a 0.70 y muy próximo a 1 , por lo que tendríamos una relación bastante cerca en cuanto al avance de los años y al crecimiento de la demanda, obteniendo así la siguiente proyección anual para los próximos 5 años: 
Tabla 8. 31: Proyección de la producción en la empresa Claudia Cupcakes.

\begin{tabular}{|c|c|c|c|c|}
\hline \multicolumn{5}{|c|}{ PROYECCIÓN DE LA PRODUCCIÓN ANUAL } \\
(UND) \\
\hline $\mathbf{2 0 1 5}$ & $\mathbf{2 0 1 6}$ & $\mathbf{2 0 1 7}$ & $\mathbf{2 0 1 8}$ & $\mathbf{2 0 1 9}$ \\
\hline $\mathbf{1 6 . 4 3}$ & $\mathbf{1 7 . 3 2}$ & $\mathbf{1 8 . 1 8}$ & $\mathbf{1 9 . 1 8}$ & $\mathbf{2 0 . 2 3}$ \\
\hline 253,050 & 314.312 & 373,125 & 442,401 & 514,346 \\
\hline
\end{tabular}

Finalmente, tomando en cuenta el pronóstico anual y considerando el índice de estacionalidad hallado inicialmente, obtenemos la proyección de la producción mensual para los siguientes 5 años, también:

Tabla 8. 32: Demanda histórica de la empresa Claudia Cupcakes.

\begin{tabular}{|c|c|c|c|c|c|c|}
\hline \multirow{2}{*}{ MES } & \multicolumn{5}{|c|}{$\begin{array}{c}\text { DEMANDA PROYECTADA } \\
\text { (Unidades de cupcakes) }\end{array}$} \\
\cline { 2 - 6 } & $\mathbf{2 0 1 5}$ & $\mathbf{2 0 1 6}$ & $\mathbf{2 0 1 7}$ & $\mathbf{2 0 1 8}$ & $\mathbf{2 0 1 9}$ & ÍNDICE \\
ESTACIONAL
\end{tabular}

\begin{tabular}{|l|l|l|l|l|l|l|} 
TOTAL & 253,050 & 314.312 & 373,125 & 442,401 & 514,346 \\
\hline
\end{tabular}




\section{$>$ Requerimiento de Materiales}

Con la información obtenida hacemos un ejemplo de requerimiento de materiales (MRP) para una producción mensual (considerando una demanda semanal constante) y considerando las Materias Primas que se requiere ingresar pedidos al proveedor y que cuentan con un lead time de entrega. Para nuestro ejemplo, tomaremos como base los meses de Enero y Febrero 2016.

Para esto, es necesario contar con lo siguiente:

- Lista de Materiales que se necesitan para cumplir de manera adecuada con la producción.

- Lead time: Tiempo de demora en la entrega del requerimiento por parte del proveedor.

- Nivel de Servicio: Tener en cuenta los datos históricos de cumplimiento del proveedor para hacer una estimación adecuada.

- Stock de Seguridad: Tomar en cuenta qué cantidad de materiales se requiere tener como "back up", a fin de ser considerado dentro del pedido general a realizar. 
Tabla 8. 33: Esquema de planeamiento de requerimiento de materiales.

\begin{tabular}{|l|c|c|c|c|c|c|c|c|}
\hline \multirow{2}{*}{$\begin{array}{c}\text { Producto: Pre - Mezcla } \\
\text { (LT: } 1 \text { semana) }\end{array}$} & \multicolumn{4}{|c|}{ ene-16 } & \multicolumn{4}{c|}{ feb-16 } \\
\cline { 2 - 11 } & Sem.1 & Sem.2 & Sem.3 & Sem.4 & Sem.1 & Sem.2 & Sem.3 & Sem.4 \\
\hline Requerimiento bruto & 25 & 25 & 25 & 25 & 200 & 200 & 200 & 200 \\
\hline Recepción programada & - & - & - & - & - & - & - & - \\
\hline Inventario disponible & - & - & - & - & - & - & - & - \\
\hline Requerimiento neto & 25 & 25 & 25 & 25 & 200 & 200 & 200 & 200 \\
\hline Plan de pedidos & 25 & 25 & 25 & 200 & 200 & 200 & 200 & - \\
\hline Lanzamiento de pedidos & 25 & 25 & 25 & 200 & 200 & 200 & 200 & - \\
\hline Producto: Masa Fondant & \multicolumn{7}{|c|}{ ene-16 } \\
\cline { 2 - 14 } (LT: 1 semana) & Sem.1 & Sem.2 & Sem.3 & Sem.4 & Sem.1 & Sem.2 & Sem.3 & Sem.4 \\
\hline Requerimiento bruto & 8 & 8 & 8 & 8 & 29 & 29 & 29 & 29 \\
\hline Recepción programada & - & - & - & - & - & - & - & - \\
\hline Inventario disponible & - & - & - & - & - & - & - & - \\
\hline Requerimiento neto & 8 & 8 & 8 & 8 & 29 & 29 & 29 & 29 \\
\hline Plan de pedidos & 8 & 8 & 8 & 29 & 29 & 29 & 29 & - \\
\hline Lanzamiento de pedidos & 8 & 8 & 8 & 29 & 29 & 29 & 29 & - \\
\hline
\end{tabular}

\section{Programa Maestro de Producción (MPS)}

Es una decisión de tipo operativa, respecto a los artículos

y cantidades que deben ser fabricados en el siguiente período de planificación. Sus características son:

- Determina qué debe hacerse y cuándo.

- Se establece en términos de productos específicos y no en familias.

- Es una decisión de lo que se va a producir, no un pronóstico más.

En este caso, consideramos información relevante de cuánto es el tamaño de lote de producción promedio, así 
como la demanda ya planificada y el inventario inicial con el que se contará en cada período. Como ejemplo, planteamos que el período a considerar sea semanal y que el tamaño de lote de producción es de 1200 cupcakes.

Como formato a considerar para el cuadro del programa maestro, tenemos:

Tabla 8. 34: Esquema de plan maestro de la producción.

\begin{tabular}{|l|c|c|c|c|c|c|c|c|}
\hline \multirow{2}{*}{ Producto: Cupcakes } & \multicolumn{4}{|c|}{ ene-16 } & \multicolumn{4}{c|}{ feb-16 } \\
\cline { 2 - 10 } & Sem.1 & Sem.2 & Sem.3 & Sem.4 & Sem.1 & Sem.2 & Sem.3 & Sem.4 \\
\hline Inventario Inicial & 0 & 200 & 600 & 600 & 800 & 1000 & 100 & 500 \\
\hline Pronóstico & 1000 & 800 & 1200 & 1000 & 1000 & 900 & 800 & 1000 \\
\hline Pedidos & 800 & 500 & 1400 & 900 & 800 & 1000 & 900 & 1100 \\
\hline Inventario Final & 200 & 600 & 600 & 800 & 1000 & 100 & 500 & 700 \\
\hline MPS & 1200 & 1200 & 1200 & 1200 & 1200 & 0 & 1200 & 1200 \\
\hline
\end{tabular}

Observamos que la principal oportunidad de mejora pasa manejar de manera más óptima siempre el tamaño de lote, pues esto permitirá planificar la producción de una manera más adecuada.

\section{Control de la producción}

Una vez establecido un adecuado plan maestro de producción, es adecuado llevar un constante control de que lo planificado se está llevando a cabo de manera correcta. Para ello, por ejemplo, dentro de las propuestas de mejora 
que planteamos para llevar una adecuada planeación y control de la producción, hemos elaborado un formato para tener en el taller a visibilidad de todo el personal en el cual se aprecie la planificación diaria de la producción:

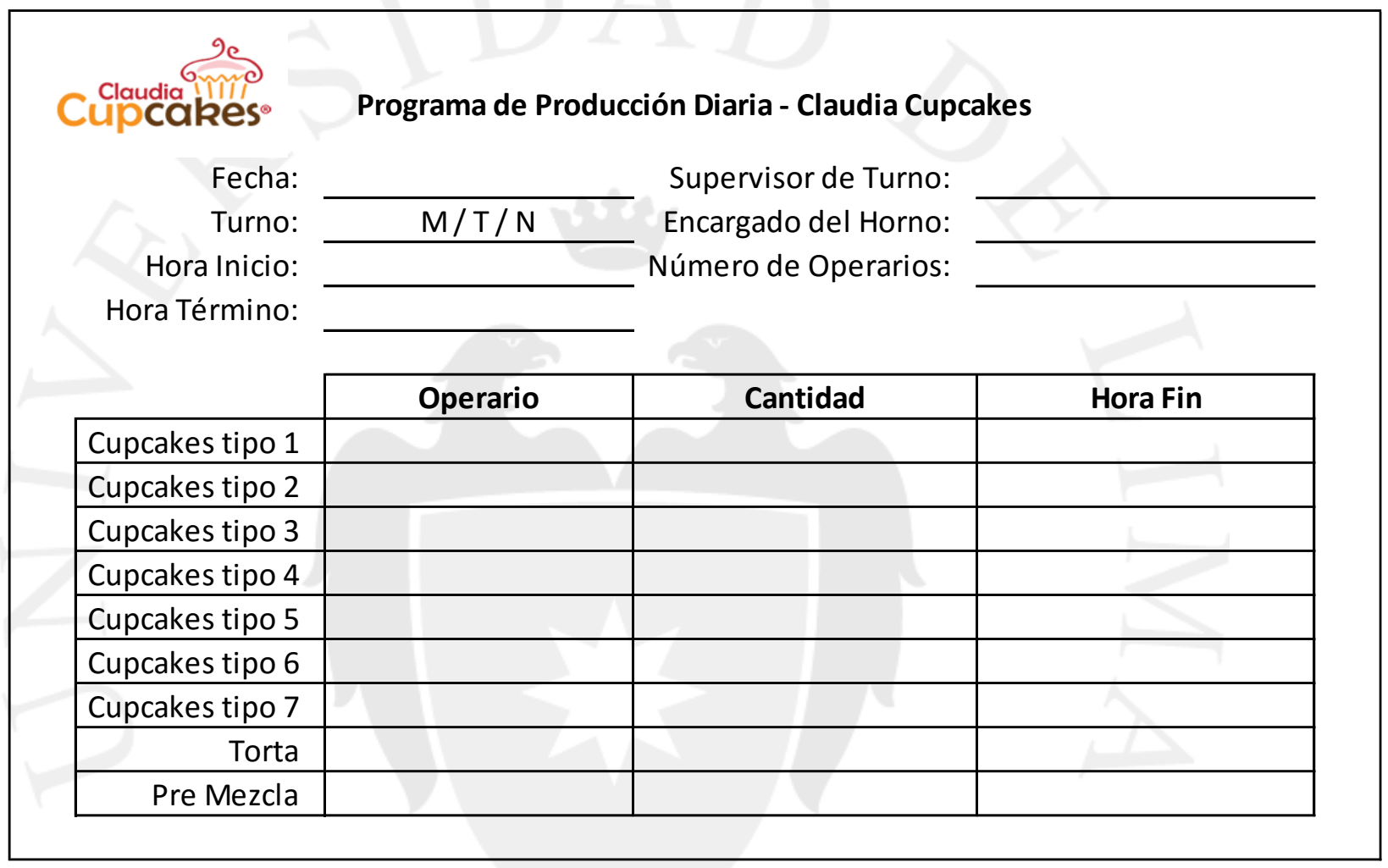

Figura 8. 11: Formato de programa de producción diario.

Fuente: Elaboración propia.

Esto nos ayudará a tener una visibilidad constante de que lo planificado se está desarrollando de manera adecuada; asimismo, sería recomendable establecer un indicador del cumplimiento de lo planificado, por ejemplo: cantidad producida / cantidad proyectada. 
Planeación agregada de la producción

Mediante este paso, podremos maximizar el beneficio.

Para ello deben considerarse todos los factores que dentro del plan afecten el costo.

- Mano de obra (costo del tiempo normal, costo del tiempo extra).

- Contratación (Entrevistas, evaluaciones, exámenes, inducción)

- Despidos (Compensaciones legales)

- Subcontratación (costo de servicio, costo de servicio y materia prima)

- Inventario (Costos de mantenimiento, costo de oportunidad)

- Ruptura de inventario o faltantes

El formato propuesto para esta fase es:

Tabla 8. 35: Esquema de plan maestro de la producción.

\begin{tabular}{|c|c|c|c|c|c|c|c|c|c|c|c|c|c|}
\hline & 2016 & Ene & Feb & Mar & Abr & May & Jun & Jul & Ago & Sep & Oct & Nov & Dic \\
\hline 1 & Días & 21 & 20 & 23 & 21 & 22 & 22 & 22 & 21 & 21 & 23 & 21 & 22 \\
\hline 2 & Suma de Días & 21 & 41 & 64 & 85 & 107 & 129 & 151 & 172 & 193 & 216 & 237 & 259 \\
\hline 3 & Demanda (Cupcakes) & 4,181 & 35,447 & 25,401 & 11,344 & 43,920 & 27,253 & 22,796 & 8,847 & 14,883 & 34,130 & 18,764 & 41,424 \\
\hline 4 & Suma de demanda & 4,181 & 39,628 & 65,029 & 76,373 & 120,293 & 147,546 & 170,342 & 179,189 & 194,072 & 228,202 & 246,966 & 288,390 \\
\hline 5 & Trabajadores & 15 & 15 & 15 & 15 & 15 & 15 & 15 & 15 & 15 & 15 & 15 & 15 \\
\hline
\end{tabular}


Como acotaciones finales para poder llevar a cabo esta implementación, se tiene:

- Un adecuado registro de la producción y venta histórica para tener la data necesaria con la cual hacer las proyecciones de la demanda. Para esto, debido al tamaño de la empresa la cual por ahora no requiere un mayor nivel de complejidad en sistemas como para implementar un software especializado, podría hacerse uso de la herramienta Microsoft Excel y una herramienta o aplicativo usado en este mismo software, llamado "solver", en donde mediante un proceso de simulación de una proyección estimada mediante un modelo de ecuación lineal, se podrá obtener la planeación requerida para un período determinado.

- Asignar a una persona específica que pueda mantener este registro de manera adecuada y pueda hacer la planificación adecuada. En vista de que no se desea hacer una inversión elevada, sería ideal contar con el apoyo de un practicante de Ingeniería Industrial de los últimos ciclos con los conocimientos de logística necesario para poder cumplir con esa función. 
- Llevar un registro de las compras de materiales e insumos. Para esto, considerar necesariamente la inversión realizada, fechas de compra, cantidades, proveedores, nivel de servicio de ellos, etc.

\section{- Beneficios}

De la implementación de estos sistemas de planificación descritos, obtenemos éstos beneficios:

- Disminuir inventarios en un estimado del 5\% anual, en base a la experiencia de mejoras de este tipo en otras empresas del rubro.

- Determinar los requerimientos necesarios de mano de obra.

- Tener una alerta temprana de posible ruptura de stock.

- Proveer un escenario de planeamiento de largo plazo. 


\section{f. Establecer las bases para un sistema de SST}

Hoy en día las empresas buscan ser cada vez más competitivas en el mercado en el cual se desarrollan, no sólo brindando un producto o servicio de calidad y que cumpla con las necesidades de sus clientes, si no también que brinde un valor agregado que no necesariamente esté ligado a su forma o aspecto final, sino algo que aporte dentro de su cadena productiva. Es así como el cuidado de los trabajadores mediante la prevención de peligros y riesgos asociados al desarrollo de sus funciones es un factor clave que hace que una empresa sea socialmente responsable y comprometida con la salud e integridad de sus colaboradores.

En lo referente a la Seguridad y Salud Laboral, hoy en día existen leyes y normas que regulan en mayor medida el cumplimiento de los estándares mínimos para el cuidado de los colaboradores en una empresa (Ley 29783: “Ley de Seguridad y Salud en Trabajo y su reglamento”) o, incluso, la certificación OHSAS 18001 para este tema. Sin embargo, debido a que la empresa en estudio es una PYME, no es necesario por ahora contar con una certificación internacional en estos aspectos, pero si llevar un cumplimiento de las leyes y normas establecidas por el estado en materia de seguridad y salud ocupacional.

A continuación, un detalle de cómo poder llevar a cabo la implementación de estos planes: 


\section{- Desarrollo}

Para poder establecer un adecuado control en los aspectos de SST (Seguridad y Salud en el Trabajo), se realizarán los siguientes pasos (considerando que son controles preventivos puesto no aplica la ley para la empresa):

- Se establecerán las responsabilidades de la empresa en los temas de SST.

- Se asignará a un supervisor de SST (considerando que son menos de 20 trabajadores de planilla).

Se hará una evaluación inicial de los Riesgos mediante la Identificación de Peligros y Evaluación de Riesgos (IPER): Como parte de nuestra propuesta de mejora, hemos hecho éste análisis y proponemos, también, el mapa de riesgos del taller de producción, los cuales mostramos a continuación, tomando en cuenta primero los criterios usados para el desarrollo de la matriz IPER:

Tabla 8. 36: Criterios para elaboración de matriz IPER.

\begin{tabular}{|c|c|c|c|c|c|}
\hline \multirow{2}{*}{ moice } & \multicolumn{4}{|c|}{ PQOQABILIDAD } & \multirow{2}{*}{ 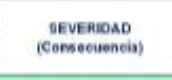 } \\
\hline & $\begin{array}{l}\text { PERsonas } \\
\text { EXPUESTAS }\end{array}$ & $\begin{array}{c}\text { PROCEDMAENTOS } \\
\text { EXISTEHTES }\end{array}$ & CAPACITAGION & $\begin{array}{c}\text { Exposkcion aL } \\
\text { RIESSOO }\end{array}$ & \\
\hline 1 & 1.2 & $\begin{array}{l}\text { Exicten son } \\
\text { Satiefactorios y } \\
\text { Siffsiemtes }\end{array}$ & $\begin{array}{l}\text { Persanal } \\
\text { ontrunade, cenese } \\
\text { ol poligro y lo } \\
\text { peeviene. }\end{array}$ & $\begin{array}{l}\text { Al menos una vaz al } \\
\text { anta } \\
\text { ESPORADICAMENTE }\end{array}$ & 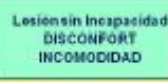 \\
\hline 2 & 4 a12 & 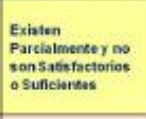 & $\begin{array}{l}\text { Personal } \\
\text { Purcialmemte } \\
\text { Entranado, conese } \\
\text { elPeligro pero no } \\
\text { Toma Retiones de } \\
\text { Conteol }\end{array}$ & $\begin{array}{c}\text { Al menos uns verz al } \\
\text { mes } \\
\text { EVENTUALIIENTE }\end{array}$ & 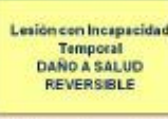 \\
\hline 3 & $12 \mathrm{amas}$ & No Eriston & $\begin{array}{l}\text { PersonalNo } \\
\text { Entranado, No } \\
\text { eonece el Poligro, } \\
\text { Ho Toma Aeciones } \\
\text { do Certrol }\end{array}$ & $\begin{array}{c}\text { Al menos una vaz al } \\
\text { dia } \\
\text { PERMANENTE }\end{array}$ & $\begin{array}{l}\text { Lesioneen Ineapaeidad } \\
\text { Peemaneete } \\
\text { DAROA L LA SALLD } \\
\text { IRREVERSBLE }\end{array}$ \\
\hline
\end{tabular}

\begin{tabular}{|c|c|}
\hline $\begin{array}{l}\text { NINEL DE } \\
\text { RIESGO }\end{array}$ & POSTURA \\
\hline $\begin{array}{c}\text { TRMIAL } \\
4\end{array}$ & - No requiare Actión Especitica \\
\hline $\begin{array}{c}\text { TOLERABLE } \\
5.8\end{array}$ & 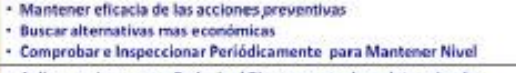 \\
\hline $\begin{array}{c}\text { MODERADO } \\
9.16\end{array}$ & 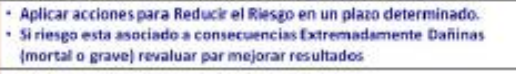 \\
\hline $\begin{array}{c}\text { MPPortante } \\
17-24\end{array}$ & 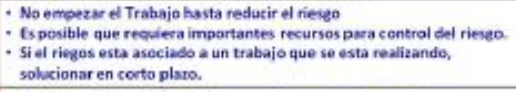 \\
\hline $\begin{array}{l}\text { INTOUERABUE } \\
25.36\end{array}$ & $\begin{array}{l}\text { - No empezar ni continuar el Proceso hasta no Reducir el Riesgo } \\
\text { - Si no es positle retucit el Riesga, prohiair el Trabajo linclesio cen } \\
\text { Recursos limitados] }\end{array}$ \\
\hline
\end{tabular}


MATRIZ DE IDENTIFICACIÓN DE PELIGROS Y EVALUACIÓN DE RIESGOS - IPER - CLAUDIA CUPCAKES E.I.R.L.

\begin{tabular}{|c|c|c|c|c|c|c|c|c|c|c|c|c|}
\hline \multirow[b]{2}{*}{ TAREA } & \multirow[b]{2}{*}{ PELIGRO } & & \multicolumn{5}{|c|}{ PROBABILIDAD } & \multirow{2}{*}{ 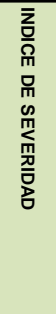 } & \multirow[b]{2}{*}{ 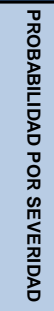 } & \multirow{2}{*}{ 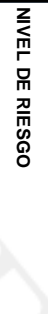 } & \multirow{2}{*}{ 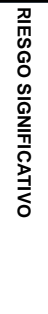 } & \multirow[b]{2}{*}{ MEDIDAS DE CONTROL } \\
\hline & & RIESGO & 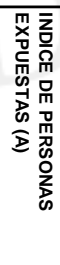 & 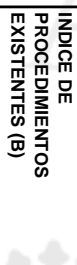 & 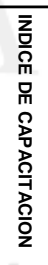 & 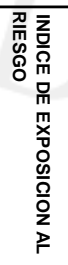 & 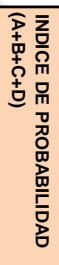 & & & & & \\
\hline $\begin{array}{c}\text { Carga de MP e } \\
\text { insumos basicos }\end{array}$ & $\begin{array}{l}\text { MP e insumos pesados } \\
\text { Movimientos indebidos } \\
\text { Espacios reducidos } \\
\text { MP e insumos amontonados } \\
\text { Obstaculos en el camino }\end{array}$ & $\begin{array}{l}\text { Caidas, tropiezos, lesiones, golpes, } \\
\text { fracturas, fatiga }\end{array}$ & 1 & 3 & 3 & 3 & 10 & 2 & 20 & 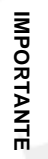 & SI & $\begin{array}{l}\text { Control de riesgos: ordenar, entrenamiento y } \\
\text { capacitacion, uso de equipos de transporte }\end{array}$ \\
\hline $\begin{array}{l}\text { Preparacion de } \\
\text { mezcla }\end{array}$ & $\begin{array}{l}\text { Mal uso de utensilios } \\
\text { Particulas en suspension } \\
\text { Inadecuada mesa de trabajo }\end{array}$ & $\begin{array}{l}\text { Cortes, lesiones, dolor de espalda y } \\
\text { cuello, asma, alergias, disminucion de } \\
\text { vista }\end{array}$ & 1 & 2 & 2 & 3 & 8 & 1 & 8 & $\begin{array}{l}\text { o- } \\
\text { 䍃 } \\
\text { 兽 } \\
\text { 而 }\end{array}$ & SI & $\begin{array}{l}\text { Tratar riesgos: uso de EPI's, sustitucion de mesas } \\
\text { de trabajo, entrenamiento }\end{array}$ \\
\hline Batido de la mezcla & $\begin{array}{l}\text { Particulas en suspension } \\
\text { Atrapamiento } \\
\text { Instalacion electrica } \\
\text { Ruido } \\
\text { Piso resbaloso }\end{array}$ & $\begin{array}{l}\text { Asma, alergias, cortes, golpes, } \\
\text { disminucion de vista, fracturas, caidas, } \\
\text { lesiones, estres, dolor de cabeza, } \\
\text { amputamiento }\end{array}$ & 1 & 2 & 2 & 3 & 8 & 3 & 24 & 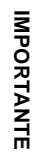 & SI & $\begin{array}{l}\text { Control de riesgos: guarda de proteccion, uso de } \\
\text { EPI's, limpieza, cambios en la instalacion electrica }\end{array}$ \\
\hline $\begin{array}{l}\text { Horneado de la } \\
\text { mezcla }\end{array}$ & \begin{tabular}{|l|} 
Temperaturas altas \\
Obstaculos en el camino \\
Movimientos indebidos \\
Instalacion electrica \\
Pisos altos \\
Espacios reducidos
\end{tabular} & $\begin{array}{c}\text { Quemaduras, heridas, caidas, } \\
\text { electrocusion, tropiezos, fatiga, estres, } \\
\text { cansancio }\end{array}$ & 1 & 2 & 2 & 3 & 8 & 3 & 24 & 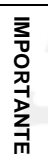 & SI & $\begin{array}{l}\text { Control de riesgos: uso de EPI's, cambios en la } \\
\text { instalacion electrica, disenio de maquina }\end{array}$ \\
\hline
\end{tabular}


MATRIZ DE IDENTIFICACIÓN DE PELIGROS Y EVALUACIÓN DE RIESGOS - IPER - CLAUDIA CUPCAKES E.I.R.L.

\begin{tabular}{|c|c|c|c|c|c|c|c|c|c|c|c|c|}
\hline \multirow[b]{2}{*}{ TAREA } & \multirow[b]{2}{*}{ PELIGRO } & \multirow[b]{2}{*}{ RIESGO } & \multicolumn{5}{|c|}{ PROBABILIDAD } & \multirow{2}{*}{ 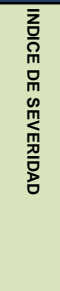 } & \multirow[b]{2}{*}{ 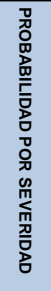 } & \multirow{2}{*}{ 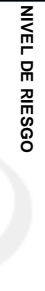 } & \multirow{2}{*}{ 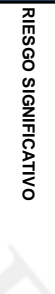 } & \multirow[b]{2}{*}{ MEDIDAS DE CONTROL } \\
\hline & & & 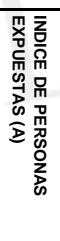 & 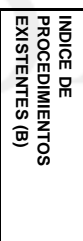 & 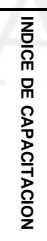 & 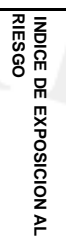 & 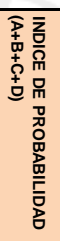 & & & & & \\
\hline Almacenamiento & \begin{tabular}{|l} 
Espacios reducidos \\
Estantes inseguros \\
Mal almacenamiento \\
Falta orden y limpieza \\
Material inflamable \\
Material pesado \\
Apilamiento inseguro \\
Insumos amontonados \\
\end{tabular} & $\begin{array}{l}\text { Caidas, tropiezos, lesiones, golpes, } \\
\text { fracturas, fatiga, incendio, cansancio }\end{array}$ & 1 & 2 & 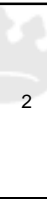 & 3 & 8 & 3 & 24 & 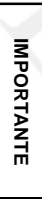 & SI & $\begin{array}{l}\text { Control de riesgos: disenio de estantes, clasificar, } \\
\text { ordenar y limpiar, entrenamiento }\end{array}$ \\
\hline Pre-decorado & $\begin{array}{l}\text { lluminacion deficiente } \\
\text { Inadecuada mesa de trabajo } \\
\text { Obstaculos en el camino } \\
\text { Estantes inseguros } \\
\text { Mal almacenamiento }\end{array}$ & $\begin{array}{l}\text { Disminucion de vista, sobreesfuerzo, } \\
\text { fatiga, dolor de cabeza, estres, } \\
\text { tropiezos, caidas, golpes, lesiones, } \\
\text { dolor de espalda y cuello }\end{array}$ & 1 & 2 & 2 & 3 & 8 & 2 & 16 & $\begin{array}{l}\text { zo } \\
\text { on } \\
\text { 夏 } \\
\text { 号 }\end{array}$ & SI & $\begin{array}{l}\text { Tratar riesgos: sustitucion de mesas de trabajo, } \\
\text { disenio de estantes, orden y limpieza }\end{array}$ \\
\hline Decorado & \begin{tabular}{|l|} 
llluminacion deficiente \\
Inadecuada mesa de trabajo \\
Espacios reducidos \\
Estantes inseguros \\
Mal almacenamiento \\
Instalacion electrica
\end{tabular} & $\begin{array}{l}\text { Disminucion de vista, sobreesfuerzo, } \\
\text { fatiga, dolor de cabeza, estres, } \\
\text { tropiezos, caidas, golpes, lesiones, } \\
\text { dolor de espalda y cuello, electrocusion }\end{array}$ & 1 & 2 & 2 & 3 & 8 & 3 & 24 & 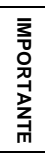 & sI & $\begin{array}{l}\text { Tratar riesgos: sustitucion de mesas de trabajo, } \\
\text { disenio de estantes, orden y limpieza, cambios en } \\
\text { la instalacion electrica }\end{array}$ \\
\hline Empaquetado & $\begin{array}{l}\text { lluminacion deficiente } \\
\text { Inadecuada mesa de trabajo } \\
\text { Espacios reducidos } \\
\text { Estantes inseguros } \\
\text { Mal almacenamiento } \\
\text { Obstaculos en el camino } \\
\text { Falta orden y limpieza }\end{array}$ & $\begin{array}{l}\text { Disminucion de vista, fatiga, dolor de } \\
\text { cabeza, estres, tropiezos, caidas, } \\
\text { golpes, lesiones, dolor de espalda y } \\
\text { cuello }\end{array}$ & 1 & 2 & 2 & 3 & 8 & 2 & 16 & $\begin{array}{l}\text { zo } \\
\text { 鬲 } \\
\text { 客 }\end{array}$ & SI & $\begin{array}{l}\text { Tratar riesgos: sustitucion de mesas de trabajo, } \\
\text { disenio de estantes, orden y limpieza }\end{array}$ \\
\hline
\end{tabular}

Tabla 8. 37: Propuesta de Matriz IPER para la empresa Claudia Cupcakes. 
Tabla 8. 38: Análisis Modal de Falla y Efecto aplicado a la empresa Claudia Cupcakes.

\begin{tabular}{|c|c|c|c|c|c|c|}
\hline \multicolumn{7}{|c|}{ AMFE: Horneado de Cupcakes } \\
\hline Elemento & Funcion & Modo de Fallo & Modo de deteccion & Efectos & Medidas preventivas & Medidas correctivas \\
\hline \multirow{4}{*}{$\begin{array}{l}\text { 1. Proceso de } \\
\text { batido }\end{array}$} & \multirow{4}{*}{$\begin{array}{l}\text { Batidora } \\
\text { industrial }\end{array}$} & Aletas mal ajustadas & Verificacion & \multirow{4}{*}{$\begin{array}{l}\text { Derrame, cortes, } \\
\text { electrocusion, rotura de } \\
\text { componentes }\end{array}$} & \multirow{3}{*}{ Verificar componentes } & Parar, limpiar, ajustar bien \\
\hline & & Tazon mal colocado & Inspeccion visual & & & $\begin{array}{l}\text { Parar, limpiar, colocar } \\
\text { bien }\end{array}$ \\
\hline & & $\begin{array}{l}\text { Tipo de tazon no } \\
\text { corresponde }\end{array}$ & Codigo, marca & & & $\begin{array}{l}\text { Parar, limpiar, cambien } \\
\text { tazon }\end{array}$ \\
\hline & & Cantidad de mezcla & Inspeccion visual & & Medir cantidades & Parar, limpiar, medir \\
\hline \multirow{4}{*}{$\begin{array}{l}\text { 2. Proceso de } \\
\text { horneado }\end{array}$} & \multirow{4}{*}{$\begin{array}{l}\text { Horno } \\
\text { industrial }\end{array}$} & Pisos mal colocados & Verificacion & \multirow{4}{*}{$\begin{array}{c}\text { Quemaduras, altas } \\
\text { temperaturas, } \\
\text { electrocusion }\end{array}$} & Verificar componentes & $\begin{array}{l}\text { Suspender, sacar, colocar } \\
\text { bien }\end{array}$ \\
\hline & & Sensor de temperatura & $\begin{array}{l}\text { Hallazgo, inspeccion } \\
\text { sensorial }\end{array}$ & & $\begin{array}{c}\text { Colocar alarma, mant. } \\
\text { Preventivo }\end{array}$ & $\begin{array}{l}\text { Suspender, reparar o } \\
\text { sustituir }\end{array}$ \\
\hline & & Sistema electrico & Verificacion & & Mant. Preventivo & $\begin{array}{l}\text { Suspender, revisar, } \\
\text { reparar }\end{array}$ \\
\hline & & Desgaste de puerta & Inspeccion visual & & Verificar componentes & Parar, reparar o sustituir \\
\hline
\end{tabular}




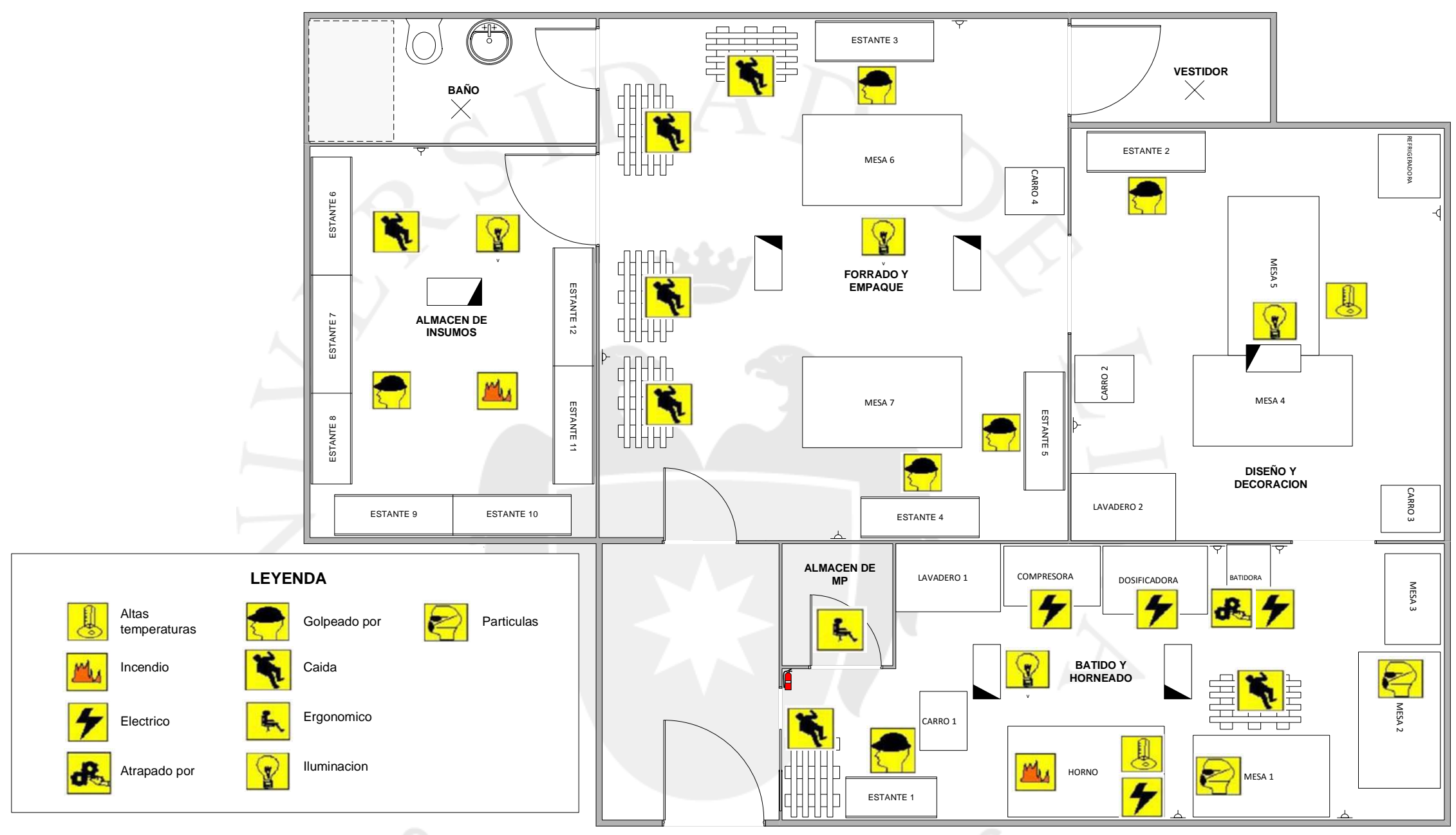

Figura 8. 12: Mapa de riesgos del taller de Claudia Cupcakes Fuente: Elaboración propia. 
- Por otro lado, en el aspecto de la Salud Laboral, se implementará un programa de evaluaciones médicas: pre, periódicas y post ocupacionales. Esto beneficiará a los trabajadores al determinar cualquier mal que pudieran tener, así como también en beneficio de la empresa para tener un "escudo" ante cualquier situación que pudiera presentarse luego de la desvinculación de un colaborador.

- Se llevará un control permanente del nivel de accidentes e incidentes que se presentan en la empresa, a fin de poder determinar con claridad el índice de éstos sucesos y poder ir tomando las medidas correctivas necesarias ante cada eventualidad.

- El indicado para medir el desempeño será:

$\frac{\text { \# accidentes }}{\text { Total de trabajadores }}$

- Se establecerán políticas, objetivos y metas en materia de SST. Asimismo, es recomendable poder documentar algunos procedimientos y formatos que permitan llevar a cabo una adecuada gestión de éste Sistema implementado.

- Se comunicará lo descrito en el punto anterior a todos los colaboradores a fin de que tengan un conocimiento claro al respecto $\mathrm{y}$, además, puedan aportar con sugerencias y/o 
propuestas para mejorar las políticas y acciones implementadas. Asimismo, pueden establecerse canales de comunicación más directa entre el personal y la Gerencia, como buzones o correos de sugerencia, etc.

- De la mano con los riesgos identificados en el IPER y el mapa de Riesgos, se establecerán las medidas de seguridad necesarias en el taller:

$>$ Extintores

$>$ Señalización de Seguridad

Facilidades de higiene permanente.

$>$ Detectores de humo y/o rociadores (especialmente para su almacén de MP y en la zona de horneado).

- Finalmente, sería adecuado poder realizar un análisis del espacio en el que se desarrollan las actividades a fin de poder determinar las condiciones no ergonómicas y adecuadas a las que están expuestos los colaboradores con la finalidad de poder determinar los controles y/o medidas correctivas necesarias en el ambiente de trabajo para que en un período determinado no se convierta en un daño potencial para ellos. 
Como parte de nuestra propuesta de implementación de este sistema, mostramos a continuación el programa anual de Seguridad y Salud en el Trabajo para el año 2016:

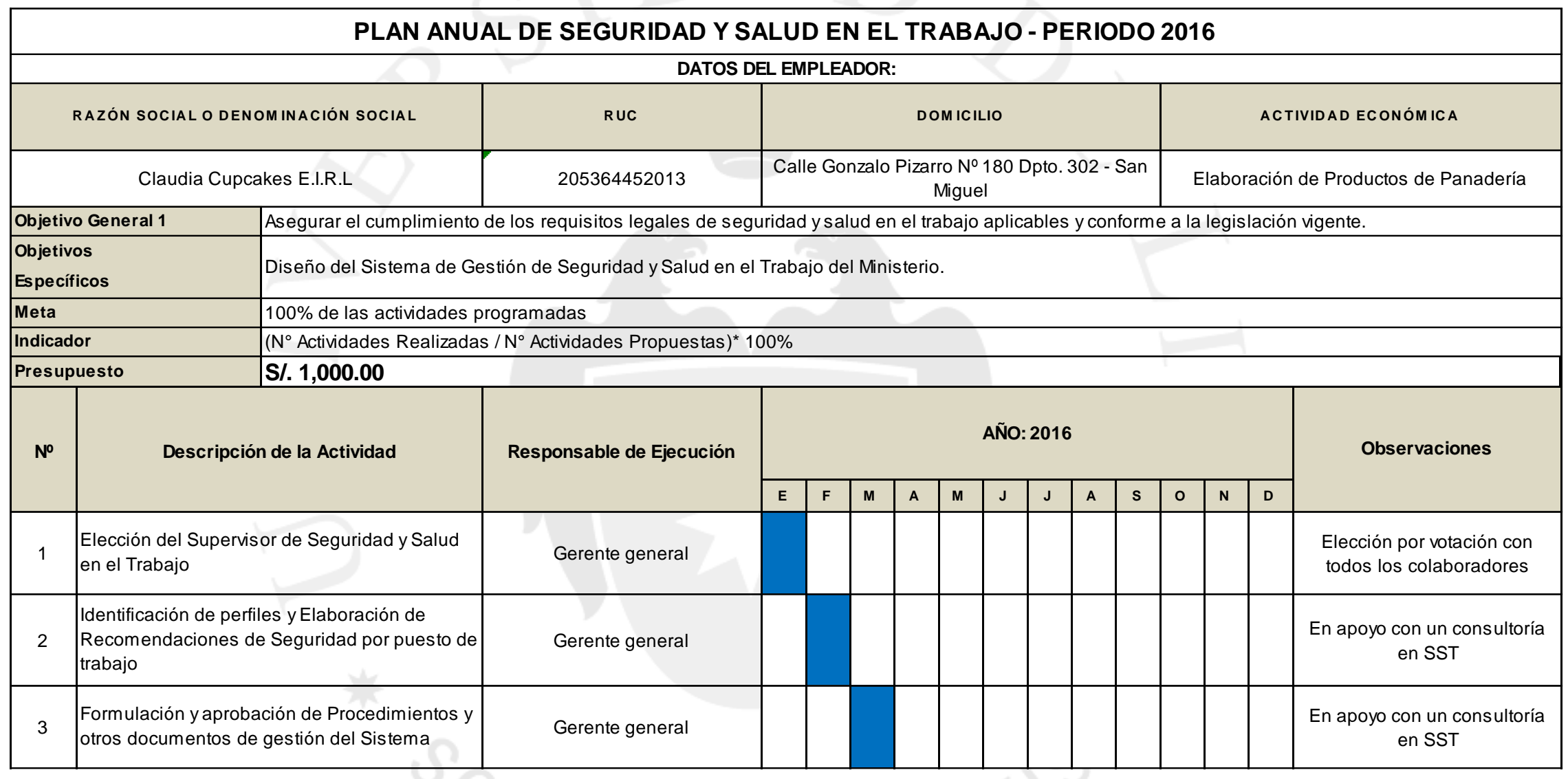




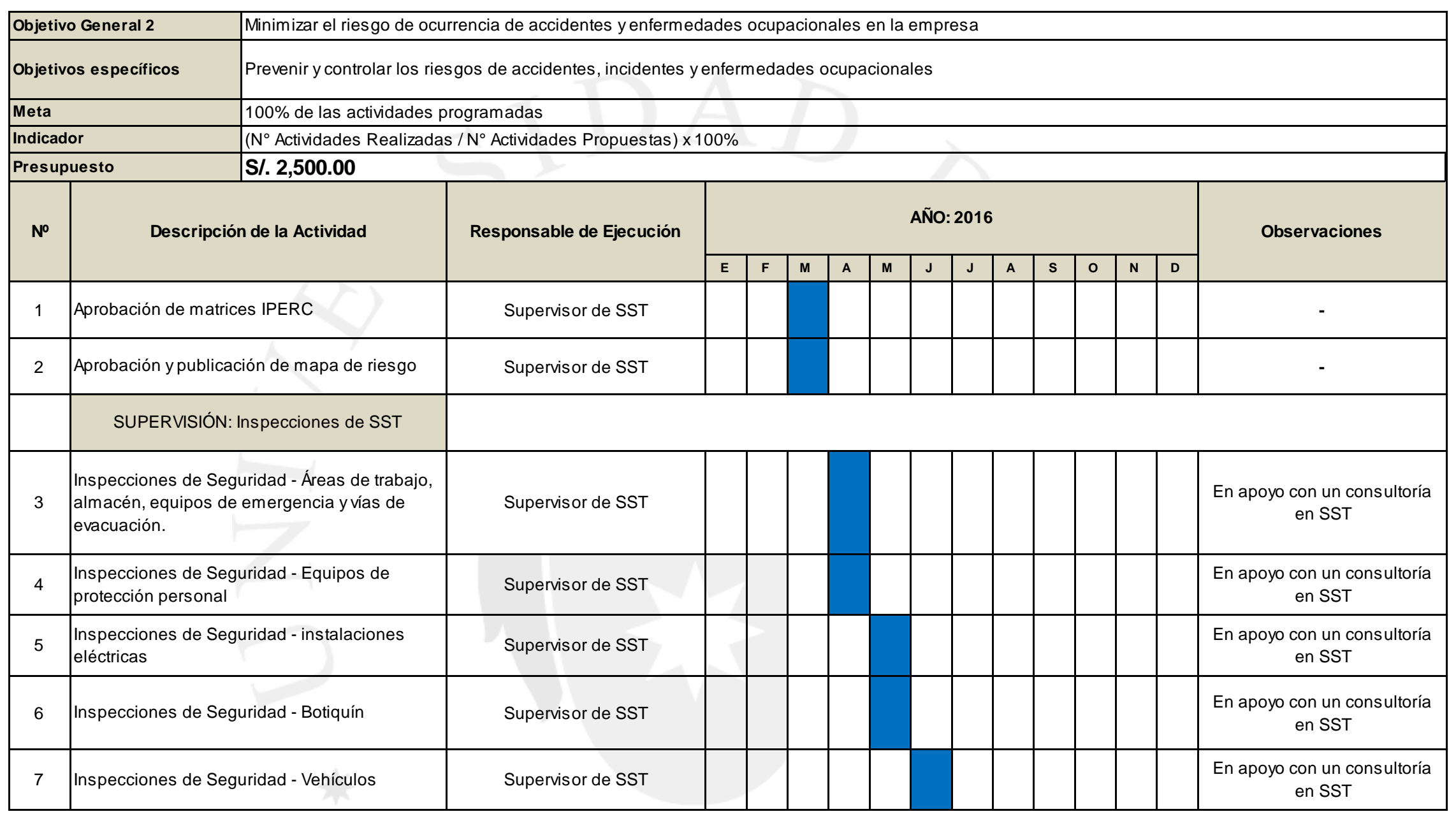




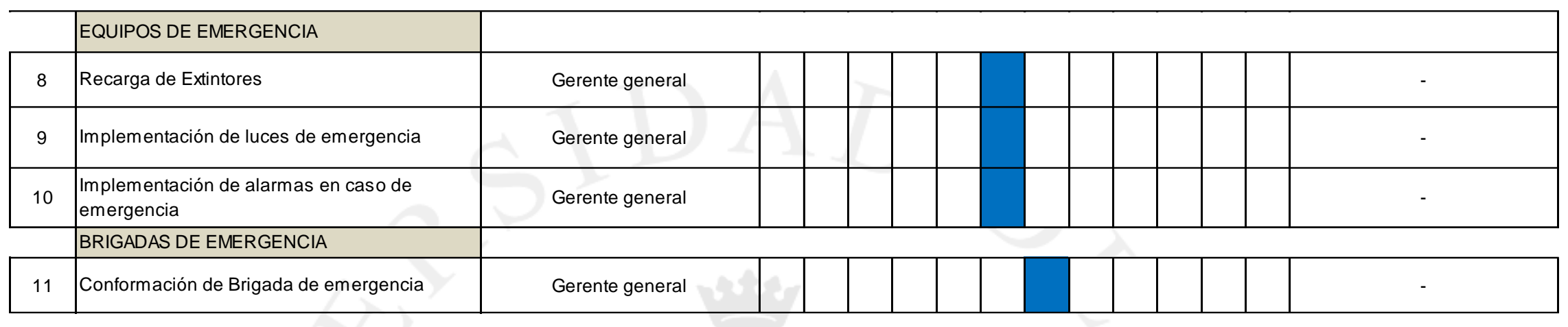

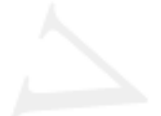

\begin{tabular}{|c|c|c|c|c|c|c|c|c|c|c|c|c|c|c|c|c|}
\hline \multicolumn{2}{|c|}{ Objetivo General 3} & \multicolumn{15}{|c|}{ Difundir y afianzar la cultura de prevención en temas concernientes a las Seguridad y Salud en el Trabajo en todo el personal } \\
\hline \multicolumn{2}{|c|}{\begin{tabular}{|l|} 
Objetivos \\
Específicos
\end{tabular}} & \multicolumn{11}{|c|}{ Realizar actividades de capacitación, inducción, entrenamientos y simulacros. } & \\
\hline \multicolumn{2}{|l|}{ Meta } & \multicolumn{7}{|c|}{ Capacitación del $100 \%$ de los trabajadores } & & & & & 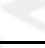 & & & \\
\hline \multirow{3}{*}{\multicolumn{2}{|c|}{ Indicador }} & \multicolumn{15}{|c|}{ (№ de capacitaciones, inducciones, simulacros ejecutados / № de capacitaciones, inducciones, simulacros ejecutados programados) } \\
\hline & & \multicolumn{15}{|c|}{ (№ de trabajadores que participaron en el simulacro / № total de trabajadores) } \\
\hline & & \multicolumn{15}{|c|}{ (№ de trabajadores capacitados por capacitación / № de trabajadores programados por capacitación) } \\
\hline \multicolumn{2}{|c|}{ Presupuesto } & \multicolumn{15}{|l|}{ S/. 1,600.00 } \\
\hline \multirow{2}{*}{ № } & \multirow{2}{*}{\multicolumn{2}{|c|}{ Descripción de la Actividad }} & \multirow{2}{*}{ Responsable de Ejecución } & \multicolumn{12}{|c|}{ AÑO: 2016} & \multirow{2}{*}{ Observaciones } \\
\hline & & & & $\mathrm{E}$ & $\mathbf{F}$ & M & A & M & $\mathrm{J}$ & $\mathrm{J}$ & A & $\mathrm{s}$ & 0 & $\mathbf{N}$ & $\mathrm{D}$ & \\
\hline 1 & \multicolumn{2}{|c|}{ Programa anual de Capacitaciones en SST } & Gerente general & & & & & & & & & & & & & $\begin{array}{c}\text { En coordiación con consultoría } \\
\text { en SST }\end{array}$ \\
\hline
\end{tabular}




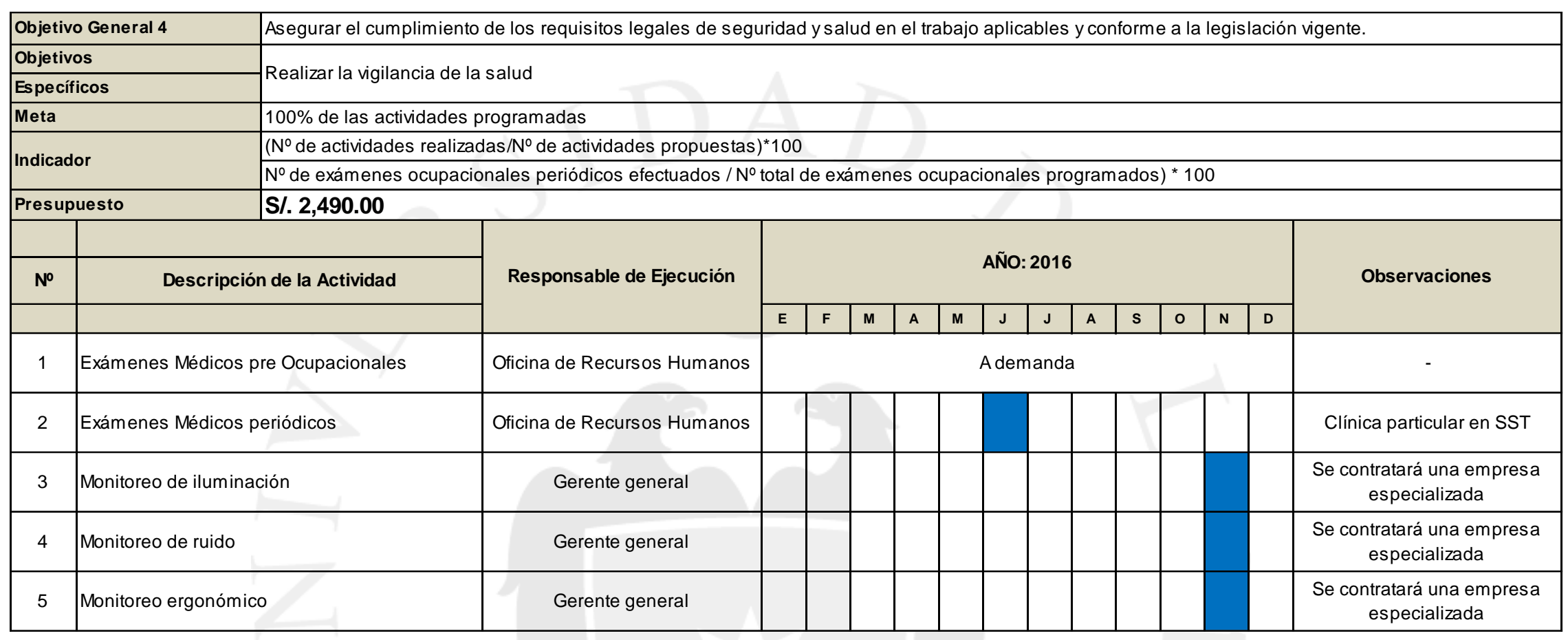




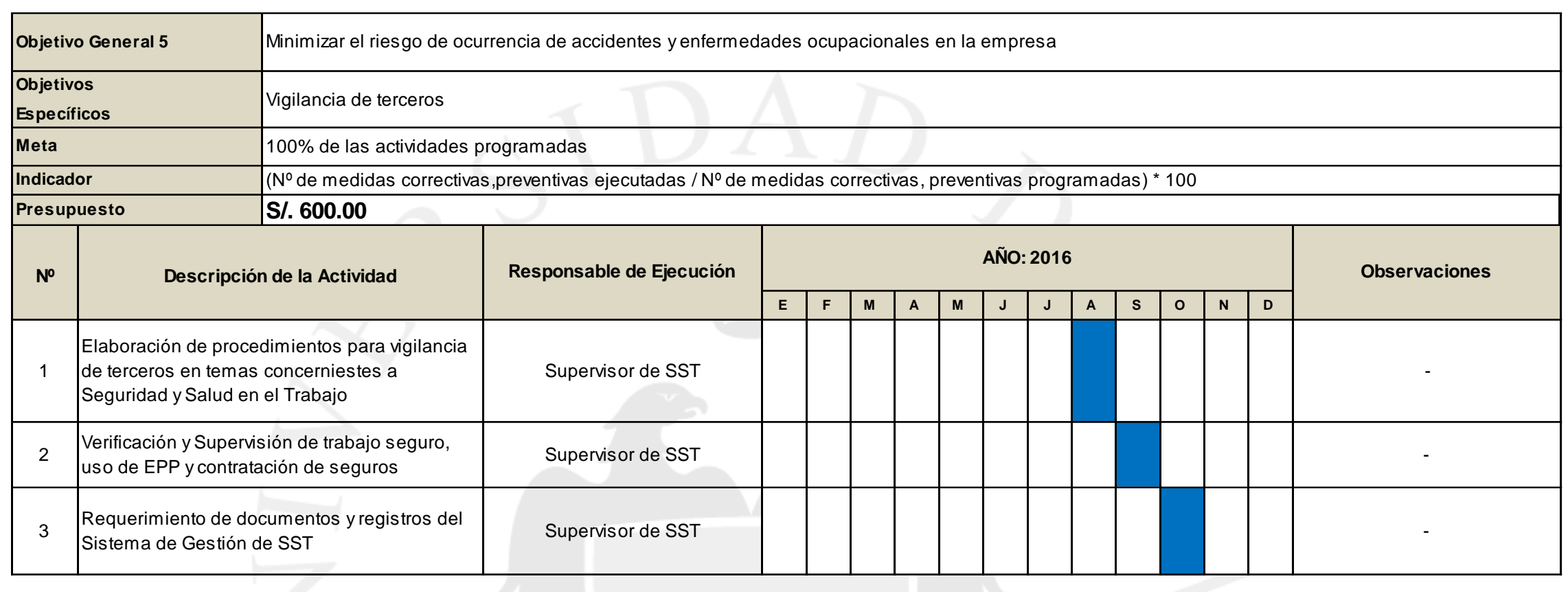




\begin{tabular}{|c|c|c|c|c|c|c|c|c|c|c|c|c|c|c|c|c|}
\hline \multirow{2}{*}{\multicolumn{2}{|c|}{\begin{tabular}{|l} 
Objetivo General 6 \\
Objetivos \\
Específicos \\
\end{tabular}}} & \multicolumn{15}{|c|}{ Difundir y afianzar la cultura de prevención en temas concernientes a las Seguridad y Salud en el Trabajo en todo el personal } \\
\hline & & \multicolumn{15}{|c|}{ Fomentar la mejora continua del sistema } \\
\hline \multicolumn{2}{|c|}{ Meta } & \multicolumn{15}{|c|}{$100 \%$ de las actividades programadas } \\
\hline \multicolumn{2}{|c|}{ Indicador } & \multicolumn{15}{|c|}{ (№ de actividades realizadas / № de actividades propuestas) ${ }^{*} 100$} \\
\hline \multicolumn{2}{|c|}{ Presupuesto } & \multicolumn{15}{|l|}{$\mathrm{S} / .800 .00$} \\
\hline \multirow{2}{*}{ № } & \multirow{2}{*}{\multicolumn{2}{|c|}{ Descripción de la Actividad }} & \multirow{2}{*}{ Responsable de Ejecución } & \multicolumn{12}{|c|}{ AÑO: 2016} & \multirow{2}{*}{ Observaciones } \\
\hline & & & & E & $\mathbf{F}$ & M & A & M & $\mathrm{J}$ & J & A & $\mathrm{s}$ & 0 & N & D & \\
\hline 1 & Investigación & dentes e incidentes & Supervisor de SST & \multicolumn{12}{|c|}{ Ademanda } & - \\
\hline 2 & $\begin{array}{l}\text { Registros de } \\
\text { № 082-2013 }\end{array}$ & gún Resolución Ministerial & Gerencia general & \multicolumn{12}{|c|}{ Mensual } & - \\
\hline 3 & $\begin{array}{l}\text { Elaboración } \\
\text { periódico mu }\end{array}$ & rial informativo en & Gerencia general & \multicolumn{12}{|c|}{ Mensual } & - \\
\hline 4 & \multicolumn{2}{|c|}{ Auditoría del Sistema de Gestión de SST } & Gerencia general & & & & & & & & & & & & & - \\
\hline 5 & Seguimiento & dores de gestión & $\begin{array}{l}\text { Supervisor de SST / Gerencia } \\
\text { general }\end{array}$ & \multicolumn{12}{|c|}{ Mensual } & - \\
\hline
\end{tabular}




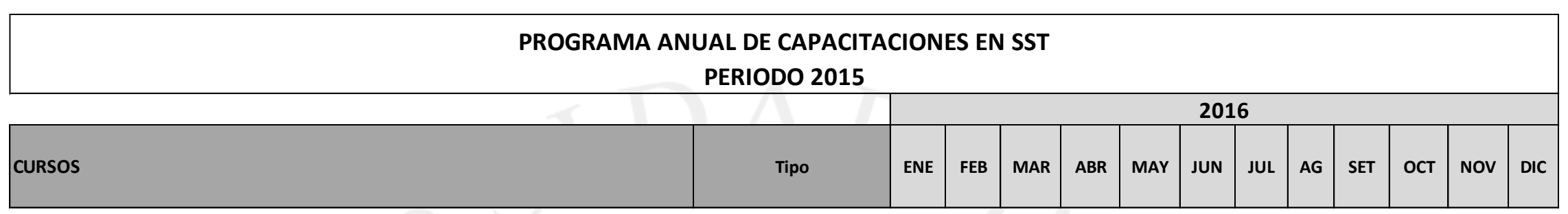

PERSONAL NUEVO

Inducción en SST

\begin{tabular}{|l|l|l|l|l|l|l|l|l|l|l|l|l|}
\hline nducción & & & & & & & & & & & & \\
\hline
\end{tabular}

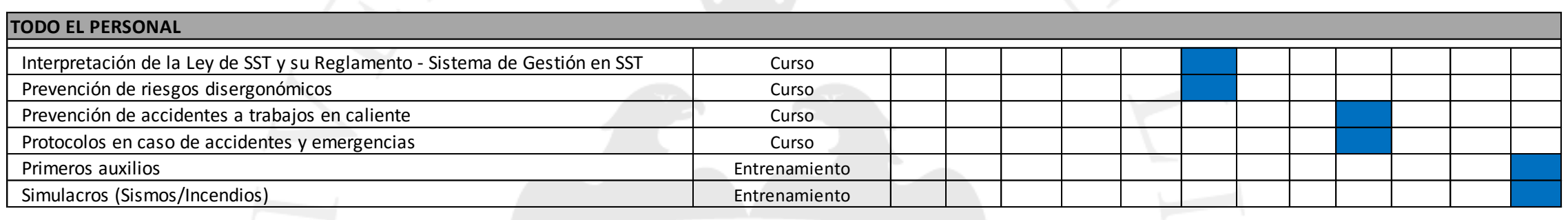

\section{SUPERVISOR DE SST}

Inspecciones de SST

\begin{tabular}{|l}
\hline Análisis de riesgos laborales \\
\hline
\end{tabular}

Curso/Taller

Curso/Taller
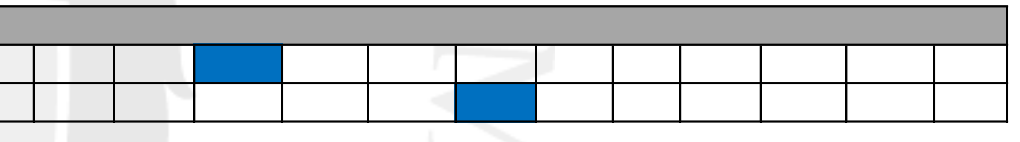

Tabla 8. 39: Plan anual de Seguridad y Salud en el Trabajo 2016 propuesto. 


\section{- Beneficios}

Una empresa socialmente responsable en sus procesos internos y en el cuidado de sus trabajadores es muy bien vista en el mercado y esto puede ser una gran puerta de entrada a nuevas oportunidades de negocio. Así, entonces, tenemos:

- Empresa con buena percepción en el mercado: "Socialmente responsable".

- Cuidado de sus colaboradores.

- Reducción o mitigación de los riesgos en sus procesos y que afecten la salud.

Como mejora, consideramos que una vez aplicado el sistema de SST en la empresa, reduciremos el Nivel de accidentes leves por trabajador a $0 \%$. Asimismo, el ahorro más importante será cuantificado mediante el riesgo de obtener una multa por inspección de la SUNAFIL y no contar con sistema de SST. El cálculo del ahorro se muestra en los siguientes cuadros:

Tabla 8. 40: Beneficios de implementar un sistema de SST.

\begin{tabular}{|c|c|}
\hline \multicolumn{1}{|c|}{ Concepto } & Ahorro (S/.) \\
\hline Costo anual de accidentes leves & 115.00 \\
\hline Multa por no contar con un sistema de SST & $28,500.00$ \\
\hline BENEFICIO TOTAL & $\mathbf{2 8 , 6 1 5 . 0 0}$ \\
\hline
\end{tabular}


Tabla 8. 41: Mejora en el indicador de Nivel de accidentes por trabajador.

Nivel de accidentes leves por trabajador

\begin{tabular}{|c|c|}
\hline Actual & Mejora \\
\hline $0.12 \%$ & $0 \%$ \\
\hline
\end{tabular}

Para nuestro análisis, consideramos que si bien hemos planteado una propuesta en la implementación de un sistema de SST, éste sería mejor elaborado y validado por una empresa consultora, la cual tendría una inversión como se muestra:

Tabla 8. 42: Inversión estimada para la implementación de un sistema de SST.

\begin{tabular}{|c|c|}
\hline Concepto & Costo (S/.) \\
\hline $\begin{array}{c}\text { Implementación de un Sistema en } \\
\text { Seguridad y Salud en el Trabajo }\end{array}$ & $8,900.00$ \\
\hline INVERSIÓN TOTAL & $\mathbf{8 , 9 0 0 . 0 0}$ \\
\hline
\end{tabular}

Cabe acotar que esta inversión será un solo flujo puesto será para contratar los servicios de la empresa consultora y que pueda dar los lineamientos para mantener la continuidad de lo propuesto. 


\subsection{Evaluación económica y social de las propuestas}

\subsubsection{Análisis Beneficio/Costo}

\section{a. INVERSIONES}

A continuación, mostramos los montos estimados de inversión para la implementación de las propuestas de mejora planteadas en el capítulo anterior:

\section{- Elaboración de un Plan Estratégico}

Para nuestro análisis, consideramos que si bien hemos planteado una propuesta en la implementación de un plan estratégico adecuado a la empresa, éste sería mejor elaborado y validado por una empresa consultora, la cual tendría una inversión como se muestra:

Tabla 8. 43: Inversión en la implementación de un plan estratégico.

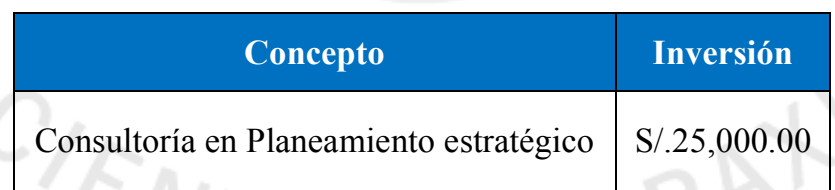

Cabe acotar que esta inversión será un solo flujo puesto será para contratar los servicios de la empresa consultora y que pueda dar los lineamientos para mantener la continuidad de lo propuesto. 


\section{- Re - disposición de planta}

El presupuesto para la adecuación de ambientes y el re disposición de la planta se muestra en el siguiente cuadro:

Tabla 8. 44: Costos de inversión para la nueva disposición de planta.

\begin{tabular}{|l|c|r|r|}
\cline { 2 - 4 } \multicolumn{1}{c|}{} & $\begin{array}{c}\text { Cantidad } \\
\text { (und.) }\end{array}$ & $\begin{array}{c}\text { Costo unitario } \\
\text { (S/.) }\end{array}$ & $\begin{array}{c}\text { Inversión total } \\
\text { (S/.) }\end{array}$ \\
\hline Desplazamiento de maquinaria & 2 & 150.00 & 300.00 \\
\hline Alquiler de espacio adicional & 1 & $1,300.00$ & $1,300.00$ \\
\hline Unificación de ambientes & 1 & 569.00 & 569.00 \\
\hline Acarreo y eliminación de desmonte & 1 & 150.00 & 150.00 \\
\hline Pallets & 2 & 30.00 & 60.00 \\
\hline Mesa de trabajo & 1 & $1,670.00$ & $1,670.00$ \\
\hline Estantes/anaqueles & 2 & 250.00 & 500.00 \\
\hline Adecuación de sistema eléctrico & 1 & 300.00 & 300.00 \\
\hline Nuevo baño & 1 & $7,500.00$ & $7,500.00$ \\
\hline \multicolumn{2}{|c}{} & & $\mathbf{1 2 , 3 4 9 . 0 0}$ \\
\hline
\end{tabular}

\section{- Aplicación de la metodología 5S}

Para la implementación de las metodología 5'S estamos añadiendo la compra de cajas que facilitarán la labor de los trabajadores. En el cuadro siguiente se muestra la inversión total para la aplicación de esta metodología: 
Tabla 8. 45: Montos de inversión para la implementación del programa 5S.

\begin{tabular}{|l|c|r|r|}
\cline { 2 - 4 } \multicolumn{1}{c|}{} & $\begin{array}{c}\text { Cantidad } \\
\text { (unid.) }\end{array}$ & $\begin{array}{c}\text { Costo } \\
\text { unitario } \\
\text { (S/.) }\end{array}$ & $\begin{array}{c}\text { Costo total } \\
\text { anual } \\
\text { (S/.) }\end{array}$ \\
\hline Tarjetas & 1,000 & 0.07 & 70 \\
\hline Proyector & 1 & 1,263 & 1,263 \\
\hline Ecran & 1 & 326 & 326 \\
\hline Cajas & 25 & 15 & 375 \\
\hline \multicolumn{3}{|c|}{ TOTAL } & $\mathbf{2 , 0 3 4}$ \\
\hline
\end{tabular}

\section{- Implementación plan HACCP}

Para la elaboración del plan se contratara una consultoría externa. La inversión anual para la contratación del proveedor se muestra a continuación:

Tabla 8. 46: Inversión para la implementación de un sistema HACCP.

\begin{tabular}{|l|c|r|r|}
\cline { 2 - 4 } \multicolumn{1}{c|}{} & $\begin{array}{c}\text { Cantidad } \\
\text { (unid.) }\end{array}$ & $\begin{array}{c}\text { Costo unitario } \\
\text { (S/.) }\end{array}$ & $\begin{array}{c}\text { Costo total anual } \\
\text { (S/.) }\end{array}$ \\
\hline Desarrollo del Plan HACCP & 1 & $12,000.00$ & $12,000.00$ \\
\hline Capacitación HACCP & 3 & 500.00 & $1,500.00$ \\
\hline $\begin{array}{l}\text { Costo de requisitos - análisis } \\
\text { microbiológico }\end{array}$ & 24 & 50.00 & $1,200.00$ \\
\hline \multicolumn{2}{|c|}{ TOTAL } & $\mathbf{1 4 , 7 0 0 . 0 0}$ \\
\hline
\end{tabular}




\section{- Implementación de un sistema de PCP en base a un MRP}

Como se mencionó anteriormente, para poder llevar a cabo la realización de éstas propuestas puede contarse con el apoyo de un practicante que conozca los aspectos básicos en estos temas; es decir, que se encuentre ya en la etapa casi final de su carrera (Ingeniería Industrial) para que de esa forma pueda aplicar sus conocimientos en la empresa:

Tabla 8. 47: Costos de implementación de un sistema de PCP.

\begin{tabular}{|l|c|}
\cline { 2 - 2 } \multicolumn{1}{c|}{} & $\begin{array}{c}\text { Costo total anual } \\
\text { (S/.) }\end{array}$ \\
\hline Practicante de Ing. Industrial & $10,150.00$ \\
\hline
\end{tabular}

\section{- Implementación de las bases para un sistema de SST}

Para nuestro análisis, consideramos que si bien hemos planteado una propuesta en la implementación de un sistema de SST, éste sería mejor elaborado y validado por una empresa consultora, la cual tendría una inversión como se muestra:

Tabla 8. 48: Inversión para la implementación de un sistema de SST.

\begin{tabular}{|c|c|}
\hline Concepto & Inversión \\
\hline $\begin{array}{c}\text { Implementación de un Sistema en } \\
\text { Seguridad y Salud en el Trabajo }\end{array}$ & $\mathrm{S} / .8,900.00$ \\
\hline
\end{tabular}


Cabe acotar que esta inversión será un solo flujo puesto será para contratar los servicios de la empresa consultora y que pueda dar los lineamientos para mantener la continuidad de lo propuesto.

\section{b. BENEFICIOS}

De la misma manera que en el punto anterior, a continuación presentamos los beneficios que estimamos percibir a razón de la implementación de las propuestas planteadas anteriormente:

\section{- Mejora en el nivel de rechazos de productos en proceso}

La implementación del plan HACCP busca asegurar inocuidad al 100\% del total de la producción de la empresa. Como no se puede asegurar que no se tendrá ningún producto defectuoso, se tomara una efectividad gradual del $25 \%$ anual de la solución propuesta.

El número de cupcakes rechazados en el proceso antes y después de la mejora se muestra a continuación:

Tabla 8. 49: Mejora en el número de cupcakes rechazados en proceso.

\begin{tabular}{|c|c|c|c|c|c|}
\hline \multicolumn{7}{|c|}{ Número de cupcakes rechazados en proceso } \\
\hline Actual & Año 1 & Año 2 & Año 3 & Año 4 & Año 5 \\
\hline 16,800 & 12,600 & 9,450 & 7,088 & 5,316 & 3,987 \\
\hline
\end{tabular}

Ahora se muestran los cálculos del costo de reprocesamiento de cupcakes: 
Tabla 8. 50: Costos de reprocesamiento de cupcakes.

\begin{tabular}{|c|c|}
\hline Costo de producción anual (S/.) & $723,983.39$ \\
\hline Producción (cupcakes/año) & 202,415 \\
\hline Costo unitario (S/. / cupcake) & 3.58 \\
\hline
\end{tabular}

Con la implementación de la mejora los costos del reproceso irán disminuyendo anualmente, la empresa generaría un ahorro importante, tal cual se muestra en el cuadro siguiente:

Tabla 8. 51: Ahorro anual de reprocesos implementando HACCP.

\begin{tabular}{|c|c|c|c|c|}
\hline \multicolumn{5}{|c|}{ Ahorro anual de reproceso (S/.) } \\
\hline Año 1 & Año 2 & Año 3 & Año 4 & Año 5 \\
\hline 15,022 & 11,267 & 8,450 & 6,338 & 4,753 \\
\hline
\end{tabular}

Finalmente, con la mejora propuesta reducimos el indicador de Nivel de rechazos de productos en proceso. Dicho indicador se muestra en el cuadro que sigue:

Tabla 8. 52: Mejora en el nivel de rechazos de productos en proceso.

\begin{tabular}{|c|c|c|c|c|c|}
\hline \multicolumn{7}{|c|}{ Nivel de rechazos de productos en proceso } \\
\hline Actual & Año 1 & Año 2 & Año 3 & Año 4 & Año 5 \\
\hline $8.3 \%$ & $6.2 \%$ & $4.7 \%$ & $3.5 \%$ & $2.6 \%$ & $2.0 \%$ \\
\hline
\end{tabular}

\section{- Mejora en el nivel de pedidos defectuosos}

De igual forma no se puede asegurar que no se tendrá ningún rechazo de producto terminado por parte del cliente, es por esto que se tomara una efectividad gradual del $25 \%$ anual de la solución propuesta. 
El número de pedidos rechazados por clientes antes y después de la mejora se muestran a continuación:

Tabla 8. 53: Mejora en el número de pedidos defectuosos.

\begin{tabular}{|c|c|c|c|c|c|}
\hline \multicolumn{7}{|c|}{ Proyección de impacto en numero de pedidos defectuosos } \\
\hline Actual & Año 1 & Año 2 & Año 3 & Año 4 & Año 5 \\
\hline 560 & 420 & 315 & 236 & 177 & 133 \\
\hline
\end{tabular}

Cabe señalar que la totalidad del pedido no se repone, por lo que consideramos que en promedio se tiene que reponer un $16 \%$ del mismo.

Tabla 8. 54: Proyección de la cantidad de pedidos a reprocesar con la mejora.

\begin{tabular}{|c|c|c|c|c|c|}
\hline \multicolumn{7}{|c|}{ Proyección de la cantidad de pedidos a reprocesar con la mejora } \\
\hline Antes & Año 1 & Año 2 & Año 3 & Año 4 & Año 5 \\
\hline 90 & 67 & 50 & 38 & 28 & 21 \\
\hline
\end{tabular}

Ahora mostramos los cálculos del costo de reposición por pedido, tomando en cuenta el tiempo de reposición promedio es de 2 horas por pedido: 
Tabla 8. 55: Proyección para los costos de reposición anual con la mejora.

\begin{tabular}{|l|c|c|c|c|c|c|}
\hline \multicolumn{1}{|c|}{ Costo anual (S/.) } & Actual & Año 1 & Año 2 & Año 3 & Año 4 & Año 5 \\
\hline $\begin{array}{l}\text { Reproceso de pedidos } \\
\text { defectuosos }\end{array}$ & 13,628 & 10,221 & 7,666 & 5,749 & 4,312 & 3,234 \\
\hline $\begin{array}{l}\text { Traslado para reposición } \\
\text { combustible) }\end{array}$ & 527 & 395 & 296 & 222 & 167 & 125 \\
\hline Traslado para reposición (MO) & 1,057 & 793 & 595 & 446 & 334 & 251 \\
\hline Costo total anual de reposición & $\mathbf{1 5 , 2 1 2}$ & $\mathbf{1 1 , 4 0 9}$ & $\mathbf{8 , 5 5 7}$ & $\mathbf{6 , 4 1 7}$ & $\mathbf{4 , 8 1 3}$ & $\mathbf{3 , 6 1 0}$ \\
\hline
\end{tabular}

Con la implementación de la mejora lograra un ahorro anual, el cual se muestra a continuación:

Tabla 8. 56: Proyección de ahorros anuales en pedidos defectuosos con la mejora.

\begin{tabular}{|c|c|c|c|c|}
\hline \multicolumn{5}{|c|}{ Proyección de ahorro anual de pedidos defectuosos (S/.) } \\
\hline Año 1 & Año 2 & Año 3 & Año 4 & Año 5 \\
\hline 3,803 & 2,852 & 2,139 & 1,604 & 1,203 \\
\hline
\end{tabular}

Finalmente, con la mejora propuesta reducimos el indicador de Nivel de pedidos defectuosos. Dicho indicador se muestra como sigue:

Tabla 8. 577: Proyección de la mejora en el indicador del nivel de pedidos defectuosos.

\begin{tabular}{|c|c|c|c|c|c|}
\hline \multicolumn{7}{|c|}{ Proyección de indicador de nivel de pedidos defectuosos } \\
\hline Actual & Año 1 & Año 2 & Año 3 & Año 4 & Año 5 \\
\hline $12 \%$ & $9 \%$ & $7 \%$ & $5 \%$ & $4 \%$ & $3 \%$ \\
\hline
\end{tabular}

\section{- Incremento en las ventas}


Por otro lado, como beneficio de establecer un planeamiento estratégico en la empresa, se espera poder tener un impacto directo en la participación del mercado de la empresa, incrementando las ventas durante el primer año en un estimado del $10 \%$, siendo moderadamente conservadores. Así, tendríamos cuantificado este impacto:

Tabla 8.58: Beneficio en el incremento de las ventas.

\begin{tabular}{|c|c|}
\hline Concepto & Valor \\
\hline Ventas anuales durante el 2014 & $\mathrm{S} / .1^{\prime}$ '410,671.11 \\
\hline $\begin{array}{c}\text { Ventas estimadas con el planteamiento } \\
\text { de la mejora }\end{array}$ & $\mathrm{S} / .1^{\prime} 551,738.22$ \\
\hline Incremento & $\mathrm{S} / . \mathbf{1 4 1 , 0 6 7 . 1 1}$ \\
\hline
\end{tabular}


Como resumen a lo presentado, tenemos:

Tabla 8.59: Resumen de flujos económicos para la implementación de mejoras.

\begin{tabular}{l|r|r|r|r|r|r|r}
\multicolumn{1}{c|}{ COSTO/INVERSIÓN } & \multicolumn{1}{|c|}{ Año 0 } & Año 1 & Año 2 & Año 3 & Año 4 & Año 5 & Total Acumulado \\
\hline Disposición de planta & 12,349 & & & & & & \\
Metodología 5S & 2,034 & & & & & 2,034 \\
HACCP & 14,700 & & & & & 14,700 \\
PCP & - & 10,150 & 10,150 & 10,150 & 10,150 & 10,150 & 50,750 \\
SST & 8,900 & & & & & 8,900 \\
Planeamiento Estratégico & 25,000 & & & & & 25,000 \\
\cline { 2 - 7 } & $\mathbf{6 2 , 9 8 3}$ & $\mathbf{1 0 , 1 5 0}$ & $\mathbf{1 0 , 1 5 0}$ & $\mathbf{1 0 , 1 5 0}$ & $\mathbf{1 0 , 1 5 0}$ & $\mathbf{1 0 , 1 5 0}$ & $\mathbf{1 1 3 , 7 3 3}$
\end{tabular}

\begin{tabular}{l|r|r|r|r|r|r|r} 
BENEFICIO/AHORRO & Año 0 & Año 1 & \multicolumn{1}{c|}{ Año 2 } & Año 3 & Año 4 & Año 5 & Total Acumulado \\
\hline Disposición de planta / 5'S & & 142,623 & 142,623 & 142,623 & 142,623 & 142,623 & 713,117 \\
HACCP NRPP & 15,022 & 11,267 & 8,450 & 6,338 & 4,753 & 45,830 \\
HACCP NPD & & 2,803 & 2,852 & 2,139 & 1,604 & 1,203 & 11,601 \\
SST & & 5,723 & 5,723 & 5,723 & 5,723 & 5,723 & 28,615 \\
Planeamiento Estratégico & & 141,067 & 141,067 & 141,067 & 141,067 & 141,067 & 705,336 \\
\cline { 2 - 7 } & & $\mathbf{3 0 8 , 2 3 9}$ & $\mathbf{3 0 3 , 5 3 3}$ & $\mathbf{3 0 0 , 0 0 3}$ & $\mathbf{2 9 7 , 3 5 6}$ & $\mathbf{2 9 5 , 3 7 0}$ & $\mathbf{1 , 5 0 4 , 4 9 9}$
\end{tabular}

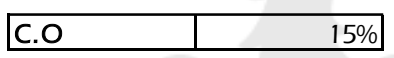

\begin{tabular}{|l|r|}
\hline \multicolumn{2}{|c|}{ Resultados } \\
\hline VAN & 384,159 \\
\hline TIR & $246 \%$ \\
\hline B/C & 3 \\
\hline
\end{tabular}

\subsubsection{Impacto social}

El proyecto generará un impacto social en los siguientes aspectos clave:

a. Satisfacción del cliente Externo: Con las propuestas planteadas, no sólo se ofrecerá un producto de calidad al cliente final para cumplir con sus expectativas; sino también, para generar una mayor satisfacción en el cliente y poder así también alcanzar las metas en el mercado propuestas por la empresa. 
b. Satisfacción del cliente Interno: Parte del objetivo del planteamiento de las propuestas presentadas, es también mejorar el ambiente laboral interno que actualmente tiene la empresa, a fin de que la satisfacción de sus colaboradores se incremente y que se sientan motivados, lo que a la larga representa también un gran beneficio para la empresa pues esto va también acompañado de un incremento de la productividad.

\subsubsection{Impacto ambiental}

Si bien es cierto, la empresa actualmente no genera algún tipo de daño al medio ambiente con la producción que se realiza, no hay mejor carta de presentación hoy en día que una empresa sea socialmente responsable, eco amigable o con un desarrollo sostenible notable, razón por la cual al promover mejoras en algunos aspectos que involucra también temas ambientales, el beneficio será incluso en no clientes, puesto el impacto ambiental que la empresa tendrá será mínimo y no afectará a consumidores y no consumidores actuales. 


\section{Conclusiones}

A continuación detallaremos las conclusiones a las que hemos llegado a partir de nuestra investigación:

- El diagnóstico efectuado en la empresa Claudia Cupcakes muestra que uno de los principales factores que reduce la productividad son: la inadecuada disposición de planta que genera desperdicios en el recorrido y la baja utilización de las máquinas y equipos, lo cual eleva el costo unitario.

- Si bien la empresa tienen un especial cuidado por la calidad de los productos entregados al cliente; la implementación de un plan HACCP se mejoraran los niveles de rechazos durante la producción, generando ahorros por aplicar un mejor plan de aseguramiento de la calidad.

- Aun cuando la empresa muestra un aceptable nivel de servicio hacia el cliente, la implementación de un sistema de PCP contribuirá a elevar la productividad de la producción debido a una mejor asignación de las cargas de trabajo y ayudaría con la mayor utilización de las máquinas.

- Una buena estrategia de marketing y comercialización debería contribuir a una mayor participación en el mercado. La empresa tiene un gran mercado a favor frente a la competencia debido a la calidad de sus productos, generando así una ventaja competitiva pero que, en caso de no mejorar incluso aún más o capacitar a quienes son parte de ello, es decir al personal, podrían correr entonces el riesgo de perderlos e ir a empresas de la competencia. 
- De acuerdo al análisis económico-financiero, el proyecto tendrá un gran impacto económico, teniendo una inversión en la implementación de las mejoras de $\mathrm{S} / .63 \mathrm{M}$, $\mathrm{y}$ teniendo un retorno esperado en el primer año de S/.1.5MM. 


\section{Recomendaciones}

A continuación detallaremos nuestras recomendaciones:

- Se recomienda implementar la metodología 5s para complementar la nueva disposición de planta y así mantener los nuevos resultados de productividad.

- La implementación del plan HACCP, debería sustentarse con un adecuado proceso de capacitación y sensibilización al personal.

- Se recomienda la implementación y seguimiento de indicadores estratégicos para evaluar la eficacia y eficiencia de la gestión empresarial y promover la toma de decisión basado en resultados.

- Es necesario el compromiso, tanto de la dirección, como de los colaboradores de la empresa, para asegurar el buen funcionamiento y control de las medidas de solución propuestas en el presente estudio.

- Fomentar al personal trabajar bajo una cultura orientada al logro de objetivo. 


\section{Referencias}

Álvarez, J., \& Cánepa, N. (2013). Perfil del adulto joven. Lima Metropolitana: IPSOS Perú.

Álvarez, J., \& Cánepa, N. (2013). Perfil del niño. Lima Metropolitana: IPSOS Perú.

Diario Gestión. (5 de Junio de 2014). Al 2019 todas las ciudades del país contarán con centros comerciales. Gestión. Obtenido de www.gestion.pe.

ESAGESAC. (2014). Los Cupcakes. Panadería y Pastelería Peruana.

Hinostrosa Molina de Clausen, G. (2002). Pastelería Peruana. Lima: USMP.

Perú.com. (29 de Octubre de 2013). Doing Business: Perú es el segundo mejor país de América Latina para hacer negocios. Obtenido de Peru.com:

http://peru.com/actualidad/economia-y-finanzas/doing-business-2014-peru-segundomejor-lugar-america-latina-invertir-noticia-205371

Salas Oblitas, L. (09 de Setiembre de 2014). Se abrirán ocho supermercados en los próximos cuatro meses. Obtenido de El Comercio: http://elcomercio.pe/economia/negocios/ochosupermercados-se-sumarian-proximos-cuatro-meses-noticia-1755562 


\section{Bibliografía}

Bernuy Gálvez, K. R. (2006). Implementación de una propuesta para la mejora de la calidad en la atención del sistema de transporte asistido de emergencias (STAE) de ESSALUD. Trabajo de investigación para optar el título profesional de Ingeniero Industrial. Lima, Lima, Perú.

Brescia Boretano, A. (1984). Estudio preliminar técnico-económico para la implementación de una panadería pastelería en el dstrito de La Molina. Trabajo de investigacion para optar el título de Ingeniero Industrial. Lima, Lima, Perú.

Castillo Medina, A. (2009). Estudio de pre factibilidad para la instalación de una planta procesadora de productos de pastelería congelados. Trabajo para optar el título profesional de Ingeniero Industrial. Lima, Lima, Perú.

Delgado Moscoso, G. E. (2013). Mejora en el proceso de producción en una empresa de artes gráficas. Trabajo de investigación para optar el título de Ingeniero Industrial. Lima, Lima, Perú.

Donayre Jáuregui, J. R. (1989). Estudio de reinversión y re-disposición de planta para ampliar la produccion y diversificación de productos de panadería y pastelería en la ciudad de Huacho. Trabajo de investigación para optar el título profesional de Ingeniero Industrial. Lima, Lima, Perú.

León-Gambetta Martin-Arranz, Á. (2011). Estudio para la mejora integral del fundo San Crispín, prouctor de café. Trabajo de investigación para optar por el título profesional de Ingeniero Industrial. Lima, Lima, Perú.

Peralta Vidal, F. E. (2012). Mejora integral de un taller de servicios del sector automotriz. Trabajo de investigación para optar por el título profesional de Ingeniero Industrial. Lima, Lima, Peru. 


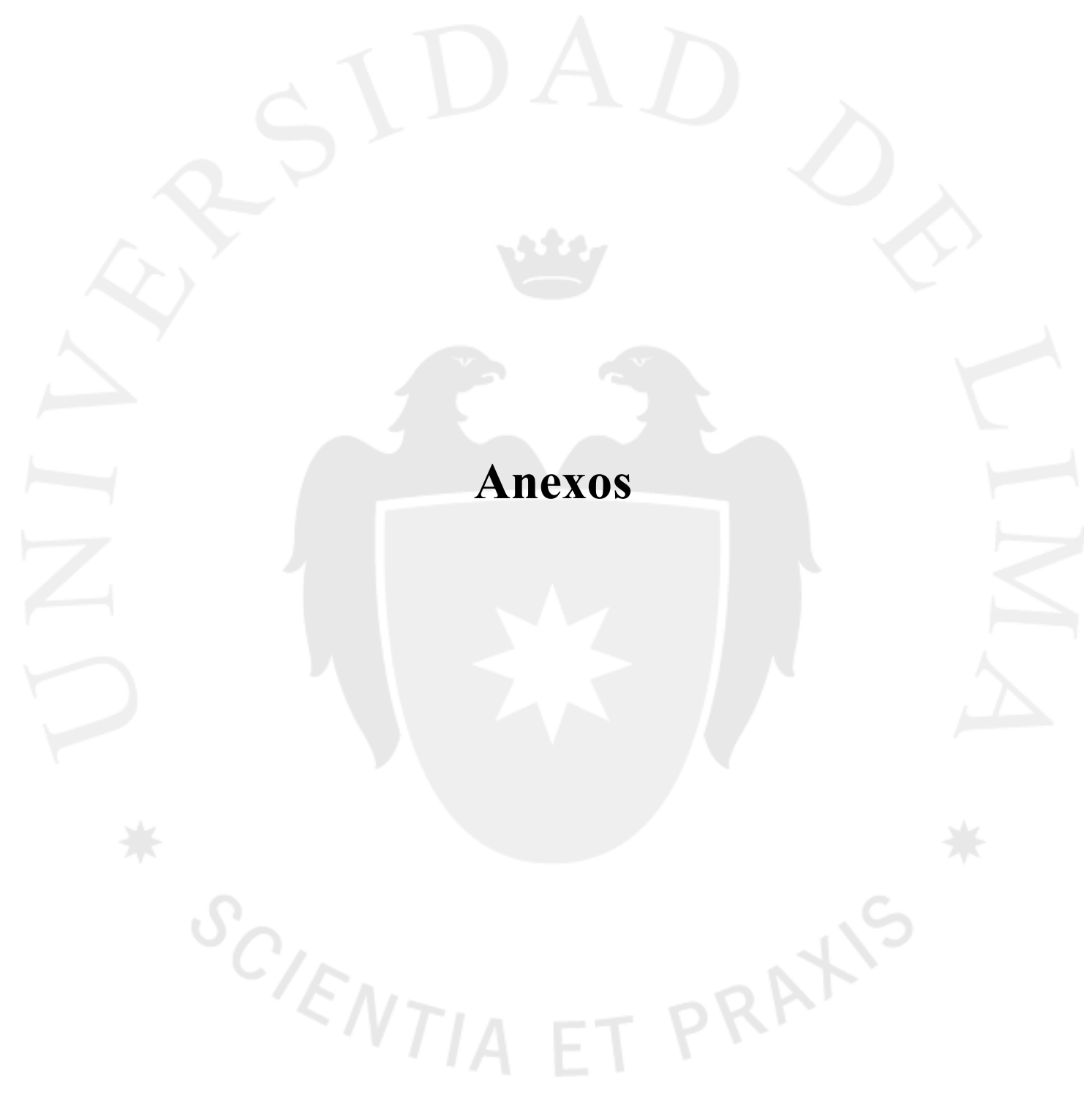


Anexo 1

Evaluación y Análisis de las 5 fuerzas competitivas de Porter aplicable a la empresa Claudia Cupcakes

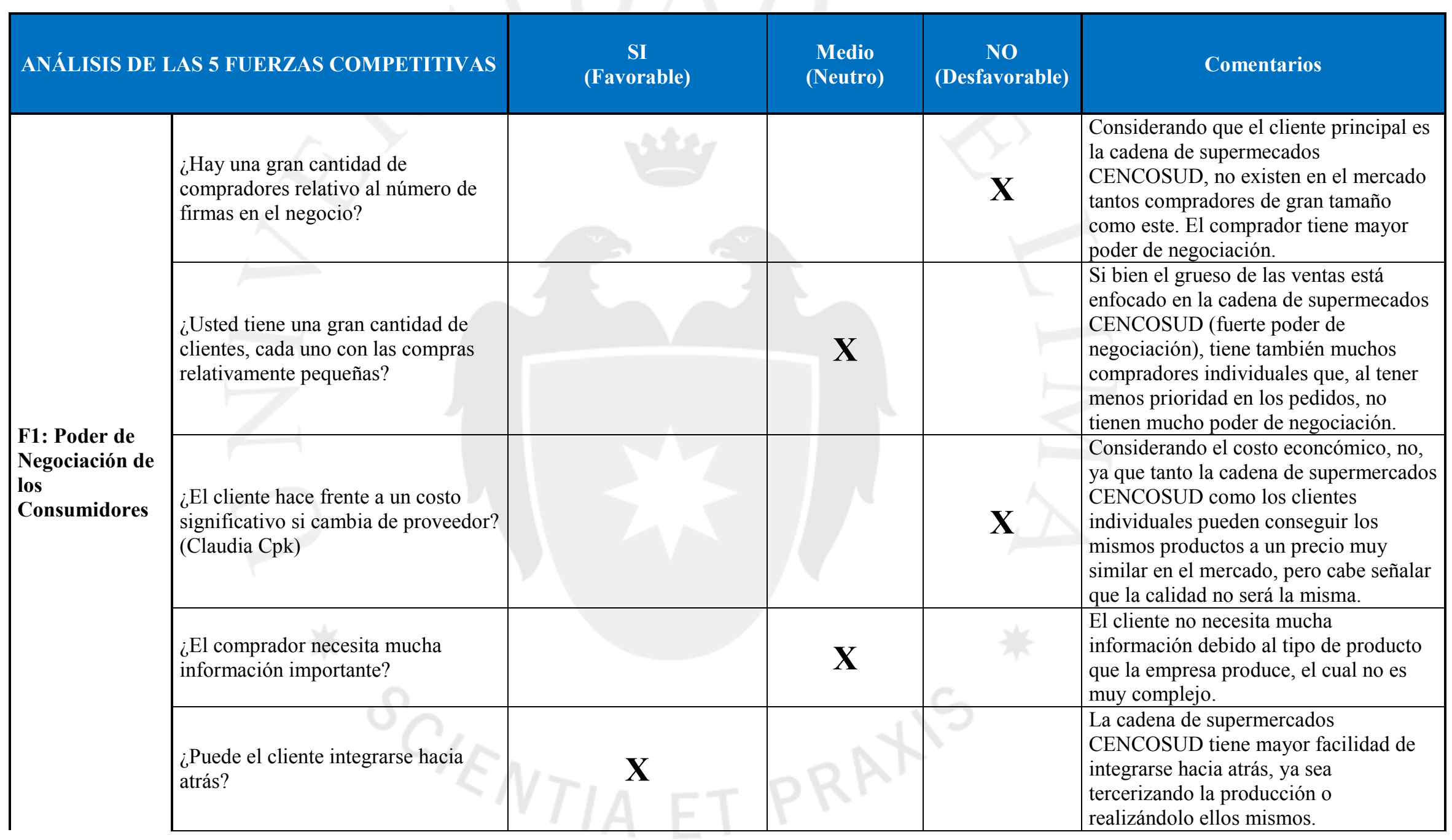




\begin{tabular}{|c|c|c|c|c|c|}
\hline \multicolumn{2}{|c|}{ ANÁLISIS DE LAS 5 FUERZAS COMPETITIVAS } & $\begin{array}{c}\text { SI } \\
\text { (Favorable) }\end{array}$ & \multirow[t]{2}{*}{$\begin{array}{l}\text { Medio } \\
\text { (Neutro) }\end{array}$} & $\begin{array}{c}\text { NO } \\
\text { (Desfavorable) }\end{array}$ & \multirow[b]{2}{*}{$\begin{array}{l}\text { Debido al sector al cual está orientado el } \\
\text { producto, además de la necesidad } \\
\text { principal por el producto en sí (diseño y } \\
\text { calidad del producto), probablemente el } \\
\text { cliente no se vea afectado por una } \\
\text { variación en el precio. }\end{array}$} \\
\hline & $\begin{array}{l}\text { ¿Sus clientes no son muy sensibles al } \\
\text { precio? }\end{array}$ & $\mathbf{X}$ & & & \\
\hline & $\begin{array}{l}\text { ¿Su producto es único en un cierto } \\
\text { grado o tiene una marca reconocida? }\end{array}$ & & & 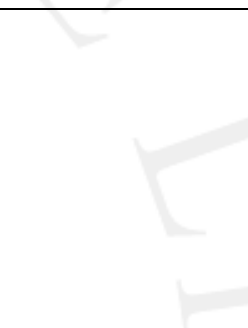 & $\begin{array}{l}\text { Si bien el producto no es algo único, no } \\
\text { por sus diseños que quizá si lo sean, si } \\
\text { no en cuanto a la finalidad de necesidad } \\
\text { de alimento, tiene si una marca } \\
\text { actualmente reconocida en el rubro, la } \\
\text { cual tiene la tendencia a seguir } \\
\text { creciendo y a seguir siendo más } \\
\text { competente en el mercado. }\end{array}$ \\
\hline & $\begin{array}{l}\text { ¿Son los negocios de sus clientes } \\
\text { lucrativos? }\end{array}$ & $\mathbf{X}$ & & & $\begin{array}{l}\text { Sólo la cadena de supermercados } \\
\text { CENCOSUD, es a quien se dirige el } \\
\text { mayor porcentaje de ventas. }\end{array}$ \\
\hline & TOTAL F1: & 3 & 3 & 2 & Alto \\
\hline \multirow{4}{*}{$\begin{array}{l}\text { F2: Poder de } \\
\text { Negociación de } \\
\text { los Proveedores }\end{array}$} & $\begin{array}{l}\text { ¿Mis insumos (materiales, trabajo, } \\
\text { provisiones, servicios, etc.) son } \\
\text { estándares más que únicos o } \\
\text { diferenciados? }\end{array}$ & & $\mathbf{X}$ & & $\begin{array}{l}\text { Por los insumos en general (harina, } \\
\text { huevo, aceite, etc.), estos son estándar, } \\
\text { mientras que los moldes, si se puede } \\
\text { considerar como tal al ser buscados y } \\
\text { comprados en el extranjero. }\end{array}$ \\
\hline & $\begin{array}{l}\text { ¿Es económico y rápido cambiar } \\
\text { entre proveedores? }\end{array}$ & & $\mathbf{X}$ & & La misma lógica que el punto anterior. \\
\hline & $\begin{array}{l}\text { ¿Mis proveedores encuentran difícil } \\
\text { entrar a mi negocio (integración } \\
\text { hacia adelante)? }\end{array}$ & $\mathbf{X}$ & & & $\begin{array}{l}\text { Si, por la especialización de los diseños } \\
\text { de los productos. }\end{array}$ \\
\hline & $\begin{array}{l}\text { ¿Puedo cambiar los insumos } \\
\text { realmente? }\end{array}$ & & & $\mathbf{X}$ & $\begin{array}{l}\text { Los ingredientes para poder hacer los } \\
\text { productos de pastelería son, en su } \\
\text { mayoría, estándar, por lo que no sería } \\
\text { algo fácil y adecuado cambiarlos. }\end{array}$ \\
\hline
\end{tabular}




\begin{tabular}{|c|c|c|c|c|c|}
\hline \multicolumn{2}{|c|}{ ANÁLISIS DE LAS 5 FUERZAS COMPETITIVAS } & \multirow{2}{*}{$\begin{array}{c}\text { SI } \\
\text { (Favorable) }\end{array}$} & \multirow{2}{*}{$\begin{array}{c}\begin{array}{c}\text { Medio } \\
\text { (Neutro) }\end{array} \\
\mathbf{X}\end{array}$} & \multirow{2}{*}{$\begin{array}{c}\text { NO } \\
\text { (Desfavorable) }\end{array}$} & \multirow{2}{*}{\begin{tabular}{|l}
\multicolumn{1}{|c}{ Comentarios } \\
$\begin{array}{l}\text { Sólo Puratos, considerando que también } \\
\text { se trasvasa la pre mezcla. }\end{array}$
\end{tabular}} \\
\hline & $\begin{array}{l}\text { ¿Tengo muchos proveedores } \\
\text { potenciales? }\end{array}$ & & & & \\
\hline & $\begin{array}{l}\text { ¿Mi negocio es importante para mis } \\
\text { proveedores? }\end{array}$ & & $X$ & & $\begin{array}{l}\text { Sólo Puratos, no se mantiene relación } \\
\text { estrecha con el resto de proveedores. }\end{array}$ \\
\hline & $\begin{array}{l}\text { ¿Mis costos de insumos no tienen } \\
\text { influencia significativa en mis costos } \\
\text { totales? }\end{array}$ & & & $\mathbf{X}$ & $\begin{array}{l}\text { Los costos de insumos son los } \\
\text { principales para la producción de la } \\
\text { empresa, por lo que en el esquema de } \\
\text { costos, éstos tienen, quizá, la mayor } \\
\text { relevancia. }\end{array}$ \\
\hline & TOTAL F2: & 1 & 4 & 2 & Medio \\
\hline \multirow{5}{*}{$\begin{array}{l}\text { F3: Amenaza } \\
\text { de nuevos } \\
\text { competidores } \\
\text { entrantes }\end{array}$} & $\begin{array}{l}\text { ¿Las grandes empresas tienen una } \\
\text { ventaja en costo o desempeño? }\end{array}$ & $X$ & & & $\begin{array}{l}\text { A más grande la compañía, } \\
\text { probablemente haya un mejor } \\
\text { desempeño de sus procesos y, por ende, } \\
\text { un mejor manejo de sus costos } \\
\text { operativos. }\end{array}$ \\
\hline & $\begin{array}{l}\text { ¿Hay diferencias en patentes } \\
\text { (marcas) en los productos de la } \\
\text { industria? }\end{array}$ & & & $\mathbf{X}$ & $\begin{array}{l}\text { No existen patentes en cuanto al } \\
\text { cupcake o al proceso de producción. }\end{array}$ \\
\hline & $\begin{array}{l}\text { ¿Hay identidades establecidas de } \\
\text { marca en su industria? }\end{array}$ & $\mathbf{X}$ & & & $\begin{array}{l}\text { Ya hay marcas grandes y medianas que } \\
\text { ya están establecidas con gran tiempo de } \\
\text { anterioridad. }\end{array}$ \\
\hline & $\begin{array}{l}\text { ¿Sus clientes incurren en costos } \\
\text { significativos si cambian de } \\
\text { proveedores? }\end{array}$ & & & $\mathbf{X}$ & $\begin{array}{l}\text { Como costo económico, no, ya que } \\
\text { tanto la cadena de supermercados } \\
\text { CENCOSUD como los clientes } \\
\text { individuales pueden conseguir los } \\
\text { mismos productos a un precio muy } \\
\text { similar en el mercado, pero cabe señalar } \\
\text { que la calidad no será la misma. } \\
\end{array}$ \\
\hline & $\begin{array}{l}\text { ¿Es necesario mucho capital para } \\
\text { entrar la industria? }\end{array}$ & & & $\mathbf{X}$ & $\begin{array}{l}\text { Se puede comenzar produciendo } \\
\text { cupcakes caseros. }\end{array}$ \\
\hline
\end{tabular}




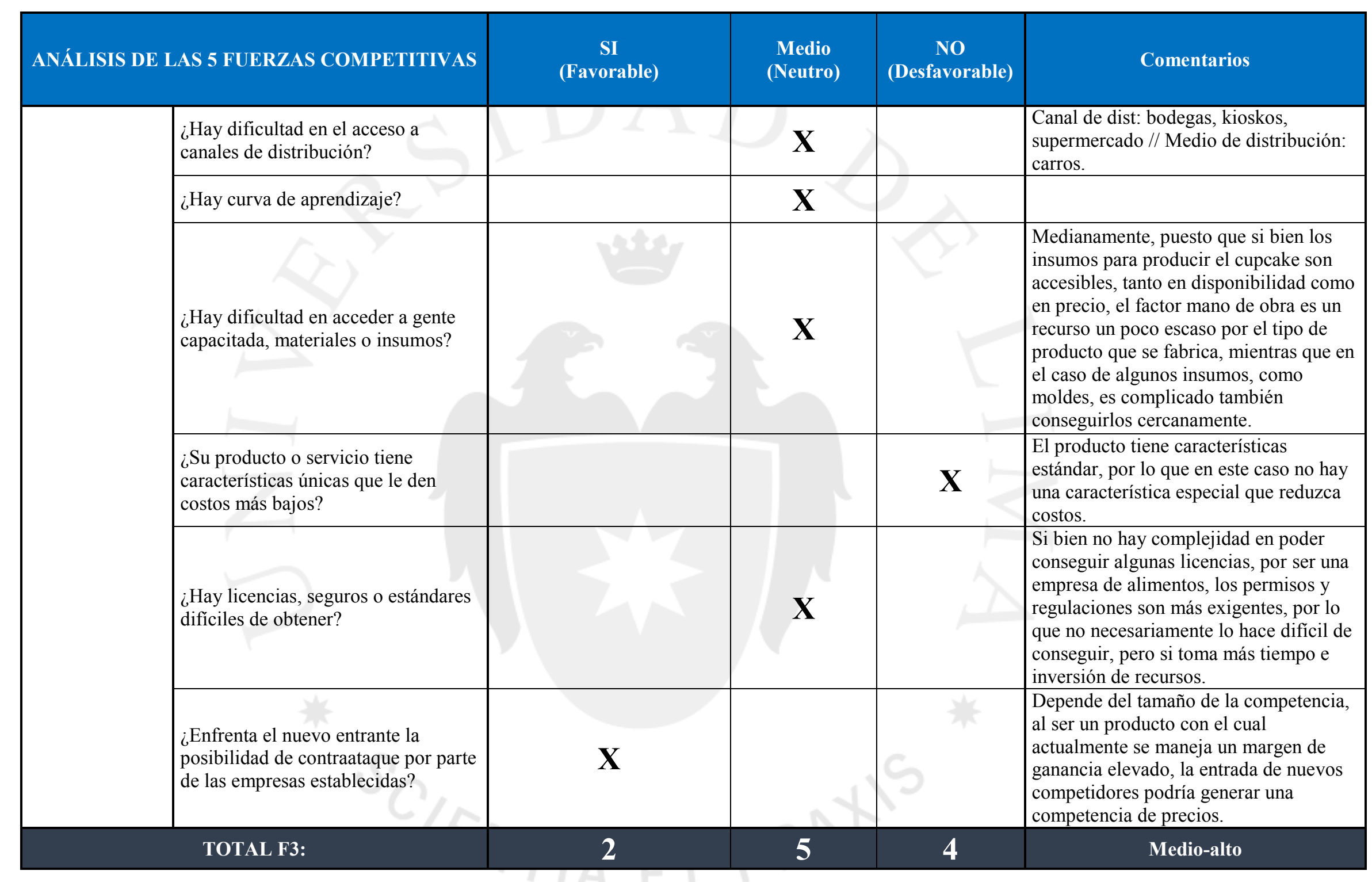




\begin{tabular}{|c|c|c|c|c|c|}
\hline \multicolumn{2}{|c|}{ ANÁLISIS DE LAS 5 FUERZAS COMPETITIVAS } & $\begin{array}{c}\text { SI } \\
\text { (Favorable) }\end{array}$ & $\begin{array}{l}\text { Medio } \\
\text { (Neutro) }\end{array}$ & $\begin{array}{c}\text { NO } \\
\text { (Desfavorable) }\end{array}$ & Comentarios \\
\hline \multirow{4}{*}{$\begin{array}{l}\text { F4: Amenaza } \\
\text { de productos } \\
\text { sustitutos }\end{array}$} & $\begin{array}{l}\text { ¿Los sustitutos tienen limitaciones de } \\
\text { desempeño que no compensan su } \\
\text { precio bajo o su funcionamiento no } \\
\text { es justificado por su precio alto? }\end{array}$ & & 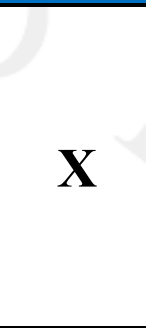 & & $\begin{array}{l}\text { Es relativo, porque si bien es cierto se } \\
\text { busca una exclusividad en cuanto al } \\
\text { diseño del producto más que por el fin } \\
\text { básico (comestible), pueden haber } \\
\text { productos sustitutos con ciertas } \\
\text { características parecidas, no iguales, } \\
\text { pero que si podrían compensar en cierta } \\
\text { medida su precio bajo. }\end{array}$ \\
\hline & $\begin{array}{l}\text { ¿El cliente incurre en costos al } \\
\text { cambiar a un sustituto (switching } \\
\text { costs)? }\end{array}$ & & & $\mathbf{X}$ & $\begin{array}{l}\text { Como costo económico, no, ya que } \\
\text { existen productos sustitos con } \\
\text { características similares al cupcake. }\end{array}$ \\
\hline & $\begin{array}{l}\text { ¿Su cliente no tiene un sustituto } \\
\text { verdadero? }\end{array}$ & & & $\mathbf{X}$ & $\begin{array}{l}\text { Existen queques, biscochos, pastelitos y } \\
\text { tortas que pueden sustituir al cupcake, } \\
\text { en cuanto a darse un gusto. }\end{array}$ \\
\hline & $\begin{array}{l}\text { ¿No es probable que su cliente } \\
\text { cambie a un sustituto? }\end{array}$ & & & $\mathbf{X}$ & $\begin{array}{l}\text { La misma justificación que el punto } \\
\text { anterior. }\end{array}$ \\
\hline & TOTAL F4: & 0 & 1 & 3 & Alto \\
\hline \multirow{3}{*}{$\begin{array}{l}\text { F5: Rivalidad } \\
\text { entre los } \\
\text { competidores }\end{array}$} & $\begin{array}{l}\text { ¿La industria está creciendo } \\
\text { rápidamente? }\end{array}$ & $\mathbf{X}$ & & & $\begin{array}{l}\text { Al ser un producto sin un alto nivel de } \\
\text { complejidad, pero quizá si de } \\
\text { especialización en diseños, hace que la } \\
\text { industria a la que pertenece se vaya } \\
\text { acentuando cada vez más. }\end{array}$ \\
\hline & $\begin{array}{l}\text { ¿La industria no es cíclica con } \\
\text { capacidad excesiva intermitente? }\end{array}$ & & $\mathbf{X}$ & 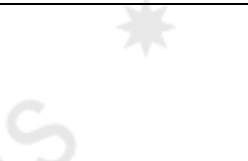 & $\begin{array}{l}\text { Hay temporadas en las que el negocio se } \\
\text { incrementa debido a una mayor } \\
\text { demanda por los tipos de producto que } \\
\text { se puede hacer (diseños específicos). }\end{array}$ \\
\hline & $\begin{array}{l}\text { ¿Los costos fijos son una porción } \\
\text { relativamente baja del costo total? } \\
\text { (Economía de escala). }\end{array}$ & & & & $\begin{array}{l}\text { El costo mayor está enfocado en la parte } \\
\text { productiva (insumos), por lo que los } \\
\text { costos fijos no representan una parte } \\
\text { significativa en los costos totales. }\end{array}$ \\
\hline
\end{tabular}




\begin{tabular}{|c|c|c|c|c|}
\hline ANÁLISIS DE LAS 5 FUERZAS COMPETITIVAS & $\begin{array}{c}\text { SI } \\
\text { (Favorable) }\end{array}$ & \multirow{2}{*}{$\begin{array}{c}\text { Medio } \\
\text { (Neutro) }\end{array}$} & $\begin{array}{c}\text { NO } \\
\text { (Desfavorable) }\end{array}$ & \multirow{2}{*}{\begin{tabular}{|l|}
\multicolumn{1}{|c}{ Comentarios } \\
La diferencia de los productos se da \\
básicamente por el diseño y la calidad \\
del producto; Además, hoy en día la \\
marca en estudio está muy bien \\
posicionada en el mercado y en su \\
rubro.
\end{tabular}} \\
\hline $\begin{array}{l}\text { ¿Hay diferencias significativas del } \\
\text { producto e identidades de marca } \\
\text { entre los competidores? }\end{array}$ & $\mathbf{X}$ & & & \\
\hline $\begin{array}{l}\text { ¿Los competidores están } \\
\text { diversificados más que concentrados } \\
\text { en algún producto? }\end{array}$ & $\mathbf{X}$ & & & $\begin{array}{l}\text { La mayoría de competidores fuertes no } \\
\text { se centran únicamente en los cupcakes, } \\
\text { por lo que la rivalidad puede disminuir } \\
\text { por ese aspecto. }\end{array}$ \\
\hline $\begin{array}{l}\text { ¿No es difícil salir de la industria } \\
\text { porque no hay habilidades } \\
\text { especializadas, instalaciones o } \\
\text { contratos de largo plazo? }\end{array}$ & $\mathbf{X}$ & & & $\begin{array}{l}\text { Por el tipo de negocio no habría } \\
\text { problema salir de la industria ante un } \\
\text { posible fracaso en el negocio, } \\
\text { considerando que la inversión en la } \\
\text { parte operativa no es tan grande al nivel } \\
\text { de poder afectar la operación. }\end{array}$ \\
\hline $\begin{array}{l}\text { ¿Mis clientes incurren en un costo } \\
\text { significativo al cambiar a un } \\
\text { competidor? }\end{array}$ & $\mathbf{X}$ & & & $\begin{array}{l}\text { Costo de oportunidad (diseño del } \\
\text { producto). }\end{array}$ \\
\hline $\begin{array}{l}\text { ¿Mi producto es complejo y se } \\
\text { requiere una comprensión detallada } \\
\text { de parte de mi cliente? }\end{array}$ & & $\mathbf{X}$ & & $\begin{array}{l}\text { El cupcake propiamente no lo es; sin } \\
\text { embargo, podría si considerarse que el } \\
\text { nivel de detalle en los diseños es algo } \\
\text { que habría hacer entender al cliente, en } \\
\text { caso lo requiera, que es lo que } \\
\text { incrementa el precio final del producto, } \\
\text { a comparación de otros competidores. }\end{array}$ \\
\hline $\begin{array}{l}\text { ¿Todos mis competidores son de } \\
\text { aproximadamente el mismo tamaño } \\
\text { que mi empresa? }\end{array}$ & & & $\mathrm{C}$ & $\begin{array}{l}\text { En el ámbito específico del cupcake, se } \\
\text { podría considerar que sí, puesto que } \\
\text { otros productos del mismo tipo son } \\
\text { producidos por empresas domésticas las } \\
\text { cuales no tienen aún la relevancia de } \\
\text { Claudia Cupcakes. }\end{array}$ \\
\hline TOTAL F5: & 6 & 2 & 1 & Bajo \\
\hline EVALUACIÓN GLOBAL DE LA INDUSTRIA & 12 & 15 & 12 & Moderado \\
\hline
\end{tabular}




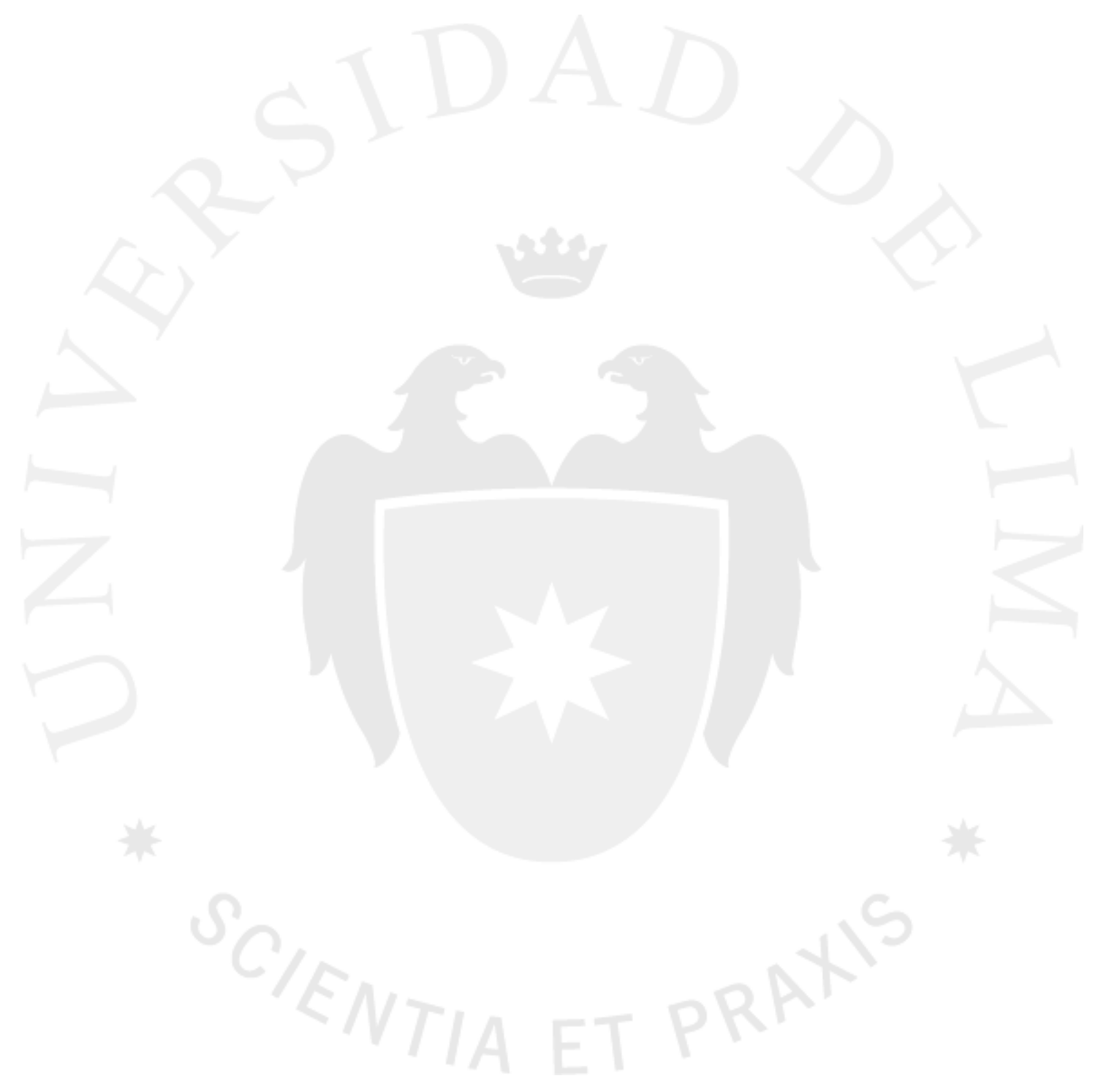




\section{Anexo 2}

Datos generales de la competencia

\begin{tabular}{|c|c|}
\hline Empresa & Datos \\
\hline Miss Cupcakes & $\begin{array}{l}\text { Av. } 28 \text { de Julio } 810 \\
\text { Miraflores, Lima - Perú } \\
\text { Teléfono: (01) 241-7545 } \\
\text { Web: www.misscupcakes.pe }\end{array}$ \\
\hline Dolce Cuore & $\begin{array}{l}\text { Av Javier Prado Este } 4200 \\
\text { Santiago de Surco, Lima - Perú } \\
\text { Teléfono: (01) 437-6833 } \\
\text { Web: www.dolcecuore.pe }\end{array}$ \\
\hline Haylli & $\begin{array}{l}\text { C.C. Plaza San Miguel, M } 102 \text { (1er } \\
\text { nivel) } \\
\text { San Miguel, Lima - Perú } \\
\text { Web: http://www.haylli.com.pe/ }\end{array}$ \\
\hline
\end{tabular}




\section{Anexo 3}

\section{Cálculo del costo de reposición de pedidos}

Yendo un poco más allá con el cálculo del posible impacto económico que esto podría presentar considerando el hacer un doble viaje para volver a entregar un pedido defectuoso, tenemos:

\begin{tabular}{|l|l|}
\hline Tiempo de viaje recorrida & 1.5 horas \\
\hline Horas/turno & $15 \mathrm{~km}$ \\
\hline Distancia promedio & \\
\hline Precio del combustible & 13.5 soles/gal \\
\hline Rendimiento del vehiculo & $40 \mathrm{~km} / \mathrm{gal}$ \\
\hline Doble viaje & 2 veces \\
\hline Sueldo del chofer & 50 soles/dia \\
\hline Sueldo del ayudante & 33.33 \\
\hline Ocurrencia por semana & 1 veces \\
\hline
\end{tabular}

Costo por consumo de combustible $=13.5 \times(1 / 40) \times 15 \times 2 \times 1=\mathrm{S} / .10 .13 /$ semana

Costo por mano de obra desperdiciada $=(50+33.33) \times(1 / 10) \times 1.5 \times 2 \times 1=\mathrm{S} / .24 .99 /$ semana. 


\section{Anexo 4}

\section{Análisis a profundidad de los métodos de trabajo}

Para el desarrollo de este punto se está tomando en consideración la producción de 45 six pack de cupcakes del modelo "Avengers", diseñado exclusivamente para la cadena de supermercados Cencosud de acuerdo a la imagen que se muestra líneas abajo:

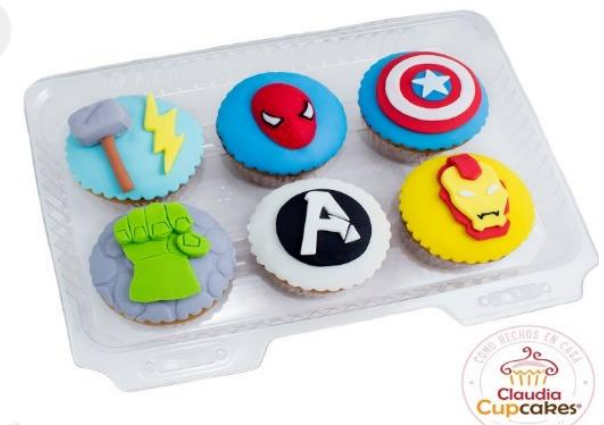

A continuación listaremos todas las actividades que se realizan en cada etapa del proceso de producción de los six pack de cupcakes "Avengers".

\section{i. Procesamiento de crudos}

a) Retirar del almacén los siguientes ingredientes: pre mezcla, huevo, agua, aceite y chispas de chocolate.

b) Pesar con la ayuda de una balanza las siguientes cantidades de ingredientes en la vasija de la batidora con capacidad de $15 \mathrm{~L}$ :

- $8 \mathrm{~kg}$ de pre mezcla satin cream cake

- 2,800 gr de huevo

- $\quad 1,840$ gr de agua

- 2,640 gr de aceite

c) Mezclar manualmente con el instrumento de la batidora. 
d) Batir por 5 minutos.

e) Pesar chispas de chocolate.

f) Retirar vasija de la batidora y echar 1,200 gr de chispas de chocolate. Seguidamente, mezclar con una espátula de madera hasta que la mezcla quede homogénea.

g) Verter mezcla en el dosificador con capacidad de 52 L y regular al 35\%, que equivale a 60 gr de mezcla por cupcake.

h) Distribuir moldes en mesa de trabajo.

i) Colocar pirotines en moldes, en total 274 pirotines. Por cada $\mathrm{kg}$ de pre mezcla, se obtienen aproximadamente 34 cupcakes.

j) Manguear hasta terminar con la mezcla.

k) Colocar moldes en el horno a $160^{\circ} \mathrm{C}$ y hornear por 50 minutos.

1) Retirar del horno, desmoldar y acomodar en bandejas.

m) Colocar bandejas en carritos. Dejar enfriar por 50 minutos a temperatura ambiente.

\section{ii. Proceso de forrado}

a) Retirar del almacén $4.6 \mathrm{~kg}$ de masa fondant y tintes de color celeste, amarillo, blanco y negro.

b) Teñir de acuerdo a lo siguiente:

- 766 gr de masa fondant de color blanco

- 766 gr de masa fondant de color plomo

- 766 gr de masa fondant de color amarillo

- 766 gr de masa fondant de color celeste claro

- $\quad$ 1,532 gr de masa fondant de color celeste 
c) Untar manjar blanco en la parte superior media de los cupcakes.

d) Enharinar en mesa de trabajo.

e) Estirar masa fondant de color blanco con un rodillo, ente 1.5 - $2 \mathrm{~mm}$.

f) Cortar masa con un cortador de $7 \mathrm{~cm}$ de diámetro. En total 45 forros.

g) Pegar forros en los cupcakes.

h) Repetir actividades de la d) a la f) para el resto de masas fondant.

Terminado este proceso tendremos 270 cupcakes forrados en 5 colores; cabe señalar que 4 cupcakes quedaran sin forrar y formaran parte de otro pedido.

\section{iii. Proceso de decorado}

a) Retirar del almacén masa fondant, tintes de colores, huevos y etiquetas.

b) Teñir masa fondant de acuerdo a los colores de los adornos.

c) Diseñar adornos de acuerdo a lo siguiente:

- 45 martillos y 45 rayos de Thor

- 45 caras de Hombre Araña

- 45 escudos de Capitán América

- 45 puños de Hulk

- 45 logos de Avengers

d) Etiquetar con fecha de producción y fecha de vencimiento en la parte inferior de cada cupcake.

e) Pegar adornos en los cupcakes con clara de huevo, de acuerdo al diseño. 
Cabe señalar que en cada actividad, especialmente en el diseño de los adornos y pegado de los mismos, se realiza inspección visual.

\section{iv. Proceso de empacado}

a) Retirar del almacén 50 envases y 50 cintillos.

b) Distribuir envases a lo largo de la mesa.

c) Empacar 6 cupcakes por envase, de acuerdo al orden establecido.

d) Colocar cintillo en cada envase.

Al final de este último proceso se realiza una última inspección visual de cada six pack de cupcakes.

A continuación mostraremos el Diagrama de Operaciones y Procesos para la producción de 45 six pack de cupcakes del modelo "Avengers" 


\section{Anexo 5}

Fichas de Máquinas

\section{FICHA DESCRIPTIVA DE MÁQUINA Y EQUIPO}

PLANTA : San Miguel - Lima, Perú

SECCIÓN : Mezclado

FICHA N ${ }^{\circ} 01$

NOMBRE : Batidora Industrial

Elaborado por:

MARCA : Nova

Elio Pérez / Daniela Martínez

MODELO : Planetaria

DATOS TÉCNICOS:

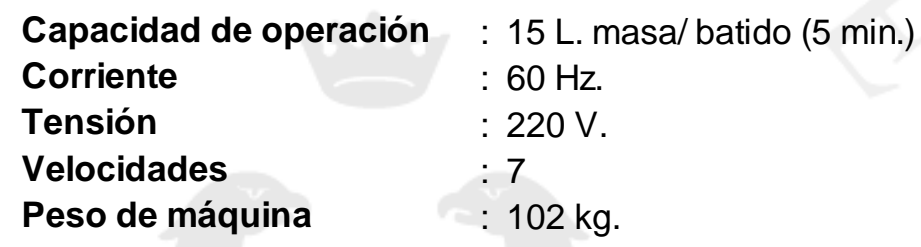

DIMENSIONES GENERALES:

Largo : $730 \mathrm{~mm}$

Ancho : $480 \mathrm{~mm}$

Alto : $1000 \mathrm{~mm}$

Valor Actual : S/. 3,342.86

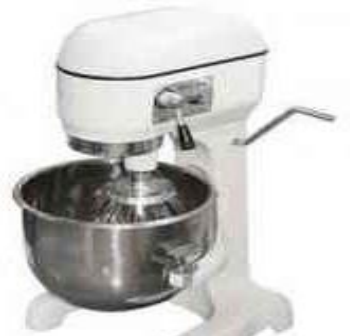

HERRAMIENTAS Y ACCESORIOS:

- Control Semi - Manual 


\section{FICHA DESCRIPTIVA DE MÁQUINA Y EQUIPO}

PLANTA : San Miguel - Lima, Perú

SECCIÓN : Mezclado

NOMBRE : Batidora Doméstica

MARCA : Kitchen Aid

FICHA N ${ }^{\circ} 02$

MODELO : Artisian KSM150PSGC

DATOS TÉCNICOS:

Capacidad de operación : $5 \mathrm{~L}$. masa/ batido (8 min.)

Corriente

: $60 \mathrm{~Hz}$

Tensión

: $220 \mathrm{~V}$.

Velocidades

$: 10$

Peso de máquina

: $11.8 \mathrm{~kg}$.

DIMENSIONES GENERALES:

Largo : $350 \mathrm{~mm}$

Ancho : $250 \mathrm{~mm}$

Alto : $430 \mathrm{~mm}$

Valor Actual : S/. 1,575.84

HERRAMIENTAS Y ACCESORIOS:

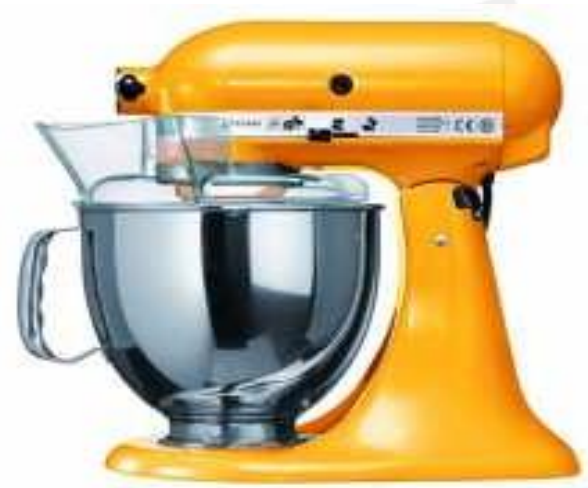

- Control Semi - Manual 


\section{FICHA DESCRIPTIVA DE MÁQUINA Y EQUIPO}

PLANTA : San Miguel - Lima, Perú

SECCIÓN : Mezclado

NOMBRE : Dosificadora

FICHA N ${ }^{\circ} 03$

MARCA : Unifiller

\section{Elaborado por:}

MODELO : Compact Bakery Depositors

Elio Pérez / Daniela Martínez

DATOS TÉCNICOS:

Capacidad de almacenamiento : 52 Lts.

Capacidad de operación $\quad: 140$ depósitos/min (2.5 dep/seg +-)

Corriente

: $60 \mathrm{~Hz}$.

Tensión

: $220 \mathrm{~V}$

Peso de máquina $: 25 \mathrm{~kg}$.

DIMENSIONES GENERALES:

Largo : $1150 \mathrm{~mm}$

Ancho : $750 \mathrm{~mm}$

Alto : $1350 \mathrm{~mm}$

Valor Actual : S/.38,097.71

HERRAMIENTAS Y ACCESORIOS:

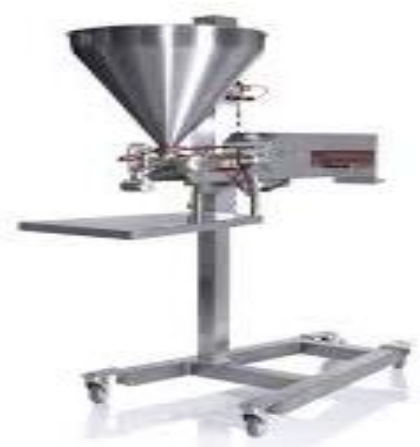

- Control Semi - Manual 


\section{FICHA DESCRIPTIVA DE MÁQUINA Y EQUIPO}

PLANTA : San Miguel - Lima, Perú

SECCIÓN : Horneado

FICHA N 04

NOMBRE : Horno Industrial

\section{Elaborado por:}

MARCA : Salva

Elio Pérez / Daniela Martínez

MODELO : Modular NXM

DATOS TÉCNICOS:

Capacidad de almacenamiento

Capacidad de operación

: 288 cupcakes ( 3 pisos de $96 \mathrm{cpk} \mathrm{c} / \mathrm{u}$ )

Corriente

: 100 cupcakes/piso $\left(50 \mathrm{~min}-150^{\circ} \mathrm{C}\right)$

Tensión

20 tortas/piso $\left(70 \mathrm{~min}-150^{\circ} \mathrm{C}\right)$

Peso de máquina

: $60 \mathrm{~Hz}$.

$: 220 \mathrm{~V}$.

: $25 \mathrm{~kg}$.

\section{DIMENSIONES GENERALES:}

Largo : $1720 \mathrm{~mm}$

Ancho : $1000 \mathrm{~mm}$

Alto : $1690 \mathrm{~mm}$

Valor Actual： S/. 8,379.84

\section{HERRAMIENTAS Y ACCESORIOS:}

- Control Semi - Manual

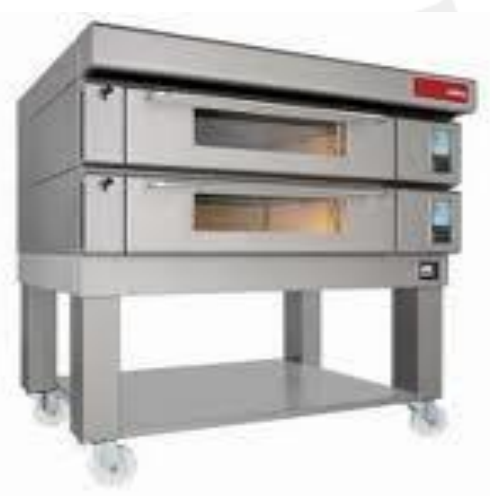




\section{FICHA DESCRIPTIVA DE MÁQUINA Y EQUIPO}

PLANTA : San Miguel - Lima, Perú

SECCIÓN : Mezclado

NOMBRE : Balanza Electrónica

FICHA N ${ }^{\circ} 05$

MARCA : Miray

DATOS TÉCNICOS:

Capacidad de pesaje

: $50 \mathrm{~kg}$.

Corriente

: $60 \mathrm{~Hz}$

Tensión

: $220 \mathrm{~V}$.

Peso de máquina

: $2.5 \mathrm{~kg}$.

DIMENSIONES GENERALES:

$\begin{array}{lll}\text { Largo } & : & 350 \mathrm{~mm} \\ \text { Ancho } & : & 330 \mathrm{~mm} \\ \text { Alto } & : & 120 \mathrm{~mm} \\ \text { Valor Actual } & : & S / .157 .84\end{array}$

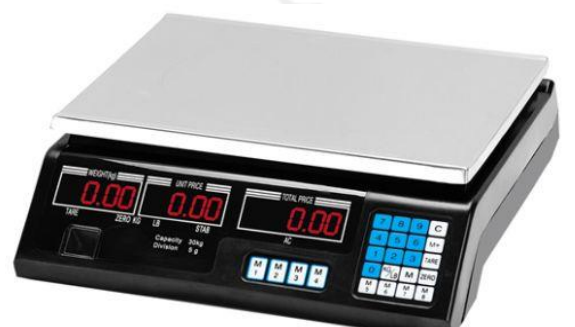

HERRAMIENTAS Y ACCESORIOS:

- Control Manual 


\section{FICHA DESCRIPTIVA DE MÁQUINA Y EQUIPO}

PLANTA : San Miguel - Lima, Perú

SECCIÓN : Varias

NOMBRE : Horno Microondas

FICHA N ${ }^{\circ} 06$

MARCA : Miray

MODELO : HMM-103

DATOS TÉCNICOS:

Capacidad de almacenamiento : $20 \mathrm{Lt}$.

Potencia

: $700 \mathrm{~W}$.

Corriente

: $60 \mathrm{~Hz}$.

Tensión

: $220 \mathrm{~V}$.

Peso de máquina

: $3.5 \mathrm{~kg}$.

\section{DIMENSIONES GENERALES:}

$\begin{array}{lll}\text { Largo } & : & 350 \mathrm{~mm} \\ \text { Ancho } & : & 510 \mathrm{~mm} \\ \text { Alto } & : & 290 \mathrm{~mm} \\ \text { Valor Actual } & : & \mathrm{S} / .224 .18 \\ & \end{array}$

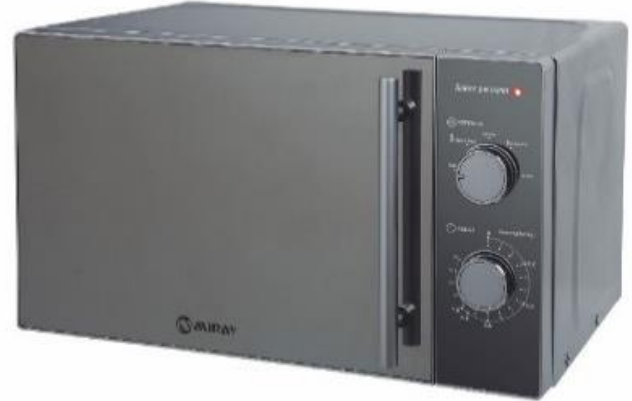

- Control Manual 


\section{FICHA DESCRIPTIVA DE MÁQUINA Y EQUIPO}

PLANTA : San Miguel - Lima, Perú

SECCIÓN : Productos en proceso

FICHA N ${ }^{\circ} 07$

NOMBRE : Rack de Pastelería

Elaborado por:

MARCA : Maquipan

Elio Pérez / Daniela Martínez

MODELO : Carro de acero inoxidable

DATOS TÉCNICOS:

Capacidad de almacenamiento : 50 cupcakes/piso (18 pisos)

Peso de máquina : $25 \mathrm{~kg}$.

DIMENSIONES GENERALES:

$\begin{array}{ll}\text { Largo } & : 650 \mathrm{~mm} \\ \text { Ancho } & : 520 \mathrm{~mm} \\ \text { Alto } & : 1600 \mathrm{~mm}\end{array}$

HERRAMIENTAS Y ACCESORIOS:

- Control Manual
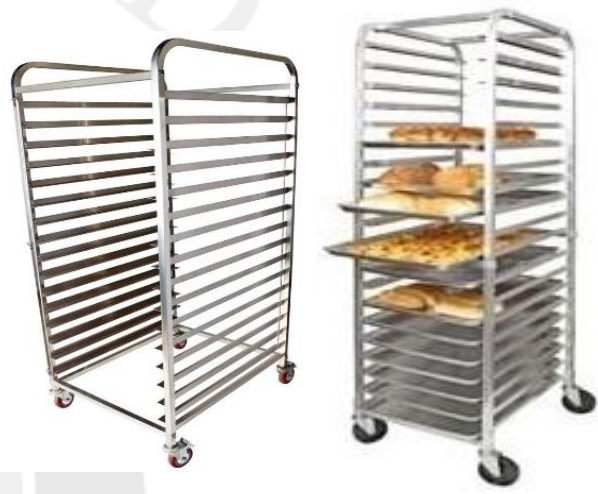


\section{FICHA DESCRIPTIVA DE MÁQUINA Y EQUIPO}

PLANTA : San Miguel - Lima, Perú

SECCIÓN : Productos en proceso

NOMBRE : Refrigeradora / Congeladora

MARCA : Bosch

FICHA N ${ }^{\circ} 08$

MODELO : ECO TT261 IXL

DATOS TÉCNICOS:

Capacidad de almacenamiento : 400 Lts.

Potencia

Corriente

: $60 \mathrm{~Hz}$

Tensión

: $220 \mathrm{~V}$.

Peso de máquina

: $56 \mathrm{~kg}$.

DIMENSIONES GENERALES:

Largo : $600 \mathrm{~mm}$

Ancho : $680 \mathrm{~mm}$

Alto $\quad: 1810 \mathrm{~mm}$

Valor Actual : S/.2,800.00

HERRAMIENTAS Y ACCESORIOS:

- Control Semi - Manual

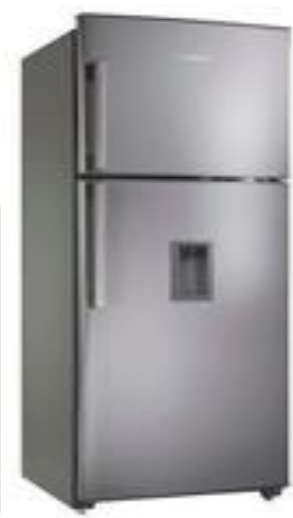




\section{Anexo 6 \\ Fichas de Perfiles de Puesto en la empresa}

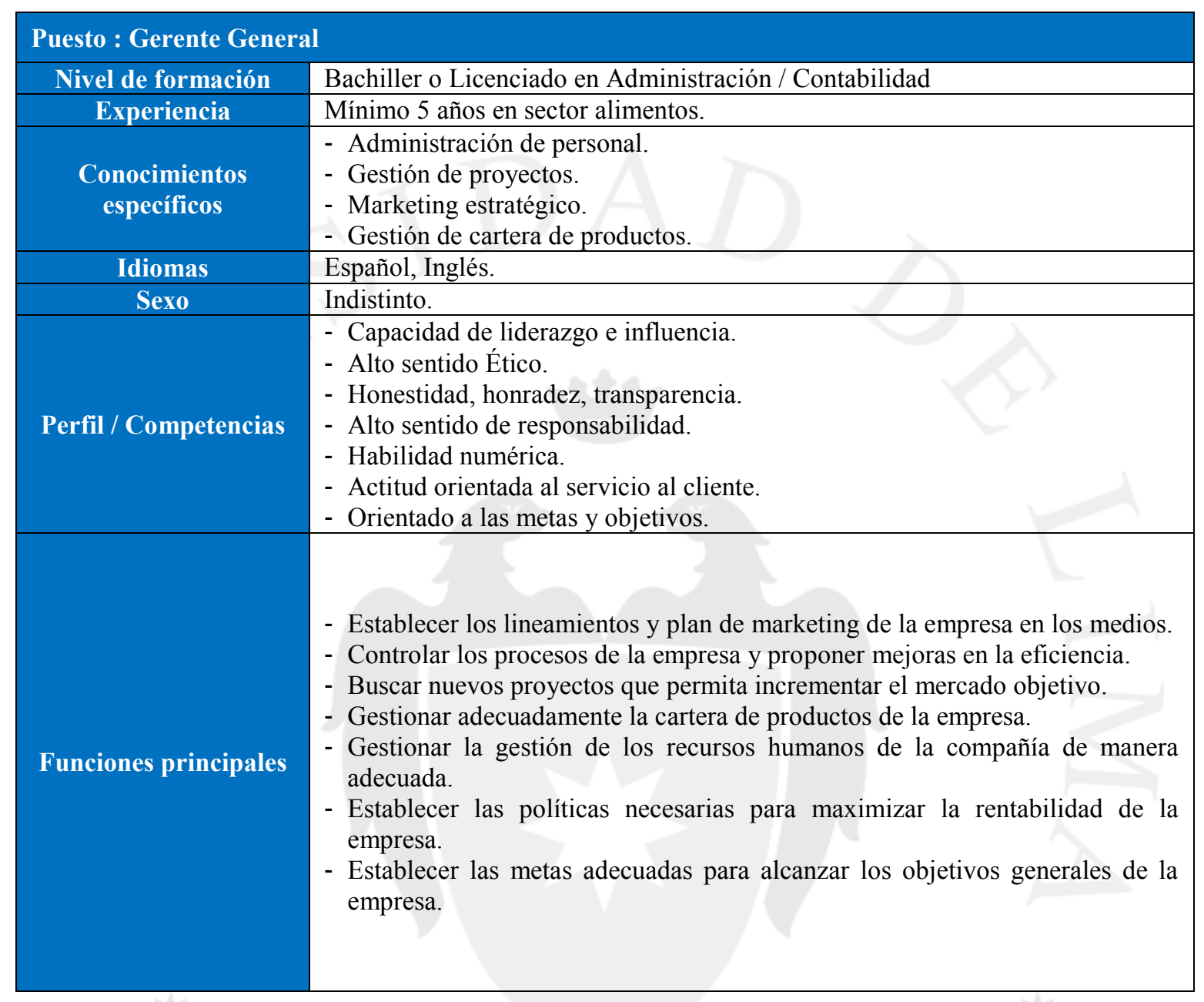

\begin{tabular}{|c|l|}
\hline \multicolumn{2}{|c|}{ Puesto : Asistente Contable } \\
\hline $\begin{array}{c}\text { Nivel de formación } \\
\text { Experiencia }\end{array}$ & Bachiller en Contabilidad. \\
\hline $\begin{array}{c}\text { Conocimientos } \\
\text { específicos }\end{array}$ & $\begin{array}{l}\text { - Control de libros contables. } \\
\text { - Contabilidad general }\end{array}$ \\
\hline Idiomas & Español \\
\hline Sexo & Indistinto. \\
\hline \multirow{3}{*}{ Perfil / Competencias } & $\begin{array}{l}\text { - Alto sentido Ético. } \\
\text { - Honestidad, honradez, transparencia. } \\
\end{array}$ \\
\hline & $\begin{array}{l}\text { - Habilidad numérica. } \\
\text { - Ordenado y con capacidad de trabajo bajo presión. }\end{array}$ \\
\hline
\end{tabular}




\begin{tabular}{|c|c|}
\hline Funciones principales & $\begin{array}{l}\text { - Controlar los estados financieros de la empresa, así como el balance general y } \\
\text { la facturación. } \\
\text { - Apoyo en gestiones diversas con la Gerencia General. } \\
\text { - Recopila y ordena la información contable de la empresa para presentar al } \\
\text { outsourcing (que maneja la contabilidad general). }\end{array}$ \\
\hline
\end{tabular}

\begin{tabular}{|c|c|}
\hline \multicolumn{2}{|c|}{ Puesto : Asistente Administrativa } \\
\hline Nivel de formación & Estudios en secretariado \\
\hline Experiencia & 1 año en sector alimenticio y ventas \\
\hline $\begin{array}{l}\text { Conocimientos } \\
\text { específicos }\end{array}$ & $\begin{array}{l}\text { - Ventas. } \\
\text { - Estrategias de negociación. }\end{array}$ \\
\hline Idiomas & Español \\
\hline Sexo & 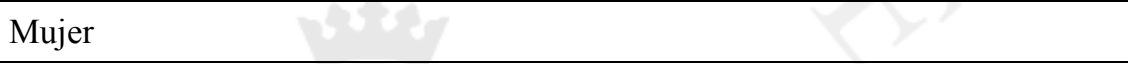 \\
\hline Perfil / Competencias & $\begin{array}{l}\text { - Alto sentido Ético. } \\
\text { - Honestidad, honradez, transparencia. } \\
\text { - Alto sentido de responsabilidad. } \\
\text { - Habilidad numérica. } \\
\text { - Ordenado y con capacidad de trabajo bajo presión. } \\
\text { - Actitud orientada al servicio al cliente. }\end{array}$ \\
\hline Funciones principales & $\begin{array}{l}\text { - Atender los pedidos ingresados por los clientes en los diversos canales de } \\
\text { venta. } \\
\text { - Generar las cotizaciones y confirmación de pedido según lo solicitado. } \\
\text { - Responder todas las consultas que ingresan por el correo electrónico. } \\
\text { - Apoyar en las diversas tareas solicitadas por la Gerencia General en aspectos } \\
\text { de marketing. }\end{array}$ \\
\hline
\end{tabular}

\begin{tabular}{|c|l|}
\hline \multicolumn{2}{|c|}{ Puesto : Practicante de Calidad } \\
\hline Nivel de formación & Últimos ciclos o egresado de Ingeniería en Industrias Alimentarias \\
\hline Experiencia & 1 año en sector alimenticio (de preferencia, en pastelería) \\
\hline $\begin{array}{c}\text { Conocimientos } \\
\text { específicos }\end{array}$ & $\begin{array}{l}\text { - Industria de la Pastelería. } \\
\text { - Normativa vigente aplicable al sector. }\end{array}$ \\
\hline Idiomas & Español, Inglés \\
\hline Sexo & Indistinto \\
\hline & $\begin{array}{l}\text { - Alto sentido ético. } \\
\text { - Honestidad, honradez, transparencia. } \\
\text { Perfil / Competencias }\end{array}$ \\
\hline & $\begin{array}{l}\text { - Alto sentido de responsabilidad. } \\
\text { - Actitud orientada al servicio al cliente. }\end{array}$ \\
\hline
\end{tabular}




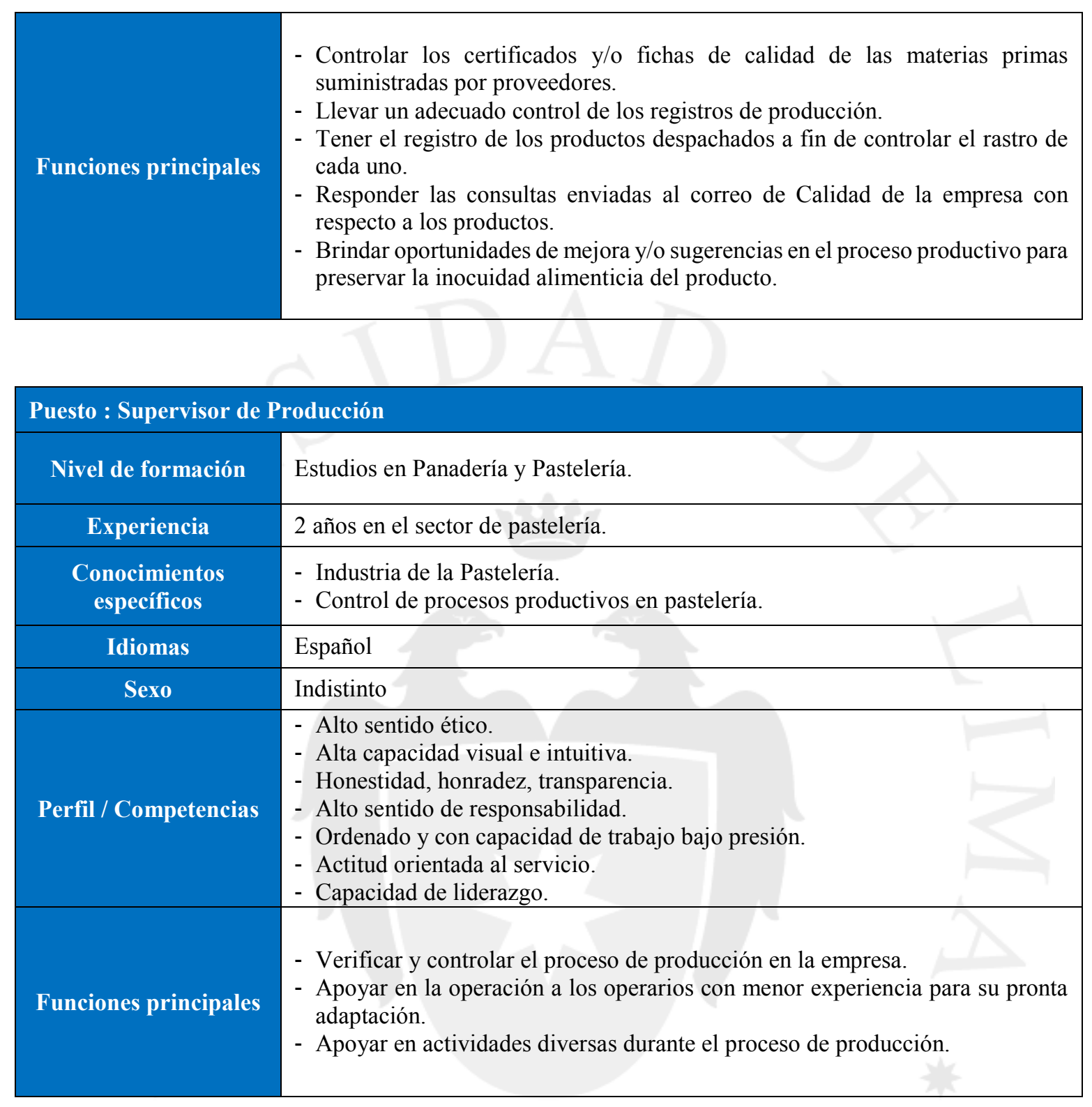

\begin{tabular}{|c|l|}
\hline \multicolumn{2}{|l|}{ Puesto : Operario de Producción } \\
\hline Nivel de formación & Estudios en Panadería y Pastelería. \\
\hline Experiencia & No indispensable \\
\hline $\begin{array}{c}\text { Conocimientos } \\
\text { específicos }\end{array}$ & - Industria de la Pastelería. \\
\hline Idiomas & Español \\
\hline Sexo & Indistinto \\
\hline
\end{tabular}




\begin{tabular}{|l|l|}
\hline \multirow{3}{*}{ Perfil / Competencias } & - Alto sentido Ético. \\
& - Honestidad, honradez, transparencia. \\
& - Alto sentido de responsabilidad. \\
& - Ordenado y con capacidad de trabajo bajo presión. \\
& - Creatividad. \\
\hline Funciones principales & - Realizar diversas tareas asignadas durante el proceso de producción en la \\
& - Appresar en el proceso de empaquetado y despacho de productos según se \\
& - Proponer ideas creativas para nuevos e innovadores diseños en los productos \\
& de la empresa. \\
\hline
\end{tabular}

\begin{tabular}{|c|l|}
\hline \multicolumn{2}{|c|}{ Puesto : Despachador / Transportista } \\
\hline Nivel de formación & Secundaria completa. \\
\hline \multicolumn{1}{|c|}{ Experiencia } & Mínimo 2 años conduciendo vehículos semi - livianos. \\
\hline $\begin{array}{c}\text { Conocimientos } \\
\text { específicos }\end{array}$ & - Contar con licencia de conducir vigente. \\
\hline Idiomas & Español \\
\hline Sexo & Indistinto \\
\hline Perfil / Competencias & $\begin{array}{l}\text { - Alto sentido Ético. } \\
\text { - Honestidad, honradez, transparencia. }\end{array}$ \\
\hline Funciones principales & $\begin{array}{l}\text { - Apoyar en el proceso de despacho de productos desde el taller de producción } \\
\text { al vehículo de transporte. }\end{array}$ \\
\hline & $\begin{array}{l}\text { Realizar el traslado y entrega de los pedidos en las tiendas (Cencosud), } \\
\text { domicilios (personales) y/o empresas. }\end{array}$ \\
\hline
\end{tabular}




\section{Anexo 7}

Detalle de Costos y Gastos al 31 de Diciembre del 2014 en la empresa Claudia Cupcakes

\begin{tabular}{|c|c|c|c|c|}
\hline $\begin{array}{l}\text { COSTOS DIRECTOS DE PRODUCCIÓN } \\
\text { (Nuevos Soles S/.) }\end{array}$ & CANTIDAD & $\begin{array}{l}\text { VALOR } \\
\text { UNITARIO }\end{array}$ & $\begin{array}{l}\text { COSTO } \\
\text { MENSUAL }\end{array}$ & COSTO ANUAL \\
\hline \multicolumn{5}{|l|}{ MATERIAPRIMA } \\
\hline - Aceite & - & $1,598.50$ & $1,598.50$ & $19,182.03$ \\
\hline - Cobertura / Chocolate & - & $3,915.72$ & $3,915.72$ & $46,988.58$ \\
\hline - Colorante & - & 150.50 & 150.50 & $1,806.02$ \\
\hline - Huevo & 8 & $1,717.17$ & $1,717.17$ & $20,606.06$ \\
\hline - Manjar & - & 565.54 & 565.54 & $6,786.49$ \\
\hline - Masa fondant & - & $3,477.71$ & $3,477.71$ & $41,732.50$ \\
\hline - Premezcla & - & $7,430.83$ & $7,430.83$ & $89,169.92$ \\
\hline - Otros & - & $11,219.39$ & $11,219.39$ & $134,632.66$ \\
\hline \multicolumn{3}{|l|}{ TOTAL MATERIA PRIMA } & $30,075.36$ & $360,904.26$ \\
\hline \multicolumn{5}{|l|}{ INSUMOS } \\
\hline - Adornos & - & 273.76 & 273.76 & $3,285.16$ \\
\hline - Bases & 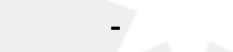 & $1,165.69$ & $1,165.69$ & $13,988.30$ \\
\hline - Bolsas & - & 456.84 & 456.84 & $5,482.08$ \\
\hline - Cajas / Envases & - & $7,060.59$ & $7,060.59$ & $84,727.04$ \\
\hline - Cintillos & - & 469.25 & 469.25 & $5,630.96$ \\
\hline - Etiquetas / Stickers & - & $2,293.99$ & $2,293.99$ & $27,527.91$ \\
\hline - Pirotines & - & $1,902.01$ & $1,902.01$ & $22,824.16$ \\
\hline TOTAL INSUMOS & & & $13,622.13$ & $163,465.61$ \\
\hline \multicolumn{5}{|l|}{$\underline{\text { SUMINISTROS }}$} \\
\hline - Utensilios & - & 626.44 & 626.44 & $7,517.28$ \\
\hline - Vestimenta & t & - & - & $2,406.16$ \\
\hline - Otros & - & 606.65 & 606.65 & $7,279.82$ \\
\hline TOTAL SUMINISTROS & & & $1,233.09$ & $17,203.26$ \\
\hline
\end{tabular}


- Mantenimiento taller

- Mantenimiento maquinaria / equipos

- Otros

TOTAL MANTENIMIENTO

\section{SALARIOS}

- Horneador

- Forrador

- Decorador

- Empacador

TOTAL SALARIOS

\section{GRATIFICACIÓN}

- Horneador

- Forrador

- Decorador

TOTAL GRATIFICACIÓN

SEGUROS Y/O BENEFICIOS (9\%)

- Horneador

- Forrador

- Decorador

TOTAL SEGUROS Y BENEFICIOS

TOTAL COSTOS DIRECTOS DE PRODUCCIÓN

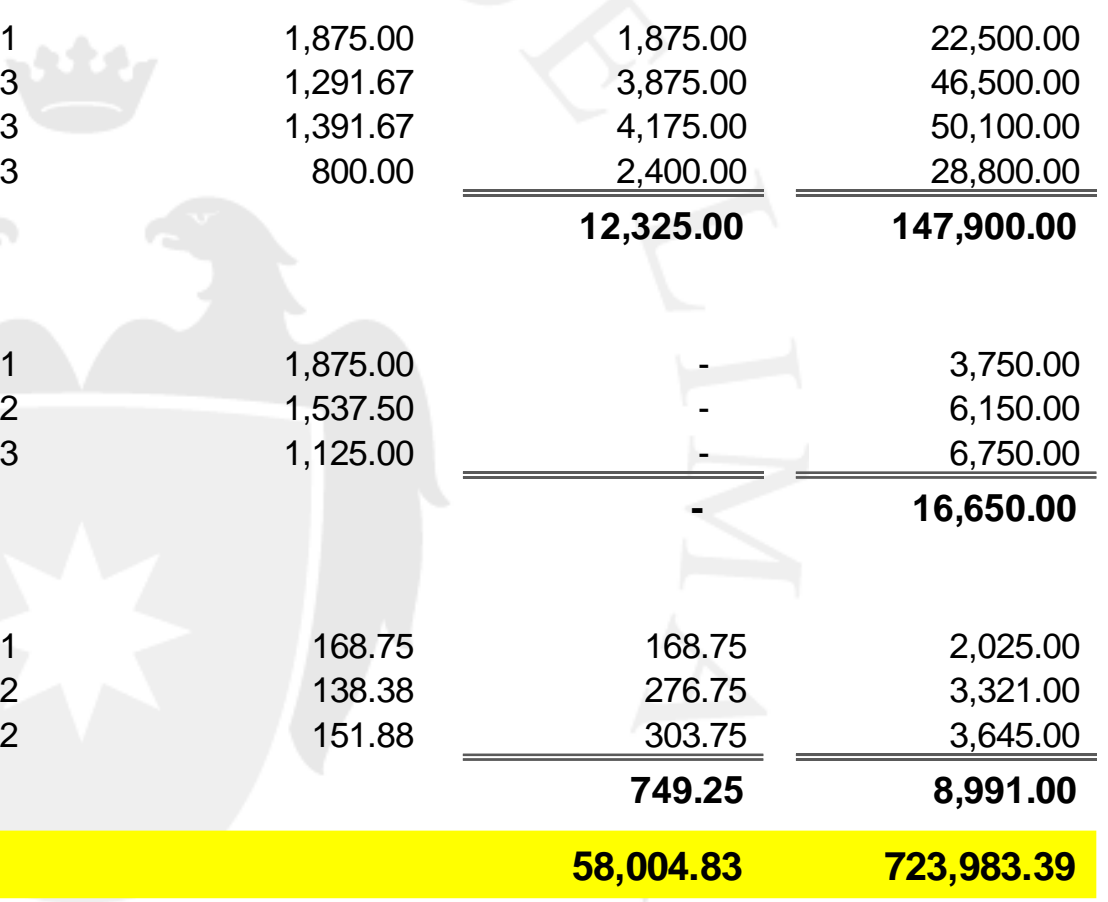




\begin{tabular}{|c|c|c|c|c|}
\hline $\begin{array}{l}\text { COSTOS INDIRECTOS DE PRODUCCIÓN } \\
\text { (Nuevos Soles S/.) }\end{array}$ & CANTIDAD & $\begin{array}{l}\text { VALOR } \\
\text { UNITARIO }\end{array}$ & $\begin{array}{l}\text { COSTO } \\
\text { MENSUAL }\end{array}$ & COSTO ANUAL \\
\hline \multicolumn{5}{|l|}{ SALARIOS } \\
\hline $\begin{array}{l}\text { - Practicante de calidad } \\
\text { - Supervisor de producción }\end{array}$ & $\begin{array}{l}1 \\
1\end{array}$ & $\begin{array}{r}800.00 \\
1,500.00\end{array}$ & $\begin{array}{r}800.00 \\
1,500.00 \\
\end{array}$ & $\begin{array}{r}9,600.00 \\
18,000.00 \\
\end{array}$ \\
\hline TOTAL SALARIOS & & & $2,300.00$ & $27,600.00$ \\
\hline \multicolumn{5}{|l|}{ GRATIFICACION } \\
\hline - Supervisor de producción & 1 & $1,500.00$ & - & $3,000.00$ \\
\hline \multicolumn{5}{|l|}{ SEGURO Y/O BENEFICIOS (9\%) } \\
\hline - Supervisor de producción & 1 & 135.00 & 135.00 & $1,620.00$ \\
\hline TOTAL SEGUROS Y BENEFICIOS & & & 135.00 & $1,620.00$ \\
\hline \multicolumn{5}{|l|}{ DEPRECIACIÓN } \\
\hline - Depreciacion de maquinaria / equipos & - & - & - & $14,361.91$ \\
\hline TOTAL DEPRECIACIÓN & & & $y^{-}$ & $14,361.91$ \\
\hline \multicolumn{3}{|c|}{ TOTAL COSTOS INDIRECTOS DE PRODUCCIÓN } & $2,435.00$ & $46,581.91$ \\
\hline
\end{tabular}




\begin{tabular}{|c|c|c|c|c|}
\hline $\begin{array}{l}\text { GASTOS ADMINISTRATIVOS } \\
\text { (Nuevos Soles S/.) }\end{array}$ & CANTIDAD & $\begin{array}{l}\text { VALOR } \\
\text { UNITARIO }\end{array}$ & $\begin{array}{l}\text { COSTO } \\
\text { MENSUAL }\end{array}$ & COSTO ANUAL \\
\hline \multicolumn{5}{|l|}{ MANTENIMIENTO } \\
\hline $\begin{array}{l}\text { - Mantenimiento de local } \\
\text { - Mantenimiento vehiculo Gerencia General }\end{array}$ & - & $\begin{array}{r}869.65 \\
81.15\end{array}$ & $\begin{array}{r}869.65 \\
81.15 \\
\end{array}$ & $\begin{array}{r}10,435.77 \\
973.75 \\
\end{array}$ \\
\hline TOTAL MANTENIMIENTO & & & 950.79 & $11,409.52$ \\
\hline \multicolumn{5}{|l|}{ SALARIOS } \\
\hline $\begin{array}{l}\text { - Asistente de limpieza } \\
\text { - Asistente administrativo } \\
\text { - Asistente contable } \\
\text { - Gerente General }\end{array}$ & $\begin{array}{l}1 \\
1 \\
1 \\
1\end{array}$ & $\begin{array}{r}750.00 \\
1,500.00 \\
1,575.00 \\
5,075.00\end{array}$ & $\begin{array}{r}750.00 \\
1,500.00 \\
1,575.00 \\
5,075.00 \\
\end{array}$ & $\begin{array}{r}9,000.00 \\
18,000.00 \\
18,900.00 \\
60,900.00 \\
\end{array}$ \\
\hline TOTAL SALARIOS & & & $8,900.00$ & $106,800.00$ \\
\hline \multicolumn{5}{|l|}{ GRATIFICACION } \\
\hline $\begin{array}{l}\text { - Asistente de limpieza } \\
\text { - Asistente administrativo } \\
\text { - Asistente contable } \\
\text { - Gerente General }\end{array}$ & $\begin{array}{l}1 \\
1 \\
1 \\
1\end{array}$ & $\begin{array}{r}750.00 \\
1,500.00 \\
1,575.00 \\
5,075.00\end{array}$ & $\begin{array}{l}- \\
- \\
- \\
-\end{array}$ & $\begin{array}{r}1,500.00 \\
3,000.00 \\
3,150.00 \\
10,150.00 \\
\end{array}$ \\
\hline TOTAL GRATIFICACIÓN & & & - & $17,800.00$ \\
\hline \multicolumn{5}{|l|}{ SEGURO Y/O BENEFICIOS (9\%) } \\
\hline $\begin{array}{l}\text { - Asistente de limpieza } \\
\text { - Asistente administrativo } \\
\text { - Asistente contable } \\
\text { - Gerente General }\end{array}$ & $\begin{array}{l}1 \\
1 \\
1 \\
1\end{array}$ & $\begin{array}{r}67.50 \\
135.00 \\
141.75 \\
456.75\end{array}$ & $\begin{array}{r}67.50 \\
135.00 \\
141.75 \\
456.75 \\
\end{array}$ & $\begin{array}{r}810.00 \\
1,620.00 \\
1,701.00 \\
5,481.00 \\
\end{array}$ \\
\hline TOTAL SEGUROS Y/O & & & 801.00 & $9,612.00$ \\
\hline
\end{tabular}


- Servicio de agua

- Servicio de consultoria

- Servicio de energia

- Servicio de gas

- Servicio de movilidad

- Servicio de RR.HH

- Servicio de seguridad

- Servicio de teléfono / internet

TOTAL SERVICIOS

\section{OTROS}

- Depreciacion de equipo de computo

- Depreciacion de vehículo

- Depreciacion de muebles/otros

- Seguro vehicular

- Aguinaldo

- Útiles / Insumos

- Otros

TOTAL OTROS

TOTAL GASTOS ADMINISTRATIVOS

\begin{tabular}{|c|c|c|}
\hline 190.00 & 190.00 & $2,279.98$ \\
\hline & . & 22,282.55 \\
\hline 816.26 & 816.26 & $9,795.12$ \\
\hline 9.98 & 9.98 & 119.70 \\
\hline 50.32 & 50.32 & 603.80 \\
\hline - & - & $4,691.23$ \\
\hline 241.67 & 241.67 & $2,900.00$ \\
\hline \multirow[t]{2}{*}{584.52} & 584.52 & $7,014.21$ \\
\hline & $1,892.73$ & $49,686.59$ \\
\hline- & - & 824.61 \\
\hline- & - & $5,820.00$ \\
\hline- & - & 2,393.92 \\
\hline 50.50 & 101.00 & $1,212.02$ \\
\hline- & - & $2,932.04$ \\
\hline 544.35 & 544.35 & $6,532.24$ \\
\hline \multirow[t]{3}{*}{774.81} & 774.81 & $9,297.70$ \\
\hline & $1,420.16$ & $29,012.53$ \\
\hline & $13,964.69$ & $224,320.64$ \\
\hline
\end{tabular}




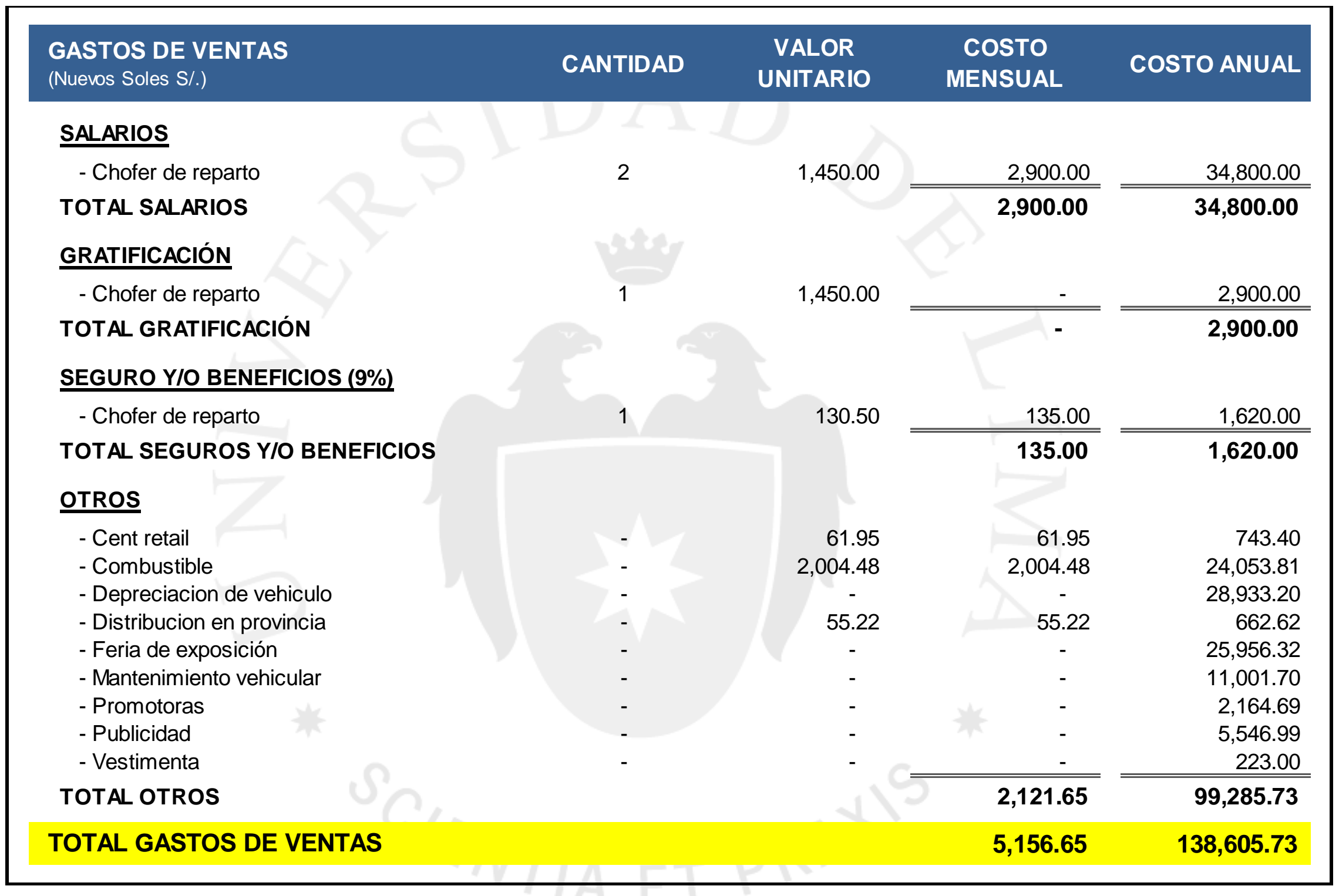




\begin{tabular}{|lrrr|}
\hline $\begin{array}{l}\text { GASTOS GENERALES } \\
\text { (Nuevos Soles S/.) }\end{array}$ & CANTIDAD & $\begin{array}{c}\text { VALOR } \\
\text { UNITARIO }\end{array}$ & COSTO ANUAL \\
OTROS & & & \\
\hline - Analisis microbiológico & 3 & 225.69 & 677.08 \\
- Certificación & 2 & $1,765.79$ & $3,531.57$ \\
- Curso & 1 & $2,240.00$ & $2,240.00$ \\
- Inspección & 1 & 619.50 & 619.50 \\
- Viajes & 1 & $1,777.19$ & $1,777.19$ \\
TOTAL OTROS & & & $\mathbf{8 , 8 4 5 . 3 4}$ \\
TOTAL GASTOS GENERALES & & & $\mathbf{8 , 8 4 5 . 3 4}$ \\
\hline
\end{tabular}




\begin{tabular}{|lrrr|}
\hline $\begin{array}{l}\text { INVERSIONES } \\
\text { (Nuevos Soles S/.) }\end{array}$ & CANTIDAD & $\begin{array}{r}\text { VALOR } \\
\text { ACTUAL } \\
\text { UNITARIO }\end{array}$ & $\begin{array}{r}\text { VALOR } \\
\text { ACTUAL }\end{array}$ \\
\hline ACTIVOS FIJOS & & & \\
- Batidora Industrial & & & \\
- Batidora Doméstica & 2 & $5,109.87$ & $10,219.74$ \\
- Celular & 2 & $1,575.84$ & $3,151.68$ \\
- Compresora & 1 & $1,102.00$ & $1,102.00$ \\
- Dosificadora & 1 & $1,611.00$ & $1,611.00$ \\
- Equipo de computo & 1 & $38,097.71$ & $38,097.71$ \\
- Equipos y accesorios de reposterĺa & 1 & $11,544.50$ & $11,544.50$ \\
- Horno & - & $8,846.40$ & $8,846.40$ \\
- Muebles & 3 & $8,379.84$ & $25,139.53$ \\
- Refrigeradora & - & $13,769.76$ & $13,769.76$ \\
- Relladora de bolsa & 1 & $2,800.00$ & $2,800.00$ \\
- Vehiculo & 1 & 150.86 & 150.86 \\
TOTAL ACTIVOS FIJOS & 3 & $32,276.60$ & $96,829.80$ \\
\hline TOTAL INVERSIÓN & & & $\mathbf{2 1 3 , 2 6 2 . 9 7}$ \\
\hline
\end{tabular}




\begin{tabular}{|c|c|c|c|c|}
\hline $\begin{array}{l}\text { INVERSIONES } \\
\text { (Nuevos Soles S/.) }\end{array}$ & CANTIDAD & $\begin{array}{l}\text { VALOR } \\
\text { UNITARIO }\end{array}$ & $\begin{array}{c}\text { COSTO } \\
\text { MENSUAL }\end{array}$ & COSTO ANUAL \\
\hline \multicolumn{5}{|l|}{ CAPITAL DE TRABAJO } \\
\hline \multicolumn{5}{|l|}{ OPERACIONES } \\
\hline - Horneador & 1 & $1,875.00$ & $1,875.00$ & $22,500.00$ \\
\hline - Forrador & 3 & $1,291.67$ & $3,875.00$ & $46,500.00$ \\
\hline - Decorador & 3 & $1,391.67$ & $4,175.00$ & $50,100.00$ \\
\hline - Empacador & 3 & 800.00 & $2,400.00$ & $28,800.00$ \\
\hline - Practicante de calidad & 1 & 800.00 & 800.00 & $9,600.00$ \\
\hline - Supervisor de Producción & 1 & $1,500.00$ & $1,500.00$ & $18,000.00$ \\
\hline TOTAL OPERACIONES & & & $14,625.00$ & $175,500.00$ \\
\hline \multicolumn{5}{|l|}{ ADMINISTRACIÓN } \\
\hline - Asistente de limpieza & 1 & 750.00 & 750.00 & $9,000.00$ \\
\hline - Asistente administrativo & 1 & $1,500.00$ & $1,500.00$ & $18,000.00$ \\
\hline - Asistente contable & 1 & $1,575.00$ & $1,575.00$ & $18,900.00$ \\
\hline - Gerente General & 1 & $5,075.00$ & $5,075.00$ & $60,900.00$ \\
\hline TOTAL ADMINISTRACIÓN & & & $8,900.00$ & $106,800.00$ \\
\hline \multicolumn{5}{|l|}{ MATERIA PRIMA } \\
\hline - Aceite & - & $1,598.50$ & $1,598.50$ & $19,182.03$ \\
\hline - Cobertura/Chocolate & - & $3,915.72$ & $3,915.72$ & $46,988.58$ \\
\hline - Colorante & - & 150.50 & 150.50 & $1,806.02$ \\
\hline - Huevo & - & $1,717.17$ & $1,717.17$ & $20,606.06$ \\
\hline - Manjar & - & 565.54 & 565.54 & $6,786.49$ \\
\hline - Masa fondant & - & $3,477.71$ & $3,477.71$ & $41,732.50$ \\
\hline - Premezcla & & $7,430.83$ & $7,430.83$ & $89,169.92$ \\
\hline - Otros & & $11,219.39$ & $11,219.39$ & $134,632.66$ \\
\hline TOTAL MATERIA PRIMA & & & $30,075.36$ & $360,904.26$ \\
\hline
\end{tabular}




\section{INSUMOS}

- Adorno

- Base

- Bolsa

- Caja/Envase

- Cintillo

- Etiqueta/Sticker

- Pirotin

TOTAL INSUMOS

$1,902.01$

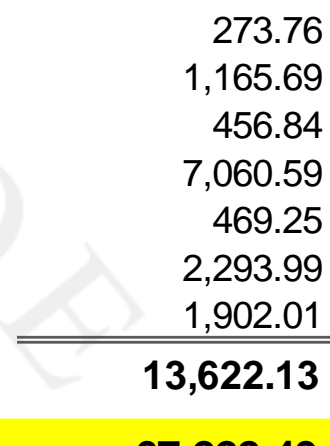

\begin{tabular}{|lr|}
\hline $\begin{array}{l}\text { GASTOS FINANCIEROS } \\
\text { (Nuevos Soles S/.) }\end{array}$ & \multicolumn{1}{c|}{$\begin{array}{c}\text { VALOR } \\
\text { ACTUAL }\end{array}$} \\
\hline \multicolumn{1}{|c|}{ Gastos Financieros } & $30,000.00$ \\
\hline TOTAL GASTOS FINANCIEROS & $\mathbf{3 0 , 0 0 0 . 0 0}$ \\
\hline
\end{tabular}




\section{Anexo 8}

\section{Encuesta de Clima Laboral 2015}

\section{Encuesta de Satisfacción Interna 2015}

La presente encuesta busca conocer el clima laboral $\left({ }^{*}\right)$ y el nivel de satisfacción del personal que labora en la empresa Claudia Cupcakes, a fin de contar con la información necesaria para mejorarlos.

(*) El clima laboral se define como el conjunto de atributos o propiedades de un ambiente de trabajo, percibidoso experimentados por las personas que componen la organización y que influyen sobre su conducta.

A. Por favor, marque su respuesta colocando una " $X$ " en el recuadro correspondiente:
1. Régimen:
Tiempo parcial
0
Tiempo completo
2. Condición:
Serv. por honorarios
8
Contratado
3. Años que labora en la empresa:

\begin{tabular}{|c|c|c|}
\hline Menos de 1 & Entre 1 y 3 & Más de 3 \\
\hline 8 & 5 & 0 \\
\hline
\end{tabular}

4. Indique el proceso al que le dedica mayor cantidad de horas:
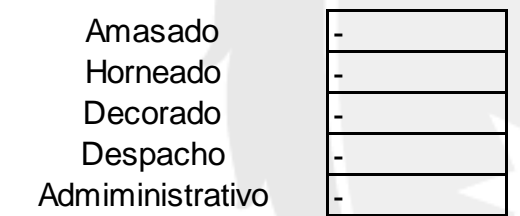
Mezclado
Forrado
Empaquetado
Distribución
Otros

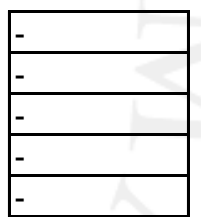

B. Mediante las afirmaciones del siguiente cuadro, indique si está de acuerdo o en desacuerdo con los siguientes enunciados, siempre que cuente con argumentos en los que pueda basar su respuesta.

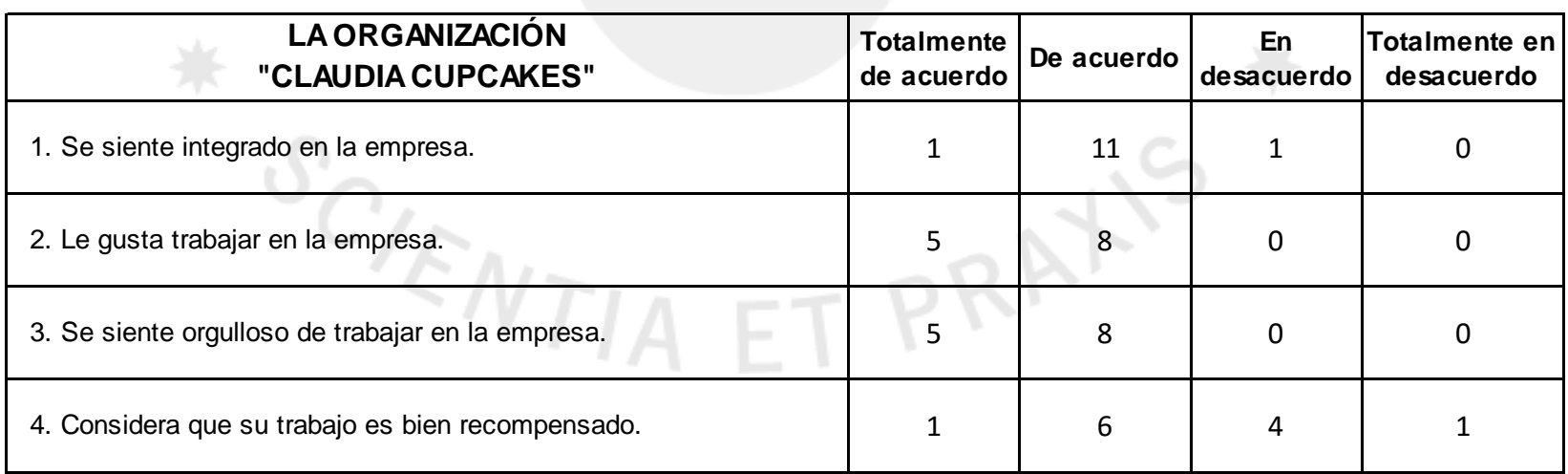




\begin{tabular}{|c|c|c|c|c|}
\hline $\begin{array}{c}\text { RELACIONES CON LA DIRECCIÓN DE LA } \\
\text { ORGANIZACIÓN }\end{array}$ & $\begin{array}{l}\text { Totalmente } \\
\text { de acuerdo }\end{array}$ & De acuerdo & $\begin{array}{c}\text { En } \\
\text { desacuerdo }\end{array}$ & $\begin{array}{c}\text { Totalmente en } \\
\text { desacuerdo }\end{array}$ \\
\hline $\begin{array}{l}\text { 5. Le parece positivo el liderazgo ejercido por la Gerencia de la } \\
\text { empresa. }\end{array}$ & 3 & 6 & 2 & 1 \\
\hline 6. Tiene claro los objetivos trazados por la empresa. & 3 & 9 & 1 & 0 \\
\hline 7. Le parece positivo el trato que recibe de parte de la Gerencia. & 5 & 5 & 3 & 0 \\
\hline $\begin{array}{l}\text { 8. Considera que la Gerencia promueve la participación y el trabajo } \\
\text { en equipo. }\end{array}$ & 2 & 8 & 2 & 0 \\
\hline $\begin{array}{l}\text { 9. Recibe un buen nivel de integración entre los miembros de su } \\
\text { equipo. }\end{array}$ & 3 & 10 & 0 & 0 \\
\hline $\begin{array}{l}\text { 10. Se comunica fácilmente con la Gerencia de la Organización y } \\
\text { puede trasmitir sus ideas y/o inquietudes. }\end{array}$ & 5 & 7 & 1 & 0 \\
\hline $\begin{array}{l}\text { 11. Siente que sus opiniones y sugerencias son escuchadas y } \\
\text { tomadas en cuenta por la Gerencia. }\end{array}$ & 1 & 8 & 4 & 0 \\
\hline COMPAÑEROS DE TRABAJO & $\begin{array}{l}\text { Totalmente } \\
\text { de acuerdo }\end{array}$ & De acuerdo & $\begin{array}{c}\text { En } \\
\text { desacuerdo }\end{array}$ & $\begin{array}{c}\text { Totalmente en } \\
\text { desacuerdo }\end{array}$ \\
\hline 12. Se lleva bien con sus compañeros de trabajo. & 8 & 4 & 1 & 0 \\
\hline 13. Se lleva bien con el personal administrativo. & 8 & 4 & 1 & 0 \\
\hline $\begin{array}{l}\text { 14. Recibió el apoyo de sus compañeros de trabajo cuando ingresó } \\
\text { a laborar en la empresa. }\end{array}$ & 7 & 6 & 0 & 0 \\
\hline CREATIVIDAD E INICIATIVA & $\begin{array}{l}\text { Totalmente } \\
\text { de acuerdo }\end{array}$ & De acuerdo & $\begin{array}{c}\text { En } \\
\text { desacuerdo }\end{array}$ & $\begin{array}{l}\text { Totalmente en } \\
\text { desacuerdo }\end{array}$ \\
\hline 15. Tiene la suficiente autonomía en su trabajo. & 3 & 8 & 1 & 0 \\
\hline 16. Siente que respalda su iniciativa en el trabajo. & 1 & 11 & 0 & 0 \\
\hline 17. El trabajo que realiza lo ayuda a desarrollar su creatividad. & 6 & 7 & 0 & 0 \\
\hline CONDICIONES AMBIENT ALES & $\begin{array}{l}\text { Totalmente } \\
\text { de acuerdo }\end{array}$ & De acuerdo & $\begin{array}{c}\text { En } \\
\text { desacuerdo }\end{array}$ & $\begin{array}{c}\text { Totalmente en } \\
\text { desacuerdo }\end{array}$ \\
\hline $\begin{array}{l}\text { 18. De acuerdo con la carga laboral que maneja, siente que cuenta } \\
\text { con un lugar dónde pueda trabajar con comodidad. }\end{array}$ & 1 & 7 & 4 & 0 \\
\hline $\begin{array}{l}\text { 19. Cuenta con los recursos necesarios para desarrollar un buen } \\
\text { trabajo. }\end{array}$ & 5 & 7 & 1 & 0 \\
\hline $\begin{array}{l}\text { 20. Está de acuerdo con las condiciones que le ofrece la } \\
\text { organización para realizar sus actividades. }\end{array}$ & 1 & 10 & 2 & 0 \\
\hline $\begin{array}{l}\text { 21. Está de acuerdo con la infraestructura disponible en la empresa } \\
\text { para el desarrollo de sus actividades. }\end{array}$ & 3 & 6 & 3 & 0 \\
\hline $\begin{array}{l}\text { 22. Está de acuerdo con las máquinas y equipos disponibles en la } \\
\text { empresa para el desarrollo de sus actividades. }\end{array}$ & 8 & 5 & 0 & 0 \\
\hline 23. Está satisfecho con la calidad del servicio administrativo. & 5 & 7 & 1 & 0 \\
\hline $\begin{array}{l}\text { 24. Se siente cómodo con la presentación y el equipamiento de los } \\
\text { baños. }\end{array}$ & 4 & 9 & 0 & 0 \\
\hline
\end{tabular}

Sugiera una recomendación que contribuya con la mejora del clima laboral de la empresa: 
Anexo 9

Resultados Encuesta Clima Laboral 2015

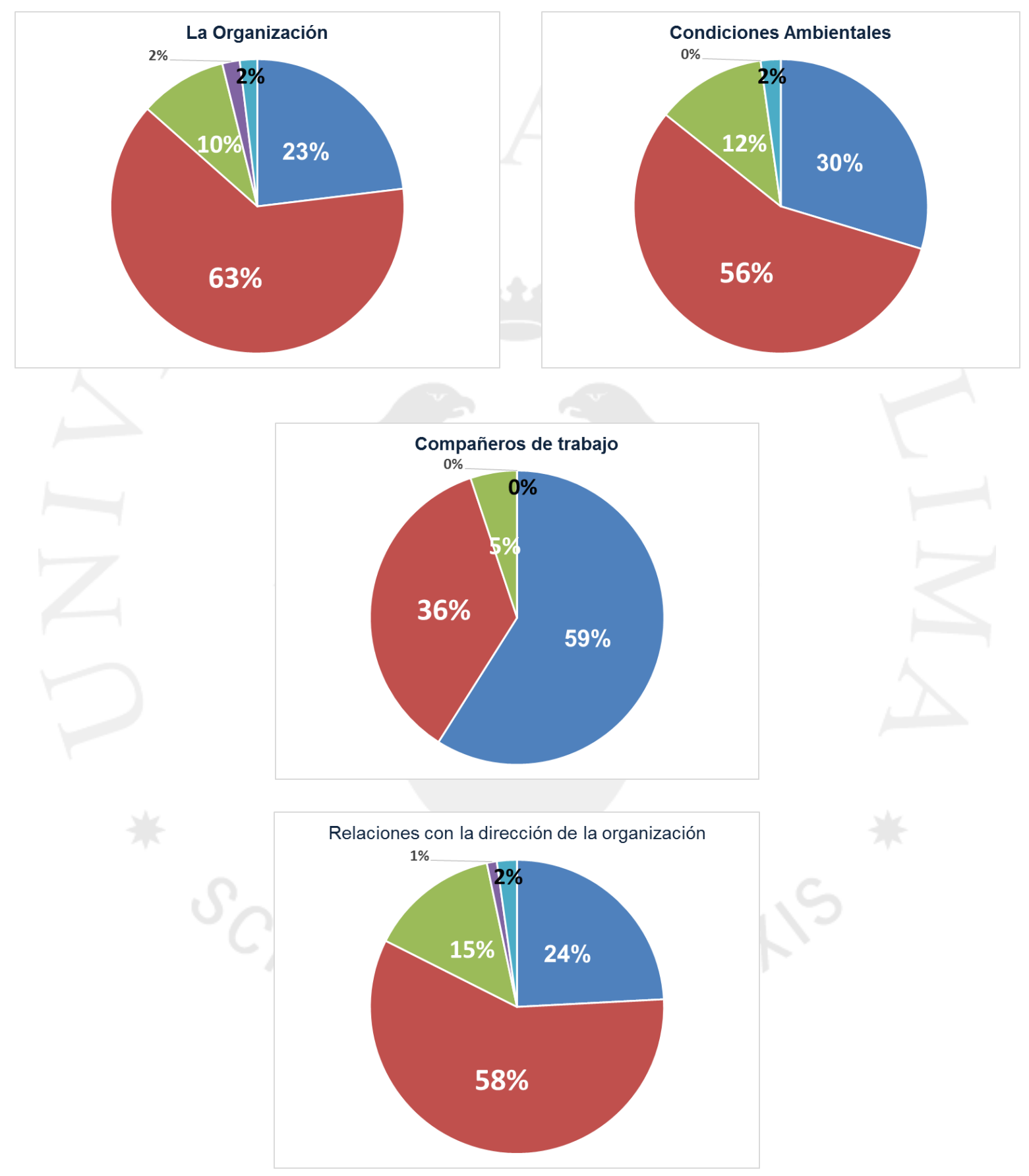




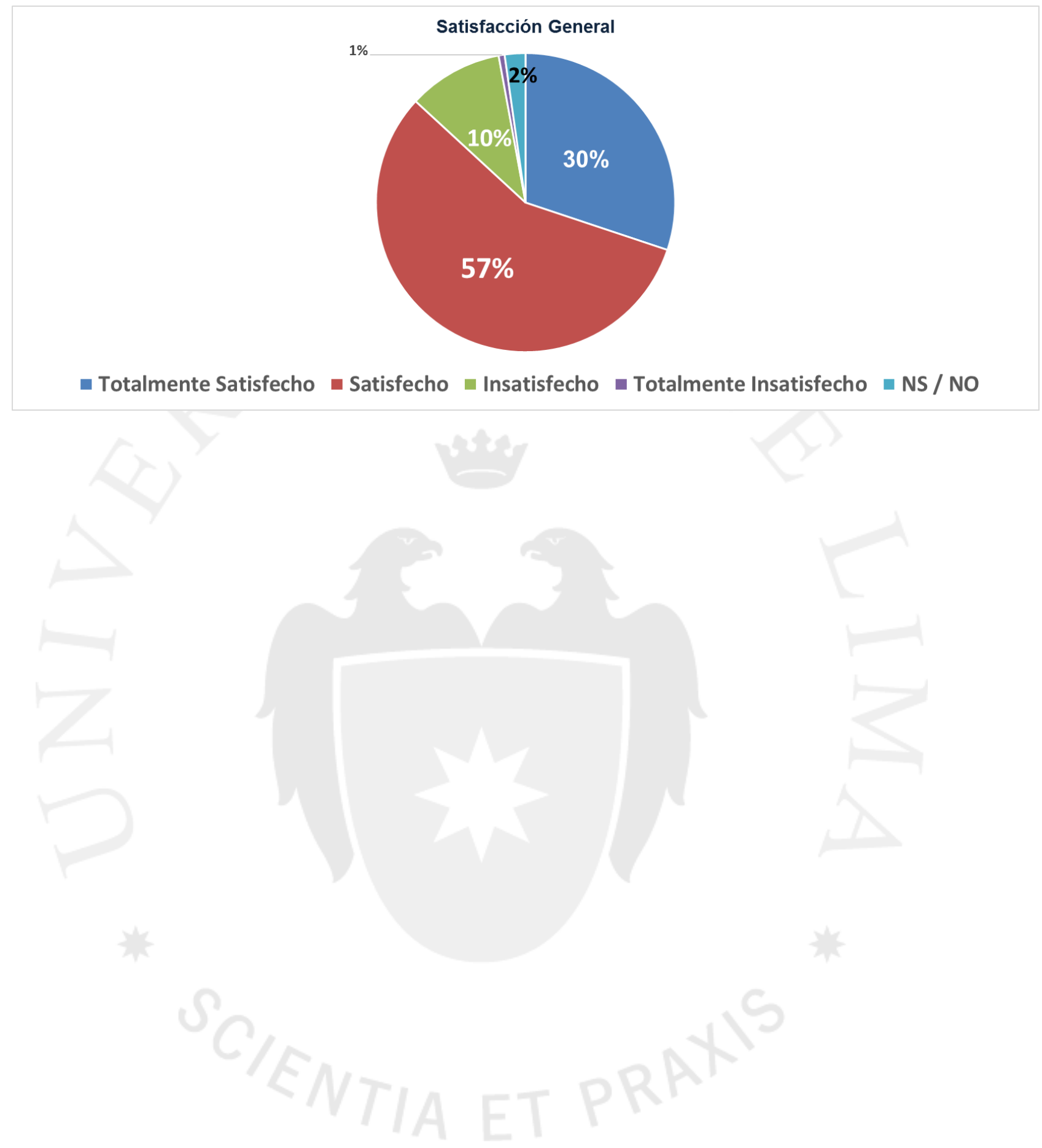


Anexo 10

Manual de Procedimientos (Manufactura)

\begin{tabular}{|c|c|l|}
\hline MANUAL DE BUENAS PRÁCTICAS DE & Revisión: 01 \\
MANUFACTURA DE CLAUDIA & Aprobado por: \\
CUPCAKES & Fecha: $\mathbf{0 5} / \mathbf{0 4 / 2 0 1 6}$ \\
\hline
\end{tabular}

I. INTRODUCCIÓN

\section{ÍNDICE GENERAL}

II. OBJETIVO

III. ALCANCE

IV. RESPONSABILIDAD 


\section{NORMAS DE REFERENCIA Y DEFINICIONES}

\section{REQUISITOS GENERALES}

\section{PROCEDIMIENTOS Y REGISTROS}

Procedimiento de Selección y Control de Proveedores

Procedimiento de Recepción y Control de Materias. Primas e Insumos

Procedimiento de Almacenamiento de Materias Primas e Insumos

Procedimiento de Control de Parámetros de Proceso

Procedimiento de Control de Calibración de escalas de Medición

Procedimiento de Mantenimiento Preventivo de Maquinarias y Equipos

\section{REGISTROS}


Tomando en cuenta "VII. PROCEDIMIENTOS Y REGISTROS" y la sección

"Procedimiento de Selección y Control de Proveedores":

\section{PROCEDIMIENTOS Y REGISTROS}

En el presente manual se ha definido un conjunto de procedimientos de manufactura asociados a las etapas de recepción, almacenamiento, Control de proceso, etc., los mismos que se presentan en la Lista de Procedimientos y Registros.

Los procedimientos establecidos generan un conjunto de formatos que una vez llenados constituirán los registros del presente manual y la evidencia de su funcionamiento. Dichos registros se muestran en orden correlativo según el procedimiento al que correspondan.

\section{LISTA DE PROCEDIMIENTOS Y REGISTROS}

\begin{tabular}{|c|l|l|l|}
\hline \multicolumn{2}{|c|}{ PROCEDIMIENTOS } & \multicolumn{2}{c|}{ REGISTROS } \\
\hline \multirow{2}{*}{ PBPM- } & Selección y control de & RBPM-001 & Ficha de evaluación para la \\
$\mathbf{0 0 1}$ & proveedores & & selección y control \\
& & & de proveedores \\
\cline { 3 - 4 } & & RBPM-002 & Lista de proveedores aceptados \\
\hline
\end{tabular}




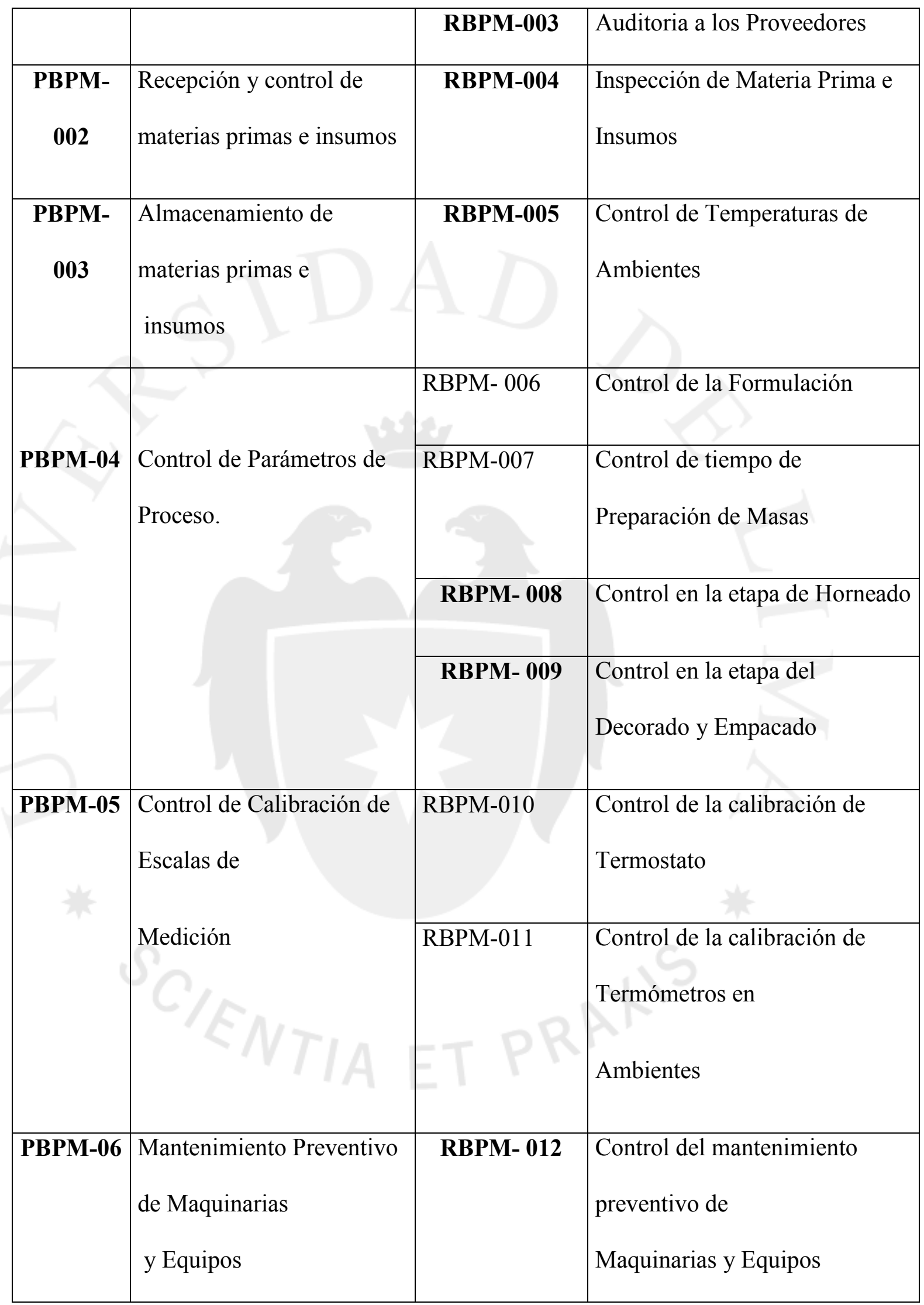




\section{PBPM-001: SELECCIÓN Y CONTROL DE PROVEEDORES}

\section{OBJETIVO}

Establecer un procedimiento para efectuar la selección y el control de proveedores de materia prima.

\section{ALCANCE}

Aplicable a los proveedores de materia prima utilizada en la elaboración de los productos que se elaboran en el taller de CLAUDIA CUPCAKES.

\section{RESPONSABLES}

La persona responsable de la selección y el control de proveedores de materia primas será el Supervisor Administrativo.

\section{EJECUTORES}

El Supervisor de Producción es el responsable de evaluar la calidad e inocuidad de la materia prima antes de iniciar la preparación. 


\section{FRECUENCIA}

Cuando se trate de seleccionar a un nuevo proveedor de materia prima, la evaluación se realizará mensualmente y/o en cada envío durante el periodo de un año.

Con proveedores ya seleccionados la evaluación se realizará anualmente.

\section{DESCRIPCIÓN}

\subsection{Selección de proveedores}

En el Cuadro 1 se muestran los criterios para la evaluación de proveedores de materias primas con sus respectivos factores de ponderación.

\section{Cuadro 1: Criterios para la evaluación de proveedores de materias primas}

\begin{tabular}{|c|l|c|}
\hline $\mathbf{N}^{\circ}$ & \multicolumn{1}{|c|}{ Criterios } & Factor de \\
& & ponderación \\
\hline $\mathbf{1}$ & Tiempo de permanencia en el & 1.5 \\
\hline $\mathbf{2}$ & mercado & 1 \\
\hline $\mathbf{3}$ & Stock adecuado de productos & 1.5 \\
\hline $\mathbf{4}$ & Condiciones de crédito & 2 \\
\hline
\end{tabular}




\begin{tabular}{|c|l|c|}
\hline $\mathbf{5}$ & $\begin{array}{l}\text { Cumple con especificaciones } \\
\text { técnicas }\end{array}$ & \\
\hline $\mathbf{6}$ & $\begin{array}{l}\text { Cuenta con algún Sistema de } \\
\text { Calidad }\end{array}$ \\
\hline $\mathbf{7}$ & $\begin{array}{l}\text { Haber aprobado la Inspección } \\
\text { Higiénico Sanitaria realizada por la } \\
\text { Empresa }\end{array}$ & \\
\hline
\end{tabular}

La evaluación de proveedores se llevará a cabo utilizando la RBPM-001: Ficha de evaluación para la selección y control de proveedores, donde se registrará la información obtenida teniendo en cuenta los criterios de calificación contenidos en el Cuadro 2.

Cuadro 2: Criterios de calificación para la evaluación de proveedores de materias primas.

\begin{tabular}{|l|l|l|l|}
\hline \multicolumn{3}{|c|}{ CALIFICACION } \\
\hline$N^{\circ}$ & \multicolumn{1}{|c|}{0} & \multicolumn{1}{|c|}{1} & \multicolumn{1}{|c|}{2} \\
\hline 1 & $\begin{array}{l}\text { Menos de un } \\
\text { año }\end{array}$ & Entre uno y tres años & Mayor a tres años \\
\hline 2 & $\begin{array}{l}\text { No cuenta con } \\
\text { stock del } \\
\text { producto }\end{array}$ & A veces cuenta con & Siempre cuenta con \\
& stock del producto & stock del producto \\
\hline
\end{tabular}




\begin{tabular}{|c|c|c|c|}
\hline 3 & $\begin{array}{l}\text { Precio por encima del } \\
\text { mercado }\end{array}$ & - & $\begin{array}{l}\text { Precio dentro del } \\
\text { mercado }\end{array}$ \\
\hline 4 & Pago al contado & - & Crédito disponible \\
\hline 5 & $\begin{array}{l}\text { No cumple con } \\
\text { todas las } \\
\text { especificaciones } \\
\text { técnicas }\end{array}$ & $\begin{array}{l}\text { Cumple con la } \\
\text { mayoría de las } \\
\text { especificaciones } \\
\text { técnicas }\end{array}$ & $\begin{array}{l}\text { Cumple con todas las } \\
\text { especificaciones técnicas }\end{array}$ \\
\hline 6 & $\begin{array}{l}\text { No cuenta con } \\
\text { sistemas } \\
\text { HACCP, ISO }\end{array}$ & $\begin{array}{l}\text { Sólo cuenta con uno } \\
\text { de los sistemas }\end{array}$ & $\begin{array}{l}\text { Cuenta con } \\
\text { sistemas HACCP, } \\
\text { ISO }\end{array}$ \\
\hline 7 & $\begin{array}{l}\text { No ha aprobado la } \\
\text { Inspección Higiénico } \\
\text { Sanitaria }\end{array}$ & $\begin{array}{l}\text { Ha aprobado } \\
\text { regularmente la } \\
\text { Inspección Higiénico } \\
\text { Sanitaria }\end{array}$ & $\begin{array}{l}\text { Ha aprobado } \\
\text { satisfactoriamente la } \\
\text { Inspección Higiénico } \\
\text { Sanitaria }\end{array}$ \\
\hline
\end{tabular}

Se aceptará a un proveedor, cuando de la evaluación que resulte del mismo, se obtenga un puntaje mínimo de 13.0, de lo contrario será rechazado. Pasada la selección de proveedores, éstos se registrarán en el formato RBPM-002: Lista de proveedores aceptados.

\subsection{Control de proveedores (Auditoria)}

Como parte de control a los proveedores se debe de realizar un seguimiento en el tiempo que se suministre las materias primas o insumos. Para lo cual se realizarán 
auditorias, las cuales consistirán en visitas a planta, para verificar la conformidad del cumplimiento de los requisitos evaluados en la selección de proveedores, para este control se registrará las observaciones en el formato RBPM-003 Auditoria a los Proveedores.

\section{REGISTROS}

RBPM-001: Ficha de evaluación para la selección y control de proveedores.

RBPM-002: Lista de proveedores aceptados.

RBPM-003: Auditoria a los Proveedores 


\section{Anexo 11}

Manual de Salubridad

\begin{tabular}{|c|c|l|}
\hline MANUAL DE HIGIENE Y & Revisión: 01 \\
SANEAMIENTO PARA EL TALLER & Aprobado por: \\
DE CLAUDIA CUPCAKES & Fecha: 05/04/2016 \\
\hline
\end{tabular}

\section{ÍNDICE GENERAL}

Pág.

I. INTRODUCCIÓN

III. NORMAS DE REFERENCIA Y DEFINICIONES 
IV. PROCEDIMIENTOS OPERATIVOS ESTANDARIZADOS DE SANEAMIENTO 6

Procedimiento de Limpieza y Desinfección de Áreas

Procedimiento de Limpieza y Desinfección de Equipos, Maquinarias y otros

12

Procedimientos de Control de la Salud, Hábitos y Capacitación del personal

Procedimiento de Control de Plagas

Procedimiento de Control de Cloro Residual

Procedimiento de Recolección y disposición de desechos de la zona de producción 
Procedimiento de verificación y validación del programa de higiene y saneamiento 33

V. REGISTROS

VI. ANEXOS

ANEXO 1. Principales Plagas en la Industria de Alimentos

ANEXO 2. Análisis Microbiológico de superficies

ANEXO 3. Productos recomendados para la limpieza, desinfección y preparación de las soluciones de higienización

ANEXO 4. Relación de rodenticidas recomendados.

ANEXO 5. Relación de insecticidas recomendados. 
Tomando en cuenta "IV.PROCEDIMIENTOS OPERATIVOS ESTANDARIZADOS DE

SANEAMIENTO" y la sección "Procedimientos de Control de la Salud, Hábitos y

Capacitación del personal”:

\section{POES 03 PROCEDIMIENTOS DE CONTROL DE LA SALUD, HÁBITOS Y CAPACITACIÓN DEL PERSONAL}

\section{OBJETIVO}

El presente procedimiento define los cuidados que debe tener el personal para evitar la contaminación del producto con patógenos por malas prácticas de los manipuladores.

\section{ALCANCE}


El presente procedimiento se aplica a todo aquel que ingrese a las áreas de procesamiento durante las horas de producción y fuera de ellas, y que participe directa e indirectamente en el proceso productivo.

\section{RESPONSABILIDADES}

El responsable de la aplicación y ejecución de este procedimiento será el Supervisor de Producción.

\section{PROCEDIMIENTO}

\subsection{CONTROL DE ENFERMEDADES}

a. Tramitar el carnet sanitario para todo el personal.

b. Guardar una copia de todos los carnets sanitarios.

c. Planificar la renovación de los carnets sanitarios.

d. En caso de presentar síntomas de una enfermedad, infección, acné cutánea, herida abierta, etc. El personal no debe ingresar al área de procesamiento y debe comunicar de inmediato al Supervisor de Producción. 
e. El Supervisor de Producción comprobará la enfermedad del operario y autorizará reposo o cambio de actividad si fuera necesario.

\subsection{HIGIENE PERSONAL}

Todo el personal que directa o indirectamente está ligado al proceso de producción debe ser adecuadamente entrenado en condiciones de higiene.

a) Mantener el rostro debidamente rasurado y el cabello limpio y recortado.

Mantener el cabello corto o recogido; reduce las probabilidades de contaminación de los productos con bacterias que normalmente se encuentran en nuestro cuerpo debido a la contaminación ambiental.

b) Lavarse y desinfectarse las manos (operarios y visitantes):

- Antes de ingresar a las zonas de procesamiento.

- Inmediatamente después de usar los servicios higiénicos.

- Luego de toser, estornudar, usar el teléfono, manipular implementos de limpieza, evacuar los desperdicios, etc. cada vez que se ensucien.

- No olvidar desinfectarse las manos utilizando solución desinfectante (jabón desinfectante o alcohol medicinal).

c) Pasar por los pediluvios o alfombra desinfectante para sanitizar el calzado antes de ingresar a la zona de procesamiento. 
d) Las uñas albergan gran número de bacterias que pasan al producto y pueden ser nocivas para la salud, por eso se deberán mantener cortas, limpias y sin ningún tipo de esmalte.

e) No usar ningún tipo de maquillaje, colonia, perfume, etc.

f) No comer, fumar, masticar goma de mascar, ni escupir en las zonas de procesamiento.

g) Evitar los malos hábitos como:

- Rascarse la cabeza o agarrarse el cabello.

- Colocarse el dedo en la nariz, oreja o boca.

- Estornudar sobre los productos, máquinas y utensilios.

- Secarse la frente con las manos o brazos.

- Secarse o limpiarse las manos con el uniforme.

- Limpiarse las manos con trapos sucios.

- Apoyarse sobre las paredes maquinarias, equipos y productos.

h) Desechar cualquier producto que haya entrado en contacto con el suelo antes de ser envasado.

i) Por seguridad e higiene se debe ingresar al área de proceso sin anillos, collares, reloj, cadenas, lapiceros, etc. porque existe la posibilidad que alguno de estos objetos caigan sobre el producto.

j) No guardar ningún objeto (lapiceros, peines, joyas, lentes, dinero, etc.)en los bolsillos del uniforme.

k) No colocar imperdibles, solaperas u otros accesorios en el uniforme.

1) No arrojar basura en el piso, ni en ningún otro lugar distinto a los Tachos. 


\section{INSTRUCCIÓN 1: LAVADO Y DESINFECCIÓN DE MANOS}

a) Humedecer las manos con agua hasta parte del antebrazo como mínimo.

b) Aplicar el jabón bactericida sobre la parte del antebrazo, manos, dedos, entre dedos y uñas formando una buena espuma por un tiempo de 15 segundos.

c) Escobillar las uñas y entre los dedos con cepillo.

d) Enjuagar con abundante agua corriente desde los dedos hacia el codo.

e) Secar.

f) Aplicar el desinfectante en las manos dejar secar por 5 segundos.

\subsection{USO CORRECTO DE LA INDUMENTARIA DE TRABAJO}

\section{Todo el personal:}

a) Vestir el uniforme de trabajo antes de iniciar el turno.

b) No depositar ropa ni efectos personales en las zonas de procesamiento.

c) Mantener el Uniforme completo durante todo el turno de trabajo.

d) No usar ropa de calle (chompas, casacas, etc.) sobre el uniforme.

e) Tanto el uniforme como los implementos (gorro y protector nazo bucal) se mantendrán limpios. 


\section{Supervisor de Producción}

Evalúa el estado de los uniformes y dispone su cambio de ser necesario.

Supervisa diariamente que los operarios ingresen a la zona de procesamiento con el uniforme limpio y completo. Este control se registrara en el formato PHS-03.

\section{Control de Higiene del personal.}

Supervisa que los visitantes ingresen a la zona de procesamiento con la indumentaria adecuada.

Si el jefe de producción detecta que un operario no cumple con las condiciones estipuladas en este procedimiento no permitirá su ingreso a la planta.

\subsection{CAPACITACION DE PERSONAL}

La capacitación de personal de producción, empaque y limpieza se realizara antes del inicio de cada producción o cuando se requiera, para asegurar las buenas prácticas de higiene y manufactura y lo llevará a cabo el Jefe de Saneamiento. 
Para el personal administrativo y jefes de planta se realizará en forma semestral mínimo como dos capacitaciones por año los temas serán todo lo referente al manejo de alimentos y la calidad de los mismos.

El registro se llevara a cabo en el formato PHS-04: Control de Capacitación del personal.

CRONOGRAMA DE CAPACITACION

\begin{tabular}{|c|c|c|c|c|c|c|c|c|c|c|c|c|c|}
\hline A Y & \multicolumn{12}{|c|}{ FRECUENCIA (TRIMESTRAL) } & \multirow[b]{2}{*}{ OBSERVACIONES } \\
\hline TEMAS & 1 & 2 & 3 & 4 & 5 & 6 & 7 & 8 & 9 & 10 & 11 & 12 & \\
\hline $\begin{array}{l}\text { Programa de } \\
\text { Higiene y } \\
\text { Saneamiento }\end{array}$ & & & $\mathrm{X}$ & & & & & & & & & & ANUAL \\
\hline НАССР & & & & & & $\mathrm{X}$ & & & & & & & ANUAL \\
\hline $\begin{array}{l}\text { Buenas } \\
\text { prácticas de } \\
\text { manufacturas }\end{array}$ & & & & & & H & & & $\mathrm{X}$ & 7 & & & ANUAL \\
\hline
\end{tabular}




\begin{tabular}{|l|l|l|l|l|l|l|l|l|l|l|l|l|l|}
\hline Riesgos & & & & & & & & & & & & $\mathrm{X}$ & ANUAL \\
asociados en las & & & & & & & & & & & & & \\
operaciones y & & & & & & & & & & & & & \\
procesos & & & & & & & & & & & & & \\
\hline
\end{tabular}

\section{REGISTROS}

PHS-03. Control de Higiene del personal.

PHS-04: Control de Capacitación del personal. 
Anexo 12

Desarrollo de la S "Seiri"

Los resultados de aplicar la tarjeta roja se encuentran en el cuadro que mostramos a continuación:

\begin{tabular}{|c|c|c|c|}
\hline Localización & Categoría & Cantidad & $\begin{array}{l}\text { Método de } \\
\text { eliminación }\end{array}$ \\
\hline \multirow{3}{*}{$\begin{array}{c}\text { Área de batido y } \\
\text { horneado }\end{array}$} & Material de acarreo & 2 & Almacenar \\
\hline & Papelería & varios & Tirar \\
\hline & Utensilio & 8 & Almacenar / tirar \\
\hline \multirow{4}{*}{ Área de forrado } & Insumo & 5 & Almacenar / tirar \\
\hline & Material de acarreo & 2 & Almacenar \\
\hline & Papelería & varios & Tirar \\
\hline & Utensilio & 2 & Almacenar \\
\hline \multirow{5}{*}{$\begin{array}{c}\text { Área de diseño y } \\
\text { decoración }\end{array}$} & Insumo & varios & Almacenar / tirar \\
\hline & Material de acarreo & 2 & Almacenar \\
\hline & Papelería & varios & Tirar \\
\hline & Producto en proceso & varios & Almacenar \\
\hline & Utensilio & 13 & Almacenar / tirar \\
\hline \multirow{2}{*}{ Área de empaque } & Insumo & varios & Almacenar / tirar \\
\hline & Papelería & varios & Tirar \\
\hline \multirow{2}{*}{$\begin{array}{c}\text { Área de } \\
\text { administración }\end{array}$} & Equipo de oficina & 1 & Tirar \\
\hline & Papelería & varios & Tirar \\
\hline
\end{tabular}




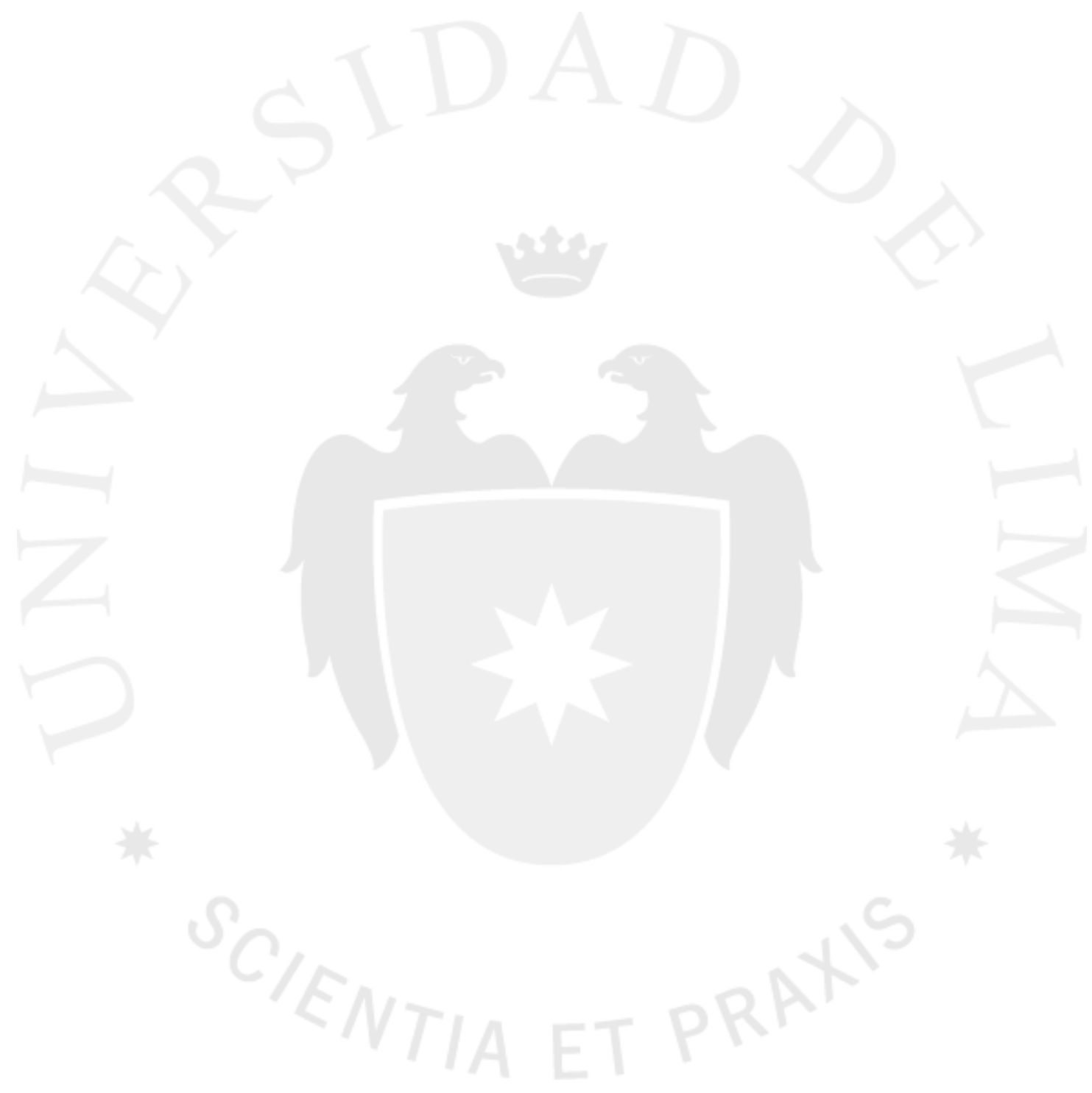


Anexo

Desarrollo de Seiso

A continuación, mostramos un cronograma de limpieza que va de la mano con la propuesta de mejora planteada.

\begin{tabular}{|l|c|c|c|}
\hline \multicolumn{1}{|c|}{ AREAS } & HORA DE & HORA DE FIN & TIEMPO \\
& INICIO & & $00: 20$ \\
\hline Horno & $07: 00$ & $07: 20$ & $00: 20$ \\
\hline Forrado & $07: 20$ & $07: 40$ & $00: 20$ \\
\hline Diseño y decorado & $07: 40$ & $08: 00$ & $00: 20$ \\
\hline Empaque & $08: 00$ & $08: 20$ & $00: 30$ \\
\hline Limpieza de oficinas & $08: 20$ & $08: 50$ & $00: 25$ \\
\hline Almacén de MP & $08: 50$ & $09: 15$ & $00: 15$ \\
\hline Almacén de Insumos & $09: 15$ & $09: 30$ & $00: 30$ \\
\hline Limpieza de cortinas & $09: 30$ & $10: 00$ & $02: 00$ \\
\hline Lavado de utensilios & $10: 00$ & $12: 00$ & $01: 00$ \\
\hline Refrigerio & $12: 00$ & $13: 00$ & $01: 30$ \\
\hline Lavado de utensilios & $13: 00$ & $14: 30$ & $00: 15$ \\
\hline SSHH producción & $14: 30$ & $14: 45$ & $00: 15$ \\
\hline SSHH administración & $14: 45$ & $15: 00$ & $00: 10$ \\
\hline Vestuario & $15: 00$ & $15: 10$ & $15: 35$ \\
\hline Áreas libres & $15: 10$ & & \\
\hline
\end{tabular}




\begin{tabular}{|l|c|c|c|}
\hline \multicolumn{1}{|c|}{ AREAS } & $\begin{array}{c}\text { HORA DE } \\
\text { INICIO }\end{array}$ & HORA DE FIN & $\begin{array}{c}\text { TIEMPO } \\
\text { TOTAL }\end{array}$ \\
\hline $\begin{array}{l}\text { Inspección visual } \\
\text { general }\end{array}$ & $15: 35$ & $16: 00$ & $00: 25$ \\
\hline \multicolumn{2}{|r|}{ TIEMPO TOTAL DE LABORES } & $\mathbf{0 9 : 0 0}$ horas \\
\hline
\end{tabular}

El programa se deberá cumplir diariamente. 